
(IEE-USP, EPUSP, FEA-USP, IFUSP) da Universidade de Săo Paulo para obtenção do título de Mestre em Energiø. 
DEDALUS - Acervo - IEE

\title{
USO EFICIENTE DE ENERGIA ELÉTRICA NO SETOR DE ILUMINAC ÃO PÚBLICA (IP) DO EQUADOR
}

\author{
Dissertação spresentada ao Programa \\ Interunidades de Pós-Graduação em Energia \\ (IEE-USP, EPUSP, FEA-USP, IFUSP) da \\ Universidade de São Paulo para obtençĩo do \\ títuln de Mestre em Energia.
}

Área de Cuncentraçãu:

Aren Interdisciplinar de Energia

Orientador:

Dr. José Roberto Moreira 
Aos meus filhos Johana, Maria Feruanda, Jorge Santiago e Verînica que têm sido a grande razāo e incentivo de meu aperféçosmento. 


\section{AGRADECIMENTOS}

Ao professor Dr. Josć Roberto Moreira por sua orientação e sugestðes na elaboraçăo deste trabaiho.

$\dot{A}$ International Ënergy Initiative (IEI) pelo apoio financeiro e ao professor Dr. Otávio Mielnik representante na América Latina.

A Empresa Elétrica Regional do Sul (EERSSA) e à Universidade Nacional de Loja (UNL) do Equador, pela minha liberação para aperféçoankento e realização deste trabalho.

Ao Instituto Equatorinno de Eletrificaçŭo (INECEL), Comissão Equatoriana de Bens de Capital (CEBCA) e concessionárias do Equador pelt sua colaboraçăo no formeximento da informaç̄ô.

Aos meus amigos e colegas pela ajuda permanente. 


\section{SUMARIO}

Lista de Tahelas

I.isla de Figuras

Resumo

"Abstract"

1. INTRODUCĀO

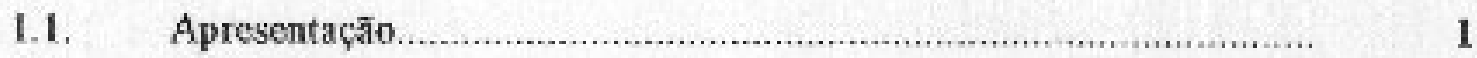

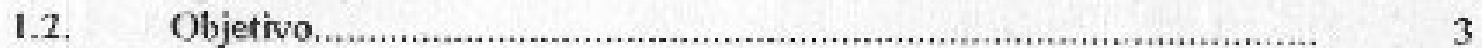

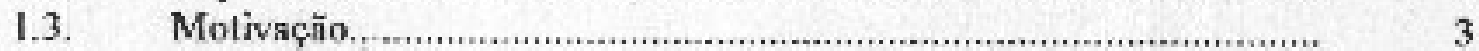

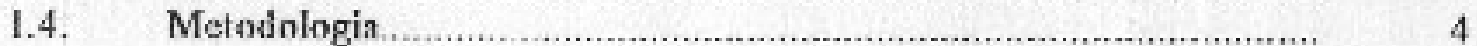

2. CARACTERÍSTICAS DA OFERTA E DA DEMANTA DE ENEIRGLA NO SETOR ELÉTRICO DO EQUADOR: O SETOR DE ULMINACÃO PÚBLICA (IT).

2.1. Carncterísticas da oferta de energia clétrica; Geração, Transmissāo e

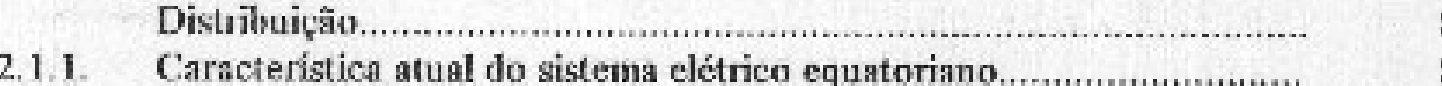

2.1.1.1. Sistema de geração.......................................................................

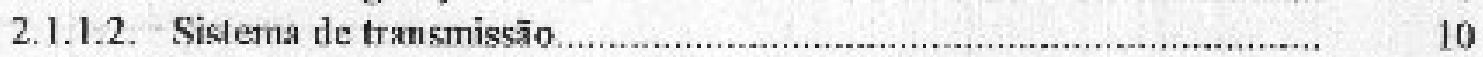

2.1.1.3. Sistema de subtransmisşio (S/T) e distribuiçũo............................... 12

2.1.2. Planejamento do sistema elétrico equatoriano...................................... 13

2.1.2.1. Sistema de geração....................................................................... 13

2.1.2.2. Sistema de transmissão.................................................................. 14

2.1.2.3 Sistema de subtranșnissão e distribuiçño.............................................. 15

2.2. Características da demanda de energia elétrica................................

2.2.1. Características históricas do merendo elśtrico equatorianc................. 16

2.2.2. Características bistóricas do mercado elétrico equaloriaro dividido em setores.

2.2.3. Projeçũo do mercado elétrico..........................................................

2.3. O setor de Thuminaçāo Pública (IP) ................................................ 25

2.4. Análise do uso da energia para Tuminação Píblicn (II) pelns concessionírias.

2.5. Usos fitais de ettergia elétricn no setor de Iluminaç̃o P’ública (IP’) do Equador.

2.5.1. Quantidade de huminárias instaladas.............................................. 30

2.5.2. Potênicia instalada uas luutiıátiats.................................................. 32

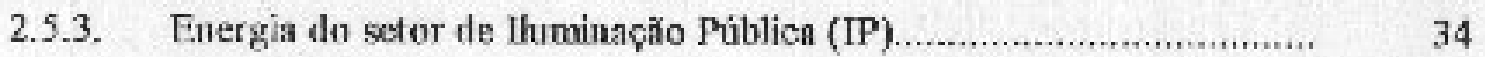


2.6 Conclusōes

3. CARACTERISTICAS DE DESENVOLVTMENTO DO SETOR ELÉTRICO EQUATORLANO (ILUMINACAO PÜBLICA - IP).

3.1. Regulamentaçâo equatoriana para uso e instalaç̂̃o de lluiminaçăo Pública (IP). Padrões Intemacionais.

3.1.1. Caracteristicas gerais e análise do padrão ushto no sistema de Dlumiuação Pŕblicn (II) do Equador.

3.1.2. Căactcrização do padrão proposto - padrỏes intemacionais.

3.2. Sistema tarifărio de energia elétrica no Equador (Tluminaçĩo Pública IP).

3.2.1. Ilistórico do sistema tarifárion......................................................... $\$ 1$

3.2.2. Custos marginaiz.......................................................................... 53

3.2.3. Caracterizaçăo do sistema tarifário ................................................. 57

3.3 Caracteristicas do oferta e demanda dos equipamentos de Iluninànăăo Pública (IP) no Equador.

3.3.1. Demasida de equipamentos.......................................................... 60

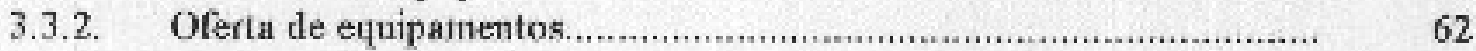

3.4. Oportumidades e Barreiras............................................................

3.4.1. Metodologia de implantaçăo de medidas no gerenciamento da demanda.

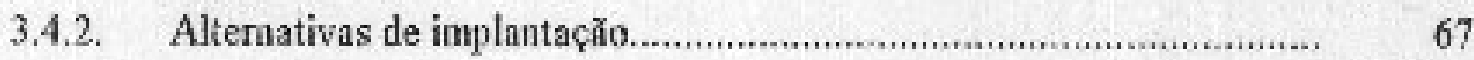

3.5 Programas de iucentivo.............................................................. 70

3.6 Experiêscias intemacionais......................................................... 71

3.6.1. Caso da Colômbia....................................................................... 71

3.6.2. Caso do Brasil. ........................................................................ 73

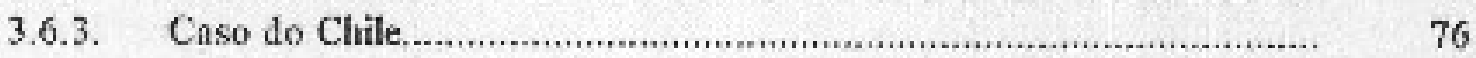

3.7. Perspectivas conn a nova Lei de Modernizaçẫo e Prívatizaçĩo do Setor Elétrico Equatoriano.

3.8. Couclusões.

4. AVALIACÃO TÉCNICA-ECONÔMICA-FINANCETRA DO USO EFICUENTE DE ENERGIA NO SETOR DE, ПLUMINAÇÃO PÚRLCA (U') DU EQUADOR...........................

4.1. Prenissns consideradas na análise econômica................................... 86

4.1.1. Taxa de descouto ..................................................................... 86

4.1.2. Preços dì eletricidade para Ilumininaçằn Píblica (TP) ......................... 87

4.1.3. I'reģos dos equipamentos .............................................................. 87

4.1.4. Vida real e estimada dos equipamentos .......................................... 89 
4.2. Carktetizaçño técnita, econômica e financeira das tecnologias convencionais e eficientes.

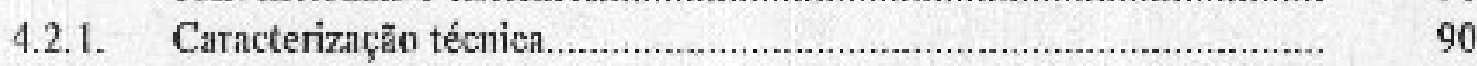

4.2.1.1. Coulingèncias nas luminírias......................................................... 90

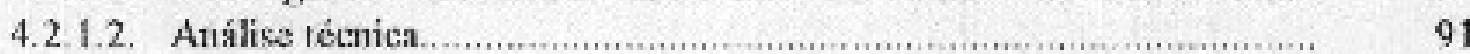

4.2.1.3. Experiência e resultados luminosos com a troca de luminátias na Colồnibia.

4.2.2. Caracterização econômica e fuanceira - Fỉguras de Mérito................. 97

4.3. Aúlise econômica-funanceira de alternativas para Ilumỉação Pública (IP).

4.3.1. Tempo simples de retorno (TSR) .............................................. $\quad 102$

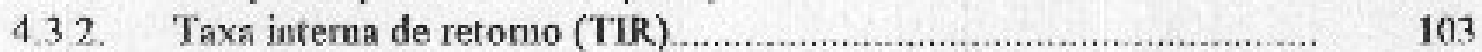

4.3.3. Cisto de energia conservada (CEC) …......................................... 105

4.3.4. Custo de potSucia conservada (CРC) .............................................. 106

4.3.5. Custo durante a vida (CDV) ....................................................... 107

4.3.6. Custo durante a vida anualizado (CDVA)...................................... 109

4.3.7. Custo durante a vida anualizado năo energético (CDVANE)............. 110

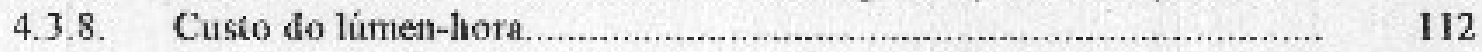

4.4. Análise de sensibilidade

4,4,1. Preço da cletricidade.............................................................. $\quad 114$

4.4.2. Horas de funciouamento ......................................................... 117

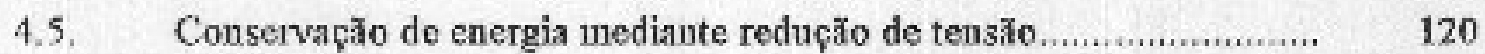

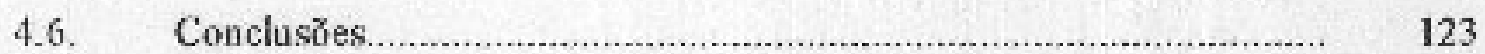

5. AVALIAÇÃO INTEGRADA DE ALTERNATIVAS DE OFERTA E ISO EFICIENTE DE, ENERGIA NO SETOR DE

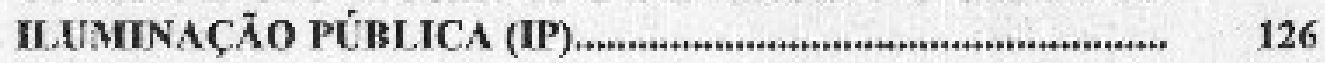

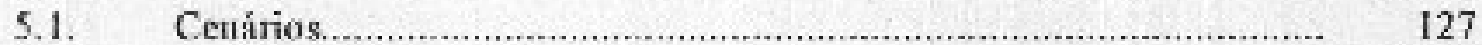

5.1.1. Cenário Eficiência Congelada........................................................ 130

5.1.2. Cenário Eficiente ou Potencial Técuico...................................... 132

5.1.3. Cenário Tendencial................................................................. 134

5.2. Alternativas de troca de lumináias eiou lâmpadas........................... 136

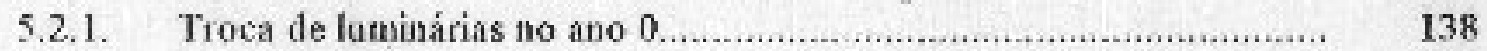

5.2.2. Troca de luminárias nos anos 1,2 e 3 ........................................... $\quad 140$

5.3. Discriminaçăo da curva integrada de recursos baseatla emi critéió de míniuno custo...

5.3.1. Curva de energia conservada baseada em critérios de mínimo custo.... 143

5.3.2. Curvas do custo unitário de geraçăo elétrica para usiuas A serem instaladas no periodo 1995-2005.

5.3.3. Ittegraçĩo oferta-demanda e análise đos impactos econômicos.......... 146 
5.3.4. Evoluçăo da capacidade de conservaçăo para o ano horizonte (2005).

5.3.5. Potencins e energias transferidas do lado da carga ao lado da gerạ̧ăo.

5.4. Estratégias para uso eficiente de energia no setor de Iluminação Pública (IP) do Equador.

5.5. Conclusōes.

6. CONCLUSŌES E RECOMENDAÇÕES. 


\begin{abstract}
ANEXOS
Anexo A Mapas geográfico e do Sistema Elétrico Equatoriano.

Anexo B Características da oferta e da demenda de energia no setor elétrico do Equador: o setor de Iluminaçåo Píblica (IP).

Tabelas.
\end{abstract}

Anexo C Caracteristicas de desenvolvimento do setor elétrico equatoriano (Tlunsiuação Pública - IP).

Tabelas.

Anexo D Avaliação técnica-econômicn-financeira do uso eficiente de energia no setor de Muntinação Pública (IP) do Equador.

Tabelas

Anexo E Avaliação integrada de alternativas de oferta e uso eficiente de energia no setor de Nluminaçăo Pública (IP).

Tabelas.

Anexo T Fstatisticas e projeçôes da populaçăo do Equador. 


\section{LISTA DE TABEIAS}

\section{CAPITULO II}

TABELA

DESCRIÇĀO

PÁGINA

2.1 Potĉucia disponfvel de geraçũo do SNI (janeiro/94)

2.2 Quantidade dos elementos elétricos das concessionárias

2.3 Capacidade instalada nos sistemas de $\mathrm{S} / \mathrm{T}$ e distribuição das concessionárias.

2.4 Plano de equipamento do SNI (geração até ano 2005)

2.5 Evolução listórica do mereado elétrico equatoriano

2.6 Evohıçăo histótica do mercado elétrico equatoriano dividido em setores.

2.7 Compnsiçâิง do comsumo dividido em setores (1982 e 1993)

2.8 Proję̧ño do mercado elétrico equatoriano $\mathrm{cm}$ sctores (19942005) ccnário de menor crescimento.

2.9 Projeçйо do mercado elétrico equatorinno em setores (19942005) ccuário de maior crescimento.

2.10 Composição do consumo dividido em setores (2005) 25

2.11 Consumo de evergia em Dluminação Pública (IP) pelns concessionírias (1993).

2.12 Quantidade de luminárias instaladas no Equador até set/95 31

2.13 Perdas de poténcia nos rentores 32

2.14 Poténcia das luminárias instaladas no Equador até set/95. 33

2.15 Energia das luminárias instaladas no Equador ató sct/95 35

\section{CAPITULO III}

3.1 Classificação da calçadn segundo recomendaçốes da CIE

3.2 Aluras minimas de montagem de luminárias 49

3.3 Itequisitos mínimos de huminância e uniformidade 50

3.4 Composiçĩo de superficies e os prováveis valores de " $q$ " 50 ressaltatite.

3.5 Custns marginais de longo prazo para o setor elétrico 55 equaroriano.

3.6 Caracteristicas do setor elétrico equatoriono em $1993 \quad 57$

3.7 Desnanta de produtos para Iluminação Pública (IP) no perícto 1993-1997.

3.8 Fúbricas de luminárias para lluminaçåo Pública (IP) no Equador 62

3.9 Canacterísticas principais das luminárias feitas no Equadot 63

3.10 Luminárias produzidas no Equador seguudo sen tipo 63 


\section{CAPTTULO IV}

4.1 Preços dos materiais para lluminaçño Públiç (IP) 88

4.2 Preços das luminárias (instaladas) materiais e instalação julho/95 89

4.3 Comparaçăo da vida útil das lâmpadas 90

4.4 Níveis de iluminação e uniformidade para calçadas 92

4.5 Cálculos técnicos de iluminação para alternativas propostas 9.4

$\begin{array}{lll}4.6 & \text { Tempo simples de retomo (TSR) } & 103\end{array}$

4.7 Exemplo de fluxo de caixa para T-1 104

$\begin{array}{lll}4.8 & \text { Taxa interna de retorno (TIR) } & 104\end{array}$

4.9 Custo de energia conservada (CEC) 106

4.10 Custo de potência conservada (CPC) 107

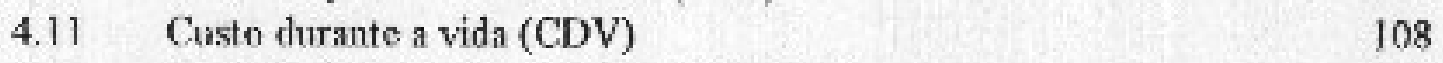

4.12 Custo durnute n vida anualizado (CDVA) 109

4.13 Custo durnnte n vida anualizado não energético (CDVANE) 111

4.14 Custo do húmen-horn couvencional ys. eficiente 113 4.15 Asálise de custos para a alternativa conservaçăo mediante
redução de tensão.

\section{CAPITULO V}

5.1 Cenário Eficiência Congelada Tluminação Píblica (IP) 132

5.2 Cenátio Eficiente do setor de Ihuminaçāo Pública (IP) 134

5.3 Cenário Teadencial do setor de Iluminação Pública (IP) 136

5.4 Resumo de potência e evergia das altemativas propostas (1995) 137

S.5 Fluxo de caixa investimento nno $0 \quad 139$

5.6 Investimento inicial, custo do consumo de energia, potência e energia do sistema de IP sob a alternativa de troca en 3 anos. 140

5.7 Fluxo de caixa investimento ano 1,2 e $3 \quad 141$

5.8 Investimento inicial, vustos e energia conservada para 1995 I44 (segunda ordem asceudente).

5.9 Cílculo dos impactos dos programas de conservaçйо de energiła 148

5.10) Potência e energia vistos do lado da geraçŭo das altenativas viáveis. 


\section{LISTA DE FIGURAS}

\section{CAPTTULO II}

FIGURA

DESCRIÇÃO

PÁGINA

2.1 Evoluçño lisstórica do mercado elétrico equatotiano

2.2 Evoluçño histórica do mercado elétrico equatoriano dividido em setores.

2.3 Projç̧̌̆o do mercado - cenário menor crescimento

2.4 Proję̧йo do mexrcado - cenário maior crescimento

2.5 Centários do setor de Thuminaçăo Pública (IP)

2.6 Curva de earga do SNI com participaçāo da Ihuminaçăo Pública (TP)

\section{CAPITIULO III}

3.1 Evoluçăo das tarifas para Ihuminaçāo Pública (IP')

\section{CAPTTLO IV}

4.1 Dimestsôes em Iluminação Pública (IP)

4.2 Comparaçäo entre alteruntivas, ganhos de potência vs. ganhos de luminànciล e iluminâกcia.

4.3 Fluxos de caixa pha troch (T-I) HG-125 W por NA-70 W 105

4.4 Custo Durante a Vila (CDV) por tipo de luminária 109

4.5 Custo Durante a Vida Anualizado (CDVA) por tipo de lomiuária 110

4.6 Custo Durante a Vida Anualizado nåo Esıergético (CDVANE) por tipo de luminárias.

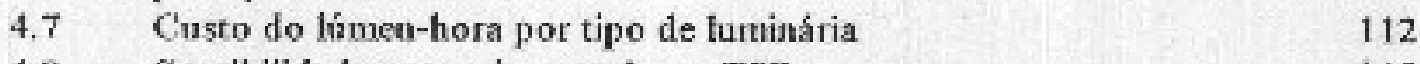

4.8 Seosibilidade preço de energia vs. TSR 115

4.9 Sensibilidade preço de energia vs. TIR 116

4.10 Sensibilidade preço de energia vs. CEC 116

$\begin{array}{ll}4.11 & \text { Sensibilidade preço de encrgia vs, \% fluxo luminoso } \\ 4.12\end{array}$

$\begin{array}{lll}\text { 4.12 Seusibilidade horns de funcionamento vs. TSR } & 118\end{array}$

$\begin{array}{lll}4.13 & \text { Seusibilidade horas de funcionamento vs. TIR } & 118\end{array}$

4.14 Sensibilidade boras de funcionamento vs. CEC 119

4.15 Sensibilidade horas de fincionamento vs. CPC 119

4.16 Altenativa para conservação de energia, variação de tensǔo $\quad$ I22

\section{CAPITLILOV}

5.1 Cenários: eficiência congclada (maior e menor), eficiente (maior e menor), tendencial (maior e menor) e cenários do INECEL 
(maior e menor).

5.2 Curva de energia conservada baseada no critério de mínimo custo para o ano 1995.

5.3 Variação dos custos unitários anualizados de potência em função do fator de carga de conservação e o fator de capacidade parn o plano de instalação de usinas 1995-2005.

5.4 Energia conservada acumulada por altemativa em funçăo do fator de efetividade de custo (1995).

5.5 Curva de cnergia conservada baseada no critério de mínimo custo para o ano 2005 - conservação maior A1.

5.6 Curva de energia conservada basenda no critério de mínimo custo para o ano 2005 - conservação menor A2.

5.7 Opoutunidades de conservaçăo para o ano atual e horizonte

5.8 Energia conservada acutnulada por altenativa de conservaçāo em funçĩo do fator de efetividude de custo parn cenário conserviç̧̄̄o maior e menor $(2005)$ 


\section{I.ISTA DE ABREVIATURAS}

\begin{tabular}{|c|c|}
\hline ABILUX & Associaçâo Brasileira da lndústria de Thuminaçăo \\
\hline BID & Banco Interamericano de Desenvolvimento \\
\hline CEBCA & Comiss̃̃o Equatoriana de Bens de Capital \\
\hline CDV & Custo Durante a Vida \\
\hline CIVA & Custo Durante a Vida Amualizado \\
\hline CDVANE & Custo Durante a Vila Amuilizado Não Energético \\
\hline $\mathrm{CEC}$ & Custo de Energia Conservada \\
\hline CIE: & Comissăto Intemacional de Iluminaçáo \\
\hline CMCl' & Custo Marginal de Curto Prazo \\
\hline CMLP & Curto Marginal de Longo Prazo \\
\hline Conv. & convencional \\
\hline CONADE & Comsello Nacional de Desenvolvimento \\
\hline $\mathrm{CPC}$ & Custo de Potência Cumservada \\
\hline E.E. & Empresa Elétrica \\
\hline Ffic, & Eficiente \\
\hline FEC & Fator de Efetividade de Custo \\
\hline ГMI & Fundo Monetátio Internacional \\
\hline FRC & Fator de Recuperaçăo do Capital \\
\hline HG-125 W & $\begin{array}{l}\text { luminária de vapor de mercúrio com lâmpsda de } 125 \mathrm{~W} \text {, com todos os } \\
\text { acessórios. }\end{array}$ \\
\hline IIG-175 W & $\begin{array}{l}\text { luminátia de vapor de mercúrio com lâmpada de } 175 \mathrm{~W} \text {, com todas os } \\
\text { acessórios. }\end{array}$ \\
\hline HG-250 W & $\begin{array}{l}\text { luminária de vapor de mercúrio com lampada de } 250 \mathrm{~W} \text {, com todos as } \\
\text { acessórios. }\end{array}$ \\
\hline HG-400 W & $\begin{array}{l}\text { luminíria de vapor de mercúrio com lâmpada de } 400 \mathrm{~W} \text {, com todos os } \\
\text { acessórios. }\end{array}$ \\
\hline INEC & Instituto Nacional de Estatísticas e Censos do Fquador \\
\hline INECEL & Instituto Equatoriano de Eletrificação \\
\hline II. & Iucremento limiar \\
\hline IP & lluminaçẫo Pủblica \\
\hline MS-160 W & luıninária mista com lâmpada de $160 \mathrm{~W}$, com todos os acessórios. \\
\hline NA-50 W & $\begin{array}{l}\text { luminária de vapor de sódio com lâmpnda de } 50 \mathrm{~W} \text {, com todos os } \\
\text { ucessórios. }\end{array}$ \\
\hline NA-70 W & $\begin{array}{l}\text { luminária de vapor de sódio com lâmpada de } 70 \mathrm{~W} \text {, com todos os } \\
\text { acessórios. }\end{array}$ \\
\hline NA- $100 \mathrm{~W}$ & $\begin{array}{l}\text { lumisnária de vapor de sódio com lâmpada de } 100 \mathrm{~W} \text {, com todos os } \\
\text { acessórios. }\end{array}$ \\
\hline NA-150W & $\begin{array}{l}\text { luminária de vapor de sódio com làmpada de } 150 \mathrm{~W} \text {, con todos os } \\
\text { acessórios. }\end{array}$ \\
\hline $\mathrm{NA}-250 \mathrm{~W}$ & $\begin{array}{l}\text { luminária de vapor de sódio com lâmpada de } 250 \mathrm{~W} \text {, com todos os } \\
\text { acessórios. }\end{array}$ \\
\hline $\begin{array}{l}\text { negawatt } \\
\text { negawatt-hora }\end{array}$ & $\begin{array}{l}\text { unidadle que representa um watt de potência efetivamente conservada } \\
\text { unidade que representa um watt-hora de cnergia efetivamente } \\
\text { conservada. }\end{array}$ \\
\hline
\end{tabular}


OLADE-SIEE Organizaçăo Latiuo Annéricana de Desenvolvimento Energético Sistema de Informaçảo Econômica Energética.

PIB Produto Inteno Bruto

PIR Planejamento Integrado de Recursos

PROCEL Programa Nacional de Conservação de Energia Elétricn - Brasil

S/E subestaçẵo

SMV Salário Mínimo Vital

SNI Sistema Nacional Interligado

SNT Sistema Nacional de Transmissăo

Sucre unidade monetária do Equador

TEC. tecnologia

TIR Taxa Intertia de Retomo

TSR Tempo Simples de Retomo

Uo uniformidade globalizada

UI uniformidade longitudinal

VPL Vulor Presente I íquido 


\section{LISTA DE SÍMBOLOS}

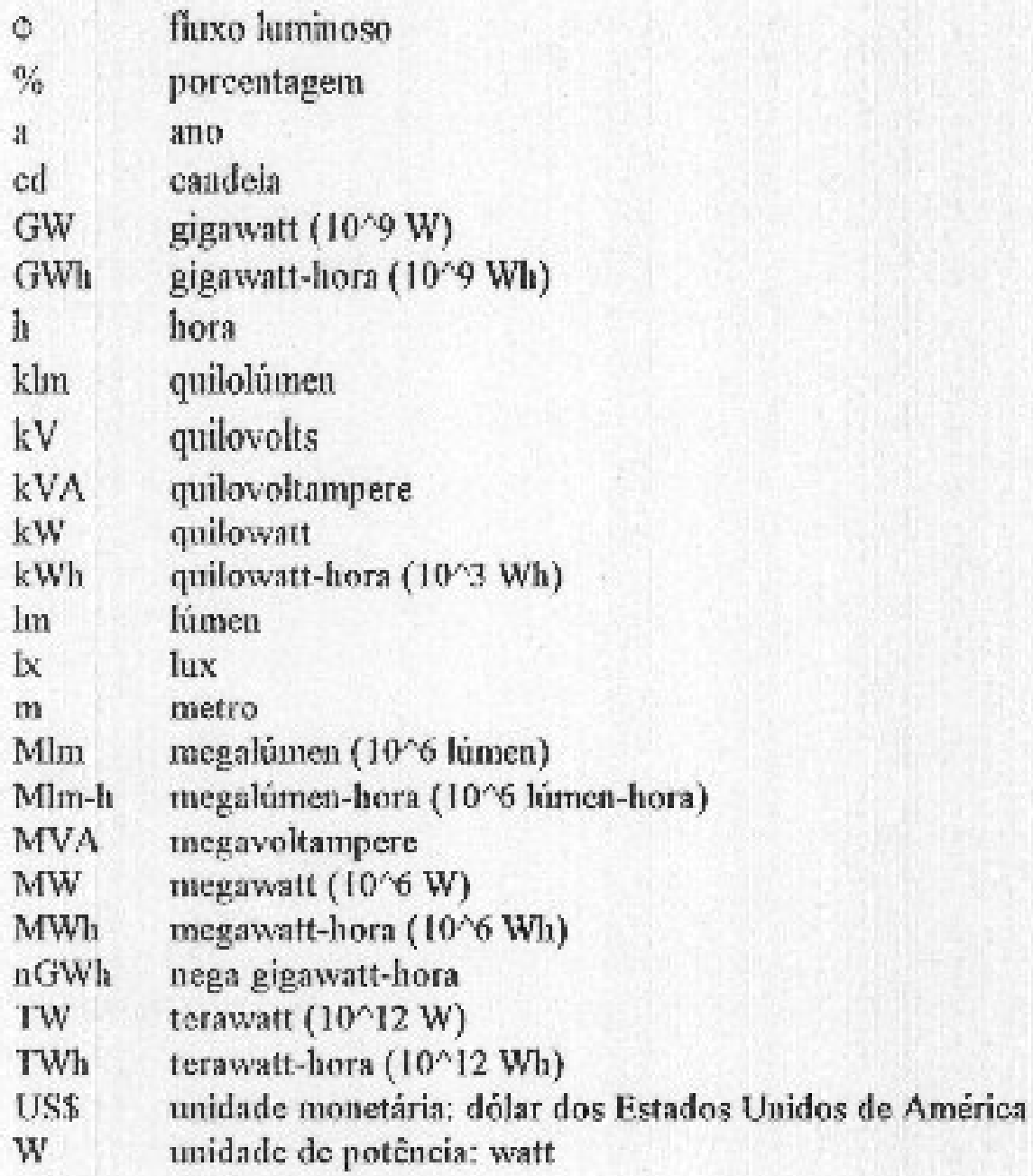




\section{RESUMO}

O setor de Iluminação Pública (IP) do Equador representa um consumo de energia de $7 \%$ do Setor Flétrico. Uma quantidade aproximada de 450.000 luminárias existem instaladas cuja potência corresponde a $90 \mathrm{MW}$ e consomem 394 GWh/ano de energia das quais $72 \%$ usam tecnologia de mercirio, $26 \%$ tecuologia de sódio e o restante tecnologias de luz mista, incandescente e fluorescente.

O potencial passivel de conservação considerando as tecnologias de mercúrio e luz mista é de $66,1 \mathrm{MW} ; 0$ maior potencial encontra-se nas luminárias HG-175 W com 35,1 MW (53\%), depois as luminárias HG- $125 \mathrm{~W}$ com 18,7 MW (28\%).

O estudo de caso propôe a substituiçăo de huminárias de vapor de mercúrio e luz uista por vapor de sódio de alta pressão nas seguintes potências: HG-125 W por NA-70 W; HG-175 W por NA-100 W; HG-250 W por NA-150 W; HG-100 W por NA-250 W; MS-160 W por NA-50 W.

Trocmndo todas as luninárias convencionais pelas recpectivas eficientes (no ano atual), a potềncia do sistema de IP diminui para $64 \mathrm{MW}$ (potência conservada de $26 \mathrm{MW}$ ) $\mathrm{e}$, a energia dimistui para 281 GWhinno (energin conservada de $113 \mathrm{GWh} / \mathrm{ano}$ ), ou seja a dimimuição ć $20 \%$ tanto en potência quanto en energin (diminuiçŭo de $2 \%$ do sistema clétricon)

O investimento para comprar 370.000 luminátias de vapor de mercúrio e luz mista e substituir por suas equivalentes eficientes é US\$ 47,7 milhões (valor anualizado de US\$ 8,1 milhões/atto). Por outro larlo, o valor CDVA das luminárias com potencial de conservaçăo de energia (luminárins de vapor đe mercirio o luz mista) é de US\$ 32,6 milltǒes/ano, com a implantação dos programas de uso eficiente de energia baixará para US\$ 24,7 millhöes/ano, que resulta em vantagem do ponto de vista ceonômico para o Equador. Alćm disso, o investimento inicial produz resultados satisfatórios uss "tiguras de mérito" tais como no CEC para o elenco de substituições que situa-se em 13,2 USS/MWh, valor inferior do que o custo marginal nédio de evergia 83 US\$/MWh. De maneirs similar, o CPC situa-se em $328 \mathrm{USS} / \mathrm{kW}$, valor inferior que qualquer alternativa de oferta de energia. Além disso, se recomenda substituir o clenco de luminárias de vapor de mercúrio o luz mista por vapor de súrín no perfodo de trẻs anos e obter a maior vantagem da TIR que situa-se em $46,7 \%$.

Os programas de uso eficiente de entergia produzem deslocamentos dos investimentos nнs árcas de geraçiöo, tranıstrisșio e distribuiçāo num valor equivalente a USS 6,1 millıôts/ano (o valor presente desta quantidade atinge USS 33,9 millóes e é igual an deslocamento nas instalą̧ð̄es para produzir e transmitir evergin com um custo unitário igual ao marginal de potência). A poupança pela diminuiç̧o de potência $\mathrm{e}$ do consumo de energia atinge US\$ 9,4 millsões'ano (US\$ 6,1 milhōes por potência e US\$ 3,3 millhōes por energia). No entatto, os custos operacionais aumentam em US\$ 1,5 milhōesiano. Portanto, o halanço abrangente de perdas e ganhos proporciona um saldo positivo de USS 7,9 millsōes'ano (o valor presente é US\$ 44,6 milhøes). 


\begin{abstract}
Equador's Public Illumination (PI) is responsible for $7 \%$ of the total electric energy consumption of the Electric Sector. There are nearly 450,000 famps installed, with an electric power demand of $90 \mathrm{MW}$ and a consumption of 394 GWh/year of energy. Mercury lamps represent $72 \%$ of the consumption, 30 dium lamps represent $26 \%$ and the remaining is used by mix, incandescent and fhorescent lamps.
\end{abstract}

The expected saving of capacity with the retrofitting of mercury and mix lamps is 66.1 MW. The grenter saving is for the lamps HG- 175 W with $35.1 \mathrm{MW}(53 \%)$ and the lamps HG-125W with $18.7 \mathrm{MW}(28 \%)$.

This thesis propose to replace mercury vapor and mix lights by high pressure sodium lamps with the following power: IIG-125W by NA-70W; HG-175W by NA-100W: HG$250 \mathrm{~W}$ by NA-150W; HG-400W by NA-250W and MS-160W by NA-50W.

If conventional cochnology is replaced by the efficient nne (at this moment), demand capacity of the If system decrease to $64 \mathrm{MW}$ (power conservation, $26 \mathrm{MW}$ ), energy consumption to 281 (GW//year (snved energy of 113 ( $\mathrm{WWh} / \mathrm{yen}$ ), that is a decrease of $29 \%$ for the pwwer and electric systems requirements (electric system decrense in $2 \%$ ).

To change 370,000 mercury and mix lamps by the efficient lights needs US $\$ 47.7$ millions (anumilized US\$ 8.4 millionsiyear). The Amualized Life-oycle Cost of the potential conservition of energy (mercury vapur lanps and mix lights) is USs 32.6 millionsiyear. This replacement decrense by US\$24.7 millions'year the electricity bill of the sector showing that Equador has economic gain. Besides that, the initial investment shows advantage on merit ligures as the Cost Saved Energy for the altematives of substitution of 13.2 US\$/MWh, that is lower than the energy marginal cost of 83 US.5/MWh. Identically the Cost Saved Power is 328 US5/kW that is lower than any other supply option. The recommendation is to distribute the replacement during three years canying out the substitution of the conventional lamps as they extinguished obtaining a best advantage in the Internal Rate of Return of $46.7 \%$.

The substitution program (energy efficient use) produces a displacenent of investments in the generation, transmission and distribution areas with a value of US $\$ 6.1$ nillionsiyear (tlis amount is similar to the displacement of installation of more system electric power at an initial cost US \$ 33,9 millions). Saved power and energy represents an amount USS 9.4 millions'yesr (USS 61 millions by power and US $\$ 3.3$ millions by energy). However the operation cost increases by US S 1.5 millions/year, therefore the balance including costs ant gains has a net positive balance of USS 7.9 millions/year (present value represents USS 44.6 millions). 


\section{CAPITIILO I}

\section{INTRODUÇÃO}

\subsection{APRESENTAÇÄO}

Antes dos anos 60 , o setor elétrico equatoriano cresceu sem plancjamento técnico, econômico ou funanceiro, descuidando-ş além destes aspectos outros como os administrativos e o desenvolvimento dos recursos humanos e, mais ainda, existiram consideraçōes localizadas e políticas que não permitiram o crescimento do setor elétrico.

No principio dos anos 60,0 governo equatoriano viu a necessidade de evitar o maior parcelamento, dispersão e brixa qualidade do serviço elétrico, que tinha atingido o selor até essa data; além disso, era necesś́rio diminuir os altos custos de operaçăo e maustençầ que oneravam os municípios no controle do setor elétrico.

Sob estes antecedentes, o governo decidiu criar um organismo estadual encnrregado do descarolvimento futuro do setor elétrico. Então, ć assim que mediante Decreto Lei No. 24 de 23 de maio de 1961, cria-ze o organismo estadual encarregado da eletrificnção do Equador em todas as úreas, isto é geração, transmisstio, distribniçฬo e comercializaçầo. O organismo clasmn-se Instituto Equatoriano de Eletrificaçño INECEI; além disso, expede-se a Lei Básica de Eletrificação. Até essa data, a eletrificaçīo do Equador era desordenada costando com $120 \mathrm{MW}$ de potência produzida pelas 1.200 usinas isoladas de geraçâo, cujos downs eram empresns públicas (municipios) e privaclas.

\footnotetext{
A Lei Básicn de Eletrificação estabeleceu facultar ao INECEL a formação de concessionárias elétricas a nível regional, que teriam sob sua responsabilidade a distribuiçño e comercialização da energia elétrica, enquanto o INECEI, seria responsável

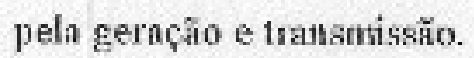


Portanto, o seinr elétrico traballın da seguinte maneira: م INECEL, responsável pela gernçăo e tranısnissāo (Sistema Nacional Interligado SNI), como organismo que traballia dentro do entomo juridico do setor público; e, 18 concessionárias subsidiárias do INECEL responsíveis pela distribuiçõo e comercialização, que trabalham dentro do entono da Lei de Companhiss. Além disso, lıa a Empresa Elétrica do Equador EMELEC INC., emp̧resa estrangeira, com área de concessão na cidade de Guayaquil, cujo contrato de concessåo terminou em 1985 e que assinou com o governo, em setembro de 1995, o contrato de transferencia dos ativos ao Estado.

O setor de Ihuminaçn̆o Píblicn (IP) é importante pela sua participaçĩo no consumo de energín $(7 \%)$ do Sistema Elétrico Equatoriano Além disso, s potência instalada representa $6,2 \%$ do valor de demanda máxima do Sistema Nrcional Interligado (SNI). Programas de uso eficiente de encrgin neste setor produzirăo mais economi่ aos usuários, devido que o consumo de energia de IP é repassado aos usuários por taxaçäo.

P’or outro lado, as estratégias para produçā̄o, transmissȟo, distribuiç̄īo e uso da energia têm um papel preponderante na busca de desenvolvimento sustentado pela humanidade. As necessidades de uma visăo global do problem e de métodos de avalinçâo que ponderem adequadamente os diversos aspectos envolvidos (técnicos, ambientais e sócioeconômicos) sằo relevantes. A energia elétrica, devido sua gran rle patticipaçăo na matriz entergética, deverá ter papel destacado neste contexto. É necessário, cntāo, que a metodologin e ícuicas de planejamento do setor elétrico sejam aperfeiçoadns para incomporar aspectos nà̀ usuais, cnfatizar alternativas nāo traricionais, e permitir participaçño de outros protagonistas envolvidos mo processo de uma forma ou de outra.

Assim, questīes como minimizaçño de pertas, programas de conservaçâo de energia, uso eficiente da eletricidade, melhoria da eficiência dos equipamentos, modemizşุầo/reabilitaçăo e uso de fontes altemativas, deven ser enfatizados no planejamento c assumidas como recursos disponiveis $\mathrm{em}$ um processo metodológico mais abrangente. Aspectos relacionados cam a prescrvaçăo do meio ambiente e os custos sociais, também devem ser incorporados. Adicionalmente, a metodologia aperfeiçoada deverí permitir avaliaçào coordenacla dos diversos protaganistas dos 
sistemas de potêacia, que deverão resultar da reorganização jastitucional em andamento 110 setur (CEDFE, 1995).

\subsection{OR.IETIVOS}

Analisar as coudições técuicn, econôinica e financeira do setor de lluminaçño Pública do Equador: baseada em dados propotcionados pelas concessionárias e pelo Instituto Equatorians de Eletrificaçĩo (INFCFI.).

Propor a troca do sistema de iluminação atual pelos sistemas eficientes cm funçåo da avaliał̧ão da conveniencicia técuica, econômica e funnceira usando metodologia desenvolvida $\mathrm{cm}$ usos fiutais (tenpo simples de retoruo, taxa iuterna de retrono, custo de. potência e energia conservada, custo durante a vida, custo do limen-hora).

Propor e orientar as estratégias para implentenlat proguamas de racionalizaçăo, conservaçāo e uso eficiente de energia no setor de lluminaçìo Pública, mediante o nso de luminárias com lâmpatas mais eficientes (o estudo nào considera outros elementos da luminaria como por exemplo o reator) e, na eventualidade, pelo uso de sistemas de controle sobre as luminárias.

Projetar a denanda de potêucia e energia a partir dos usos finais do setır de Iluminaçūo Pública, descnvolvendo a metodologia de cenários para a determinaçōo da demanda de potência e energin a partir do mno base 1994 até o tno horizonte 2005.

Determintar a conventência da implantação de programas de uso eficicnte de cnergia e seus resultados para uma etapa compreendida entre as anos 1995 e 2005 , baseads na avaliação integrada de allemativas de ofert. de mergia e uso eficiente de energia no sctor de Ihumintação Piblica.

\subsection{MOTIVAC (̂̀)}

Un dos setores importantes no país pela sun porcentagem de consumo de energia elétricu $(7 \%)$ é o setor da jluminaçấo pública. 
Anteriormente foram feitos outros estudos (Mahauad 1994; e, Paliîo') de uso eficiente de energia elétrica para os setores Residencial e Comercial. Com o presente estudo o Equador tew ferramentas para aplicar programas de uso eficiente e conservaçăo de energia elétrica sobre $61 \%$ do consumo total (39\% Residencial, 15\% Comercial e $7 \%$ Ilumiunaçẫo Pública).

0 país nâo diłp̣ôe dos recursos econômicos suficientes para a coustrução de novas usinas elétricas, sendo assim os programas de uso eficiente e conservação de energia, com estns características, sĭo a melhor alterıativa.

$\Lambda$ implantaçũo de programas de uso eficiente e conserwaçăo de energia na llumínação I’ública é nuito fícies de ser feita, porque eles precisam da decisăo de poucas pessoas no nível administrativo.

\subsection{METODOIOGIA}

A metodologin utilizada será a de usos finais com ênfase no uso racional e conservação de energiit.

O consumo de energia por uso final é obtido partindo de dados desagregados proporcioatados pelas concessionárias do Equador. O primeiro objetivo é identificar a quastidade e os tipos de luminárins (incandescente, fluorescente, vapor de mercúrio, huz mista, vapor do sódio) e, posterinrmente calcular suas potências e energias (coụjunto lâmpaม่ $\mathrm{c}$ reator).

A partir das ínịóteses de redação de:

- potćncia e consumo de energia pelo uso de lâmpadas eficjentes; e,

- custos adiciontais envolvidos pela sua utilizaçăo,

analisa-se economicamente e avalia-sc o potencial de redução mediante a substituiçăo dos equipamentos convencionais, para cada altemativa de uso final. No processo,

${ }^{1}$ Encontra-se clatworando a Dissertaçăo do Mestrado pasa o sctor Comercial. 
calcnla-se as seguntes figuras de mérito: tempo simples de retomo, taxa interna de retono, custo de potência e energia conservada, custo durante a vida, custo durante a vida anualizado, custo durante a vida anualizado năo energético, custo do lúmen-hora. Cada uma đestas ferramentas fornece informações sobre a viabilidade econômica do investimento a ser realizado, quer seja pelo país (INECEL), quer seja pelas concessionárias.

No entanto, a luminária tem outro equipamento que também dispõe de potencial de conservação como o caso do "reator", neste estudo de caso não so considera esta altemativa pois essa tecnologia ainda se encontra em processo de desenvolvimento para a Unminação Pública; entũo, o estudo estí dirigido ḋ troca de: a) lâmpadas eficientes com scus acessórios ou, b) luminárias com lâmpadas eficientes.

A projeçio do consumo em Iluminą̧ăo Pública será feito por concessionária usando o critério de "consumo especifico" (razão entre o consumo de potência em Ilutninaçăo Púbica e o aúmero de habitantes atendidos), baseado na projeçāo demográfica do INEC $^{2}$ e em parâmetros explicativos do indice de habitantes por clienle e do indice de atcudimento (grau de eletrificnçăo).

$\Lambda$ evoluçũo demográfica é proporcionada pelo Instituto Nacional de Estatisticas e Censos (INEC) do Equador para o periodo 1994-2005.

Com esta infoumaçẵo, simula-se programas de uso eficiente e conscrvaçăo de energia sob critérios dos segiuates cenários: eficiêacia congelada, tendencial e eficiente.

Eliciência Congelada: tal proję̧đo considera que a cficiência dos equipamentos utilizados no ano projetado seja a mesma dos equipamentos do ano base; além disso, considera-5e que durante o periodo pode existir mellhorín nos niveis de iluminaçŭo pública dos setores urbanos num porcentagem de $10 \%$. O consumo projetado por este cenário fornece um extremo supetior.

${ }^{2}$ Instituto Nacional de Estatisticas e Censos (INEC) do Equador, organismo estadual encarregado de cbter, processar, netnitir a informaçăo e cstatisticas dos indices da propulaçấo, conıomia, inflação, etc. 
Tendencial: considera um aumento da eficácia natural e de uma evoluçăo tecuológica dentro das expectativas. Assim, o numento da eficiência é considerado natural, decorrente de uma evoluçāo tecnológica natural dos equipamentos colocados no mercado. O aumento na penetraçăo das tecnologias mais eficientes se deve às mudlanças dos equipamentos no fim da vida útil $\mathrm{e}$ ao crescimento vegetativo do número de luminárias. Não cxistem programas ou incentivos de conservaçāo ou uso eficiente de energia.

Fficiente on Potencial Técnico: assume-se o uso de equipamentos mais eficientes disponíveis em codu ano para substituiçāo daqueles que terminaraın a sua vida útil e além disso considera-se o crescimento vegetativo do número de luminárias.

Sob estes cenários, calcula-se os impactos econônicos de programas de uso eliciente e conservaçăo de energin e, se propæe estratégias para a sua implantação. 


\section{CAPTTULO II}

\section{CARACTERISTICAS DA OFERTA F DA DEMANDA DE ENERGIA NO SETOR ELÉTRICO DO EQUADOR: O SETOR DE ILUMINACÄO PÚBLICA} (IP).

A populaçåo do Equador, estimada em dezembro de 1992, ntingiu 10.091.000 babitantes, dos quais 7.590 .000 dispunham do serviço elétrico, o que significa em termos de porcentagem $75,2 \%$.

As moradias com serviço clétrico (ano 1992) na área urbana atingin 05\%, e na área rural $52,1 \%$. Isto dá a idéia do grau de cletrificação do Equador e as medidas que se devem implementar para subir estas porcentagens tentando atingir $100 \%$.

As 19 concessionśrias no ano 1993 ateuderam a 1.714 .000 clientes, cujo consumo total fui $5.533 \mathrm{GWh} / \mathrm{ann}$. Fistes dados proporcionam o resultado de consumo médio anual $3.228 \mathrm{kWh} / \mathrm{cliente-ano,} \mathrm{equivalente} \mathrm{ao} \mathrm{consumo} \mathrm{mélio} \mathrm{anual} \mathrm{per} \mathrm{capita} \mathrm{de} 340$ kWh/hahitaute. Entretanto, outros paises de América Latina têm consumos per copita muito maiores, en média $1.350 \mathrm{kWh/habitante-ano} \mathrm{e,} \mathrm{mais} \mathrm{ainda,} \mathrm{os} \mathrm{países}$ desenvolvidos cujos consumos per capita são maiores que $10.000 \mathrm{kWh} / \mathrm{habitante-ano.}$

No ano 1992, o preço médio de venda de energia nos clieaces foi 39,7 USS/MWh, valor pequeno para que o setar elétrico possa cobrir a despesa de operaçåo e manutençăo, o serviço da divida e dispor de um excedente para imvestimentos na expanșo. 


\subsection{CARACTERÍSTICAS DA OFERTA DE ENERGIA ELÉTRICA: GERAC̆̃̃o, TRANSMISSÃo E DISTRUUIÇC̃̃o.}

A distribuição e comercialização de energia elétrica propriamente dita, está sob o coutrole de dezenove (19) concessionátias de características diferentes tanto em área de serviço, capacidade instalada, controle de potência e energia, etc., interligadas todas elas ao Sistewa Nacional Interligado (SNI) do INECEL, estaudo nssim integradas as regiōes da costa e serra, filtando ainda a regiǒo oriental.

As concessionárias tền caracter de fiuncionamento de compantias privadas e eståo regulamentadas pela Lei de Companhías. No entanto, a maior parte das açŏes, em todas as concessionirias, pertence no INECEL.

\subsubsection{CARACTERISTICA ATUAL DO SISTEMA ELÉTRICO EQUATORIANO.}

\section{2,1.1.1. SISTEMA DE GERAÇȦO}

O Sistema Naciomal Interligado SNI, compreende todas as instalaçōes de geraçăo (hidrelétrica e termoelétriç) do INF.CFI, além das concessionárias, que estāo interligadas ao Sistema Nacional de Transnissăo SNT. Na TABEL.A 2.1 apresenta-se a estrutura de geração do SNI para janeiroig4.

O potencial hidrelétrico do Equador segundo OLADE-SIEE é de $21.520 \mathrm{MW}$, embora o Banco Central do Eqquador (Benalcázar, 1989) quota o valıo de 93.400 MW de potência, dos quais $68.960 \mathrm{MW}(74 \%)$ corresponde Às vertentes do Amazonas e $24.470 \mathrm{MW}$ às vertentes do Pacífieo. As maiores bacias pertencem ac Amazonas e seus rios são o Nap̧o, Pastaza e Santiago que em conjunto atinge $52,500 \mathrm{MW}$. Tem 2.53 lugares possíveis para a constunçăo de obras hidrelétricas. 
Tomando o primeiro valor da OLADE para fazer a anślise, no ano $1983 \mathrm{com}$ a construção da usina hidrelétrica "Paute" na primeira fase, a capacidade hidrelétrica instalada total no pais chegou a 742 MW on seja, um aproveitamento de apeaas $3,5 \%$ do potencial. No ano de 1987 foi construída outra usina hidrelétrica de grande porte "Agoyán", sendo aumentada a capacidade instalada total para o valor de $911 \mathrm{MW}$, ou seja un aproveitamento de $4,2 \%$. No ano de 1991 é terminada a construçāo da segunda fase da usina "Paute", com a qual a capacidade instalada em lidreletricidade atinge 1.484 MW, ou seja um aproveitamento de $6,9 \%$ do potencial.

A oferta de energia elétrich é a capacidade de geração elétrica do Sistema Elétrico do Equador. Essa capacidade é de $2.268 \mathrm{MW}$ de potência, dos quais 1.471 MW (65\%) s্র̄o de origem hidráulica; $508 \mathrm{MW}(23 \%$ ) de origem térmica (vapor ou gís) e o restante 289 MW (12\%) térunica Díesel.

A capacidade instalada de geraçŭo de propriedade de INECFL é de 1.693 MW (75\%) e 575 MW $(25 \%)$ sĩo propriednde das concessionárias regionais. O setor privado do pais tem investimestos em usinas térmicas, instaladas nas cidades de Quito e Grayaquil 108 MW (4,8\% da cnpacidade totaI) c clas operam somente quando o INECEL precisa dessa energia elétriç (especialmente na temporada de seca), pelo qual tem um contrato de compra venda de energia entre esses setores.

No ano 199.3, a demanda máximn foi de $1.271 \mathrm{MW}$, o que representa $86 \%$ da capacidade itstalada nas usinas hidrelt́tricas to SNI; em julho/95 a demanda máxima foi $1.441 \mathrm{MW}$, - que representa $98 \%$ da capacidade em hidrelétricas. Existe um eminente risco de que n potência nominat instalada năo possa garantir o aprovisionamento na temporada de seca, nos tueses de dezemlıro a março (verăo nห regiàn Oriental do Equador). 
O país dispōe de $2.268 \mathrm{MW}$ de potència itstalada ( $64 \%$ corresponde a lidreletricidade e $36 \%$ a termoeletricidade), dos quais estão prontos para operação $2.152 \mathrm{MW}$, e o resto $116 \mathrm{MW}$, corresponde a grupos térnicos que se encontram em processo de manutenç̧ิ๐.

Da potência total instalada (2.268 MW), somente $95 \%$ (2.152 MW) cstá pronta para operar; 10 caso disto acontecer, $89 \%$ (2.008 MW)) pode ser obtida nos terminais dos geradores, e $70 \%$ (1.590 MW) pode-se obter ao nivel de subestação do SNI.

TABELA 2.1: FOTÊNCIA DISPONIVEL DE GERACC̄̃O DO SNI (IANEIROM94)

\begin{tabular}{|c|c|c|c|c|c|}
\hline 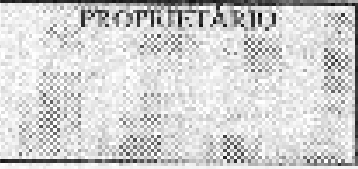 & $\begin{array}{l}\text { HWIENWE } \\
\text { TSTALADA } \\
\text { (NW) }\end{array}$ & 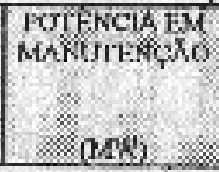 & 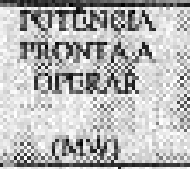 & 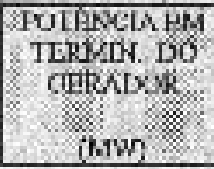 & 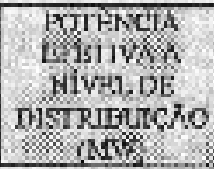 \\
\hline \multicolumn{6}{|c|}{ 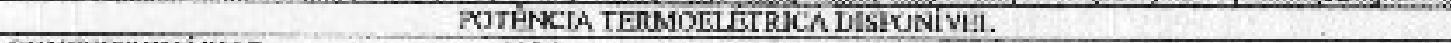 } \\
\hline CUNCHESICINAHAS & 405,1 & 116,7 & 288,5 & 217,7 & 291,3 \\
\hline INFXril. & $591, f$ & 0,0 & 391,6 & 329,3 & 2079 \\
\hline TOTAL TERHOELTIRICO & 796,8 & 115,7 & coso, 1 & 547,0 & 4992 \\
\hline \multicolumn{6}{|c|}{ PUTENCLIA WORELETRICA DTSPONIVHL } \\
\hline CONCESSIONARIAS & 100,6 & 0,0 & 170.6 & 169,1 & 73.7 \\
\hline DTCIEL & 13010 & 0,9 & 13010 & $129 ! 9$ & 1817,0 \\
\hline TOTAL IIIPRIEISRICXI & 1171,6 & 0,0 & $1471 \mathrm{~K}$ & 11613 & 1090,7 \\
\hline TOTAL DSSPONIVEL & 2268,3 & $115_{1}, 7$ & $215 t, 7$ & 2008,7 & $1,589,9$ \\
\hline
\end{tabular}

FONTE: INECEL - ATUALIZAÇX̄O DO PLANO NACIONAL DE ELETRIFICAÇĀO, OUT/M4

O motivo da diminuiçăo dos valores de potência iustalada até a potência em terminaís dos geradores, deve-se no caso de grupos térmicos, de condiçües operativas derivadas da sua antigüidade, assiun como também à diminuição da eficiência pela altura sobre o nível do mar; 10 caso de grupos hidrelétricos, tal dimizuição estú associada com a eficiếncia das instrlaçöes eletromecânicas.

A diferenç entre potêntcia efétiva $\mathrm{cm}$ termimais de gerador com a potência efetiva a nfvel de subestaçăo principal, é devido às perdas técnicas no sistema de transmissũo.

\subsubsection{SISTEMA DE TRANSMISSẢO}

O Sistema Nacional de Transmissão SNT, tem os seguintes objetivos básicos: transmitir a potência gerada pelas usinas hidrelétricas e termoalétricns do SNI; transportar o 
distribuir esta potêcia até os principais centros de consumo de energia clétrica do Equador, uas izellıwes condições de operação, segurança e confiabilidade; e, facilitar a iltegração de todas as províncias do país ao sistema elétrico macional, procurando obter maiores benelícios sócio-econômicos e menores custos de operaçån.

Baseado em eśttdos técnico-econômicos de vírias altentativas de expansão da rede elétricn nacionâ, realizados desde o ano 1966, o INECEL planejou a construção de um anel de transmissão de $230 \mathrm{kV}$, duplo circuito, cujo percurso permite unir os centros de gernçĩo e consumo do SNL. Deste anel de $230 \mathrm{kV}$ construiu-se linhas de transmissão rudial a $138 \mathrm{kV}$, pelas quais fomcoe-se energia elétrica aos centros de consumo afastado deste anel.

As caracteristicas mnis importantes do anel são as seguintes:

- Disthancia relativamente pequena entre os centros de geraçû̃o e consumb.

- Cargas elétricas concentradas no ancl privcipal; entre estas estão as cidades mais importantes do pais, Quito e Guayaquil.

- A curto e tuédio prazo nào é uecessário fortalecer o anel, nem aumentar o nivel de tessiño.

No ano 1994, o SNT tinha a seguinte conformaçăo: $820 \mathrm{~km}$ de liuhas te transmissão de $230 \mathrm{kV}$ (correspontente ao antel principal de duplo circuito), $1.306 \mathrm{~km}$ de $138 \mathrm{kV} \mathrm{e}$, 4. 168 MVA de capacidade OA' em subestaçōes de reduçăo (1.894 MVA) e de elevação (2.274 MVA)

\footnotetext{
${ }_{3}^{3}$ Oil Air: capacidade coun resfriamesto natural (טก̆о tent fesfrlamento forçndo)
} 


\subsubsection{SISTEMA DE SUBTRANSMISSÄO (S/T) E DISTRIBUIÇÄO}

O sistema de subtransmissão e distribuiçăo é explorado, operado e mantido pelas concessionárias e dispōe, em conjunto, do seguinte (ver TABLL $\mathcal{A}$ 2.2):

\begin{tabular}{|c|c|c|}
\hline DENOMINACCRO & UNIDADE & QUANTIDADE \\
\hline SUBESTAÇŌES DE DISTRIBUTÇÃO & MVA & 1.959 \\
\hline LINHAS DE SUBTRANSMISSAO & $\mathrm{km}$ & 2.742 \\
\hline REDES PRIMARIAS & $\mathrm{knt}$ & 22.852 \\
\hline TRANSFORMADORES DISTRIBUICYČO & MVA & 1.926 \\
\hline 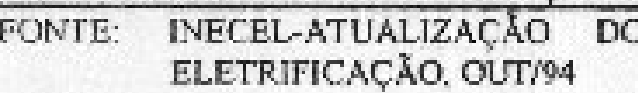 & LANO & CIUTAL \\
\hline
\end{tabular}

As características principais de cads concessionária estâo apresentadas na TABELA 2,3.

TABELA 2 3: CAPACIDADE INST ALADA NOS SISTEMAS DE STT E DISTRIBUCุ̃̃O DAS CONCESSIONARIAS

\begin{tabular}{|c|c|c|c|c|}
\hline $\begin{array}{l}\text { CONCDSSIONRKIA } \\
\text { (n) }\end{array}$ & 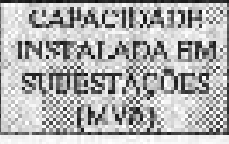 & $\begin{array}{l}\text { 1.INHASIB \&/: } \\
\text { 34:5-10-138kV } \\
\text { (vii) }\end{array}$ & 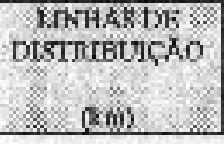 & 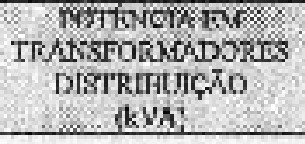 \\
\hline O1 FMFI.NORTES $\lambda$ & 56.55 & 205,00 & $1.064,64$ & 57.175 \\
\hline$n_{2}$ RFOIDNAL, DEL STIR BA. & 43.40 & 172.90 & $1.332,94$ & 13307 \\
\hline 03 crtopaxis. & 44.25 & 81,00 & $1.445,10$ & 74.694 \\
\hline 04 ESMIIEALMASSA. & 31.25 & 145,00 & 355.76 & 38322 \\
\hline 05 \&NNTE DOMARKiOB R.A. & $40, \infty 6$ & 125,00 & $1.127,00$ & $\cos 78 B$ \\
\hline UG MANAHIS.A & 100,50 & 35600 & 2.260 .40 & 129.723 \\
\hline 07 GLWYARTOSIRHS SA & $11,3,5 \mathrm{n}$ & 315,00 & $1.136,00$ & 124725 \\
\hline I8 MUAC;I) S.A & 51,75 & $1 \pi 100$ & 868,20 & 65.727 \\
\hline 09 SANT $A$ EILFNA $S A$. & $8 n, 130$ & $34 \times 0$ & 725,00 & 47.005 \\
\hline 10 ErAEIOKOS RA. & $7 m, \mathrm{~m}$ & $1.36,00$ & $816, \infty$ & \\
\hline 11 AMLL'AX 8.A. & $75, \mathrm{mo}$ & $112 \mathrm{~m}$ & $2.000,00$ & 90619 \\
\hline 12 CENTRO SUK C.A. & 127,50 & 265,00 & $2.228,00$ & 195.870 \\
\hline 13 RJOLAMTLSA. & 61.79 & 11900 & $1.430,00$ & 74.785 \\
\hline 14 HOLIVAK S.A. & $6,5 \mathrm{n}$ & 3200 & 589,72 & 11.234 \\
\hline 13 b.4Xs katss S.A & 38.75 & 104.50 & 83290 & 59.935 \\
\hline 16 AxoGutses. & & & 246,85 & 3,745 \\
\hline 17 R.K. (U) & $55,7.90$ & 214.79 & $3.460,00$ & 829,000 \\
\hline 18 EREIJCIVL. & $46 \mathrm{~m}, \mathrm{IM}$ & $154 \mathrm{~m}$ & 834.50 & \\
\hline TorAL & $1.958,50$ & 2.711 .50 & 22.85221 & 1.925 .541 \\
\hline
\end{tabular}


Observa-se que em todos os componentes do sistema elétrico, as concessionárias EMPRESA ELÉTRICA QUTTO S.A. e EMELEC INC. que oferecem serviço às cidades de Quito e Guayaq̧uil respectivamente, săo aquelas que têm a maior quantidade; assim ć que em conjunto os seus consumos de energia no ano 1993 foram $58 \%$ do total do pais, o que indica a importância destes mercados.

\subsubsection{PLANEJAMENTO DO SISTEMA ELÉTRICO EQUATORLANO}

O periodo de planejameuto da análise compreende os anos 1995 e 2010.0 planejamento a curto prazo (1995-2000), permite determinar as "decisões" que devem ser tomadas; de médio prazo (2001-2005), permite determinar as "яções": c, de longo prazo (2006-2010) ajudará a determinar os "estudas de viabilidade" que devem ser desenvolvidos.

O estudo de mereado e equipamento foi feito pela Direção de Plarıjamento e Tarifas do INECEL onde cieterminou-se dois cenários de demanda elétrica, o primeiro chamado de menor crescimento $(B)$ e o segundo chamado de maior crescinento $(\Lambda)$. Em função destes cenários, estabeleceram-se várias alternativas para as instalações, procurando sempre obter o mettór risco econômico.

\subsubsection{SISTEMA DE GERAÇÃ̄o}

Após a análise de várias alteruativas de instalaçőes, determinou-se uma alteruativa que apresenta um menor custo no curto e médio prazo, pelo qual a tomada de decisōes sobre as instalaç̄̄es cm sunes imediatos, não afeta o plançamento, alérn de ser possível mudar o plano de instalaçieses para longo prazo.

O equipamento determinado como ótinto, não é necessariamente de custo míninto. $O$ plano de custo winimo estabelece um programa de obras para depois do ano $2000 \mathrm{com}$ a instalaçăo de usinas térmicas de geraçăo, que usaråo como combustivel gás aatural do 
"Golfo de Gnayaquil" (o gís do Golfo está em processo de exploraçăo, tendo portanto um risco de disponibilidade). O plano de equipanento ótimo segundo estas consideraçōes, em resumo, é o seguinte (ver TABELA 2.4):

Segundo o INECEL, este programa de obras não é limitante à íntervençño dn empresa privada na constraçĩo de outros empreendimentos, como exemplo os projetos hidrelétricos Toachi-Pílatão (171 MW) e Angamarca (50 MW).

Os investimentos para o setor de geraça้o sึ̃o da orden de 1.300 milthöes de dólares correspondente ao periodo 1994-2006, dos quais para o curto prazo (1994-1998) é necessário 373 millıōes de dólares.

TAEELA 2,4; FL,ANO DE EQUIPAMENTO DO SNI (GERAC ĀO ATÉ ANO 2005)

\begin{tabular}{|c|c|c|c|}
\hline $\begin{array}{l}\text { THO EQUIPAMFNTO } \\
\end{array}$ & 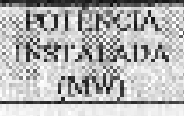 & $\begin{array}{l}\text { custo } \\
\text { Lovitunio } \\
\text { (ussiniv) }\end{array}$ & $\begin{array}{l}\text { ANDTE } \\
\text { OHERACRO }\end{array}$ \\
\hline 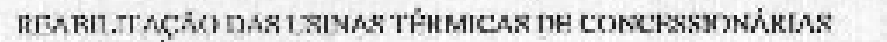 & 116 & & CUT $/ 1994$ \\
\hline UENAAOSISWTULAL & 182 & .798 & Ort $: 1995$ \\
\hline LEINA A GAS NATUEAL & 30 & $54 !$ & cyor \\
\hline ISINA A VAFOR & 125 & 1.241 & O18T 11997 \\
\hline URINA HIJRES.ETRICA DMULE PERLA & 130 & (2). 1.85 & mit:198 \\
\hline 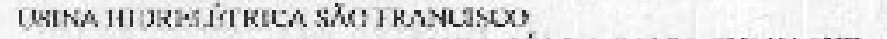 & 230 & 1017 & DEC, 11999 \\
\hline 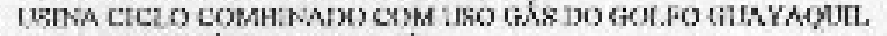 & 160 & $\$ 10$ & OLT $/ 200 \mathrm{~L}$ \\
\hline USTNA IMDZFi IITRICA ATMQUI & 36 & 2.457 & $01: 1 / 200 t$ \\
\hline USWNA IIDORELITRICA PUTE-XAZA & 180 & 1.875 & $01: 1 / 2000$ \\
\hline 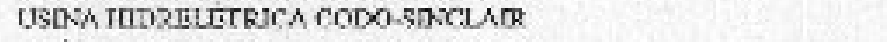 & 4.32 & -164 & ot:1/2006 \\
\hline TOTAL & 1.561 & & \\
\hline
\end{tabular}

FONTE: INECEL $A T$ TALIZACZAO DO PLANO NACIONAL DE ELETRIFICAC

NOTA: (†) Näo inclui o custo da linha de transmissio

\subsubsection{SISTEMA DE TRANSMISSÃO}

O plano de equipumenlo estabelecido, considera três periodos de construçāo da5 obra: curto. médin e longo prazo.

No curto prizo (1975-1999), inclui-se obras que est3o taato em processo do constrnçāo come aquelas que devem ser construidas de invediato para entrar em fincionatmento no 
auo 1998. Estas obras são os sistemas: Paute-Pasquales-Trinitaria, a Fase $\mathrm{C}^{\mathrm{C}}$, a Fase D1", ampliação da subestação Portoviejo, ampliaçẫo do sistemı Milagro-Machala e subestação Dos Cerritos.

Para o mécdio prazo (1999-2003), esta prevista a construção das liuluas de transmissăo e subcstações, em conjunto com os projetos de geração (Săo Francisco, usiaa térmica de ciclo combinado e Apaqui), e outros projetos que reforçarăo a configuração do SNT.

Para o longo prazo (ano 2003 em diante), considera-se novas ampliaçőes para reforçar a configuraçĩ̄o do $\mathrm{SNT}$, assim como também a linha de tranșnissão do projeto CocaCodo-Sinciair que o ligará com o SNI.

O custo dos investimentos deste setor atiuge 247 millızes de dólares.

\subsubsection{SISTEMA DF SUBTRANSMISS ĀO E DISTRUBUIÇĀO}

Os equipamentos e instalaçōes atualmente em serviço do sistema de sublrausmissäo e distribuiç̧̄io, nāo satisfazem as condiçōes de qualidade e confiubilidade dos atuais clientes, assim como também dos futuros usuários do serviço elétrico, sendo portanto necssśrio implementar um programa de obras em torlas as concessionánias do pais.

O plano de obras estabelece a construção de $1.242 \mathrm{~km}$ de linhas de subtransonissino, em diferentes tensĩes e setmes: $93 \mathrm{~km}$ em linhas de $138 \mathrm{kV}$, e $1.149 \mathrm{~km}$ em linhas eutre 69 $\mathrm{kV}$ e $46 \mathrm{kV}$.

\footnotetext{
4. As inslalaçöes desta Tase inclui obras para a provincia de Carçi e inslalaçäo de capacitores no SNI.

"Instalaçōes ce expantsiso do SNI (provincias de Carchi, Los Rios. Cotopaxi, linbabura o Zamora Chinchipe).
} 
Em subestaçōes de distribuição serõo instalados 2.140 MVA de capacidade, dos quais 560 MVA correspondem ì tensăo de $138 / 69 \mathrm{kV}$ e $138 / 23 \mathrm{kV}$, e 1.580 MVA serão de tensฐ̄o $69 / 22 \mathrm{kV}, 69 / 13,8 \mathrm{kV}, 46 / 23 \mathrm{kV}$ e $46 / 6,3 \mathrm{kV}$.

Além disso, o programa coutém as instalaçōes complementares que incluem redes primarias, transformadores de distribuição, redes secundárias, ligações e equipes de mediçâo; juntamente com as instalaçōes atuais permitirăo satisfazer a demanda dos atuais clientes, alén de incorporar 860.700 novos clientes, dos quais 501.806 serão urbanos e 358.894 seråo rurais.

O investimento para este setor (período 1994-2003) atinge 1.078 millhōes de dólares, dos quais 331 millhōes de dólares ș̆o para subtransmissão, 341 milhôes de dólares ș̃o para obras de distribuiçà̃o vas concessionánías, 126 milhôes de dólares para geraçåo das concessionárias e o resto para investimentos gerais nas concessionárias, assim como também em programas de obras ua região oriental e Galápagos.

\subsection{CARACTERISTICAS DA DEMANDA DE ENERGIA ELÉTRICA}

\subsubsection{CARACierísticas históricas do MERCADO ELÉTRICO EQUATORLANO.}

A pesar de ter potencial hidrelćtrico bastante grande seguudo já indicado, o potencial usado é pequenn, sento o Equador un dos paises de menor consumo de eletricidade per capita na Américu Latina; em 1950 esse consumo per capita foi somente 37 kWh/habilante, e a potêncis elétrica instalada nesse ano $39,9 \mathrm{MW}$, correspondendo 18,7 MW de hidreletricidade (46,8\%) e 21,2 MW térmico (53,2\%) No ano 1993, o consumo per capita atingiu $492 \mathrm{kWh} / \mathrm{habitante.}$ 
A suálise listórica fin feita para o periodo 1977-1993, cuja informaçĭo apresenta-50 na TABELA 2.5 e mostra-se na FIGURA 2.I.

No periodo 1977-1980, as taxas de crescimento sĭo altas (consumo de energia 16,6\%, energia disponivel $16,0 \%$ e demanda máximn $12,5 \%$ ). As perdas de energia estiveram entre $14,0 \%$ e $16,5 \%$, enquanto o fator de carga subiu de $50 \%$ para $55,7 \%$.

Neste mesmo período, o crescimento ecomômico do país, calculado através da evolução do PIB foi sempre positivo e decresceste; sun variaçāo estava entre $6,5 \%$ em 1977 a $4,9 \%$ em 1980.

No período entre 1981-1989, se observa taxas de crescimento menores às antes ditas (consumo de energia $5,7 \%$, energiн disponível $6,6 \%$ e demanda máxima $6,1 \%$ ). As perdas de energia aumentaram de $13,7 \%$ em 1981 para $19,4 \%$ em 1989 , empuanto o fator de carga aumentou até atingir 59,4\% em 1989.

TABELA 2.5: EVOUUCÃO HISTÓRICA DO MERCATDO ELËTIUTCO EQUATORIANO

\begin{tabular}{|c|c|c|c|c|c|c|c|c|}
\hline ANC & $\begin{array}{l}\text { EonstImI) } \\
\text { (Givili) }\end{array}$ & $\begin{array}{l}\text { TAKA } \\
\text { XXi }\end{array}$ & 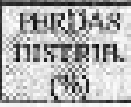 & $\begin{array}{l}\text { ENERgth } \\
\text { Drgmonive. } \\
\text { (4wh) }\end{array}$ & $\begin{array}{l}\operatorname{tn} \times A \\
m \\
\end{array}$ & 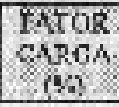 & 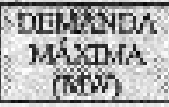 & $\begin{array}{l}\text { Trzi: } \\
(\%)\end{array}$ \\
\hline 1977 & $1.63 \%$ & & & 1.035 & & 31 & 434 & \\
\hline 1978 & $1.9 / 4$ & 19,9 & 14.1 & 2.328 & 18.3 & 53 & 494 & 1.1.7 \\
\hline 1979 & 2.211 & 12.6 & 165 & 2.649 & 15.8 & 94 & 957 & 12.7 \\
\hline 1990 & עי & 17, & 140 & 3022 & 14,1 & 56 & 618 & 11.0 \\
\hline 1981 & 2.824 & 8,6 & 13.7 & 3.273 & 8,3 & 57 & 659 & G.1 \\
\hline 1982 & 3.069 & 8.7 & 15.5 & 3634 & 11,0 & 98 & 714 & 9.18 \\
\hline 1993 & 3.2 .37 & 5,5 & 15.4 & $3 \mathrm{k25}$ & 5,3 & 61 & 712 & $-0,4$ \\
\hline 198.4 & 3.247 & 1,1 & 18.1 & 4012 & 4,9 & 61 & 751 & 5.5 \\
\hline 1985 & 5.538 & 7,6 & 18.7 & 4.314 & 7,5 & 60 & 821 & 9,3 \\
\hline 1906 & 3.830 & 8,3 & 18.4 & 4.695 & 8,8 & 50 & 912 & 11,1 \\
\hline 1987 & 4.3114 & $9, x$ & 17.6 & 5.101 & 8,6 & 61 & 955 & 4.7 \\
\hline 1988 & 4.316 & 2,7 & 19,2 & 5. 46 & 8,8 & 62 & 990 & 3.7 \\
\hline 19: & 4.413 & 2,3 & 19.4 & 5477 & 3,4 & 59 & 1,053 & 63 \\
\hline 1995 & 1.797 & 8,7 & 20.3 & 6.020 & 9,9 & 99 & 1,164 & 10,6 \\
\hline 1921 & 3.267 & 7,6 & 20,3 & 6604 & 9,7 & 61 & 1.246 & 3,0 \\
\hline $192:$ & 5.4134 & 4,4 & 19,7 & 6587 & 3,4 & $1 / 2$ & 1,252 & 0.5 \\
\hline 1935 & 5.151 & $-0,5$ & 22,4 & 7.022 & 2,9 & 59 & 1,753 & $g_{1}$, \\
\hline
\end{tabular}

Segundo esta desaceleração da atividade elétrica, neste periodo (1981-1989); O PIB evoluin com taxas inferiores às observadas no perfodo anterior; assim, por exemplo, a 
taxa de 1983 fri $-2,8 \%$ e do ano 1987 foi $-6,0 \%$, como resultado dos desastres naturais nesses anos e que restringiram, respectivamente, as exportaçбes agrícolas e petroleiras, principais compunentes da receita do país.

No perído entre os anos 1990 e 1993, verificon-se que o setor elétrico evoluin com taxas de crescinento ainda mais baixas que em todos os periodos da análise (consumo de energia $4,4^{\%} \%$, energia disponível $5,3 \%$ e demanda máxima $5,1 \%$ ). As perdas de energir aumentaram de $20,3 \%$ em 1990 a $22,4 \%$ em 1993 e o fator de carga esteve com variaçãu entre $59,0^{\mathrm{m}} \%$ e $62,1^{\%} \%$, sendo de $59,2 \%$ em 1993.

Neste período, a evoluçâo média do PIB for $2,7 \%$; no entanto, o selor elétrico manteve tendêncì de desaceleraçīo devido a outros fatores, dentre estes os aumentos dos preços das tarifas. Além disso, observa-se que no período de análise (1977-1993) somente no ase 1993 a taxa de crescimento do consumo de energia foi negativa $(-0,6 \%)$, comio resultado de diminuiçăo uo consumo industrial e comercial, e de menor incióência do setor residencial.

\section{FIGURA 2.1: EVOLUCৃÃO HISTÓRICA DO MERCADO ELÉTRICO EQUATORLANO}

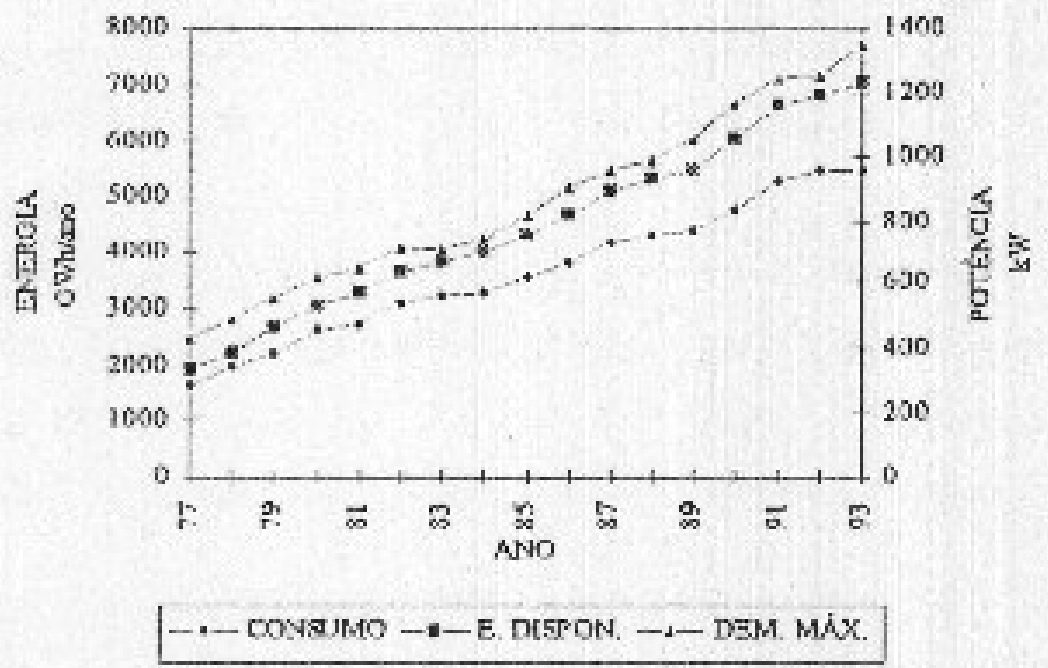


Coun respeito is este periodo de análise, pode-se couchuir que as principais causas que explicuriam esta evoluçio do mercado elétrico equatoriano, săo a desaceleraçâิo da atividade econônica (diminuiçăo do PIB) e os acréscimos do sistema tarifário em outubro de 1992 e maio de 1993 , e por outro lado, a decisão adotada por vários clientes industriais, de participar na cogeração de eletricidade, como resposta aos altos níveis tarifários, nos que se incluem outros valores (impostos) diferentes ao consumo de energia elćtrica (IP, coleta de lixo, eletrificaçăo rural, etc.).

Além disso, deve-se considerar as medidas emergentes que foram tomadas no ano 1993 , para poupar etuergia, pela possivel temporada de seca (o resultado foi 93,0 GWh de diminuiç̧ิ no consumo) e de igual maneirn, a paralisaçåo da usina hidrelétrica Paute (a muior usina do país), pelo dessstre natural de "Ta Josefina" (diminuiçn̆o da oferta de energia $20,6 \mathrm{GWh})$.

\subsubsection{CARAKTERÍSTICAS IISTÓRICAS DO MERCADO ELÉTRICO EQUATORIANO DIVIDIDO EM SETORES.}

No periodo 1982-1993, o consumo de energia elétrica cresceu em todos os setores com as seguintes taxas de crescimento: residencial $78 \%$ (média anual de $5,4 \%$ ), comercial $77 \%$ (média aaual de $5,3 \%$ ), industria1 52\% (média anual de $3.9 \%$ ), ontros $171 \%$ (média anual de $9,5 \%$ ) e IP $230 \%$ (média anual de $11,5 \%$ ), sendo este último setor o de maior crescimento frente aos outros, ao contrário do setor industrial que someute cresceu em $52 \%$. O cresciumento total do setor elétrico neste periodo foi $81 \%$ (média auual de $5,5 \%$ ).

Na TABELA 2.6 apresentam-se os dados históricos de crescimento dos setores Residenciai, Comercial, Industrial, IP e Outros desde o ano 1982 até 1993. 
TABELA 2.6: EVOLUÇÃo HISTÓRICA DO MERCADO ELÉTRICO EQUUATORIANO DIVIDIDO EMM SETORES

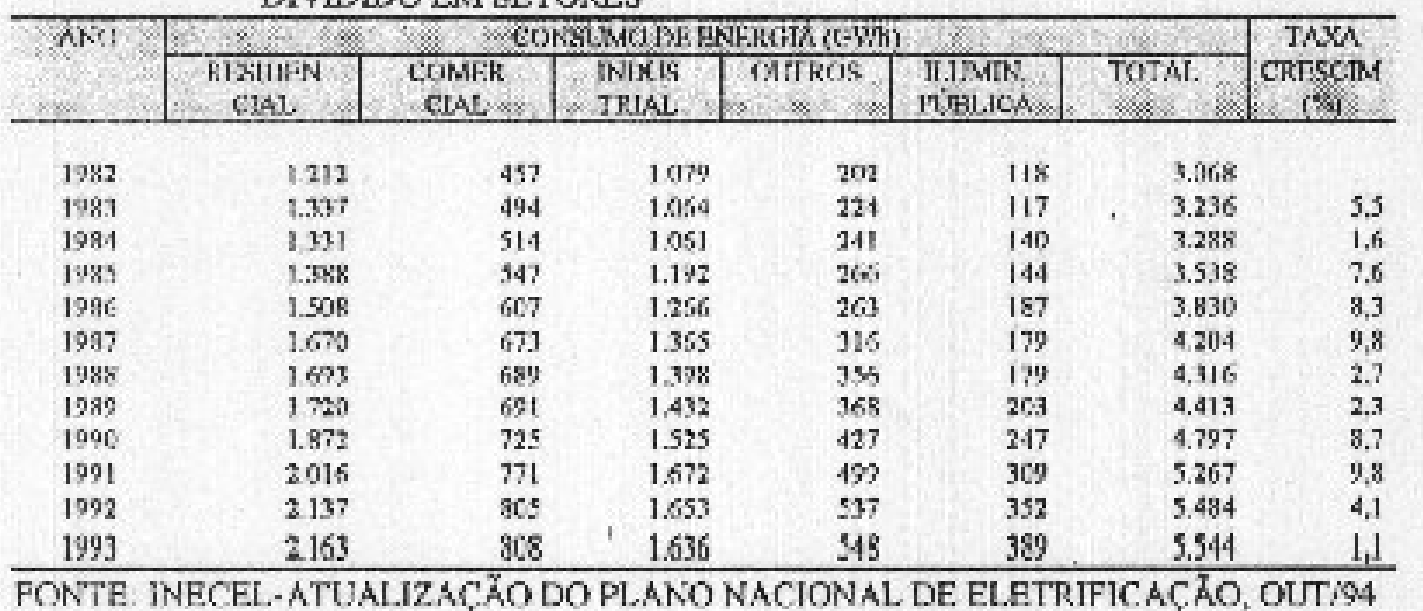

Na FIGURA 2.2 mostra-se os dados apresentados nห TABELA 2.6. FIGLTRA 22: EVOLUCÁO HISTÓRICA DO MERCADO ELÉTRICO
EQUATORIANO DIVIDIDO EM SETORES

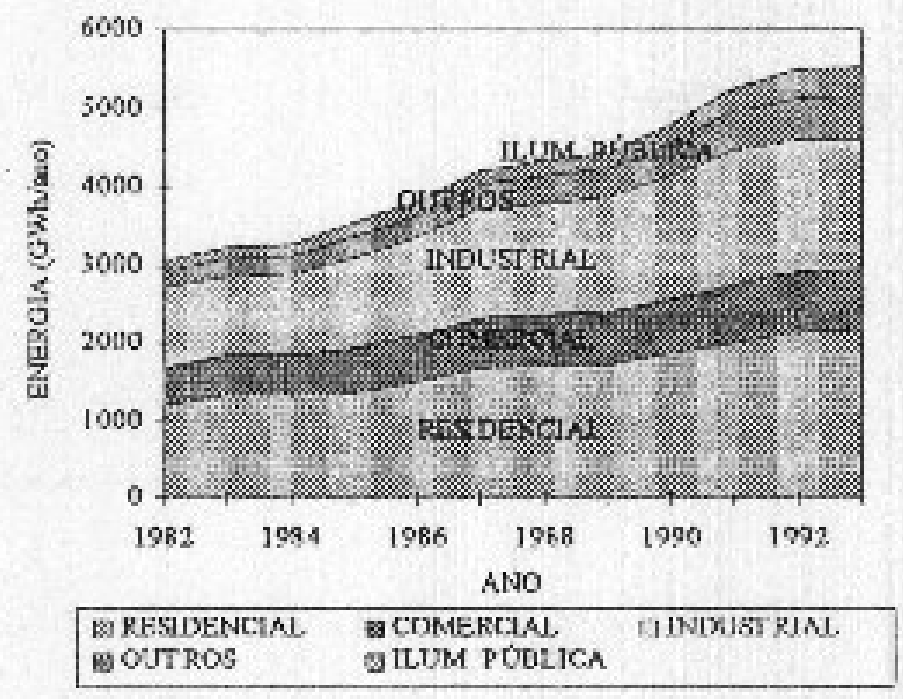

Tomando os anos 1982 e 1993 para fazer uma análise da evolaçũo, o consumo de energia dividido em setores é mostrado na TABFI.A 2.7. Segundo o consuno de energia, o setor residencial teve maior consumo que o resto de setores, a sua porcentagen (39"\%) foi de igual valor para os dois anos da análise (1982 e 1993); no segundo lugar esteve o setor industrial, que no ano 1982 foi $35 \%$ e no ano 1993 foi $29 \%$, observando-se diminuição inuportante neste setor pelos motivos indicados no ponto 
anterior; no terceiro lugar, esteve o setor comercial, cuja porcentagem manteve-se igual nos dois anos da análise, isto é $15 \%$; no quarto lugar, esteve o setor denominado outros (entidades oficiais, assistència social, bombeamento de água) com 0 valor de $10 \%$ para 0 ano 1993 e somente $7 \%$ para o ano 1982; e finalmente, está o sctor de IP, cuja porcentagem for $4 \%$ para o ano 1982 aumentando ate $7 \%$ em 1993.

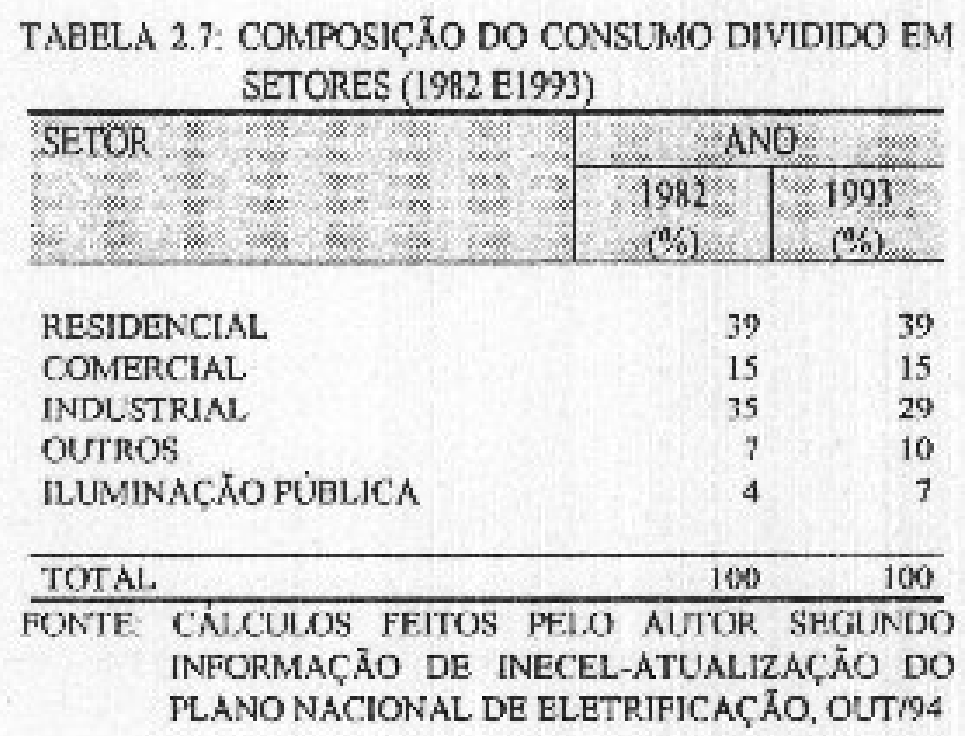

\subsubsection{PKOJEÇĀO DO MERCADO ELÉTRICO}

As projeçōes de demanda máximn e consumo de energia para o setor elétrico equatoriano foram feitas pelo INECEL - Direçāo de Planejamento e Tatifas em outubro/94.

O estudo estabelece dois cenários (maior e menor erescimento) de cvolução para as variáveis do mercado elétrico: consumo de energia, energia disponivel e demanda míxima. Estos cenários estāo baseados em variátcis macrocconôtnicas, como o caso do crescimento do país, que foram proporcionadas pelo CONADE ${ }^{r}$ para 1994 , e as metas de atendimento elétrico tanto urbano como rural, estrhelecidas pelo INECEL.

\footnotetext{
- CONADE: Consellso Nacional de Desemvolvimento do Equador. Organismo estadual sob o controle do Vire-presi dente da República, encarregado do planejamento integral.
} 
As variáveis macroeconômicas usadas nos estudos de demanda, parn o caso do cenário de menor crescinsento supoem 3\% para o produto interno bruto (PIB) duraute o período 1994-2000 e 4\% para o periodo 2001-2005. Para as metas de atendimento elétrico a premissa foi muater os atuais níveis, isto é, $95,2 \%$ para o setor urbano e $53 \%$ para o setor ruxal.

No outro ccuário proposto de maior crescimento, usou-se $4 \%$ para o PIB no periodo 1994-2000 e $6 \%$ no periodo 2001-2005. Para as metas de atendimento elétrico, a premissa foi de $98 \%$ para o setor urbano e $65 \%$ para o setor rural.

Na TABEI $\wedge 2.8$ observa-se os resultados da "projeç̆о̆" do consume de energia pata o cenário de mestor crescimento. No período estahtelecido 1994-2005, o setor residencial crescerá $52 \%$ (médín anual de $3,9 \%$ ), o setor comercial $51 \%$ (média anual de $3,8 \%$ ), o setor industrial $55 \%$ (média anual $4,1 \%$ ), o setor dettominado como outros $34 \%$ (média aunal de $2,7 \%$ ), e finalmente o setor de IP $58 \%$ (média anual de 4,2\%). O crescimento de todo o setor elétrico sob este cenário será $51 \%$ (médin anual de 3,8\%).

TABRLA 2.8: PROJEÇX̃O DO MERCADO ELÉTRICO EQUATORIANO EM SETORES (1994-2105) CENARLO DE MENOR CRESCIMENTO

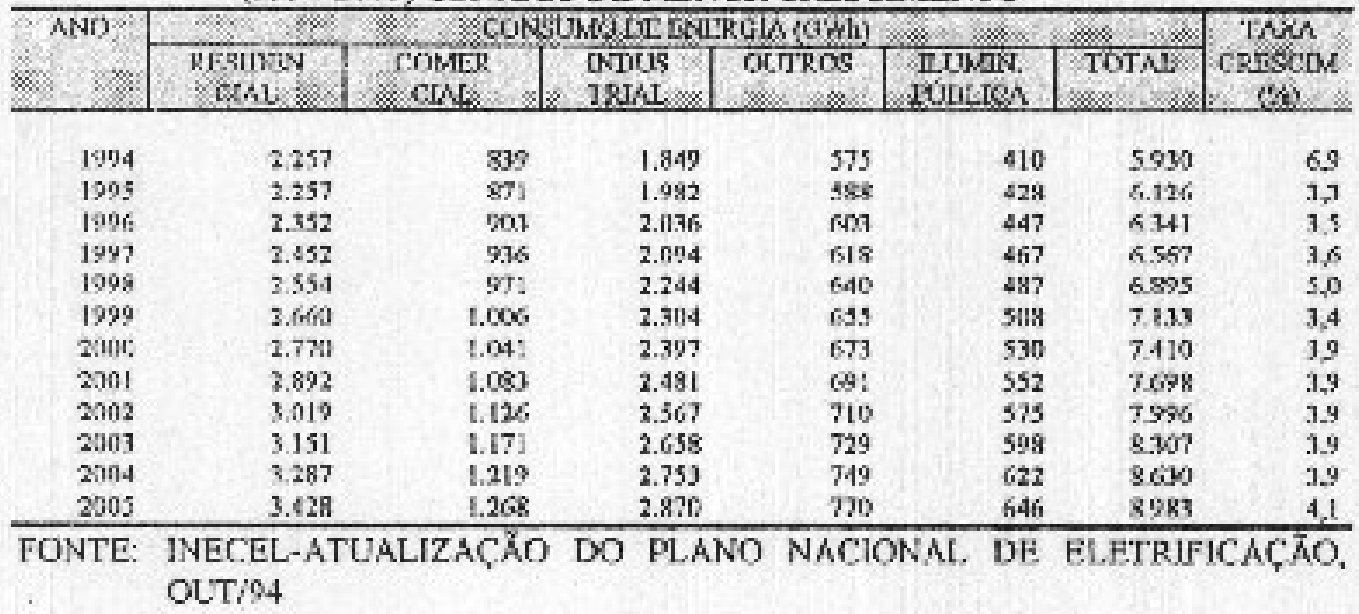

Na FIGURA 2.3 apresenta-se em forma gráfica os dados que foram indicados na tabela anterior. 
FIGLRA 2.3: PROIEC A̧O DO MERCADO-CENARIO MENOR CRESCIMENTO

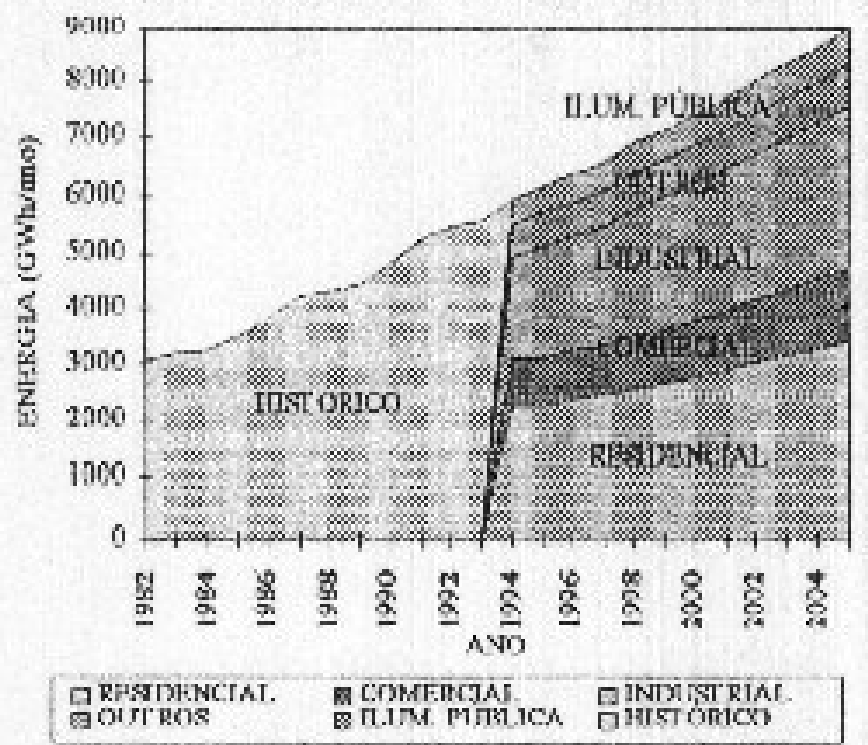

Na TABEI.A 2.9 observa-se os resultidos da "projeçăo" do consumo de energia para o cenário de maior crescimento. No perindo estahelecido 1994-2005, o setor residencial crescerá $73 \%$ (média anual de $5,1 \%$ ), o setor comercial $76 \%$ (média auual de 5,3 ), o setor industrial $77 \%$ (média anual de 5,3\%), o setor denominado como outros $47 \%$ (médin amual de $3,6 \%$ ), e finalmente o setor de IP $78 \%$ (média amal de $5,4 \%$ ). $O$ crescimento de todo o setor clétrico sob este cenário de maior crescimento será $72 \%$ (média atual de $5,1 \%$ ), em relação ao cenário anterior de menor crescimento que foi de $51 \%$ (média anual de $3,8 \%$ ).

\begin{tabular}{|c|c|c|c|c|c|c|c|}
\hline \multirow{2}{*}{$\begin{array}{r}n N 1 \\
-\quad \\
\end{array}$} & \multicolumn{6}{|c|}{ 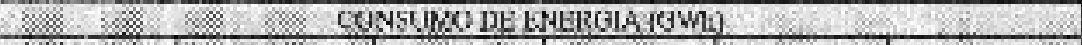 } & \multirow{2}{*}{$\begin{array}{c}\text { IAXA } \\
\text { cmiscmis } \\
x\end{array}$} \\
\hline & $\begin{array}{l}\text { KRELIIN } \\
\text { CELI }\end{array}$ & $\begin{array}{l}\text { CoMili } \\
\text { Clai }\end{array}$ & $\begin{array}{l}\text { Dintas } \\
\text { TRIAL. }\end{array}$ & OUTTED & $\begin{array}{l}\text { II IONTN } \\
\text { MIIIIICA. }\end{array}$ & Trom & \\
\hline 199.4 & 2281 & 897 & 1.864 & 579 & 115 & 5.999 & 8.0 \\
\hline 1995 & 2.284 & KES & 2.914 & 394 & 458 & 6.218 & 3,8 \\
\hline 1996 & $2 \angle 08$ & 900 & 2.084 & 613 & 463 & 6.499 & 4,5 \\
\hline 1997 & 2539 & 974 & 2.162 & 6.12 & 489 & f. 796 & 4,6 \\
\hline 1998 & 3676 & 3.019 & 2.352 & es9 & 516 & 7.2012 & 6,0 \\
\hline 1999 & 2.819 & 1.066 & 2.414 & C\$D & 545 & 7.523 & 4,5 \\
\hline 2000 & 2.968 & 1.114 & 2.530 & 709 & 574 & 7.898 & 4,9 \\
\hline 2001 & 3.149 & 1.181 & 2.661 & 730 & 605 & 9. 321 & 5,5 \\
\hline 20003 & 3331 & $\$ .251$ & 2.790 & $7 \leq 8$ & 637 & 9. 776 & 5,5 \\
\hline 2003 & 3537 & 1.326 & 2.948 & 787 & 670 & 9.218 & 5,5 \\
\hline 2004 & 3.352 & $\$ .406$ & 5.107 & 818 & 704 & $9.76 \%$ & 5.9 \\
\hline 2005 & 3.948 & 2.450 & 3.294 & 8.51 & 720 & 10,323 & 5,7 \\
\hline
\end{tabular}


De igual maneira que o caso anterior, na FIGURA 2.4 mostra-se em gráfico os dados da TABELA 2.9 .

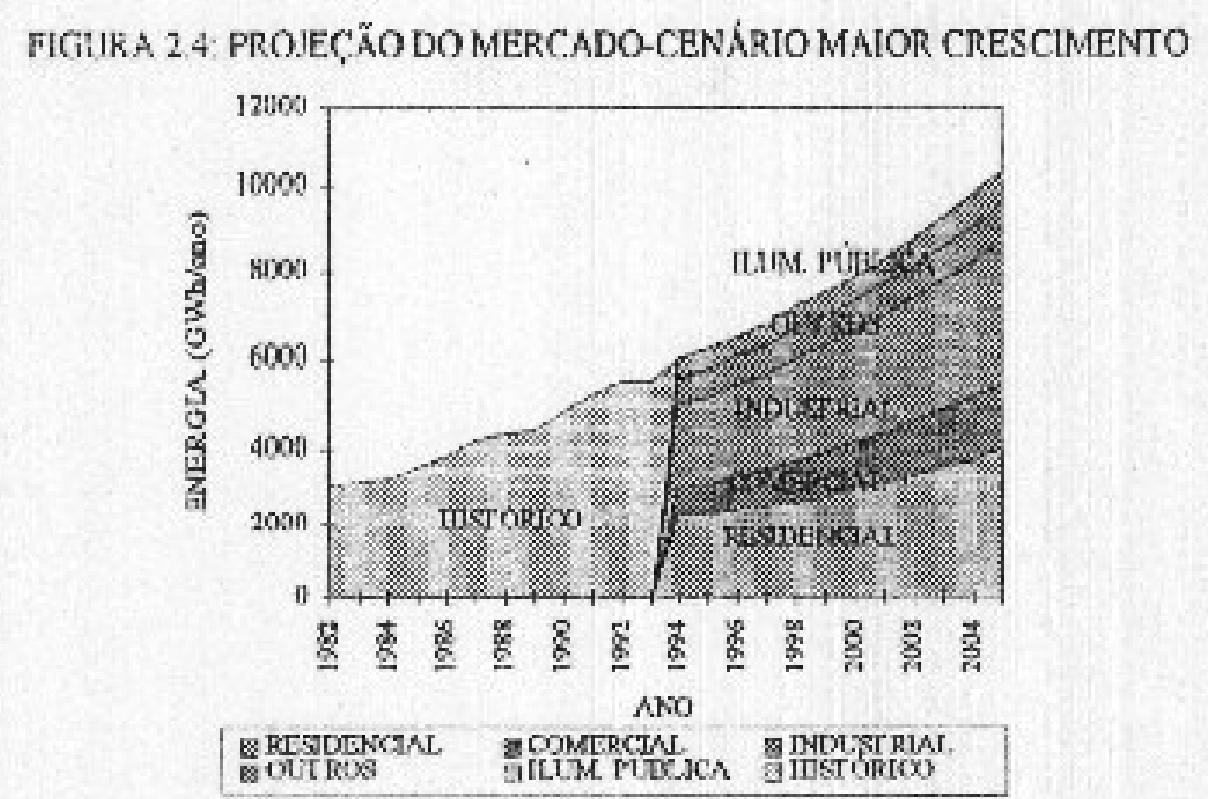

Observa-se na TABELA 2.10, a composiç̄o do setor elétrico parn o ano 2005 Estes valores såo muito semellıantes aos da TABELA 2.7, nos casos dos setores residencial, cowercial e IP; culretauto, o setor iudustrial terá sumento passando de $29 \%$ em 1993 para $32 \%$ em 2005 , e o setor denomiuna como outros terá diminuiçāo passando de $10 \%$ em 1993 para $9 \%$ em 2005 (cenário de menor crescimento) on $8 \%$ em 2005 (cenário de maior crescimento).

Por outro lalo, comparando as porcentagens de complosiçăo do setor elétrico entre os cenários de unist e menor crescimento no sho projetodo 2005, obserwa-se que estes valores stīo quase iguais, com pequenas variaçōes. 


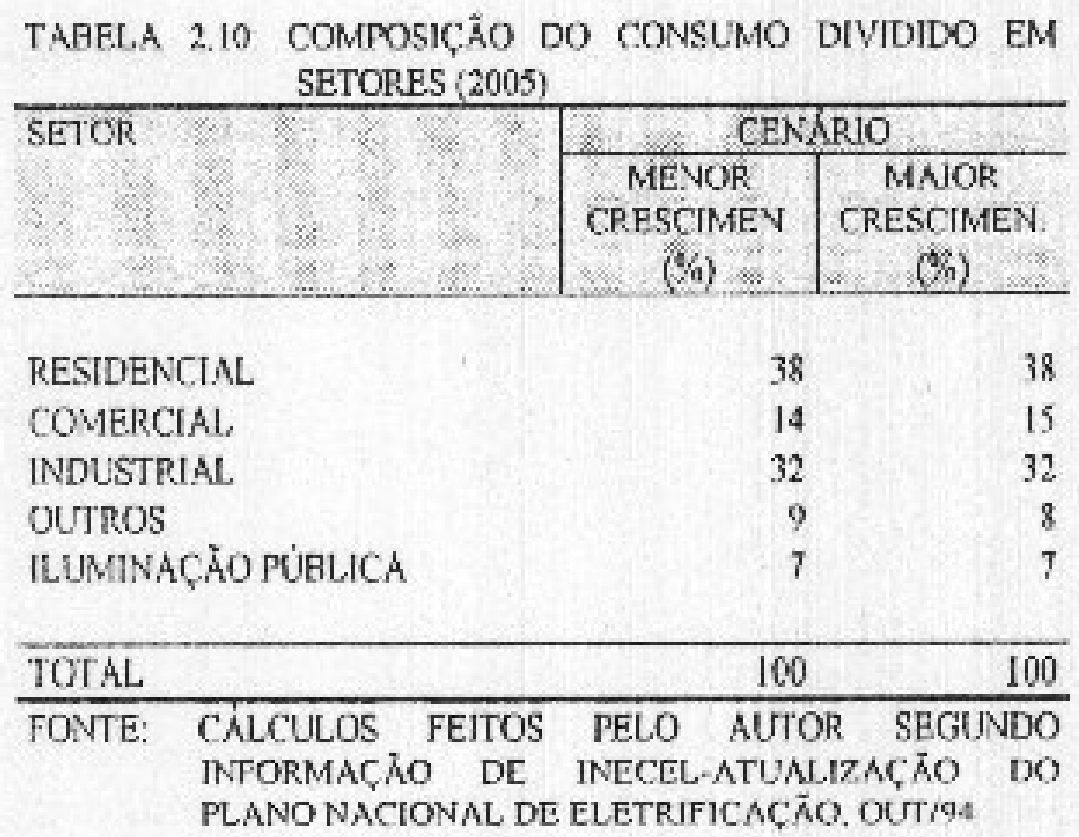

\subsection{O SETOR DE ILUMINACÃO PÜBLICA (IP)}

$O$ crescimento do setor de IP no Equador para o periodo 1982-1993 fui relativamente maior que todos os outros setores; sua taxa de crescimento neste periodo foi $230 \%$ (métlia antual de $11,5 \%$ ) frente a $78 \%$ do residencial (média anual de $5,4 \%$ ), $77 \%$ do comercial (média anual de $5,3 \%$ ), 52\% do industrial (média anual de $3,9 \%$ ), $171 \%$ do denominato outros (média anual de $9,5 \%$ ). $O$ consumo de energia do setor de IP cm 1982 foi 117,7 GWh e subiu em 1993 para 389,4 GWh.

No ano 1982, o setor de IP tínla seu consumo relativo em relaçắ ao consumo nacional de $3,8 \%$. Depois de alguns anos, esta porcentagem evoluiu por exemplo para $4,9 \%$ em $1986,5,1 \%$ em $1990,6,4 \%$ em 1992 e $7,0 \%$ em 1993. Isto se deve entre outras coisas às açî́es politicas de govenos ao nivel nacional ou setoriais, de instalar II nos setores afastados, assim como também aos planos de mellıoria nos niveis de iluminaçẫo dns ruas e avenitas tas principhis cidades do Equador.

$O$ consumo especifico de energia para IP ao nivel nacional no ano 1993 foi 219 kWhicliente-ano. 
O INECEL usou o conceito de "consumo especifico de IP" para projetar o consumo em IP. valor que ć calculado como a relaçẫo entre, o consumo de energia em IP e o número de clientes residenciais somados com os comerciais. Para obter a energia anual projetada, multiplicou-se este consumo especifico pelo número de clientes residenciais somados aos comerciais projetados.

A taxa de crescimento para o periodo 1994 e 2005 no cenário de menor crescimento extima-se igual a $58 \%$ ( média anual de $4,2 \%$ ), e para o cenário de maior crescimento $78 \%$ (média anual de $5.4 \%$ ). Estas taxas sn̆o muito pequenas em relação h̀ taxa do periodo imediato anterior e que foi $230 \%$ (média anual de $11,5 \%$ ), emblura o periodo tenha igual quantidade de amos.

$O$ consumo de energia de $414,7 \mathrm{GWh}$ em 1994 passarí a $646,4 \mathrm{GW}$ l em 2005, segundo as estimações do cenário de mentor crescimento. Entretanto, as estimativas para o cenário de maior crescimento são de 740,0 GWh no ano 2005.

E Equador devido a ser um pais localizado na latitude $0^{\circ}, 0$ tempo de luz solar incidente sobre a superficie é quase igual para todos os dias do ano, de igual maneira que o tempo do dia é, aproximadamente, igual no da noite, isto é 12 horas. Deste ponto de vista, todas as concisssionárias calculam os consumos de energia elétrica $\mathrm{cm}$ função do fermpo de trabalho dos equipamentos de IP, tempo igual a 12 borasidia.

Com a aplicação desta premissa, a demanda máxima de IP calculadn, usando os dados da TABELA 2.6, foi 26,9 MW em 1982, e passou para 88,9 MW em 1993. No ano 2005, o cenário de menor crescimento dá um valor de demanda máxima $147,6 \mathrm{MW}$ e o cenário de maior crescimento 169,0 MW (ver FIGURA 2.5). 
FIGURA 2 5: CENÁRIOS DO SETOR DE ILLMINAÇÃO PÚBLICA (IP) (INECEL)

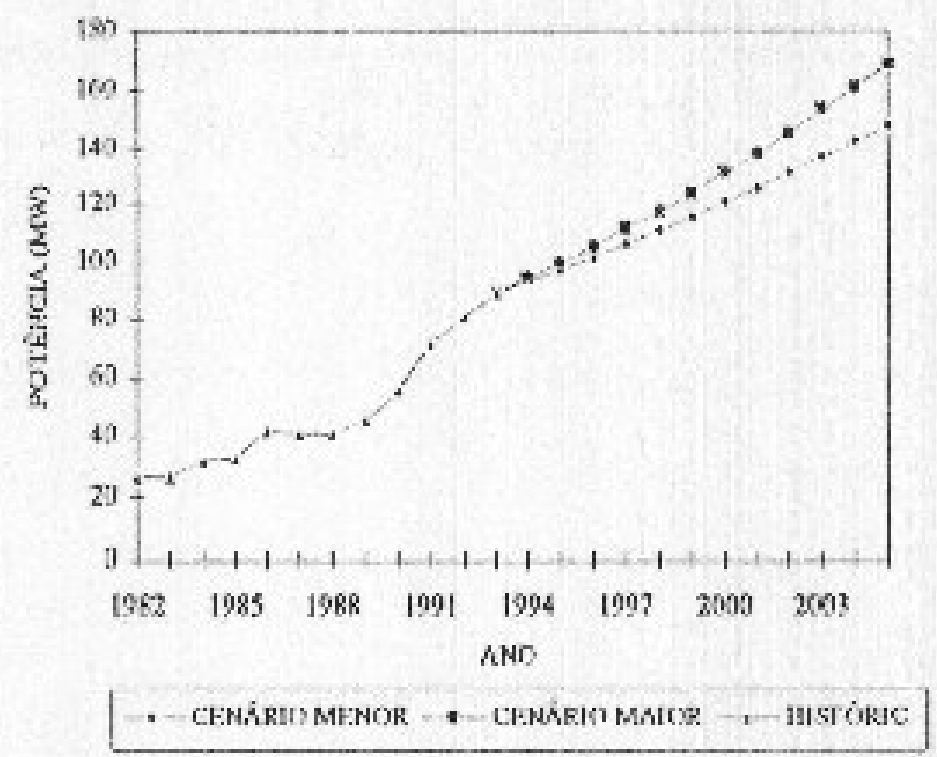

\subsection{ANÁL.JSE DO USO DE ENERGLA PARA ILUMINACĀO PÍELICA (IP) PELAS CONCESSIONÁRIAS.}

O consumo total de mergia no Equador no ano 1993 foi $5.533 \mathrm{GWh}$, dos quais 375 GWh foram para o setor de IP, o que representa uma porcentagem de $7 \%$.

A EMPRESA FLÉTRICA QUTTO S.A. é a concessionária com maior consumo do energia em IP do Equador com 27,1\% (ver TABEL.A 2.11), embora este consumo em relaçã̃o ao comsumo tofal da concessionária seja somente $7,3 \%$. O principal centro da írea de concessão é a cidade de Quito e algumas árens da província de Pichincha; além disso, o seu consumo especifico em IP por consumidor é $285 \mathrm{kWh} / \mathrm{cliente-ano.}$

Em scgundo lugar encontra-se a EMPRESA ELÉTRICA DO EQUADOR-EMELEC INC., cuja direa de concessăo es o centro da cidade de Guayaquil $A$ porcentagem de conśumo em IP em relação no consumo nacional, corresponde a $17 \%$. O consumo especifico desta empresa tem o valor de $236 \mathrm{kWh} /$ clicnte-ano. No entanto, est. concessionínia tem no país, a menor participaçāo do setor de IP em relaçăo ao seu

'Este valor (5.533 GWh) foi extraido da TABELA 2. 11, sendo diferente da TABELA 2.5 e cujo valor ó 5.451 GWh; a pesar da fonte ser o mesma (TNECEL), os departantentos sต๊o diferentes. 
consumo total, com somente $3,5 \%$. O motivo disto pode ser o näo investimento em cxpansĩo e manutenção, devido ao problemn de transferência das nçŏes da companhia ao Estido.

TABELA 2.11: CONSUMO DE ENERGIA EM ILUMINACXXO PÜGLICA (IP) PELAS CONCESSIONÁRIAS (1993)

\begin{tabular}{|c|c|c|c|c|c|c|}
\hline \multirow{2}{*}{ CONEFSSIONAR1K } & \multirow{2}{*}{8} & \multirow{2}{*}{$\stackrel{4}{*}$} & \multicolumn{3}{|c|}{ CONSUMO DE ENLRGL (MW) } & \multirow{2}{*}{$\begin{array}{l}\text { PORCENTMGEM } \\
\text { (\%) }\end{array}$} \\
\hline & & & Hinstracho & PORCFNTSEFM & $\begin{array}{l}\text { TUTAl, } \\
\text { covisisis }\end{array}$ & \\
\hline
\end{tabular}

\begin{tabular}{|c|c|c|c|c|}
\hline 01 E. QUT:CSA. & 101.806 & 27,1 & 1.199.496 & 73 \\
\hline 02 lNDACLINC, & 69,862 & $17 \%$ & 1.819569 & 35 \\
\hline 03 1EMTAMANA & 59.935 & 159 & 351304 & 17.1 \\
\hline O4 CF.NTRO SUR C.A. & $2 n .922$ & 56 & $27 k .717$ & 2.3 \\
\hline OS EM:LOROSA & 16.9 .79 & 4.5 & 215,412 & 7.9 \\
\hline OG FNTENORTE & 14.650 & 39 & 69813 & 8,6 \\
\hline a7 GiIAYAE-ISXS HIKM SA & 14,581 & 39 & $3006<5$ & 4.9 \\
\hline OX SANTA EI.FNA C.A & 13,003 & 0.5 & 101093 & 13,9 \\
\hline 09 ANRWTORA. & 12,430 & 3.3 & 182.871 & 8,1 \\
\hline 10 IRPTIONAL. DHI. STU S.A & 10.455 & 28 & 82559 & 12,7 \\
\hline 11 ESMIERLDASSA & 9.995 & 2,6 & 103683 & 9.5 \\
\hline 13 SRET O DOH-ATNGo S.A & 7.9 .18 & 2,1 & 95.374 & 8.3 \\
\hline 13 MIRAOHOSA & 6660 & 18 & 189604 & 5,6 \\
\hline 16 ROBAMTA $8 \mathrm{~A}$ & 5.986 & 1,6 & 95,451 & 6,5 \\
\hline 15 corrorAxis $5 A$ & 5016 & 1.3 & 97195 & 5,1 \\
\hline 16 LCOSRIOSSA & 4.919 & 1,7 & 98.911 & 5,0 \\
\hline 17 sucomme:s sA & 2.496 & 0,7 & 17532 & 14,2 \\
\hline 18 NOBGILESA. & 2.208 & 0,6 & 23.880 & 9.2 \\
\hline 19 HOHXAK 5.2 & 1.779 & 0.5 & 12.805 & $9 . n$ \\
\hline TOTA & 375.488 & 100,2 & $1.533,404$ & 6.8 \\
\hline
\end{tabular}

FONTE: INECEL-ESTATISTICAS ELÉTRICAS-BOLETIM No. 28

A EMPRESA EIÉTRICA DE MANABI-EMELMANABI com área de concessāo ua província de Mauabi encontra-se em tereeiro lugar e seu consuno de energia em IP $\dot{6}$ $15,9 \%$ em relaçŭo do país. O comsumo específico desla comcessionạ́nia tem o valor de $554 \mathrm{kWh} / \mathrm{clliente}^{-2 n o}$, o valor mais afto do país. Analogamente a porcentagem do setor de IP em relaçăo ao sen consumo total é $17,1 \%$, também o mais alto do país; isto se deve çue a concessionária tem regulamentado a instalaçâo de luminárias de vapor de mercúrio de 175 W para ruas secundárias, lugares suburbanos e murais, enguanto para nuss principais instalant-se luminárias de vapor de sídio de $400 \mathrm{~W}$.

A EMPRESA ELÉTRICA REGIONAL CENTRO SUR C.A. tem a áren de concessão nas provincias de Azuay e Caliar, sendo o centro de consumo principal a ciclade de Cuenca. O sen consumo de energia ратя IP em telaçăo ao nível nacional tem a 
porcentagem de $5,6 \%$. O seu consumo específico é $159 \mathrm{kWh} /$ cliente-ano. O consumo de energia do setor de IP' em relação an sen comisumo total é 7,5\%.

Algumas concessionárias tem alto componente (porcentagem) de IP em relaçĩo ao seu consamo total; EMELMANABI é a concessionária com maior valor $17,1 \%$, segundo fora dito, seguidi pela SUCUMBIOS S.A. com 14,2\%, SANTA ELENA C.A com $12,9 \%$, REGIONAL. DEI. SUR S.A. com 12,7\%, ESMERAIDAS S.A com 9,5\%, dentre as principais (ver TABELA 2.11).

A soma do consumo de energía em IP' (ano 1993), das cinco concessionárias com mainr cousumo neste setor é 263,5 GWW/ano, fiente ao consumo total nesse setor no país de 375,5 GWh/ano; isto expressn em termos de porcentagem é $70 \%$. Apenas as concessionatrias que prestam serviço vas duas cidades maiores do Equador (Quito e Guayaquil), aprosentam consumo de energia em IP em relação ao do pais de $44 \%$. Isto da a idéia de nrandera e a imprortância dessas concessionárias.

\subsection{USOS TINAIS DE ENERGLA ELETTRICA NO SETOR DE ILUMINACÄO PÚBLICA (IP) DO EQUADOR}

Segundo a pesquisa feira pelo sutor nas concessiontrias do Equador, foi possínel obter informaçāo em 15 delas, das quหis sú uma năo dispôs de toda a informação e além disso ten muitos enos; este é o caso de EMELMANABI, a pesar de ser a comecssionária dentre as de maior consumo de energia em IP. Em outras 4 concessionárias (MII AGRO S.A., LOS RIOS S. A., SUCUMBIOS S.A. e BOLIVAR S.A.) que em conjuuto somam una porcentagem de $4,3 \%$ do consumo em IJ' em relaçĩo no total do país, năo foi possivel obter informação, portanto a quantidade de luminárias daquelas concessionárias foi estinuada. Portanto, os dados pesquisados estão baseados em $95,7 \%$ do consumo real. 


\subsubsection{QUANTIDADE DE LUMINÁRIAS INSTALADAS}

No Equador estão instaladas 449.019 huminárias (o detallı esta apresentado no ANEXO B e corresponden pesquisa feita em setembro de 1995), das quais 358,411 luminárias $(79,8 \%)$ ș̃o de vapor de mercúrio, 75.816 luminárias $(16,9 \%)$ são de vapor de sódlio (a maioria em alta pressão), 12.045 luminárias $(2,7 \%)$ săo de luz mista, 2.172 luminárias $(0,5 \%)$ sio incandesceutes e 575 huminárias $(0,1 \%)$ sāo fluorescentes. 0 detalhe é apresentado sa TABELA 2.12.

A quantidade de luminarias de vapor de mercuirio instaladus é 358,411 , das quais $31,8 \%$ sāo de $175 \mathrm{~W}, 38,1 \%$ ș̃o de $125 \mathrm{~W}, 7,2 \%$ șio de $250 \mathrm{~W}, 2,3 \%$ sh̃o de $400 \mathrm{~W}$, e $0,6 \%$ sĩo de 100 W. A EMPRESA FI.ÉTRICA RIOBAMRA S.A. é a única concessionária que tem instalado luminírias de vapor de mercúrio de $100 \mathrm{~W}$. A luminária de vapor de mercuíio de 175 W é majoritariantente instaladn pelas concessionárias, mas acontece que ela não é apresentatla ern alguns catálogos.

Observa-ca que a maioria das concessionairius têm como caracteristioa o uso, de luminárias de vapor de mercírio de $125 \mathrm{~W}$ on de vapor de mercirio de $175 \mathrm{~W}$; por exenplo, a EMPRESA TIÉTRICA QUITO S.A. tem instalado 95.000 huminírias de vapor de mercuitio de $125 \mathrm{~W}$, especialmente nos setores rurais a suburbanos, e nenliuma luminária de vapor de mercúrio de $175 \mathrm{~W}$. Entretanto EMHLORO tem instalado 17.901 luminárims de vapor de mercútio de $175 \mathrm{~W}$ e somente 2.606 luminárias de vapor de merciirio de $125 \mathrm{~W}$. No entanto, a maior qununtidade de Juminárias instaladas no país ș̃o de vapor de mercúrio de $175 \mathrm{~W}$.

A tecuologia etm sódio é usada em todas as concessionárias, em maior on menor porcentngem. As luminárias de vapor de sódio instnladas no pais atinge a quantidade de 75.816 ; considcrando este valor. $42.0 \%$ ( $7,1 \%$ do total $)$ das luminárias sān de $250 \mathrm{~W}$, $32,6 \%$ (5,5\% do total) das luminárias são de $400 \mathrm{~W}, 13,9 \%(2,3 \%$ do total) dHs luminárias sāo de $150 \mathrm{~W}$. O tipo de luminária majoritariamente usada pelas comcessinnárias 6 vapur de sódio de $250 \mathrm{~W}$; a luminária de vapor de sódio de $50 \mathrm{~W}$ năo 
é usada, e a laminaria de vapor de sódio de 70 W é usada numa pequena porcentagem de somente. $2,3 \%(0,4 \%$ do total)

\begin{tabular}{|c|c|c|c|c|}
\hline 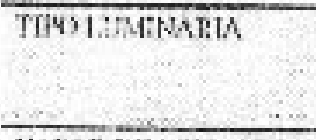 & $\begin{array}{l}\text { IRIJYCIA } \\
\text { IINITiRIA }\end{array}$ & $\begin{array}{l}\text { DUMNTIDKB: } \\
\text { (ii) }\end{array}$ & $\begin{array}{c}\text { POFCENT WGEK } \\
\text { (8) }\end{array}$ & 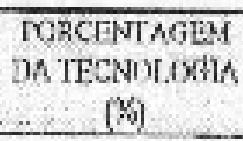 \\
\hline VAOR IDE BIRCIRIO & $\begin{array}{l}1701 \% \\
125 \% \\
175 \% \\
350 \% \\
4111 \%\end{array}$ & $\begin{array}{r}2.979 \\
1.76 .573 \\
185.766 \\
25.924 \\
8.179 \\
\end{array}$ & $\begin{array}{r}0.5 \\
31.4 \\
41.4 \\
5.8 \\
1,8 \\
\end{array}$ & $\overline{708}$ \\
\hline VAVIR IIE SÓDTK & 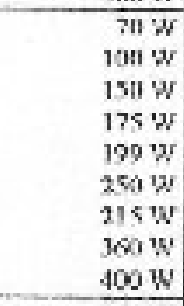 & $\begin{array}{r}1.749 \\
16 \\
10.546 \\
5.716 \\
1.210 \\
31.950 \\
2901 \\
76 \\
74.74 \\
\end{array}$ & $\begin{array}{l}0,4 \\
0.0 \\
2,3 \\
1.2 \\
0.3 \\
7,1 \\
0.1 \\
0.9 \\
3.5 \\
\end{array}$ & 16.9 \\
\hline 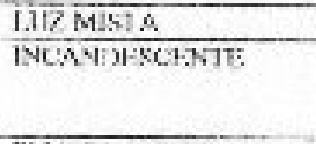 & $\begin{array}{r}100 \mathrm{w} \\
100 \mathrm{w} \\
100 \mathrm{w} \\
130 \mathrm{w}\end{array}$ & $\begin{array}{l}12045 \\
113 \\
795 \\
958\end{array}$ & $\begin{array}{l}\frac{2.7}{01} \\
0.2 \\
0.2\end{array}$ & $\frac{3.7}{0.5}$ \\
\hline TIIKORESCPNIE & $\begin{array}{l}2=20 \mathrm{~W} \\
4 \times 40 \mathrm{~W} \\
120 \mathrm{~W}\end{array}$ & $\begin{array}{l}152 \\
2 x y \\
135\end{array}$ & $\begin{array}{l}8.0 \\
0.1 \\
51, n\end{array}$ & Di \\
\hline $\mathrm{IOT} A \mathrm{~L}$ & & 499.619 & 100,0 & 1001.6 \\
\hline
\end{tabular}

FONTE: PESOUISA PELO ALTOR NAS CONCESSIONARIAS

Poucas concessionárias ainda têm luminàias de luz mișa, e o escopo - segundo fora dito pelos funcionáros dessas empresas- é eliminar e trocar pela nova tecnologia de sódio. No pais estio instaladas 12.945 luminárias deste tipo, emborn sua porcentagem $(2,7 \%)$ em relaçâ์ aถ nivel uacional sẹja muito pequena.

Outras tecnologins como a caso de luminatias incandescentes e fluorescentes, niuda estrio sendo usadns pelas cottcessionárias na H', embora a sus porcentagem seja muito pequena da orden de $0,6 \%$. 


\section{5,2. POTÊYCLA INSTALADA NAS LUMINÁRIAS}

Antes de fazer o cúlculo da potência instalada nas luminárias, é necessúrio determinar os valores das perdas de potência nos reatores. Com o objeto de usar neste estudo de caso os mesinos valotes usados pelas concessionárias, pesquisou-se nnquelas os valores de perdas, sob o suposto que clas deveriam ter esses dados; mas acontecen que poucas usam as plerdas มล faturaçño e outras só faturam a potêsıcia da lâmpada.

A IEMPRESA ELÉTRICA QUITO S.A. usa somente na faturaçăo a potência da lampada c nāo a perda de potência no reator.

As concessionárias EMEL.FC INC., REGIONAL DO SUI. S.A., REGIONAL CENTRO SUL C.A. usam os valores apresentados na TABELA 2.13; além disso, npresenta-se os dados assumidos ueste estudo de caso e que foram obtidas des catálogos de PHII.IPS:

TAHELA 2.13: PERDAS DE POIENNCLA NOS REATORES

\begin{tabular}{|c|c|c|c|c|c|c|c|c|c|}
\hline \multirow{2}{*}{ TIPOLIRTANRIS } & \multirow{2}{*}{$\begin{array}{l}\text { THTESCK } \\
\text { NOB-IINAL }\end{array}$} & \multicolumn{4}{|c|}{$\begin{array}{c}\text { TOTENCK RTATOI } \\
\text { (W) }\end{array}$} & \multicolumn{4}{|c|}{ 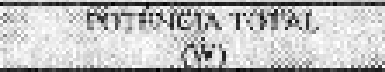 } \\
\hline & & (i) & $\sqrt{(2)}^{2}$ & (3). & (4) & (1) & (2) & & $(4)$ \\
\hline \multirow[t]{4}{*}{ WMLOR DES Arizctikin } & $325 \mathrm{~W}$ & 37 & 12.5 & 129 & 12 & 163 & 137.5 & 137.5 & 137 \\
\hline & $175 \mathrm{~W}$ & 25 & 15 & 175 & 11 & 200 & 170 & 192, & J69 \\
\hline & $250 \%$ & 50 & 20 & 25 & 16 & 300 & 270 & 275 & 266 \\
\hline & $400 w$ & 50 & 25 & 40 & 25 & 450 & 425 & 440 & 125 \\
\hline \multirow[t]{4}{*}{ 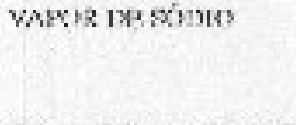 } & $100 \mathrm{w}$ & 17 & 21 & 10 & 16 & 117 & 121 & 110 & 116 \\
\hline & $1.50 \mathrm{~W}$ & 20 & 32 & 15 & 20 & 171 & $1 \mathrm{Kz}$ & 165 & 170 \\
\hline & $2.50 \mathrm{~W}$ & 50 & 35 & 25 & 2.9 & $3 ?$ & $2 \mathrm{RS}$ & 273 & 273 \\
\hline & $400 \mathrm{~W}$ & 50 & 5it & 40 & 50 & 451 & 4511 & 4411 & 450 \\
\hline
\end{tabular}

FONTE: PESQUISA PELO AUTOR

NOTA: (1) DADOS DE EMFLEC INC.

(2) TEEGIONAL DO SUL S.A.

(3) REGIONAL C.ENTRO SUL C.A.

(4) VAIORES ASSUMTDOS NESTE ESTUDO DE CASO

O restante das coucessiouátiıs nã่อ entregarнm a informuçẫo.

Olsserva-se ta TABELA 2.13, que a EMELEC INC. tem os maiores valores de porcentagens de perdas que outras concessionárias. $\mathrm{O}$ cáleulo de potência no sistema da 
EMELEC INC., segundo seus valores, da 14,3 MW, enquanto usando valores de perdas usstumilas neste esludo de caso, o resultado é $12,6 \mathrm{MW}$, sendo a sun diferença $13 \%$. Estima-se que os valores assumidos pela EMELEC INC. são nuito graudes em relaçñ̆o ros valores renis.

Usando as quantidades de lumintínas assinaladas no ponto anterior, considerando a potência das lâmpadas e as perdas de potência nos reatores (aprescutadas ua TABELA 2.13), calcula-se os valores de potência do conjunto de luminárias ligadas às redes secundarias das concessionáaias do Equador. Os resultados são apresentados na TABELA 2.14.

\begin{tabular}{|c|c|c|c|c|}
\hline TTOLUMINGRLA & $\begin{array}{l}\text { Turtace } \\
\text { intrikia }\end{array}$ & $\begin{array}{l}\text { PoTkActK } \\
\text { f(TrAl: } \\
(\mathrm{kW})\end{array}$ & $\begin{array}{c}\text { FORCANTKCEM } \\
\text { (\%) }\end{array}$ & 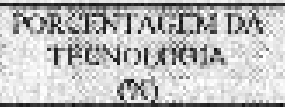 \\
\hline WhEOK DIS MIIRCIIRIO & $\begin{array}{l}150 \mathrm{w} \\
125 \mathrm{~W} \\
17.2 \mathrm{~W} \\
250 \mathrm{w} \\
400 \mathrm{w}\end{array}$ & $\begin{array}{r}225 \\
18.711 \\
35.598 \\
6.605 \\
3.475\end{array}$ & $\begin{array}{r}0,7 \\
20,8 \\
319 \\
7.7 \\
3,9\end{array}$ & 71.6 \\
\hline VATVI! [SE \& & $\begin{array}{l}70 \mathrm{w} \\
110 \mathrm{w} \\
150 \mathrm{w} \\
175 \mathrm{w} \\
199 \mathrm{w} \\
250 \mathrm{w} \\
219 \mathrm{w} \\
360 \mathrm{w} \\
4150 \mathrm{w}\end{array}$ & $\begin{array}{r}1.45 \\
2 \\
1.739 \\
1.063 \\
277 \\
8.773 \\
69 \\
10 \\
11.137\end{array}$ & $\begin{array}{l}0.2 \\
00 \\
1.9 \\
1,2 \\
0.7 \\
0.8 \\
0.1 \\
0.0 \\
12.4\end{array}$ & 35,9 \\
\hline UIZMEIA & $1601 W$ & 1.527 & 2,1 & 2,1 \\
\hline TWCANDESCBNTE & $\begin{array}{l}60 \mathrm{~W} \\
100 \mathrm{~W} \\
150 \mathrm{~W}\end{array}$ & $\begin{array}{r}25 \\
43 \\
144\end{array}$ & $\begin{array}{l}0,0 \\
0.1 \\
0.2\end{array}$ & 0,3 \\
\hline FLIDIRESCENE & $\begin{array}{r}2+20 \mathrm{~W} \\
4+413 \% \\
120 \%\end{array}$ & $\begin{array}{l}9 \\
59 \\
27\end{array}$ & $\begin{array}{l}0.0 \\
0,1 \\
0,0\end{array}$ & 0,1 \\
\hline TOTAL & & 89.590 & 100,0 & 100,0 \\
\hline
\end{tabular}

FONTE: CALCULOS FETTOS PELO AUTOR

O Fquador tem $89,9.10 \mathrm{~kW}$ (ver TABELA 2.14) de poténcin instalado no sistema de IP, isto i $6,2 \%$ do valor de demmda míxima (1.441 MW em julho de 1995$)$, dos quais $64.416 \mathrm{~kW}$ para a tecnologia de mercúrio $(71,6 \%) ; 23.273 \mathrm{~kW}$ jara a teenologia de sódio $(25,9 \%) ; 1.927 \mathrm{~kW}$ para luz mista $(2,1 \%) ; 249 \mathrm{~kW}$ para luminárias incandescentes 


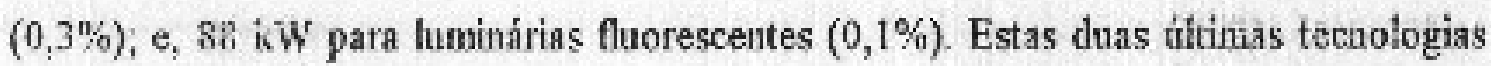
têm menor potência instalada e as concessionírias já tền programas de troca para usar luminarias eficientes.

A participaçi̊o do setor de IP dentro do sistemn elétrico do Equador, apresenta-se na seguinte figura (ver FIGURA 2.6).

\section{FIGURA 2.6: CURVA DE CARGA DO SNI COM PARTICIPAÇÃO DA ILUMINACß̊O PÚBLICA (IP)}

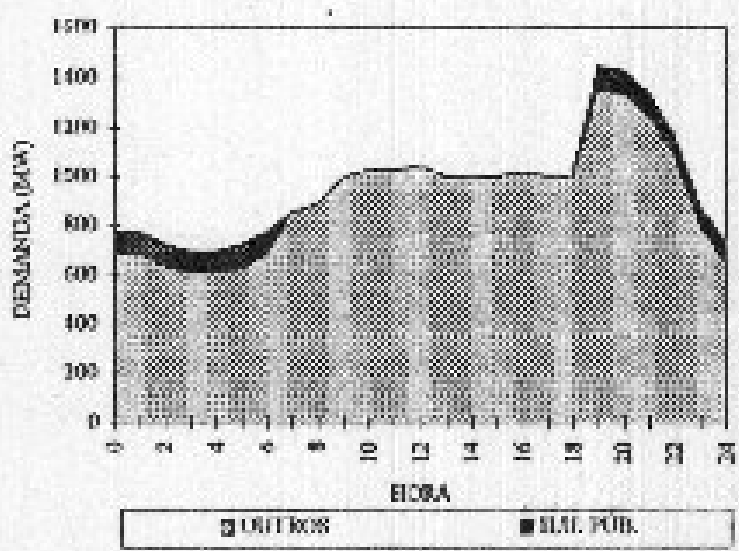

\subsubsection{ENRRGIA DO SETOR DE ILUMTNACÃ̃ PÚBLICA (IP)}

A premissa para o cálculo de encrgia é que as luminárias estão ligadas às redes secum darias 12 horas ao dia, em condiçōes de tensāo nominal.

O consumo total de energì do setor de IP em 1995 serú 394 GWh/anto (ver TABELA 2.15), dos quais 282 GWh/ano são da tecnologia de mercúrí $(71,6 \%)$ : $102 \mathrm{GWh} /$ auo săo da tecuojogia de sódio $(25,9 \%) ; 8 \mathrm{GWh} / a n o$ em luminárias de luz mistn $(2,1 \%) ; 1$ GWhinno en luminárias incandescentes $(0,3 \%) ; \mathrm{e}, 0,4$ GWh/ano em huminárins fluorescentes $(0,1 \%)$. 
0 consumo fotal de energia do setor elótrico equatotianto no ano 1995, segundo o cenário de menor crescimento será 6.126 GWh/ano e no cenário de maior crcscimcuto será 6.218 (GWlisno, O consumo total de energia em IP calculado pelo método de usos finais scrá $394 \mathrm{GWl} / \mathrm{ano}$. As porentagens destas relaçỏes șío $6,4 \%$ e $6,3 \%$ respectivamentc. Estas porcentagens săo semelhantes a participaçĩn do setor no ano 1993 e que foi $7 \%$

\begin{tabular}{|c|c|c|c|c|}
\hline TTTOIUHAINRTR & $\begin{array}{l}\text { POCHACIK } \\
\text { WNTNRM }\end{array}$ & $\begin{array}{l}\text { TNIERGIK } \\
\text { ToTAT } \\
\text { (BSHTho }\end{array}$ & $\begin{array}{l}\text { PORCENTAOEH } \\
\text { (3) }\end{array}$ & 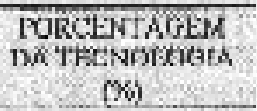 \\
\hline 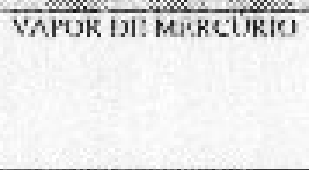 & $\begin{array}{l}100 w \\
12.5 w \\
175 w \\
2.50 w \\
400 w\end{array}$ & $\begin{array}{r}986 \\
81.1952 \\
153.731 \\
.0 .204 \\
15.225\end{array}$ & $\begin{array}{r}0,3 \\
20.8 \\
39,0 \\
7.7 \\
7.5\end{array}$ & 71.5 \\
\hline WATOR DE SÖDIO & $\begin{array}{l}70 w \\
100 w \\
190 w \\
175 w \\
190 w \\
250 w \\
215 w \\
160 w \\
100 w\end{array}$ & $\begin{array}{r}616 \\
8 \\
7.853 \\
4654 \\
1212 \\
38424 \\
704 \\
61 \\
1878\end{array}$ & $\begin{array}{c}0.2 \\
0.0 \\
2.8 \\
1.2 \\
0.3 \\
5.8 \\
0.1 \\
0.0 \\
12.1\end{array}$ & 25,9 \\
\hline 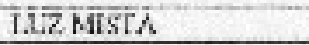 & $160 \mathrm{w}$ & $8 . t+1$ & 2.1 & 2,1 \\
\hline INCANDESCFNTE & $\begin{array}{l}60 w \\
100 w \\
150 \mathrm{w}\end{array}$ & $\begin{array}{l}110 \\
348 \\
629\end{array}$ & $\begin{array}{l}0,0 \\
0,1 \\
0,2\end{array}$ & 0,3 \\
\hline FEKXRLSLLEAIL & $\begin{array}{l}2 * 00 w \\
1 * 00 w \\
121 w\end{array}$ & $\begin{array}{r}79 \\
257 \\
86\end{array}$ & $\begin{array}{l}0.1 \\
0.8 \\
0.0\end{array}$ & 0.1 \\
\hline TOIA]. & & 303519 & 1000 & 100,9 \\
\hline
\end{tabular}

FONTE: CALCULOS FEITOS PELO AUTOR

Segundo a projeçio do INECEL para 1995, o consumo de energia no cenário de menor crescimento es 428 (jW/hano e para o cenário de maior crescimento 438 GWh/ano, estes valores săo maiores no cálculo pelo método de usos finais (394 GWhiano); comparativamente o primeiro caso é maior em $9 \%$ e o seguudo caso $11 \%$. 


\subsection{ConClusóes}

O consumo de energia elétrica no Equador durante o periodo 1982-1993, aumentou com a média anual te 5,5\%, isto é, de 3,1 TWh em 1982 atingin 5,5 TWh em 1993.

A capacidade do Fquador para gerar energia elétrica é $2.268 \mathrm{MW}$ de potência instalada, đos quais 1.47I MW (65\%) são de origem lidráulica; $508 \mathrm{MW}(23 \%)$ de origem térmich e 0 resto $289 \mathrm{MWW}$ ( $12 \%)$ térmica Diesel.

O nivel de eletrificą̧⿸丆o (atendimento) \& de $75,2 \%$, segundo dados estimados no ano 1992, ou seja dos 10.091 .000 habitantes somente 7.590,000 tinham serviço elétrico.

O setor de IP' teve a maior taxa de crescimento anual, $11,5 \%$, a seguir o sctor denomitudo outros com $9,5 \%$, o setor residencial com $5,4 \%$, o setor comercial com $5,3 \%$, e, o setor industrial com $3,9 \%$.

O setmr te IP com um consumo de $3,8 \%$ (118 GWh) em relaçăo no consumo nacional no ato 1982, uos seguintes anos evoluin para 3,6\% (1983), 4,3\% (1984), 4,1\% (1985), $4,9 \%(1986), 4,3 \%(1987), 4,1 \%$ (1988), 4,6\% (1989), 5,1\% (1990), 5,9\% (1991), $6,4 \%$ (1992) atć atingir $7 \%$ no ano 1993.

Segundo as projeções do INECEL no cenário de menor crescimento, o setor elétrico equatoriaun terí suma taxa suual de crescimento de $3,8 \%$, isto é, de 5,9 TWh em 1994 evoluir até 9,0 TWh en 2005; no entanto, segundo o centário de maior crescitnento a taxa serí $5,1 \%$ por ano e o consumo de 6,0 TWh em 1994 evoluirá até 10,3 TWh em 2005.

Segundo as mesmas projeçöes do INECEL, no cenário de menor crescimento, o setor de IP cresccrá uuma taxa média anual de $4,2 \%$, isto é de $410 \mathrm{GWh}$ cm 1994 evoluiráa até 
$646 \mathrm{GWh}$ em 2005 ; no entanto, segundo o ceuário de maior crescimento a taxa será $5,4 \%, 0$ consumo 415 GWh em 1994 evoluirá até 740 GWh em 2005.

Em ordem decrescente de consumo de energia em IP, estăo as seguintes concessionárias: Empresa Elétrica Quito S.A. $(27,1 \%)$, Emelec Inc. $(17,0 \%)$, Emelmanabi $(15,9 \%)$, Centro Sul C.A. (5,6\%), Fmeloro (4,5\%), Emelnorte (3,9\%), Guayas-Los Rios $(3,9 \%)$, Santa Elena S.A. (3,5\%), Ambato S. $\Lambda .(3,3 \%)$, Regional do Sul S.A. $(2,8 \%)$, etc.

No Equador estão instaladas 449.019 luminárias, das quais 358.411 luminárias são de vapor de mercírio, 75.816 luminárias sĩo de vapor de sódio (a maioria em alta pressăo), 12.045 luminárias sāo de luz mista, 2.172 huminárias sāo incandescentes c 575 luminárias sīo fluorescentes.

O Equador tem $89.940 \mathrm{~kW}$ de potência instalada no sistcma de IP, isto é $6,2 \%$ do valor da dentanda náxina (1.441 MW em julho de 1995), dos quais $64.406 \mathrm{~kW}(71,6 \%)$ é tecmologia de mercírio com poteacial te conservaçăo de energin; $23.273 \mathrm{~kW}(25,9 \%)$ tै tecmologia de sódio; $1.927 \mathrm{~kW}(2,1 \%)$ de luz mista também com potencial de conservaç̧o de energia; $249 \mathrm{~kW}(0,3 \%)$ en luminárias incandescentes; e, $88 \mathrm{~kW}(0,1 \%)$ em luminárias fluorescentes. Estas duas últimas tecnologias têm potencial para conservaçẫo de energia; no entanto, o seu valor é relativamente peçueno e as concessimuátias já têm programas de troca para lâmpadas eficientes.

O consumo total de energia do setor de IP em I995, com a aplicação do cálculo pelo método de usas finais, será $394 \mathrm{GWh} / \mathrm{Gno}$ dos quais 282 GWh/ano $(71,6 \%)$ sāo com tecnologia de mercútio; $102 \mathrm{GW} / 1 /$ ano $(25,9 \%)$ săo com tecnologia de sódio; 8 GWhiano $(2,1 \%)$ em luminárias de luz mista; I GWh/ano $(0,3 \%)$ em luminárias incandescentes; e, $0,4 \mathrm{GWh} / \mathrm{ano}(0,1 \%)$ em luminárias fluorescentes. 


\section{CAPTIILO III}

\section{CARACTERISTICAS DE DESENVOLVIMENTO DO SETOR ELÉTRICO EQUATTORIANO (ILUMINACC̃̃O PÚBLICA - II)}

A crise enfrentada pelo Equador, de igual maneíra que outros paises na América Latina, nos últimos anos, näo impediu que a denเanda de energia elétrica contimusse crescente, exiginto partanto a expansĩo do sistema elétrioo para atende-la.

As dificuldades econômico-fiuauceiras, geradas pela crise cconômica, conduriratt a drásticos cortes nos investimentos para expansio do sistema, comprometendo seriamente, em qualidade e quantidade a cletricidade fornecitla ans consumidores. Assim, o pleno atendimento da demanda esbarra hoje em dificuldades:

a) técnicas, tais como: carência da oferta de energia, de redes de transmissāo e de distribuiçāo; $\mathrm{e}$

b) econômico finauceiras, tais como: tarifas que nāo permitem acumulaçño de recursos próprios para investimctitos futuros; e, níveis tle endividamento do setor elétrico que impedem a obtençăo de novos financiamentos.

Muitos paises estâo tomando consciência da maneira como a energia está sendo produzida e consumida; sobre tudo quando aqueles encontram-se experimentando:

a) crescimeate contínuo da demanda de energia;

b) limitaçūes financeiras para o sctor energéticn;

c) pressōes en matéria de preservaçāo do nucio ambiente;

d) ineficiéncia do setor energético e portanto insatisfação dos consunidores, e

c) reavaliaçīo das fumçōes dos governos e dos setores público e privado no precesso de desenvolvimento. 
Todos estes fatores ohrigam aos govemos a abordagem da quesนăo -por muito tempo descuidada- do desperdicio de energia, tanto na produçào quanto no consumo final

Os governos devem examinar todas as opções entergéticas integradas, tanto da perspectiva da oferta quanto da demanda, e determinar as prioridades que impedem a melhoria na eficiência energética desde o ponto de vista da produçẫo até do consumo.

Alguns paises em desenvolvimento, formularam estratégias energéticas integradas abordando questões especificas pelo lado da demanda, tais como: fixar preęos da energia; fomentar a concorrência dos mercados, e adotar medidas na éren de informação. A abordagem da questão pelo lado da oferta poderia ser: adolar refomas institucionais e regulamentadoras destinadas a sensibilizar os responsáveis pelo fornecimento de eletricidade sobre as necessidades; e, realizar investimentos em atividacles que aumentem a eficiência, tuis como recuperação de usinas e climinuiçŭo de perdas na cadeia de transporte.

Outros aspectos prioritários, como facilitar a transferêncì de tecuologia e maior atençăo na cadeia de transporte de energia, requerem medidas por ambos lados, da oferta $\mathrm{e}$ da demanda.

Una forma de medir empiricamente a eficiência energética, usada com muila freqüência É " "intensidade energética" (relaçăo uso de energia por unidade de PIB). No entanto, no contexto dos paises em desenvolvimento é mais importante a taxa de rentabiliclade econônica do capital, e nño o uso de energia pror unidade de PIB. Procurar aumentar a eficiência energética por si mestmo poderia resultar custoso; deve-se tentar atingir essa meta qunndo a variaçã̃o na taxa de rentabilidade econômica scja zcro ou negativa (visto pot outro lado, quando a taxa de rentabilidade econômica for maior que o custo do capital, ou pelo menos igual).

Gerenciamcnto da carga, define-se como a açāo de controle da carga mediante incentivos econônicos, intervençôes diretas ou uso de novas tecnologias. Transferindo a carga da ponta ao "vale" de clemanda, ou simplesmente conn a diminuição de demanda na 
ponta, postergando, assim, a instalação de novas usinas; alsm disso, transfere-se a carga das instalaçõ̃es de geração de ponta às instalaçōes de geraçĩo de base mais eficientes do ponto de vista ecouômico.

Gerenciamento da demanda, define-se como a ação de identificar e aplicar medidas de melhoria no uso de capacidade de oferta de energia, mediante modificą̧ões das caracteristicas dn demanda. Este tipo de gestão pressupõe a mistura de politicas tarifŕrias e outras medidas de adninistraçâo da carga e estratégias de conservação, concebidas com o objetivo de incentivar o uso eficiente da energia (Banco Mundial, 1993).

\subsection{REGULAMENTAÇÃO EQUATORIANA PARA USO E INSTALAÇÃo DE ILUMUNAÇÃO PÚBLICA (IY), PADRŌES INTERNACIONAIS.}

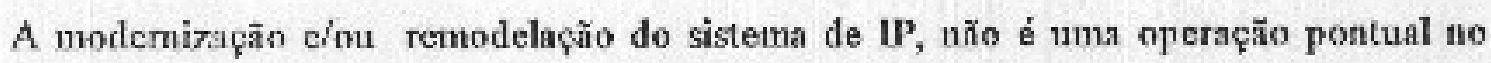
tempo, mas deve ser projetada no decorrer dos anos com a implementaçŭo de novas e eficicntes tecuulugias, embora as concessionárias se esqueceram deste ultimo ponto, usando altas taxas de penetração da tecnologie convencional. No entanto, ainda pode-se implementar programas intensivos de troca de luminírias eficientes.

O estudo de uso eficiente de cnergia deve conter dois pontos de vista:

a) ecouômico, bascado em critérios de otimizaçăo, porém não eminentcmente uma stuilise de menor custo; e

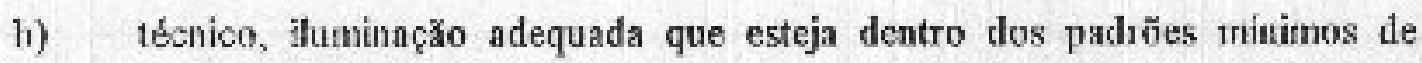
qualidade.

A otimizaţằo (écuico-econônica tem como objetivo misturar adequadamente os custos baixos e iluminaçăo satisfatórin.

Deve-se considerar que a IP possibilita aos usuários das vias, quer seja pedestre, quer seja veiculo, circular com seguranç̧a, comoditdade, visibilidade côtioda, mobilidade rípida e segira durante a noite, tudo isto proporcionado por uma adcquada ilunninหçăo. 
A seguir serí feito uma análise do padrão usado no Equador e suas alteruativas para mellurrí-lo, baseado em critérios de padrões internacionais.

\section{I.1. CARACTERÍSTICAS GERAIS E ANáLISE DO PADRĀO USADO NO SISTEMA DE UUMIVAÇĀO PÚBLICA (IP) DO EQUADOR.}

Neste ponto será feita uma análise técnica do padrão usado no setor de IP do Equador.

Em primeiro lugar, de forma geral o sctor se desenvolveu num mareo de ausência de padrōes e regulamentaçōes; tal é assim que, segundo a pesauisa feita pelo autor nas concessionárins, nenhuma daquelas exigin apresentaçīo de justificativas técuicas de IP nos projetos de eletrificação com orçamento privado. Os projetistas têm se habituado simplesmente em colocar nos projetos certos tipos de luminárias de uso cornun.

Eim segundo hugar, se os projetos nño contêm características de qualidade de IP, \& fácil supor que os empreendimentos elétricos tenham níveis mínimos de iluminação. Além disso, no momento de se aceítar o empreendimento de eletrificaçŭo pela concessionárin, não se verifica o cumprimento de níveís míninos de iluminaçũo das vias.

Deutro dos planos de eletrificação de certas concessionárias, exemplo E.E. Quito, Regional Centro Sul, Ambato S.A., existem projetos de melhoria na IP a partir do ponto de vista eminentemante técnico, para se incrementar os niveis de iluminaçăo usando lumiutrias eficicates (vapor de sódio) e, como conseçüência, obter dimiouiçîto de potência e energia. Estes programas ainda nศ̆ têm o conceito nem săo aplicados como gerenciamento da carga ou gereucinmento da demanda.

Conforme já dissemos, a E.E. Quito, única concessitonárias do Equador que dispōe de um padrĩo "Normas para Sistemas de Distribución", dentro daquele existe um pouto pequeno sobre iluminaçâo de vias "Nlumbrado de vías (generaf)". No entanto, este padrão é vellio (janeiro 1979) e não se encontra dentro dos princípios de modernizaçăo e eficiância. Algunas concessionárias do Equador aceitaram como o scu padrão aquele da F.E. Quito. 
O padrão da E.E. Quito tem conceitos e caracteristicas de IP muito gernis, tais como:

- O projeto de redes de distribuiçâo, também deverá considerar a instalação de IP.

- $\quad 0$ projeto selecionará as fontes luminosas en finção dos níveis e fatores de iluniıação, assim como os elementos para sua montagem.

- O projeto deverá considerar as características de iluminação das áreas adjacentes.

- Os níveis de iluminaçño adotados, serão funçâo da intensidnde de tráfego vcicular e de pedestre; estes por sua vez eståo relacionados com as carncteristicas e dimensões da pista e calçada. Assim, tem se dcfiuido 5 tipos de vias zegundo a municipalidade do Municipio de Quito.

- Depois, aptesenta-se uma tabela com valores mímimos de iluminação; ectes variann entre 10 lux para a via No. 1 e 35 lux para a via No, 5. De igual maneira, os fatores de uniformidade variam entre 0,20 e 0,30 respectivannente. $O$ detallhe desta tahela apresenta-se no seguinte capitulo (ver TARELA 4.4).

- $\quad$ EE. Quito aceita a instalaçāo de luminárias mcandescentes nas áreos rurais, entrefanto nos centros povoados apenas luminárias de vapor de mercítio e sódio.

- I.uminárins com potências maiores de $400 \mathrm{~W}$ tem controle individual, entretanto para potências menores o controle será coletivo.

\subsubsection{CARACTFRIZAÇÃo do PADRÃo PROPOSTO - PADRŌES INTERNACIONAIS}

O escopo deste ponto é proporcionar critérios que possam servir de base para a claboração de un "padrão de IP", unificando assim critérios de instalação, equipamento, qualidade de iluminaçño", uniformidade, tipo, potência, controle, etc.; isto será fẹto

\footnotetext{
- "A análise de um conceito com tantos aspectos como a qualidade de iluminaçầo nầ pơde basear-ga numa simples medida ou tume simples técnica de mediçî̉o A qualidado de um ambiente ilumiınde consiste en atrendir a diversas necessidades do ser humano, como:
} 
baseado nos padrǒes intemacionais e experiências de concessionárias de outros países, apticando, alèrm disso, princípios de uso eficiente de energia com critérios de modenização, otimizaçẫo e de administraçăo da carga.

a) Objetivos to padrão

O padıão fixa requisitos, considerados cotne tuínimos necessírios a iluminação de vias públicas, os quais são destimados a propiciar algum nivel de segurança aos tráfegos de pedestres e veiculos.

b) Caracterizaçĩo Geral

A distribuição apropriada da intensidade luminosas das luminárias é un dos fatores cssenciais de iluminaçāo eficiente em vias. A intensidade emitida pelas luminárias é controlada na sua direçầo $\mathrm{e}$ distribuída segundo necessidlade para visibilidado adequada (rápida, precisa e coufortível). A distribuição de intensidade é geralmente projetada para uma faixa típica de condiçzes as quais incluem altura de tnontagem de lumintátias, posiçāo transversıl da lumiuảrias (avanço) espaçamento, posicionamento, largura das

- desempanho pós-visual (desempanho de tarefas e outros efeitos comportamentais),

- interaçĩo c comunticaçāo sociais:

- estado de aspirito (felicidade, atençăo, satiefaçiso, preferêneia);

- saide;

- julgamentos estéticos (delerminaçâo do aspecio do local ou da iluatinaço).

A qualidade da ilusninaçầs, portanto, năo é đirelamente mensurível es sim, é um estaxo eunetpente criado pela interaçíio entre o ambiente iluminado e a pessoa que estí no ambiente. Existe uma lxa qualidado de iluminaçåo quando o sistema de iluminaçă

- cria boss condiçб̃es de visfilo;

- petmile o desempenton de tarefias ou comportamentos arlequados,

- fiverrser a comunicaçio a a interaçio adequadas;

- contribui para estados de espirito apropriados;

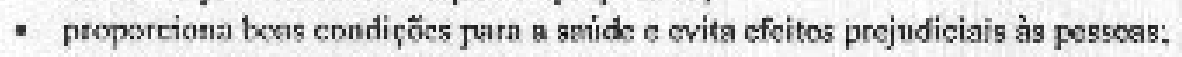

- centribui para a aprocisç̄̄o estética do ambiente.

Avaliar a gualidade de um ambiente iluminado é medir seus efeitos nas pessoas, levando om cousideraçíio todos os tranttexdos relevantes para o local e para os indrvíduos que o utilizam. A qualidade

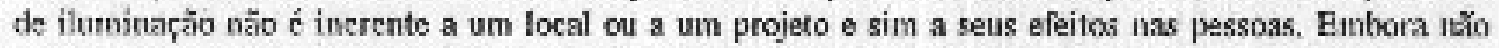
possua unia medicla ahsoluta, é possivel utilizar métodos padronizados de estudo de comportamente para prever os efeitos de um dado projeto nos prowífveis ustárics do lacal. O projeto experimental descrito a s:guir adota exatamente tal enfoque." (Revista Eletricidade Moderna, pígina 60. 1995) 
vias a serem efetivamente iluminadas, porcentagem do fluxo luminoso na pista e áreas adjacentes, mantida a eficiencia do sistema.

Toda lnminária deve ser classificada de acordo com sua forma de distribuição de intensidade (em relação às vias) luminosa lateral e vertical.

Difereutes distribuiçôes laterais sño disponíveis para diferentes relações entre a largura da via e a altura de montagem.

c) Defiatiçōes

- Altura de montagem: distĥnciú vertical entre a superficie da pista e o centro ajparente da fonte de lus ou da luminária.

- Espaçamento: Distâncił entre sucessivas unidlates de tlumìnaçñ̆o medicla paralelamente ao longo da linha lengitudimal da vis.

- Fator de uniformidade da ilumintância (U): razăo entre a iluminância mínima e a ilumiâancia méclia em un planı especifícado.

- Manutençĩ̄o: combinação de todas as ações técujicas e administrativas, incluindo as de supervisio, destinadas a manter ou recolocar um item em um estado no qual possa desempenhar uma funçăo requerida.

- Vias arteriais: vias exclusivas para tráfego motorizado, que se caracterizam por grande mobilidade e pouco acesso de tráfego, várias pistas, cruzamentos em dois planos, escoamento continuo. Geralmente nẳo existe ofuscament" pelo tráfego oposto, nâก existindo construções ao longo da via. $O$ sistema arterial serve mais especificamente à graudes geradoras de tráfego e viageus de lougas distâucias, mas octsionalmente pode servir para o tráfego local.

- Vias coletoras: vias exclusivamente para tráfego mototizado, que se снгкclerizam por umas mobiliclade do tráfego inferior e por um acesso de tráfego superinr, àquelas das vins arteriais. 
- Vias especiais: são considerados os acessos eiou vias exclusivas, de pexlestres, jardins, praças, etc.

- Vias irregulares: são passagens criadas pelos moradores, de largura, piso, declive e arnaamento variáveis, que dão acesso á pedestres e, em raros casos, à veículos, com traçado irregular, na maioria dos casos determinado pelos usúríos do local ou pelas próprias construçôes.

- Vias de ligaçăo: ligações de centros urbanos e suburbanos, porém não pertencendo an grupo anterior. Geralmente, só têm importância para tráfego local.

- Vias locais: vias que permitem acesso às propriedades rurais com grande нсеsso e pequena mobilidade de tráfego.

- Vias normais: são consideradas vins principais as avenidas e ruas asfaltadas ontle hห́ predomiuâncił de construç̃̃es comerciais, assim como trînsito de pedestres e de veículos.

- Vias rurais: vias mais conhecidas como estradas de rodagem e que nem sempre apresentam exclusivamente tráfego motorizado.

- Vias secundárias: sĩo consideradas como vias secundárias as aveuidas e ruas com ou sem calçamento, onde hí construçŏes, e o trânsito de vcículos e pedestres não ć intenso.

- Vias urbunas: sâo caracterizadas pela existência de construçũes às suas margens, e a presença de tráfégo motorizado e de pelestrea em maior ou menor escala.

- Lúmen"(lúmen); é a unidade de medida do fluxo luminoso. Fluxo luminoso é a potência de radiação total emitida por uma fonte de luz e avalinda pelo otho humano.

- Candela (od): é a unidade de intensidade fuminosa, equivalente à quantidade de fluxo luminoso de 12,57 lúmens emilido em eerta direçāo sob 1 esferoradiano (unidade de àngulo sólido) ou $1 / 60 \mathrm{da}$ intensidade luminosa de um materiul preto em $2.046 \mathrm{~K}$

\footnotetext{
Q a unidade de inedida do fluxo luninoso, equivalente à quantidade de luz envitjda por uma fonte Luminosa de $1 / 680$ W de potência na longitude de conda de 5.555 . Angstrons durante I segundo.
} 
- Lux (lıx): é a unidade de medida da iluminância. Tluminância é a telação fluxo fussizoso/superficie. A iluminâucia será de 1 lux quando, o fluxo de 1 lúmet incidir unifontemente numa superficie de $I \mathrm{~m}^{2}$.

- Lumiunancia (L) (numa certa direção, no ponto da superficie da fonte luininosa ou no ponto do trajeto do feixe luminoso), razìo entre o fluxo luminoso que está saindo, chegando ou atravessa un elemento de superficie num determinado ponto e irradiado nas direçōes definidas por um elemento de cone que contèm as mesmas, dividido pela área da projeção ortogonal do elemento de superficie nurna superfície perpendicular à direp̧ăo dada. Unidade $\mathrm{cd} / \mathrm{m}^{2}$.

- Cocficicnte do lumiuância (q): as características de reflexão da superfície de umเ via poderão ser indicadas por meio do cocficiente de luminância, q. Este coeficiente é definido como a razāo da luminância em um ponto, pela luminância horizontal no mesmo ponto. $O$ coeficiente de luminância depende das posiçōes do observador e da fonte de luz em relaçăo ao ponto na via soh consideração.

d) Caracteristicas da luminária

- As caracteristicas de fotometria devem corresponder à classilicaçũo da norma CIE 12;

- O refletor deverá evitar que os feixes passem pelo tubo de descarga da lầıphada;

- Todos os acessórios deverŭo resistir ans elementos ambientais;

- O acesso para o sistema ótico ou porta acessórios será independente;

- O cripo poderá ser metálico on de material sintético de menor peso possivel;

- O refletor será de alumínio de uma pureza múnima de $99,9 \%$;

- A cuherta inferior poderí ser de vidro, acrílico transparente ou policarbonato transpurente; 
- O recinto porta acessórios permitirá adequada instalação dos acessórios e sua teusperatura máxima será $75^{\circ} \mathrm{C}$.

e) Tipos de luminárias

As luminárias usadas em IP deverào ser de vapor de sódio de alta pressão com eficiêncin maior do que $70 \mathrm{~lm} / \mathrm{W}$ (inclui perdas no rentor). Poderá se usar vapor de sódio baixa pressão onde a reprodução de cores não é importante. Eventualuente quando seja de mérito e caso excepcional sob demonstraçăo, poder-se-á usar luminárias de vapor de mercúrio alta presșio ou luzz mista. Não se accita o uso de luminárias incandescentes ou fluorescentes.

As potêncins das lâmpadas normalizadas serăo as seguintes: $50 \mathrm{~W}, 70 \mathrm{~W}, 100 \mathrm{~W}, 150$ $\mathrm{W}, 250 \mathrm{~W}=400 \mathrm{~W}$.

- Vapor de sódio de alta pressāo:

A carncteristica mais importante da lâmpada de vapor de sóclio de alta jressăv é a sua grande eficiência luninosa, traior do que qualqquer outro tipo de fonte luminosa policromática para uso generslizado. Sua aparência é de cor tranca - amarelada, agradável, apresentando uma grande vida média, scndo sua vida útil maior quando se usa acendimento contínuo. U/m excessivo aumento de tensăo causa reduçāo do vida da làmpada.

- Vapor de súdio baixa pressão:

Sũo tampadas muito eficientes, produzindo até $200 \mathrm{~lm} / \mathrm{W}$ e toruando o projeto muito mais econômico. Esta lâmpada tem o inconveviente de ter curva de distribuip̧ão espectral monocromática na cor amarcla, distorendo totalmente as outras cores. Por esta razāo, este tipo de lâmpada encontra sua aplicaçăo onde a reprodução de cor é mentos importante $\mathrm{c}$ onde o reconlhecimento por contraste é predominante. 
f) Diminuiçāo de potência

No cstado atual da capacidade de geração do Equador toma-se relevante o uso eficiente do energia. Visto que a luminária fica encrgizada por periodo de aproximadamente 12 boras, considera-se aqui que reduções na potência absorvida, após transcorridas pelo menos 6 horas da sua energizaçăn, em até $20 \%$ da potêncin nominal, podem ser implementados (mediante reduçà̃o de tensăo).

\section{g) Classificaçño das vias}

As vias do Equador classificam-se em 5 categorias: $\Lambda, B, C, D$, e E, cacla uma daquelas é funçīo do tipo de tráfego, velocidade dos veiculos, densidade de tráfego pedectre c véculos, ummero de pistas, tipo de acesso, tipo de conexåo, etc., scgundo a recomendação da CIE (Comissăo Intemacional de lluminaçāo). A seguir apresenta-se a classificaçáo (ver TABEI.A .3.1)

TABELA 3.1. CLASSIFICACÃO DA CALCADA SEGUNDO RECOMENDACŌES DA CIE

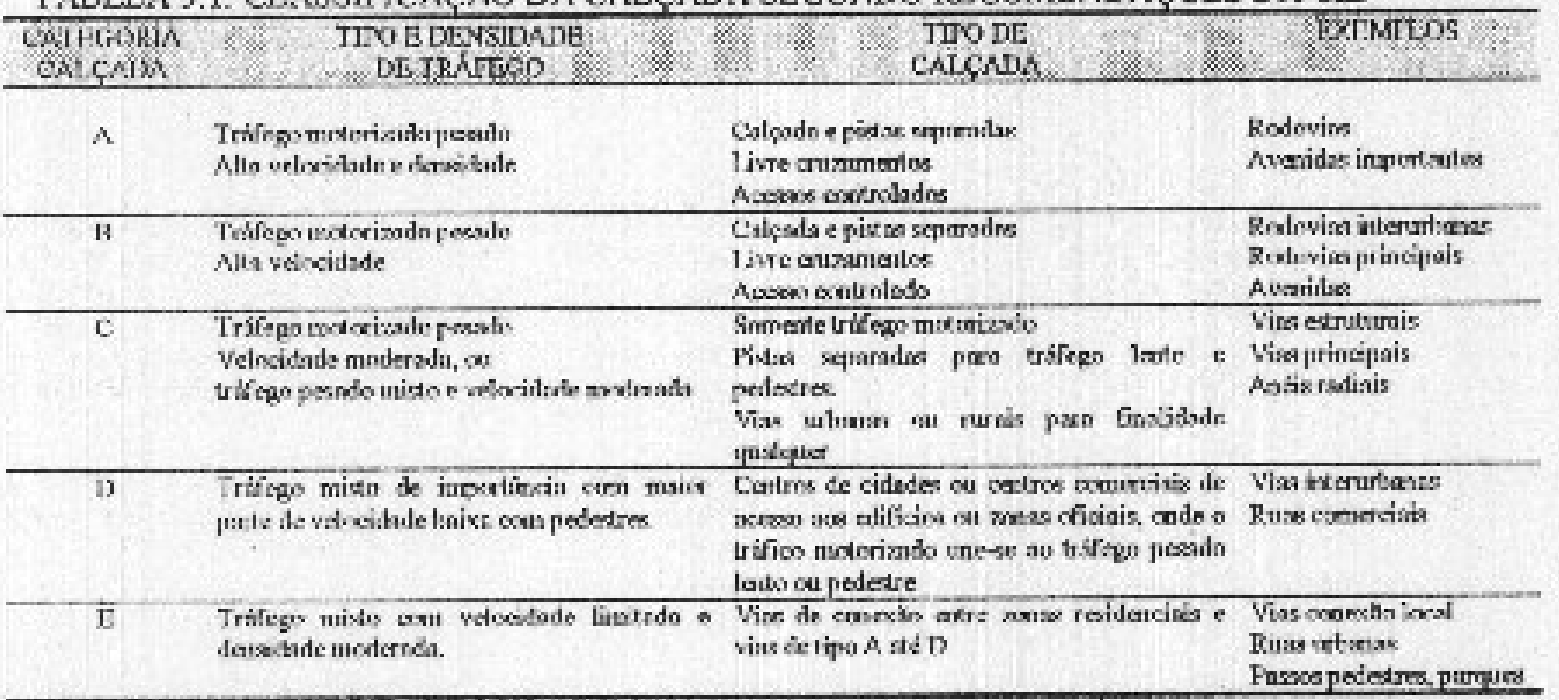

FONTE: ILUMINAÇAO - GRASL, COMTONENTES E MATERLAL. ELETRICO No. 41/1993. 
h) Alturas miuimas de montagem

$A$ altura de montagem será umit fimçno da categoria da via e mais especificamente the definitá o futor de uniformidade; além disso, encontra-se na seguinte tabela a disposiçāo recomendada de lumiunárias e a relaçăo D/H (ver TABELA 3.2):

TABELA 3,2; ALTURAS MINIMAS DE MONTAGEM DE LUMINARIAS

\begin{tabular}{|c|c|c|c|c|c|}
\hline Mifourik & 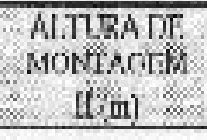 & : & $\begin{array}{l}\text { RTACWO } \\
\text { D/H }\end{array}$ & 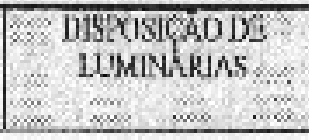 & $\begin{array}{l}\text { WRRGUKR IR Vh } \\
\mathrm{L}(\mathrm{m})\end{array}$ \\
\hline A & $10 \cdot 13$ & & $2.5-3$ & 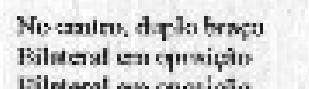 & $\begin{array}{l}x+612 m \\
+616 m\end{array}$ \\
\hline$H$ & 25.10 & & $3 \cdot 4$ & Filderal escapcticin & $a t+12 \mathrm{~m}$ \\
\hline$c$ & $3 \cdot 10$ & & $3-4$ & 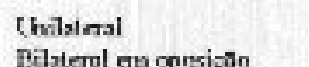 & $\begin{array}{ll}\mathrm{L} & \leq \mathrm{H} \\
\mathrm{H} & \mathrm{S}\end{array}$ \\
\hline o & $7.5 \cdot 10$ & & $3-5$ & 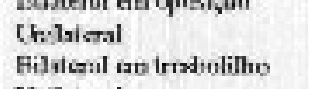 & 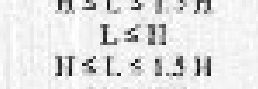 \\
\hline E & $4-10$ & & $4-5$ & Chilsterol & $4 S \mathrm{LSH}$ \\
\hline
\end{tabular}

FONTE: ILUMINAÇÃO - BRASIL, COMPONENTES E MATERIAL ELÉTRCO No. 4l/1993.

i) Niveis de luminància

Existem técnicons diferentes no cálculo de IP, das quais duas sāo mais utilizadas: luninâancin e ilumintı̂ncia. Alguns paises ndotaram estes métodos, como por exemplo:

- Iluminância (E): Itííis, f́ndia, USA, Japส̃o, Alemanha, Brasil.

- Luminància (cd/m²): Holanda, Suécia, Rússia, C.I.F., França, África do Sui, Peru.

No entanto, ìs vezes os cálculos são feitos em iluminância e depois couvertidos em luminância $\left(\mathrm{cd} / \mathrm{m}^{2}\right)$.

Para o padrão equatoriano, adota-se o método da luminância, cujos niveis minimos médios e coeficientes de uniformidade sāo apresentados na TABEL A 3.3; os mesmos encontram-se listados cm funçăo dos tipos de vias segundo definiçôcs da TABELA 3.1. 
TABELA 3.3: REOUISITOS MÍNIMOS DE LUMIN ふ̇NCLA E UNIFORMIDADE

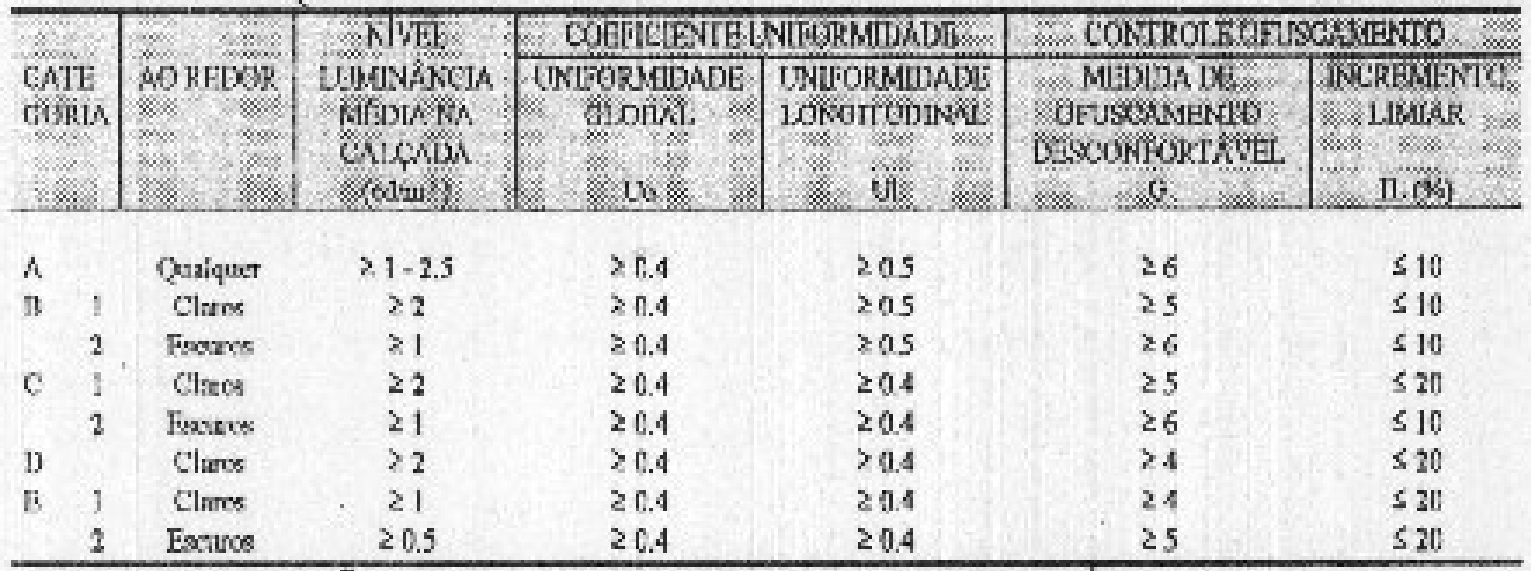

FONTE ILUMINACYAO - BRASIL, COMIPONENTES E MATERIAL ELÉTRICO No, 41/1993,

NOTA: $U_{D}=$ uniformidade global (razào da luminância minima de uma trilha de calçada à Iuminåncia média da mestna).

UI - unifonwitade longítudinal (razĭo da luminância mínina à máxima no trąjeto de unsa tintı parajela ao eixo da calçada passando pela posição do observador).

G - medida de ofuscamento desconfortável (número que indica o gratu do que esla controlado o ofuscantento munta deterninada iustataçăo de iluninaçăo).

$\mathrm{IL}(\%)=$ incremento limiar (número que indica o limite da diminuiçäo de contraste, provocado pela huminância veladora ou o grau do que esta linnitada uma luminária do ofuscamento)

j) Características de reflexâo de superficies de vias

A fim de calcular a luminância da superficie de uma via, as caracteristicas de raflexāo da superficie deverāo ser conhecidas. A CIE recumenda usar os segunintes valures (ver TABELA 3,4);

TABELAA 3.4: COMPOSIÇÃO DE SUPERFICIES E OS PROVRVEIS VALORES DE "q" RESULTANTE

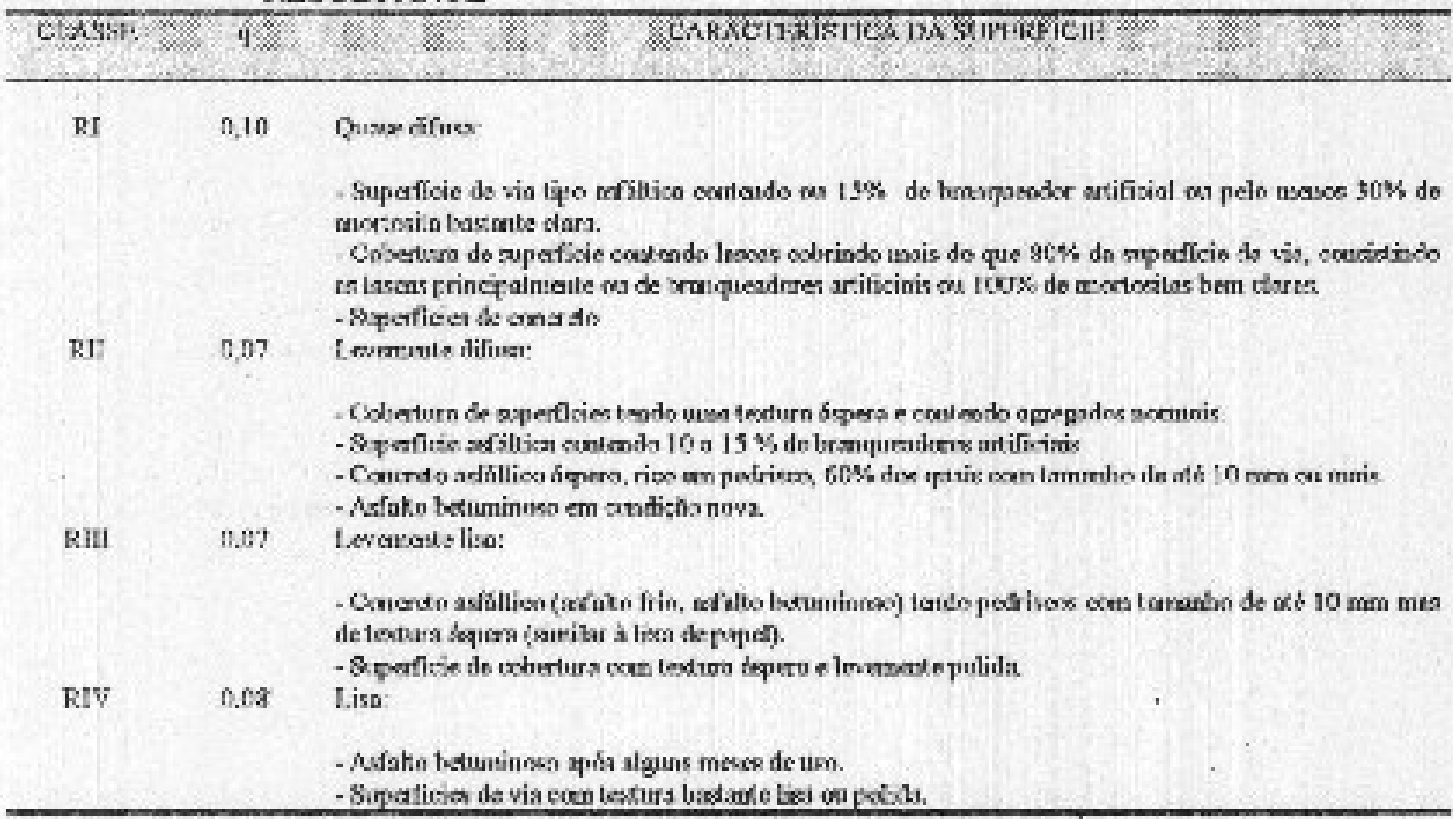




\subsection{SISTEMA TARIFÁRIO DE ENERGIA ELÉTRICA NO EQUADOR (ILUMINAÇÃO PÚBLICA - IP)}

A manutençăo, por longo periodo, das tarifas de energin elétrica abaixo dos custos de produçăo vem provocando efeitos desastrosos sobre a saúde fuluaceira das concessionárias em muitos países, especinlmente na América Latina.

A propriedade estatal da maior parte das concessiontárias e sua condiçño de monopólios regulamentados têm permitido aos governos a manipulaçăo das tarifas de energia elétricn, com objetivos macroeconômicos de curto prazo e objetivus distrihutivos (Bitu e Bom, 1993).

O INECEL além da fimçăo de gerar cletricidade também regula o setor. As concessionárias devem se subnteler às tarifas aprovadas pelo Conselho Diretivo do INECEL. Este, na prática, estabelece tarifass baseada na política tarifária do govemo.

As dificuldades vividas no periodo impôs contínuos desafios ao Setor Elétrico, principalmente na busca de melthor utilizaçno da capacidade instalada do Sistemn e un

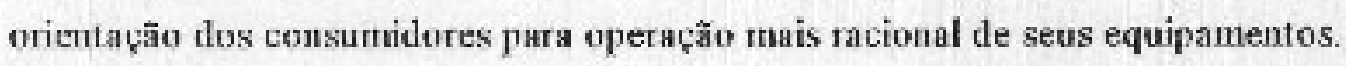

Na busca dessa raciounlizaçầo, verificou-se que incentivos tarifärios poderiam induzir os consumidores a programarem mellıor suas demaudas. Obter-se-ia, assim, minimizaç̆̃o de custos para o atendimento de um mesmo consumo, pelo uso mais racional das instalaçñes existentes.

\subsubsection{HISTÓRICO DO SISTEMIA TARIFÁRIO}

Apresentando o histórico da cvoluçăo das tarifass, scgundo resoluçăo do "Diretério do INECEL" de data 8 setembro 1988, estabeleceu-se o nivel de tarifa referencial de venda de energin elétrica pelas concessionárias ans usuérios finais, no valor médio de 13,4 
sucres ${ }^{10} / \mathrm{kWh}$ (30 USS/MWh). Por outra parte, estabeleceu-se incremento mensal de $3 \%$ cumulativo para todos os setores de consumo, exceto usuários residenciais e comerciais cujo consumo mensal seja menor do que $80 \mathrm{kWh}$. 0 incremento da tarifa para estes usuários somente seria feito com 0 incremento do salário mínimo vital (SMV). Em novembro de 1900 muda-se a resoluçn̆o para os clientes residenciais com consumo menor do que $200 \mathrm{kWh} / \mathrm{mes}$.

Assim, a partir de 1988 até agosto de 1992, aplicou-se incrementos mensais de $3 \%$ no sistema tarifario sté agosto de 1992, exceto em janeiro de 1991 quando se aplicou um incremento extraordinário de $15 \%$; a partir de setembro de 1992 as tarifas permaneceram constantes (não têm incremento) até abril de 1993. Em maio de 1993, produziu-se incremente nas tarifas de $55 \%$; a partir dessa data até o presente as tarifas ramutêm-se constantes.

A segtait, ilustru-se na FIGURA 3.1 a evolução das tarifas para IP a partir de jullo de 1987 atć oulubro de 1995. Os valores tem sido apresentados em sucres" $/ \mathrm{kWh}$ o USSIMWh.

FIGLRA 3.1: EVOLUÇAO DAS TARIFAS PARA ILUMINAÇĀO PÚBLICA (IP)

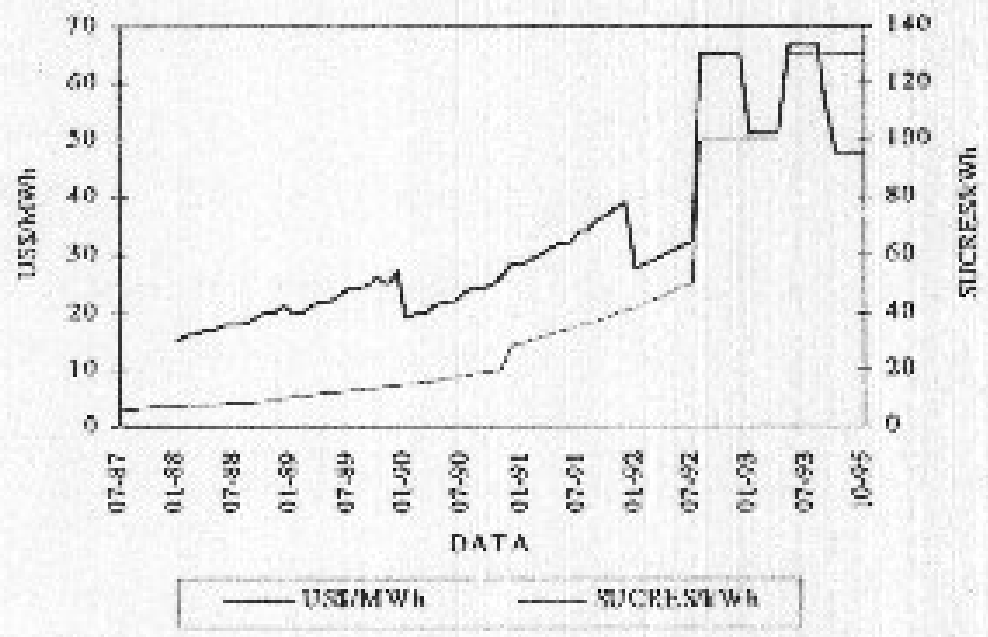

\footnotetext{
${ }^{10}$ Cêmbio da moxda equatoriamą (1988) 450,0 suctes por LSS I

"Câıbio da moeda oquatoriana (sucres); sucres (S') per US\$ 1- 1.947,1 (outubro de 1993); 1.534,0 $(1992) ; 1.046,25(1991) ; 767,8(1990) ; 526,35$ (1989); 450,0 (1988).
} 
Observa-se na FIGURA 3.1 que a tarifa evoluiu de 16 USS/MWh $(5,7$ sucres/kWh) em 1987 até 50 US\$MWW (130,0 sucres/kWh) em outubro de 1995, a porcentagem de incremento resulta ser $213 \%$ em moeda forte (o equivalente em moeda local foi $2.180 \%$ ). A tarifa média do setor elétrico equatoriano tem aproximadamente a mesma forma de evolução da figura indicada e similares porcentagens de incremento.

\section{3,2.2. CUSTOS MARGINAIS}

O INECEL no ano 1988 decidiu empreender um programa de estudos tarifátios chamado "Estudos Tarifärios do Sistema Elétrico Equatoriano", baseado na Teoria de Custos Margioais, anteriormente aplicada com sucesso em diversos paises do mundo. $O$ custo marginal informa o custo que será incorrido pelo sistema elétrico para atender o crescimento do consumo. O programa for financiado através de um empréstimo do Banco Mundial.

Defue-se custo marginal, como aumento dos custos da empresa cansado pclo incremento de produçẫo de uma unidade adicional. Fixar um preço igual ao custo marginal, consiste eth estabelecer o preço de um artigo qualquer igual ao custo de protuzir uma unidade adicional desse artige. $O$ custo marginal representa o custo de oportunidade -ou o sacrificio total para a sociedado- para a produção de um artigo (Banco Mundial, 1993).

Os conceitos de custo marginal se apoiam tha teoria microeconômico, existindo duas variantes: a tarifa de custo marginal de curto prazo (CMCl') e a tarifa de custo marginal de longo prazo (C.MI.P).

O custo margiual de curto prazo (CMCP) on custo marginal de operaçān é o custo de atendimento de uma unidade adicional de demanda, considerando o sistema elétrico existente. Ou seja, o atendimento da carga adicional é feito com o aumento da geraçăo téruniç éou com a diminuiçäo da qualidade do serviço. 
A tarifa no custo marginal de curto prazo é geralmente fixada para periodos anuais e reajustada quando ocorrem variaçōes significativas desse custo. $O$ Chile aplicn esç uodalidade de tarifa desde 1972 (Bitu e Borm, 1993).

O custo marginal de longo prazo ou custo marginal de expansāo é o custo de atendimento de uma unidade adicional de demanda, considerando a expaus̆̃o do sistema e permitindo também a alteração da qualidade do scrviço e dos níveis de geração têrmica.

As tarifas de custo marginal de longo prazo (CMLP) sŭo geralmente calculadas a partir de custos incrementais associados a planos de expansão especificos. Considerando a expansĩo ótima dos sistemas, alguns paises têm usado essa modalidade de tarifa, com resultados hașante positives, conno é o caso da França (Bitu e Born, 1993).

Quando o sistema é otimamente planejado e operado, CMCP e CMLP coincidem. Portanto, o uso dos custos marginais na tarifaçăo é mais simples quando n sistema está próximo de seu pounto ideal de operação.

Outra variaçăo é a tarifa com base nos custos marginais ou "tarifa integrada". Nessh modalidade, tanto o nivel como a estrutura das tarifas são estabclecitos guardando a maior coeréncia possível com os custos marginais e, além disso, levando em consileteraçŭo outrus princípios básicos de tarifaçåo e os objetivos atribuidos an setor elétrico (Bitu e Born, 1993).

O Equator tem bem marcada a diferença entre a estação de seca -pcriodo entre outubro e fevereiro- época de reduçño drástica de potência e cnergia do SNI, entretanto os meses restantes do ano apresentam disponibilidade de energia, motivo pelo qual o INECEL detcruninou custos marginais de longo prazo parcelados para cada uma das estaçōes (ver TABELA 3,5).

O cousunidor que demanda evergia ao SNI no período năo crítico (cataçaิo úmiła) é responsável somente pelos custos de operaçño, e estes valores săo baixos devido 
fundamentalmente ao tipo de geraçâo hidrelétrica. Entrctanto, o consumidor que demanda energia na estaçăo de seca é responsável alćm dos custos de operaçăo (custos altos), e pelos custos de equipamentos futuro destinados a manter a capacidade geradora requerida pelos incrementos de demanda de energia nesta estação.

TABELA 3.5: CUSTOS MARGINAIS DE LONGO PRAZO PARA O SETOR ELÉTRICO EQUATORIANO

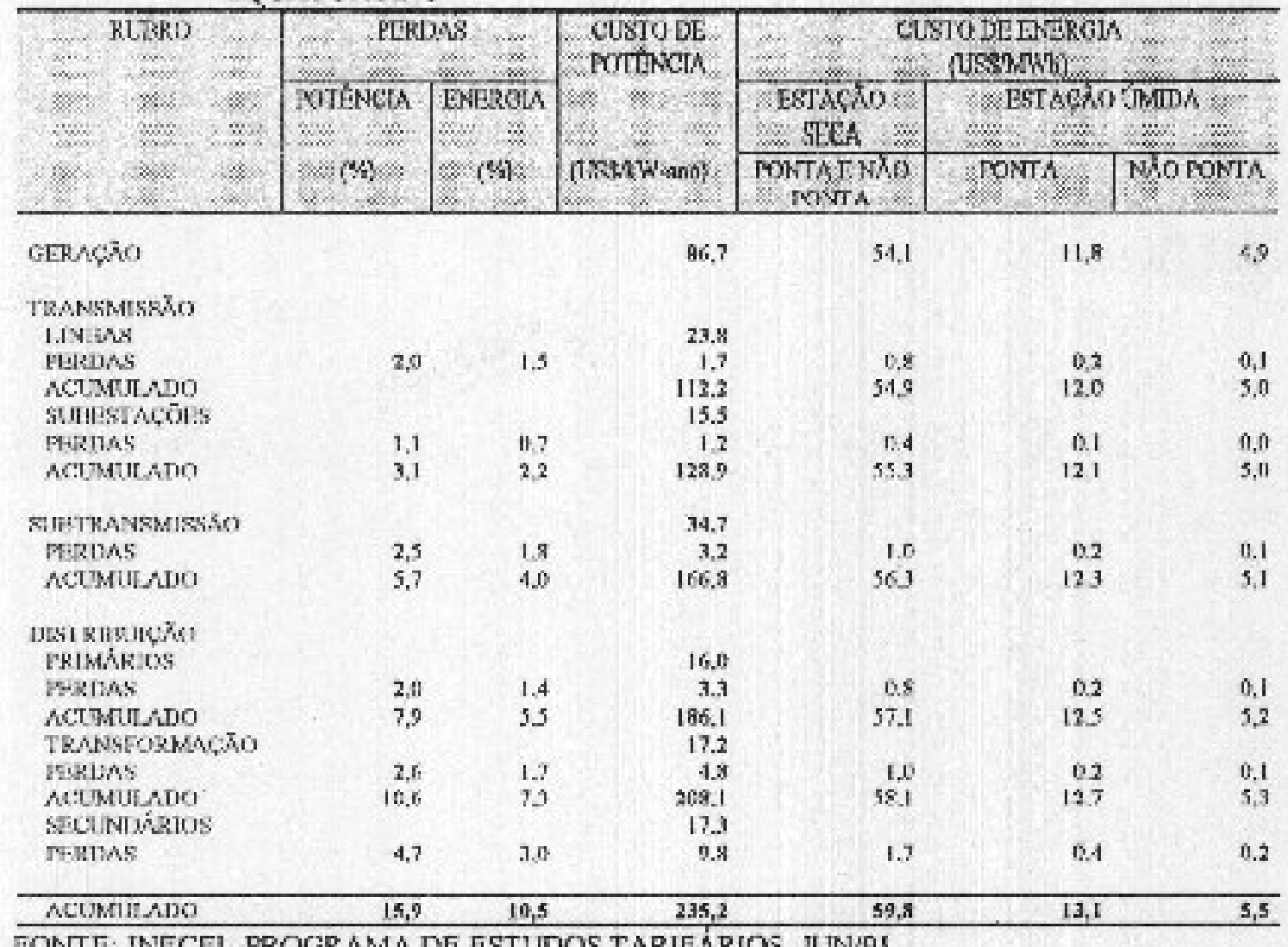

FONTE: INECEL-PROGRAMLA DE ESTUDOS TARIF ARIOS, $\pi$ UN/9I

O custo marginal de energin de longo prazo ao nivel de rede secundária para a estação seca (ponta e fors de ponta) é 59,8 US\$/MWh; entretanto, para a estação úmida no período de ponta 13, I US\$MWWh, e na mesma estaçăo porém fora de pouta 5,5 USS/MWh. O custo marginal de potêtıcia atinge 235,2 USS/kW-ano. Na determinaçăo destes valores foi necessirio aplicn as porcentngens de perdas tanto de potência quanto de energia incorridas na cadeia de transporte a partir da geração até o nível do consumidor: O INECEL determinou as perdas totais que atingem $15,9 \%$ para potência e $10,5 \%$ para energia. 
O preço médio referencial de venda de energia do SNI às concessionárias foi previsto pelo INECEL nos seguintes valores (INECEL, 1993):

\begin{tabular}{|c|c|c|}
\hline ANO & US\$MWh & INCREMENTO \\
\hline 1993 & 40 & . \\
\hline 1994 & 46 & $15 \%$ \\
\hline 1995 & 46 & $0 \%$ \\
\hline 1996 & 56 & $22 \%$ \\
\hline
\end{tabular}

Scguado o INECEL, esta tarifação produzirá receita ao setor elétrico de US\$1.358 milhōes no periodo 1993-1996, dos quais USS 1.118 nilhŏes perlencem ao INECEL (pelo serviço de geraçíio e transmissāo) e o resto USS 240 milhōes para as cuncestienárias (pelo seı viço de distribuiç̣̃o).

Do valor do faluramento de US\$ 1.358 mithǒes, deduzida a despesa operacional US\$ 547 vilhōes no mesmo período, a receita líquida do setor elétrico equatoriano será US\$ 811 millōes, que nāo satisfaz as necessidades de expansão (seguttdo a CEBCA e o INECEL, as necessidades para o periotlo 1993-1997 serăo USS 1,34 bilhßes).

Segundo fora dito, a "receita bruta" do INECEL será US\$' 1.118 milhōes para o período 1993-1996, dos quais USS 694 milhŏes ( $62 \%$ ) serăo destinadıร so pagamento da divida extemn, enquanto US\$ 424 millıǒes ( $38 \%$ ) serăo destinados para a expansăo do sisterna elétrico.

A "receita brut" " das concessionárias será US\$ 240 milhöes, dos quais US\$ 29 millıð̌es (12\%) serīo destinados para o pagamento da đívida externa e interna, enquanto US\$ 211

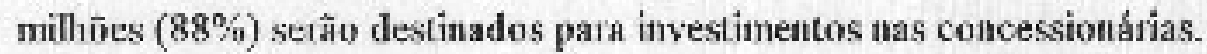

O preço médio referencjal de venda de energia das concessionárias aos nsuírios funais foi pevisio pelo TNECEL nos seguintes valores (INECEL, 1993): 
ANO USSTMW/ [NCREMENTO

1993 61

$1994 \quad 64 \quad 5 \%$

$\begin{array}{lll}1995 & 64 & 0 \%\end{array}$

$\begin{array}{lll}1996 & 76 & 19 \%\end{array}$

\subsubsection{CARACTERIZAÇÄO DO SISTEMA TARIFÁRIO}

Analisando as caracteristicns gernis do sistema tarifărio no ano 1993, a faturamento do setor elétrico equatorinno atingiu USS 345,6 millozes, pelo consumo de $5.533 \mathrm{GWh}$, portanto o preço médio de venda de energia sos clientes finais atingiu 62,4 US\$/MWh (valor perto do projetado). Além disso, foram atendidos 1.714.441 clientes, dos quнis 87 $\%$ pertencem ao setor residencial, $11 \%$ ao setor comercial, $1 \%$ so setor industrial c $1 \%$ outros setores.

Na TABELA 3.6 apresenta-se as tarifas médias de venda aos clientes fmais por setores de cousumo e certas caracteristicas gerais desces setnres.

TABELA 3.6: CARACTERISTICAS DO SETOR ELÉTIRICO EOUATORIANO EM 1993

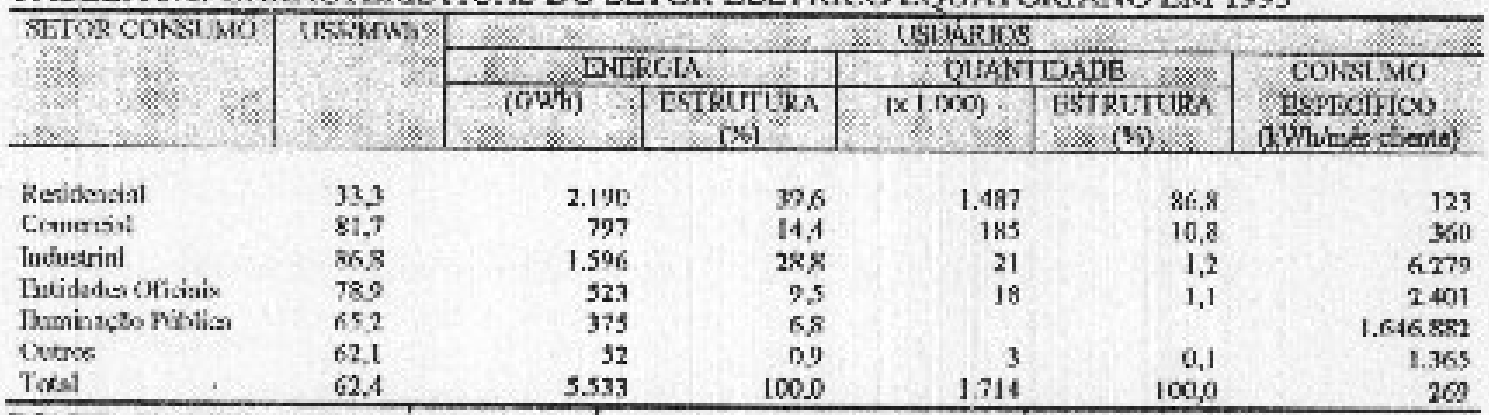

FONTE: INECEL - ESTATISTICAS ELEETRICAS, BOLETIM ESTATISTICO No, 28

O preço médio de venda para o setor residencial no ano 1993 foi mais baixo que todos os setores; o setor comercial pagou uma tarifa $145 \%$ do valor da tarifa residencial, o setor industrial pagon $161 \%$ mais que o residencial e, o setor de IP pagou $96 \%$ mais que o residencial.

As tarifas de eatergia clétrica no Equador foram calculadas basendas em critérios contábeis, partindo do principio que aquelss devem colvir o custo do serviço além de 
uma quantidade retribuida pelo investimento (rentabilidade); a mesma deveria ser $8 \%$ da "base de tarifas" (formada pelo ativo fixo liquido $\mathrm{cm}$ operaçăo).

Na práticn, cont a apliçção desse sistema tarif́rio, poucas concessionárias atingiram a rentabilidade propostn de $8 \%$; a maioria delas tiveram perdas econômicas assumidas pelo INECEL em forma de capitalização e dessa maneira foi tomado efetivo o sabsidio de energia aos usuários por parte do governo. Isto provocou contribuiçōes especificas do governo para colurir obrigą̧ões financeiras, especialmeste externas, que o setor elétrico não teve possibilidades de atender.

Uma análise đit estrutura tarifaria equatoriana, cm geral, mostra que a mesma é composta de dois tipos: mnnômia ${ }^{12}$ e hinômia ${ }^{13}$.

Apliç-se taîił monônia ans usı́rios residenciais, assistéucia social e IP; entretanto, tarifin binômiu aอs ustúrios comerciais, industriais, entidades oficiais e bombeamento de água. No eutanto, há tarifas monômins para usuńrios comerciais, industriais e entidades oficiais quasdo in sua carga elétrica instalada é menor do que $10 \mathrm{~kW}$.

No ANEXO C observa-sc como exemplo a estrutura tarifătia da E.E. Regional do Sul S.A.

O usuário do serviço elétrico além do pagamento pelo consurto, tem outras taxas que รั̆ as seguintes:

- Iluwinaçio Pública (IP): o consumo de encrgia em IP é repassado aos usúxios por taxaçăo, que é cobrada pela ioposição de porcentagens

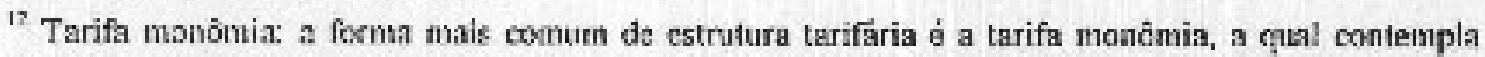
somente o uso de un preço para eretgia consumida (quilawats-hora) an longo de un periodo de tempo, en peral, um nôs.

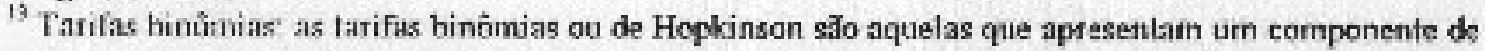
energia e outio de potencia. A forne mais utilizada é aquela qua considera o faturamento separado do consamo da entergia e da deuanda de potência máxiına. Deve-se chservar que, se a máxima demanda de polûncia do conssumidor nâo é observada no periodo de ponta do sistema, ela é penplizado de forma
} incberente resu ne custos que impöe so sistema. 
sobre o vator do pagamento pelo consumo de eletricidade, segundo o critério da concessionária.

- Eletrificição Rural: $10 \%$ do valor de pagamento por consumo de eletricidade, aplicado aos clientes comerciais e industriais.

- Bombeires! valor fixo varia entre 0,02 USS/cliente e 1,20 USS/cliente, aplicado aos clientes residencinis, comerciais e industriais.

- Seguro contra incêndio: valor fixo varia cutre 0,04 US\$/cliente e 0,20 USS/cliente, aplicado aos clientes residenciais e comerciais.

- Custos de comercialização: valor fixo aplica-se paru todos os clientes, varia entre 0,20 USS/cliente e 1,60 USS/cliente.

- Colela te lixo: uma porcentagem fixa sobre o pagamento por consumo de cletricidade, aplicado nas principais cidades do Equador (Quito, Guayaçuil e Cuenca)

O valor faturato pelo consumo de potência e energia mais os custos de comercializaçăo sâo arrecadid dos pelas concessionárias, enquanto, os inipostos anrecadatos são cntreguẹ aos organismus concespondentes (corpo de hombeiros, municipios, etc).

Fin média, o cliente paga $30 \%$ a mais do valor pelo contsumo de eletricitade, devido a imposiç̧̄e destes impostos.

A tarifa tnédia por consumo de energia elétrica no Equador está atingindo prę̧os internaciouais, segundo era o escopo do INECEL por decisĩo do govemo e pelas politicas de elintizaçăo de subsídios dos organismos internacionais como o Banco Murdial (Bauco Múudial, 1993, página 16), F.M.I., BDE, etc.

Comparando ns tarifas entre países', por exemplo, a tarifa média "a Bolfvia 60 US $\$ / M W h$, to Peru 80 US\$/MWh, no Brasil 54 US\$/MWh, OECD 81 US\$/MWh (Banco Muidia1, 1993), as tarifas no Equador aínda sño baixas. Comparando as tarifas do setor tesideacial com ontros paises, a tarifa média em 1993 do Equador foi 33,3 
US\$/MWh, do Paraguai 45 US\$MWh, do Peru e do México 50 US\$MWh, do Chile 115 USSrMWhi, da Argentina 125 US\$/MWh (Vieira de Carvalho, 1994).

0 relatónio do Banco Mundial (Banco Mundial, 1993) diz "As tarifas baixas provocam demanda excessiva, dimimuem a receita das concessionárias e produzem teduçăo da capincidade para proporcionar o serviço e manter o fontecimento. Os paises em desenvolvituento usam em torno de $20 \%$ mais eletricidade, do que usariam se tivessem que pagar o verdadeiro custo marginal. Além disso, as tarifas por demais baixas desestimulam o investimento $\mathrm{cm}$ novas tccnologias menos poluentes a de maior eficiência entergćtica" . Informe que por si mesmo retrata a política do organismo iuternacional e as conseq̨üências dos baixos preços da energia.

\subsection{CARACTERÍSTICAS DA OFERTA E DEMANDA DOS EQUIPAMENTOS DE ILUMINACXOO PÚBLICA (IP) NO EOUADOR.}

\section{3,3.1. DEMANDA DE EQUTTAMENTOS}

A Comissño Fquatoriana de Bens de Capital - CEBCA, com o objetivo de pôr ao conhecimento das empresas nacionais, a demunda potencial de bens e serviços, investimentos, cronogramas e requerimentos dos principais itens de intervenţâo nos projetos programados pelo setor elétrico equatoriano, emprceadieu uo ano 1993 uma pesquisa dirigida para determinar a demands de produtos no periodo 1994 até 1997 nas áreas de gerą̧āo, transmissão, subtransmiissão c distribuiçño. A informaçăo foi obtida através de pesquisas ao INECEL e às 19 concessionárias.

Segundo a CEBCA, o Equador precisa de US\$ 1,34 bilhǒes ( $11 \%$ da divida externa) para investimentos no setor elétrico no períndo 1993-1997.

Na TABELA 3.7 apresenta-se os principais itens demandados pelo setor de IP segundo presyuiss da CEBCA para o periodo 1993 a 1997. 
Analisando as nacessidades de luminárias, observa-se as porcentagens para cada tipo de tecnologia: $82 \%$ em mercúrio, $17 \%$ em sódio e $1 \%$ em ostros típos de equipamentos. Resultados similares às porcentagens de luminárias atualmente instaladas e que foram apresentados no Capitulo II, onde lembramos os valores de $80 \%$ para tecnologia de mercúrio, $17 \%$ para tecnología de sódio e $3 \%$ para outras tconologias. Portanto, concluise a tendência de continuar usando igual equipamento nos novos empreendimentos de iluminação.

TABELA 3.T: DEMANDA DE PRODUTOS PARA ILLMTNACAZO PIBBI.ICA (IP) NO PERJODO 1993-1997

\begin{tabular}{|c|c|c|c|c|c|c|}
\hline \multirow{2}{*}{ 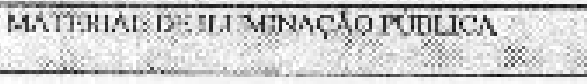 } & as & 8. & \multicolumn{3}{|c|}{ 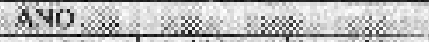 } & \multirow{2}{*}{ TOThL } \\
\hline & 1993 \& & 2994 & .1593 & 1996 & $190 \%$ & \\
\hline \multicolumn{7}{|c|}{ LUMTERRLAS } \\
\hline BERCUMO, APEXTAATIS $175 \mathrm{~W}$ & 111.182 & 10.505 & 11.276 & 11.746 & 10214 & 43.92 .3 \\
\hline 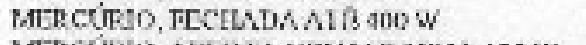 & 2.713 & 2.900 & $2.96 !$ & 2003 & 3.077 & 14.687 \\
\hline 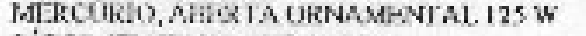 & 81 & 84 & 88 & 9.3 & 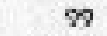 & 445 \\
\hline SÜDO, НЕCHAIX ATE +DI K' & 1.429 & $1.4 \times 2$ & 1.1 .12 & 1613 & 1.300 & 7.756 \\
\hline 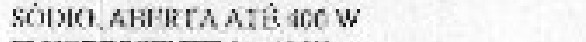 & $1.29 x 1$ & 1.3 .37 & 1.360 & 1.101 & 1.124 & 6.822 \\
\hline FUOORESCENTE $2 \times 10 \mathrm{~W}$ & 40 & 42 & 43 & 46 & 49 & 220 \\
\hline FC:IVIITX $2 \times 43 W$ & 24 & 25 & 26 & 28 & 29 & 1,32 \\
\hline FAROI. TTRT COTONIAL & 32 & 3.3 & 35 & 57 & 19 & 176 \\
\hline TOTAL & 15791 & 16.411 & 17.121 & 13.593 & 16.51 & 84.161 \\
\hline \multicolumn{7}{|c|}{ IÄMPAIMS } \\
\hline F.IXIR $\triangle$ SE:FIF, $A T E: \angle 0 \mathrm{w}, 120 \mathrm{~V}$ & 1.295 & 1.348 & $1.4: 13$ & 1,490 & 1.580 & 7.120 \\
\hline INCSANIYESCEEINTE, ATI $120 \mathrm{~W}, 125 \mathrm{~V}$ & 3.174 & 3.306 & 3.440 & 3.654 & 3.882 & 17.456 \\
\hline INCANDESXTDNE. $220 \mathrm{~V}$ & 1.768 & 1843 & 1.917 & 2.036 & 2.163 & 9.727 \\
\hline LUZ MIST, $160 \mathrm{w}, 22 \mathrm{v} v$ & 2.205 & 2.397 & 2.38u & 2.538 & 2.696 & 13.125 \\
\hline SI DIO ALTA PRLES & 918 & 949 & 975 & $1 . n 93$ & 1.143 & 5.078 \\
\hline 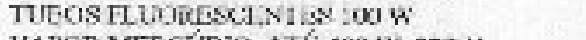 & 43 & 45 & 17 & 50 & 5.3 & 278 \\
\hline 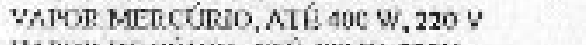 & 29.203 & 90178 & 32.116 & 33.920 & 35.322 & 260660 \\
\hline 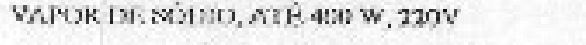 & 4.600 & ARSR & $\operatorname{son} \pi$ & 5797 & $57 n 3$ & 25625 \\
\hline \multicolumn{7}{|c|}{ Actiseikios } \\
\hline 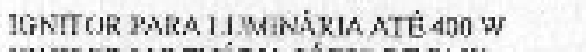 & $1.808^{\circ}$ & 1.894 & 1.560 & $20 \mathrm{k} 2$ & 2213 & 9.946 \\
\hline IGNTTOR IMANARIA SÓDTO DE $70 \mathrm{~W}$ & 116 & 121 & 126 & 131 & 112 & 6.19 \\
\hline 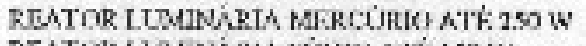 & 1.346 & 1.165 & $t .522$ & 1.617 & 1.518 & 7.667 \\
\hline REATOK LLMENARLA SÜIIO AIT ISD W & 276 & 283 & 299 & 318 & 337 & 1.518 \\
\hline 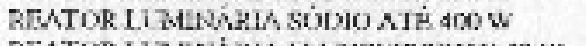 & 560 & 583 & 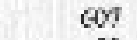 & G5 & 685 & 3.116? \\
\hline 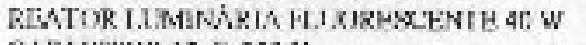 & 48 & 50 & 52 & 5.5 & 19 & 264 \\
\hline CAPACTOOIH 15 E, $250 \mathrm{~V}$ & 169 & 167 & 173 & 184 & 195 & 879 \\
\hline
\end{tabular}

FONTE COMLSAO EQUATORIANA DE BENS DE CAPTTAL - CEBCA, 1993

A análise tle usos finais proporciona a potência média instalada por fuminárin, com tecnologia de mercúsio, de 183 W/uminária, com tecnologia de sódio, de 307 W/lumbiniria, incluindo as perdas no reator. Sob a premissa de continuar igual tendência de instalaçйо, devido яo fato de nส̃o haver programas de uso eficiente de energia, 
calcula-se a peléncia adicional instalada por ano: $3.209 \mathrm{~kW}$ em $1993 ; 3.334 \mathrm{~kW}$ en $1994 ; 3.509 \mathrm{~kW}$ en 1995; $3.647 \mathrm{~kW}$ em 1996; e, $3.413 \mathrm{~kW}$ em 1097.

0 imvestimento em novas luminárias no periodo 1993-1997, usaudo as quantidades pesquisadas pela CEBCA e os preços unitários de luminárias no Equador, será de US\$ 11 milhōes (preços de 1995); este valor inclui materiais, acessórios e gastos para instalação (não se conki่idera elementos da rede secundária).

A taxa de crescimento anual da quantidade de luminárias e a sua potência instalada é $3.9 \%$ para o periodo $1993-1997$.

\subsubsection{OFERTA DE EQUIPAMENTOS}

No Equador existem 7 fábricus de luminárias para IP. Deve-se deixar claro que a maioria dos insumos para a montagem, tais como lâmpada, rentor, iguitor, capacitor, porta

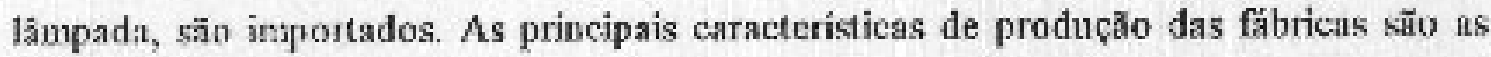
seguintes (ver TABELA 3.8):

TABELA 3.8: FÁBRICAS DE LUMINÁRIAS PARA ILUMINAC̨ÃO PÜBLICA (IP) NO EQUADOR

\begin{tabular}{|c|c|c|c|}
\hline Jikikion & 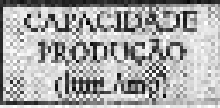 & $\begin{array}{l}\text { ARFA } \\
\left(\mathrm{xi}^{2}\right)\end{array}$ & 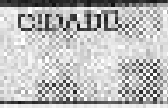 \\
\hline 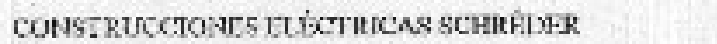 & $15 \mathrm{ISOO}$ & $2.70 \%$ & وито \\
\hline INLWNGLS & 1.000 & 4.210 & Q QIT० \\
\hline TNUUSTRLAS METHUCAS MANABITAS & 300000 & 8.700 & BNWTA \\
\hline HNTEISTRIMS AUSTTOLLIZ & 4.800 & 348 & CU⿴囗十⺝ \\
\hline INIROTISI. & 16000 & 2.5010 & Qtitro \\
\hline 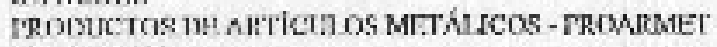 & $24.0 \times 0$ & 5.950 & cinerics \\
\hline STCOMner & 15000 & 15.000 & Qumrs \\
\hline TOTAL & .155890 & & \\
\hline
\end{tabular}

FONTE: COMISSAO EQUATORIANA DE BENS DE CAPTAL - CEBCA, 1995

A oferta atiage 395.800 luminúriss/ano, entretanto a demanda é somente 17.321 lumináriasiano (1995), portanto existe excesso de oferta do produto. 
A TABELA 3.9 apresenta as principais caracteristicas das luminárias para IP feitas no Equador. Observa-se que não há produtores de huminárias de vapor sódio de baixa potência como 0 caso de $50 \mathrm{~W}, 70 \mathrm{~W}$ e $100 \mathrm{~W}$.

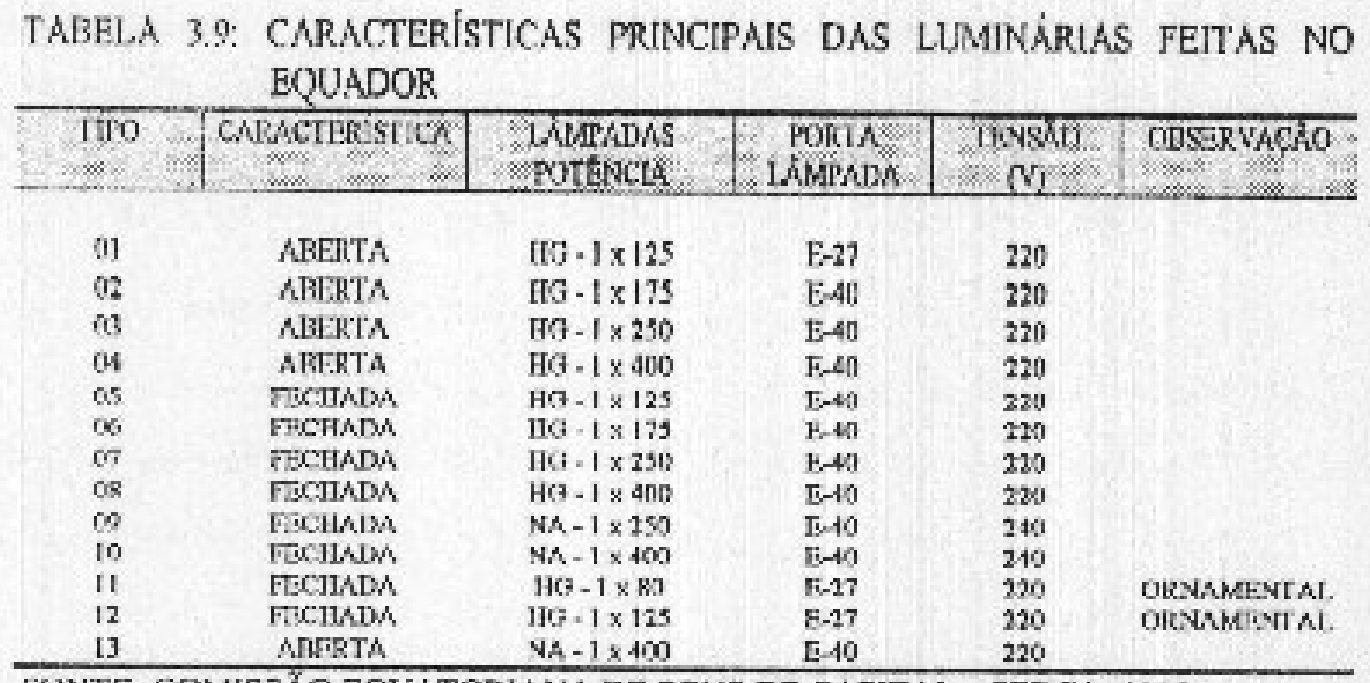

FUNTE: COMISSÅO EQLATORIANA DE BENS DE CAPITAL - CEBCA 1995

NOTA: A especificaçito de todas as luminárias exige refleter de aluninio anodizaclo brilhante Fator de potência e cor corrigido Reator para $60 \mathrm{~Hz}$. As luminárias fechadas stio herméticas contra cutrada de pó e umidade, con protetor ou refsater do vidro.

A luminária ornansental para disposiçào vertical em poste, hase e coberla de à่umónio.

A TABFIA 3,10 apresenta os tipos de huminárias produzidas no Equador; 4 fábricas produzen todos os tipos, entretanto 3 produzem somente algums tipos.

TABELA 3.10. LUMINÁRIAS PRODUZIDAS NO EQUADOR SEGUNDO SEU TIPO

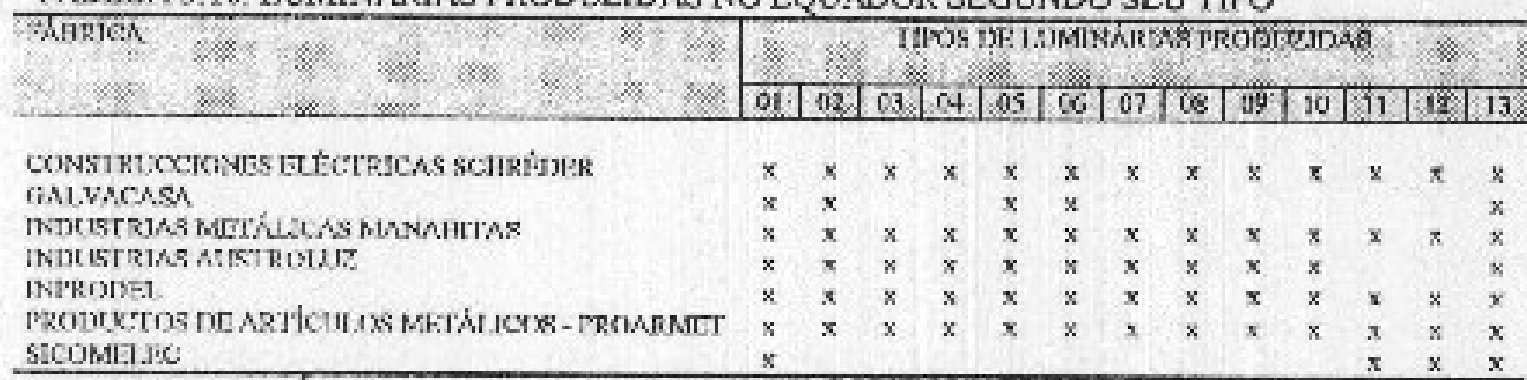

FONTE COMISSAO EOUATORIANA DE RENS DE CAPITAL - CEBCA, 1995

Deve-se considerar que os fornecedores de luminárias nĩo exibem etiquetas de controle de qualidade, portanto as huminárias nẫ têm garantia de funcionamento. 


\subsection{OPORTENTDADES E BARREIRAS}

O escopo desto ponto é discutir as possíveis oportunidades e barreiras que se poderiam ser encontradas ta implantação de programas de uso eficiente de emergia e assium exploras a sun origem e recomendar medidas para superí-las.

De forma geral, os resultados da avaliaçăo econồmica de medidas para o gerenciamento da demanda, indicam vantagens importantes na sua aplichção; além disso, existem diversas barreizas que impedem sua grande penetração no mercado. Essas barreiras envolvem ớversos aspectos de ordem financeira, técnica (incluindo falta de iufracstrutura adequada), cultural, comercial, interna ao setor elétrico, legal, politica e administrativa,

A maiơia das medidas de gerenciamento da carga não apresentam restriçð̃es ou risco técnico e superar essas barreiras sob condições próprias dos paises em desenvolvimento, requer seguir uma estratégia de implantaçāo gradunl das mesmas. Isto pennite ganhar experiência c aumenta probabilidade de êxito dos programas de gerenciamento da carga no miérlio e longo prazo (Vieira de Carvalho, 1994).

A curência de conthecimentos está presente desde a falta de controle, verificado sobre a vida útil das lâmpadas, passa pela aplicação de equipamentos inprópirio an uso da tecnologia de súliu alta pressão (geralmente não săo usados teatores de potência constante), indo até a aplicaçăo de tipos de lâmpadas (como vapor de súdlio de $360 \mathrm{~W}$ ), exclusivamente en fimçăo do custo inicial reduzido ou decisð̉es politicas equivoeadas que เnão conduzen aos menores custos durante a vida útil do sistema (Custo Durante a Vila).

O nivel de tensioo da rede do alimentação tem influência marchnte na operaçåo das lâmpadas, quer sejant incandescentes, quer sejam vapor de sódio alta pressão, bem como na escollha do tipo de reator a ser usado (Burini et al. 1994). 


\subsubsection{METODOLOGH DE IMPLANTACÃO DE MEDIDAS NO GERENCIAMENTO DA DEMANDA}

Os programas de garenciamento da demanda são diferentes aos de oferta de energia; sua execuçiio apresenta maiores dificuldades que os projetos para produzir e distribuir energia elétrica. No processo de implantaçăo de programas de gerenciamento da demanda surgem novos problemas de cnmercializaço ou de mercado; portanto é indispensivel fazer previamente o seguinte:

- diagnosticar ns nocessidades dos clientes;

- identificar as medidas mais razońveis para servir essas necessidades e quantificí-las;

- capacitar as clientes ua adoçio de novas tecnologias;

- persuadir as fabricantes e construtores para que incluam nos 5 ens aparelhos eficiência encrgética

Considera-se fundamental que as concessionárias disponham dos recursos finnnceiros para aquisiğ̨ôto de equipamentos e assistência técnicn.

Depois da implantação do programa, convém estabelecer mecanismos de acompanhamento para deturminar os heneficios obtidas e introduzir as correçoes carrespondentes (Vieira de Carvalho, 1994).

Por vutro lade, deve-se considerar que os padröes de consumo de energia globalizades são complexns porque dependem de um grande número de consumidores, cadu un dos quinis escolhe as distintas formas de uso de energia. Aiém disso, outros protagonistas estî̀ envolvidos to processo e é necessánio saber responder ou se alinhar com seus interesses e métodos de trabalho. 
Entāo, os pradrôcs de consumo de energia são ajustados pela açăo de um grande numero de atores, às vezes aluando simultnueamente, desde vários niveis da sociedade, como é o caso de:

- geradores, tlistribuidores e consumidores de energia;

- fabricastes e fomecedores de equipamento de uso final;

- fornecedores e consumidores de serviços;

- organismos reguladores (exemplo INECEL) e concessionárias elétricas;

- cogeradores :tuais e potencinis;

- institưções financeiras locais e nacionais:

- governos cion paises;

- agências de fundos ou ạjuda de organizaçōes internacionais e multilatcrais de paises desenvolvidos.

todos estes com o objetivo de atingir melhoria no uso eficiente de energia, a partir de convênios e alinuças de cooperaçåo técnico-comerciais entre atores, inclumulo, alén das convessionírias os clientes de energia elétrica atuando em comjunto. Esses couvêtnios permitifão atingir maiores vantagens no setor, compartillhando adequadamente os beneficios restatantes. No entanto, podem strgir em todos os níveis barreiras para implantaçāo dessas melhorias (Reddy, 1994).

No caso equatoriano, as concessionírias tèm conhecimento das vantngens to uso de tecnologias eficientes (luminárias de vapor do sódio), porém continuam comprando e usando tecnologia convencional (luminárias de vapor de mercúrio). $O$ fato que as concessjoúnirias cstejam bastante informadas acerca dos benteficios da efiviência energética, 'nũo significa que estas espontaneamente investisão em equipamentos eficientes. Uan dos motivos deve-se, geralmente, ao fato que os equipamentos de alta eliciênucia encrgética tềm alto custo inicial.

A mainr vantagem dos programas de uso eficiente de ettergia no setor de IP, é que podem ser impientados pela decisano de poucas pessons so nivcl de 'tomadores de 
decisōes". As decisões tornamt-se efetivas através de mecanismos legais ou regulamentaçōes; assim, por exermplo, no caso equatoriano, o programa poderia ser implantado peia imposiçāo das seguintes alternativas:

- Decreto lei da Presidència da República;

- Lei do Congresso Nacional;

- Acordo Ministeriai do Ministério de Energia e Miuas:

- Resoluçio do Diretoria do INECEL;

- Resolução das próprins ooncessionátias

\subsubsection{ALTERNATIVAS DE IMPLANTAC $\bar{X} O$}

Existe diversidade de métodos para implantaçăo de medidas de gerenciamento da denanth e cada un deles propiciam resultados diferentes. $\Lambda$ decisão de escollher 0 métodio depende evidentemente da própria medicla, do tipo de cliente de energia o das condiçōcs especificas de cada mercado.

E importante comsiderar as tatifas existentes (subsidios); assim, deve-se considerar as tarifas de longo prazo que deverăo corrigir certas distorçōes tais como disponibilidade de recursos finatceiros e carncterísticas especificas dos clientes (inclusive o sen comportamento e a sua psicologia) e das concessionárias participantes (especialmente custos de getaçño, trausunissĩo e distribuição).

Os métodos de promoçăo das medidas acima listadas podern ser os seguintes: iaformaçño, diminuuç̧йo de preços, empréstimos, contratação baseado no desempenliho, instalaçāo direta integgral ou mediante licitaçñes (também coulhecida como a compra de "wegawatts"). O oljectivo final é harmonizar as medidas mais interessantes e com maior probabilidade de êxito.

Sem dúvida atealuma, os programas de IP são diferentes dos programas residentciais e comerciais, pois que estes últimos têm maiores dificuldades no processo de 
desenvolviuento, pela grande quantidade de atores euvolvidos situados em distintas camatis sociais, cconômicas e culturais, enfrentando problemas de ignorância, pobreza, difusio da informação, indiferença, incerteza c acompanhamento. Portanto, os iavestimentos secundários ${ }^{12}$ destes tipos de programas sào maiores ao quase nenhum investimento sccundário em programas de IP.

Considera-se accessário o desenvolvimento da infra-estrutura local. Pode-se incluir incentivos para criaçăo de companhias clıamadas de "serviços energéticos", freqüentemente originadas un industria de equipes de controle e consultoria em engeuhata. Estes tipos de companhias têm-se consolidado em alguns países desenvolvidos (especialmente nos Estados Unidos) com suficiente experiçncia para oferecer ampla variedade de serviços especializados, incluindo projeto, fabricaçăo e instalação dos equipamentos de controle; além disso, possuem uma variedade de serviços complementares para fomecer opcraçāo eficiente e efetiva dos sistemas integrados de gerenciamento sla dermanda.

Por outro lado, as concessionárias tèn vantagens como promotoras potenciais de atividades relacionadas com o gerenciamento da demanda, devido as permanente contatn com scus clientes e pela infra-cstrutura que dispoiem. A hamonizaçīo destas vantagens thes permitirá aproveitar certas economias de escala para identificar, comercializar $\mathrm{e}$ instalar tecnologias apropiriarlas para o gerenciamento da dentanda. Além disso, a sua experiencia no controle de importantes investimentos thes situa em melhor posiçāo con relaçăo às outras entidades, não obstante, o gerenciamento simultâneo da oferta e demanda represcnta um problema para mainría das concessionḱrias.

De qualquer maneira, a experiência internacional demostra que um grande uproveitamento das opottunidades de gerenciamento da demanda no futuro, não acontecerí de forma eqpontânea. Existem restrições e imperféç̧̄es do mercudo qque impeden aos clientes de energia elétrica tomar medidas para atingir a eficiência desejada.

${ }^{14}$ Delius-se "irvestinento secundário ou custo transacinnal" todo investimento que nĒo seja para compra dos cquipamentos, operacĭco e ntanutençāo ou consumo de energia. 
Portanto, ó indispensível projetar respostns que levem em conta estas situaçôes, para produzir condliz̧ŏes necessárias e adotar politicas de mérito.

Tem-se demostrado empiricamente que numentar somente a informação aos clientes é insuficiente para atingit as metas do gerenciamento da demaada previstas pelas concessionárias. Geralmente é necessário implementar incentivos financeiros para obter exito. Os programas com preços reduzidos para os clientes ou com maiores incentivos financeiros e adequada assistència técrick, permitem obter majores níveis de penetração, purticipaçăo e conservação de energia, que outros tipos de programas (Vieira de Carvalho, 1994).

Devo-se contemplar of formecimento de dispositivos de controle e aparalbos eficientes que atualmente nãn estho disponíveis no mercado lochl, devido basicamente ao fato que os faltricantes deste tipo de tecnologia preferem manter maior oferta daqueles produtos que represtntam menor custo de investimento inicinl (equiparnentos menos eficientes), motivados pelos altos niveis de vendlas.

Assim, os produtos eficientes encontram-se disponiveis sum mercado que estí sob condiçōes do inuperfeiçăo (oferta - demanda). Desta forma, não existe presș̄o do mercado, nem lei, nem regulamento para revelar o desempenho dos cquipamentos de uso funa. No entanto, esle lipo de barreira pode ser superada peln intervençåo do govemo mediante intposiç̆io de padrões de eficiência e efiquetagem de aparelbos c equipamentos de noso finai.

Além deste problema, as fályricas de huminárias do Equador importam insumos procurando sempre obter os de menor preço; assim săo montadas luminátias com peças de distintos foncoedores sob caraclerísticas diferentes e pelo mentos as concessionárias atribuetn este fato para explicar a reduzida vida útil de certos equiparnentos.

Os programas de gerenciamento da demanda deverān ser avaliados permanentemente, analisando os cfeitos colaterais, custo total dos mesmos, impactos econômicos e resposta dos coosumidores para conseguir efetiva pronoçāo da eficiência energética. 


\subsection{PROGRAMAS DE INCENTIVO}

No Equador não existem programas de incentivo ao uso eficiente de energia, devido especialmente aos baixos preços da mesma (altos subsidios). Mas parece que programas de uso eficicnte apareceråo quando os preços da energia forem reais. Sob este contexto, a medida da reforma estrutural (pretendida pelo goveno) com maior prioridade será deixar os preços refletirem os custos reais de fomecimento, incluido os custos pela redução da contaminação e prejuizo ao meio ambiente.

Requer-se que a fixaçäo de preços se aproxime às práticas comerciais para obter recursos com fins de investimento, facilitar um ambiente de concorrência, mellorar a eficiéncia e fomentur setores de energia com vísbilidade econômica e funanccira.

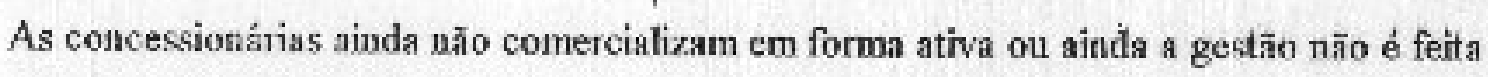
com o objetivo de atingir eficiéncia cnergética. Deveria se estimular as concessionárias à adoç̃o de estratégias de comercializaçชo para obter mellhoria de fatores de capacidade das usinas, redup̧ão das cargas na ponta e minimizaçăo das necessidades de instalaçăo na geraçāo de alto custo na ponta, com o objetivo de reduzir a construçâo de novas wsinas de geraçâo e evitar a queima de combustiveis. Isto supбe adotar programas energéticos de gerenciamento da demanda.

Por outro lado, pars estimular a eficiêtıcia energética no fornecimento e consumo fiual, o govemo deve reduzir os obstáculos que impedem o estabelecimento de setores comerciais e iudustriais privados dinâmicos funcionando em mercados competitivos. Entāo, é necessário eliminar barreiras industriais e comerciais protecionistas e além disso elininar graduafmente as restriçōes comerciais e controlc do mercado de câtnbio.

Numerosos estudos determinam que os paises onde adotam-se uovas tecnologias com maior eficiêncin energética, são os paises com mercados concorrentes (Banco Mundial, 1993). 


\subsection{EXPEUÉNCIAS INTERNACIONAIS}

\subsubsection{CASO DA COLOMBIA}

Segundo o relatório do "Instituto de Ciencias Nucleares y Energias Altemativas" (INEA) da Colômbria, estima-se instaladas no país 1,5 millones de luminárias para IP, das quais $80 \%$ usitn tecnologia de mercírio, $15 \%$ usam tecnologia de sódio alta pressăo e $5 \%$ usam outras tecuologias.

A potência total instalada em IP é $205 \mathrm{MW}$ e o consumo anual de cuergin $898 \mathrm{GWh}$; sol) estă canacterísicans os custos operacionais sāo US\$ 5,7 milhōes para matutençāo de lâmpadas e US\$ 39,5 milhôes pelo consumo de entergia (preço médio de energia 100 USS/MWh).

O INFA iadica que, desde o ponto de vista técnico apresentam-se limitaçōes pela incompatibilidide entre luminária, lâmpada e reator. As luminárias tipo vertical com lâmpada incandescente ou vapor de mercírio en forma de ovóide, nh้o perrmitem o uso de limpadas de vapor de sódio. Portanto, devc-se trocar toda a luminária. As luminárins tipo horizontal com låmpala de mercírio somente em certos casos permitirīo a troca da lâmpada por sua equivalente de sódio, enquanto for trocudo também o reator.

O governo da Colômbia tem proposto metas de troca de luminárias. Para junho de 1996 deve-se trocar $100 \%$ das luminárias incandescentes por suas equivalentes eficientes (sódio). enquanto para junho de 1998 deve-se trocar 100\% das luminárias de mercúio por suas equivalcutes eficientes (sódio), ou seja, após junho de 1998, o país deve ter instalado IP com tocnologin de sódio.

As estratégias que o governo está aplicando são as seguintes:

- As liovas instalações usarão só luminárias eficientes de sódio.

- Nas instalaçóes cum luminárias incandescentes deve-ze trocar toda a lumańría por sódio quando terminar a vida útil da lâmpada. Isto significa 
a troca total de luminárias incandescentes num periodo menor que um ano.

- Nas isatilaçōes con luminárias de mercúrio deve-se trocar a lâmpada e reator por seus equivalentes de sódio quando terminar a vída útil, sempre que baja compatibilidade técnica entre elementos e cumpra as normas de ilumi:açăo; caso contratio deve-se trocar toda a luminária.

- No caso que tecnicamente seja viável (reproduçāo de cores e baixo fator de tniformidade) deve-se considerar a instalação de luminárias de sódio de baixa pressão.

A Eumpresa de Energia de Bogotá iniciou um programa de instalaçŭo de 240,000 luminárias de vapor mercírio de $125 \mathrm{~W}$ por sótlio de alta pressão de $70 \mathrm{~W}$. Esle programn dimuinuirá em $60 \mathrm{GWh} /$ ano o consumo de energia e em $13,7 \mathrm{MW}$ a potência $O$ periodo do programa de troca ś de 3 anos.

As "Empresas J"útlicas de Medellín" (EPM) trocarh̆o 60.000 lâmpadas de luminárias tipo horizontal por suas equivalentes de sódio de alta pressãn de $70 \mathrm{~W}$ tipo ovóide fosforoso com ignitor incorporado, mantendo a mesma carcaça. O periodo do programa de troca é de 4 anos.

A "Centrales Eléctricas del Norte de Santander" está trocando 800 luminárias de vapor de mercúrio $125 \mathrm{~W}$ por sódio de alta pressão de $70 \mathrm{~W}$.

En Cartagena iustalou-se 10.000 luminárias de sódio de baixa pressāo de $26 \mathrm{~W}$ até jumlo 1993.

Segundo o relatório do INEA, o programa de uso eficiente de energia na Colôtmbia deslocará a instalação de capacidado em usinas equivalente a 83 MW, poupando US\$ 124,5 millhøes de investimento em empreendimentos de geraçŭo, no periodo de 3 anos. Além disso, a energí conservada será $366 \mathrm{GWh} / a n o$ equivalente à poupança anual de UISS 36,4 milliōer. 
O custo dos investimentos para trocar todas as luminárias de forma completa é de USS 36,1 milhões. No caso de trocar somente lâmpada e reator, o investimento será ainda mennr.

\subsubsection{CASO DO BRASIL}

Os programas de conservação de energia no Brasil são chssificados, descnyolvidos e promovidos pelo "Programa Nacional de Conservaçĩo de Energia Elétrica" - PROCEL. Este organismo foi ingtituído $\mathrm{cm} 1985 \mathrm{com}$ o objetivo de promover a raciomalizaçiono da produçìo e do uso da energì elétrica e, como decorréncia da maior eficiência, propiciar - mesmir produto ou serviço com menor consumo, eliminando desperdícios e Hssegurando a redução global de custos e investimentos para o Brasil.

Para isso, o proOCEL atua definimdo estratégias e mobilizhnto os segmentos representativos da sociedade, vomo empresas de energia elétrica, órgăos de govemo em nivel federal, estadual e mumicipal, universidades, ccutros de pesquisa, associaçるอร e segmentos que representam consumidores, setores comercial, industrial e de serviços,

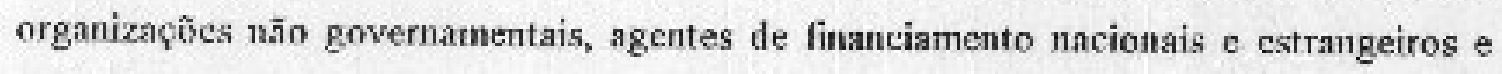
entidades internacionais.

A iluminaçiono representa cerca de $17 \%$ do consumo de energia elétrica un Brasil. É responsável por $25 \%$ da encrgia consumida no setor residencial e $44 \%$ no setor serviços. Este consumo está distribuido entre mais de 30 milhöes de domicilios e 3 milhões de estahelecimentos, respectivamente.

Contribuem para a produçẫo de lâmpadas no Brasil, quatro grandes fabriçntes mundiais fqui estabelecidos industrialmente, associados à Associaçăo Brasileira da Industria de Iluminห⿻冖一า (ABILUX).

A IP responde por $3,5 \%$ do mercado brasileiro de energia elétrica $\mathrm{c}$ ainda apresenta um significativo grau de desperdicio energético, quer prela instalaçăo de exuipamentos 
ineficientes, quer pela utilizaçăo plena do fluxo luminoso em horários de baixa densidade de tráfego.

Conquanto o PROCEL e algumas concessionárias e prefeituras têm incrementado progratnas de substituiçầ de lâmpadas, o pnrque brasileiro ainda npresenta uma grande participaç̧⿰彳 de lîmpadas incandescentes e mistass, bem como luminárias de baixa eficiência. Ilá uma dispcrsão de padrões de projetos e equipamentos, diferentes modalidades de contratos entre concessionárias e prefeituras, agravadas pelas baixas tarifas a um significativo úulice de inadimplência.

Em outubru de 1994, realizou-se um semittário intermacional "Sistemas de lluminação Eficientes" com participação de fabricantes, projetisłas, consunidores, concessiontrias c represcntantes da Governo Federal. Em resumo, as conclusĩes foram as seguintes:

- A participação dos produlos eficientes no mereado brasileiro de iluminną̧á́o ainda é insignificante;

- $O$ consumidlor desconhece os produtos eficicntes e suas vantagens;

- A cetificaşăo é um requisito fundamental para nssegurar a eficiêncin e a qualidade dos produtos;

- É descjível uma legislaçåo que possa estimular a penetraçåo dos produtos eficientes no mercado e inibir a participaçăo dos inelicientes;

- O Procel deverá priurizar suas açōes no sentido de fomentar o mercado dos produtos eficientes e viabilizar programas de incentivo a screm implententados pelas concessionárias.

Baseado nestss conclusóes, O PROCEL tem estruturado quatro estratégias básicas: incentivo ao mercatto; apoio a certificaçŭo; promoçño, educaçâa o difusão; c, desenvolvimento tecnológico (PROCEL, 1995).

Dentro da cstratégia "incentivo so mercado" encontra-se os seguintes projetos e as suas característions: 
- Ilumituçã̃o pública (IP): incentivar a substituiçāo de I milhão de lîmpadas incundescentes com redução equivalente de $408 \mathrm{GWh} /$ asso e 1.375 GWhivida útil;

- Ilunuinaçẫo comercial: viabilizar linha de financiamento para "retrofits", divulgaçāo de estudos de casos, projeto piloto;

- Ilumiliação residencial: incentivar a instalação de 1,1 millhẫo de làmpadas fluorescentes eficientes no setor residencial com redução equivalente de 52. GWW/auv e 377 GWh/vida útil;

- Estudos e suporte lahoratorial para certificaçŭo: propor recomendaçôes aos fabricantes, revisāo de normas técricas e estabelecer índices mínimios de eficiència com reduผ̣̆o equivalente de 171 GWh/ano c $\$ .130$ GWh/atto.

Segundo o relatórin do PROCEL, estima-se economizar até o final deste milênio através de scus projet.os de ilımminaçăo eficiente aproxinadamente $5.500 \mathrm{GWh}$, equivalentes a uma demanda de 270 MW (PROCEL, 1995).

Confroutando-se com o custo marginal da geraça, estimado $\mathrm{em} 41$ US\$/MWh", o custo de conservaçũo avaliado em 6,27 US\$MWh (PROCEL, 1995) proporciona urta relnçăo custo beneficio de 1:6,5. Ou seja, os US5 27 milhôes investidos nos projetos de iluminaç๊ิเ eficiente permitirão aก Brasil postergar investimentos de US\$ 175 milhões na expansâo de seu sistema clétrico. A análise destes projetos será ainda mais favorável se forem considerados os custos de transmissảe e distribuiç̧̃o de energia.

Funcionários do PROCFL infornaram, que essa entidade encontra-se promovendo programas đe substituiçāo de luminárias cficientes no setor de IP, programas cxecutados pelas concessionárias de energia com o apoio financeiro do PROCELELETROBRÁS. A partir de 1987 ate meados de 1995 foram substituídas 400.000 luminárias, equivalentes a

\footnotetext{
15 Este custo é muito discutido. Conforme mostrado por Morcira (Moraira, 1995) os investimentos no selor clitirico trasileiro chegam a USt 172 bilhöes (USS de 1995) no periodo 19701993. Isso significa

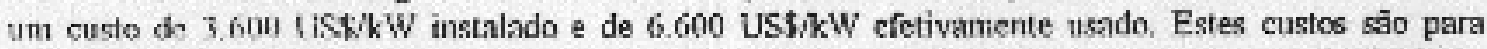
geraçāo, transutisgšn e distribuiçẩo, porèm sâs incompativeis com o custo de 41 USSMWh,

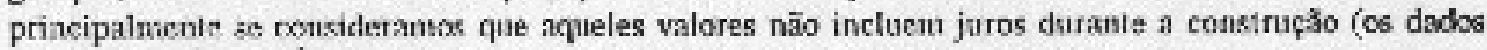
s.̃o da ELETROBSR $(S)$,
} 
uma energia conservida de 122 GWh/ano (potência couservada 27,9 MW). Desde 1986 foram investidins qquase US\$ 7 millı̄es, proporcionnndo uma economia em geraçశo, tiansmissĩo e distribuição de energia de aproximadamente US\$ 45 millhões (Revișa Iluminação Brasil, No. 5I, pagima 24, 1995).

A perspectiva do PROCEL é dar continuidade aos programas de incentivos, iucluindo financiamentos para a instalaçăo de iluminaçăo eficicnte (lànpadas, lutnintárias e reatores) no segmento da IP.

O relatório do Banco Mundial sobre uso eficiente de energia no Brssil diz "...o projeto de transmissīo e conservação de energia no Brasil empreendido pelo Banco cm 1990, tinlı por finalidade aumentar a eficiência da IP mediante a substiluição de lâmpadas incandescentes de $175 \mathrm{~W}$ por lâmpadas fluorescentes de $80 \mathrm{~W}$ e latmpadas de scódio de alta presçio de 50 W. O Brasil tem 770,000 luminárias incandescentes na IP. Esperavase que o programa diminuiria 103 GWh/ano, permitindo liberar $27 \mathrm{MW}$ de capacidade adicional, com poupartça de investimento de USS 40 milhões. Lamentavelmente, o projeto foi cancelado devido que o Brasil não satisfez a concliçẫo do convênio sobre tarifas de thetricidade..." (Relatório do Hanco Mundial, página 22, 1993). Este relatório permite observat o grau de importância que os organismos interıacionais proporcionam às variáveis tarilits, consumo e uso eficiente de energin.

\subsubsection{CASO DO CHILE.}

O setror clétrico chilent tem uma capacidade instalada de geraçăo de cerca de 5,000 MW; no ano 1991 foram gerados $18 \mathrm{TWh}$, dos quais $16 \%$ consumiu o setor residencial, $7 \%$ o setor comercinl, $68 \%$ o sctor industrial e mineiro, $3 \%$ IP e $6 \%$ outros setores.

A scguir apresenta-se a experiência do programa de uso eficiente de energia no setor de II da província de Talca - VII Regiăo (Comisión Nacional de Energia de Chile - CNE, 1994). 
A concessionária tem instaladas 15.425 luminárias dos quais $50 \%$ são com tecuologia de mercuivo, $39 \%$ com tecnologia de sódio e $11 \%$ com tecuologias incandescente e luz. mist.n.

Assint, dentro do programa encontra-se projetndo trocar as seguintes huminárias:

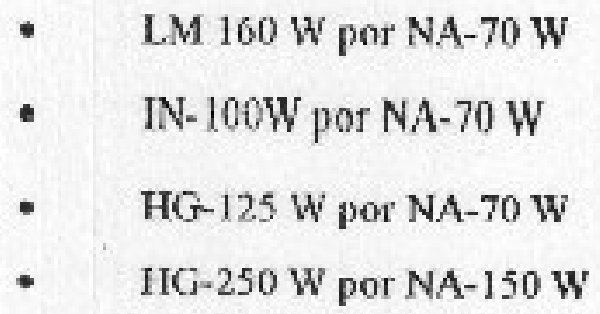

$O$ potencial de liminárias a serem trncadas atinge 9.356 , com investimento inicial de US\$ 961.000 e neste valor incluj-se o equipamento e a måo de obra.

A energia conservada atinge 2,7 GWh/ano equivalente à economia de 163.000 US\$/ano. A potência conservada atinge $544 \mathrm{~kW}$ equivalente à economia de 153,000 US5/ano.

Os cálculos foram feitos (pela concessionária) na base de 4.017 horas de utilizaçăo por ano e considerou-se preços de energin correspondentes à tarifa BT2 para setores urbanos e nurais da VIII Regiศ̊o.

Também existe informaçăo do Municipio de Autofugasta, que decidiu trocar as lunimáaias mistas de $160 \mathrm{~W}$ por luminárias de vapor de sódio de 70 W. Para isto, proceden solicitar ao Ministério da Fazenda a autorizaçäo para execuçằ do programa via "leasing", ou sejja alugar os equipamentos com opø̨īo de compra (Comisión Nacional de Energia de Cliils-CNE, 1994).

A quantidade de luninírias a serem trocadas foi 7,053, com um investimcuto imicial de USS 675,000 . A poupanç pela diminuiçăo do consumo de energia atinge 210.000 USS/ano. A potêncis conscrvada é $521 \mathrm{~kW}$ cquivalente d̀ timuimiçŭo de 90.000 USS/ano 
Por outro lado, a Comissāo Nacional de Energia (CNE) iniciou um programa de uso eficiente de energia no Chile, com o objetivo de mellotar o sistema de IP. O fundamento deste programi deve-se aos efeitos colaterais esperados nas áreas locais e nacional, no referente ao econûnico e ao social. No âmbito local, espera-se resultados econômicos pela dimúnuiçăo de consumo de energia, modernizaçăo e melhoria da qualidade de IP. No âmbito nacional, espera-se adiamento de investimentos em usinas de geração.

Não obstaıłe, a pincipal motivação do CNE é realizar projetos demonstrativos, com alto potencial de conservação, que empurrem e sensibilizem outros organiemos públicos e privados tha tealizaçẫo de projetos similares. A CNE encontra-se interessada em desenvolver projetos desta natureza no menor tempo possivel, portuoto, estí apta em fimecer assistência técnican e assessoria às municipalidades, com o objetivo de orientar e susteritar os procedimentos para efetivar estas iniciativas em todos os lugares do pais.

O programa năo utiliza investimentns do orçamento público, nล̃o aumenta a despesa, só considera a redistribuiçăo da despesa existente pela diminuiçâo do consumo de entergia.

\subsection{PERSPECTIVAS COM A NOVA LEI DE MODERNIZACÃO E PRIVATIZACCÃO DO SETOR ELÉTRICO EQUATORIANO.}

Praticameute cm fodo o mundo a indústria de eletricidade encontra-se em um processo de transiçũo, marcado pela desregulamentaçāo, como por exemplo o Reino Unido, Chile, Peru, Argentina, ete.

O modéo tradicional de desenvolvimento do setor elétrico equatoriano encontra-se basende na injję̧ào peumancnte de recursos do governo nas áreas de geraçāo,

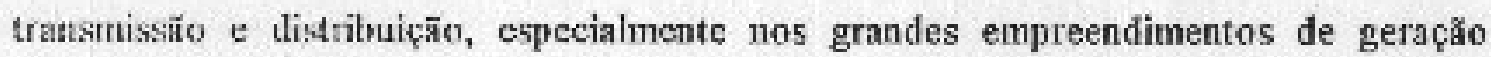
lididrelétricn, tuis como as usinas Paute (1.075 MW). Agoyán (156 MW) e Pisayambo $(69,2 \mathrm{MW})$, oxa em fuucionamento.

Os recursos' financeiros foram obtidos de empréstimos de banco e de organismos de desenvolviuentu internacional, aumentando assim notavelmente o valor da dívida 
externa. Mais aindin, quando as tarifas nâo refletem o custo ceal da energia, isto tem provocado contribuiçôes especificas do governo para cobrir obrigaçōes financeiras internacionais.

Sob estes antecedeutes, a participaçño de capitais privados na indústria elétrica se torna necessária, especialmente porque o estado não dispőe dos recursos econômicos para empreendimentos capazes de cobrir a crescente demanda energética. Segundo foi apresentado, o Equador precisa de USS 1,34 bilhôes ( $11 \%$ da dívida extema) para investimentos dee expansão do setor clétrico no período 1993-1997. Entretanto, as tarifas produzirăo receita de US\$ 1,36 billhōes no periodo 1993-1996, existindo déficit para os programas de expanš̃o.

Assim, o gwemo elaborou dois projetos de lei para restruturação do setor elétrico, os que foram, respectivamente, enviados no Congresso Nacional para sua discussīo e aprovaç̃ó; nāo obstaute, depois do processo de Lci, os projetos voltaram reprovados h̀ Presidêncis.

O úllimo projcto enviado em setembro de 1995 "Proyecto de Ley de Régimen del Sector Eléctrico Eeuatoriane" oontêm artigos que permitem a participação privada uas áreas de geraçẳo, transmissān c distribuiçāo, sob princípios de fivтe concorrêncin e contratos de concessño, assumindo os investidorcs todos os riscos. As características principais desse projeto de lei sî́o as seguintes:

- A geraçãn, atualmente feita pelo INECEL, será dividida em varias empresas geradoras com características de companlua anônima concorrendo entre elas e com o setor privado sol as mesmas normas;

- Só existirá urma empresa con concessão para transrrinisș̃o;

- A distrithuiçăo seria considerada como um conjunto de monopólios regionais, realizados através de contratos de concessãn, dande estabclevem-se aspectos fundamentais tais como: tarifas, qualidade do setviço, obrigatoricdade de prestação do serviço. 
- O Canselko Nacional de Elctricidade (CNE) seria o novo organísmo regulidor, substituindo o INECEL e estará vinculado à Presidência da República com autonomia econôtnica e administrativa.

- O metcado elétrico majoritário estabelece-se com dois sistemas de comercitlização: a) mercado spot e, b) mercalo de venda \& longo prazo.

Futretanto, segundo o critério de Bitu e Born (Bitu e Bom, 1993), a venda imediata de empresas de energia elćtrica somente é recomendável em casos extremos, onde a adequada prestaçăo dos serviços pelas atuais concessionárias seju virtualmente impossivel.

Eim situxp̧ūes menos criticas, é conveniente iniciar-se o processo de privatização "marginalunente". Devent-se criar condiçōes para que o capital privado, especialmente aquele pertencente \& grandes consumidores, se interesse pela expansão dos sistemas elétricos.

O escopo do Banco Mundial é atingir eficiência energética e uso econômico da entergia, portanto os crédlitos a paises em desenvolvimento serão seletivos e estes deverão cumprir requisitos tais como: implementaçăo de preços reais da energia; reforma institucional referente à oferta; criação de mercados cmeorrentes; intervcnģăo nos mercados para redurit os custos relativamente altos da informaçåo; e transferência de tecnologia.

A opinião do Banco Mundial (Banco Mundial, 1993) é que as decisões de investimento nas empresis de fornecirnento de energia foram desacertadas, resultaudo em considerńveis custos ecouôtricos e grandes perdas financeiras. Portanto, a restruluraçāo pelo lado da oferti terá por meta dar maior autonomia e transparência ao processo decisćrio. A cficiềncia adininistrativa derivará da reforma institucional e pela participaç̃o do setor privado.

A participação do setor privado depende da obrenç̧̄o de altas taxas de rentabilitade financeira que the permita rcalizar tarefus de manutenção c reduzir as perdas materiais. 
As exigências do Banco para financiar projetos e programas baseia-se que estes sejam de custo mínimo e além disso o cumprimento das normas em matéria ambiental.

Por outro lado, a proteçăo da industria nacional frente à concorrència foi um fator importante no cousumo de energia relativamente alto por unidade de produçŭ̃o. O Banco vai promover ativamente políticas que contribuain ao estabelecimento de mercados concorrenciais de uso final da energia.

Até aqui apresentou-se duas vertentes, uma em favor da livre concorrência e participaçăo privada nos mercados energéticos c outra contra. Igualmente acontece no Equador, onde os sindicatos do setor público, incluido os energéticos, encontram-se alinhados contra as teses de desregulamentaç̧̌o, fazendo resistência e oposiçăo aos projetos de lei

Com todos estes nntecedentes, a participaçāo privada no setor elétrico equatoriano será um fato; 50 b os critérios e as experiências do Bamco Mundial sabre desregulamentaçẫo, 0 mercado elélaico eụuatoriano estará caracterizado por eficiência energética e uso racional de estergia em vários setores: residencial comercial, industrial e IP após se produzir a desregulamentação.

\subsection{Conclusões}

O INECEL cons otganistru estadual cncarregado da regulamentaçăo do setor elétrico, tleveria exigir das concessionárins a adoçăo de um prudraัo, não somente para IP, mas este deveria ser pnra todas as áreas de distribuiçāo, sob os conceitos de modernizaçåo, otimização e uso eficiente de energia.

O novo pzdrĩo equatoriano para IP estarḱ haseado no método de huminância que considera as características da via, As hıminárias usadas na II' serâo as de vapor de sódio a alta preșân, on baixa de pressāo nos lugares que não precisam de reprodução de cotes. 
O sistema tarifário atual não cobre os custos operacionais e de expansão do sistema alétrico equatoriano e além disso produz incficiência nos diferentes setores: geraçăo, transmisš̃o o distrihuiçño. Um dos motivos da crise energética equatoriana atual deve-se a isto. Isto demastra-se pelos baixos preços em relação a outros países da América Iatina.

O consumo ce energia em IP é repassado aos clientes e cobrado como taxa no seu pagamento metusit. Cada concessionárin tem в sua porcentagen de taxação ao cliente e o objetivo delas é cobrir através dos clientes o consumo total com IP

O custo marginal de energía para a estaçăo úmida é relativatnente baixo, devido fundamentalmentc an tipo de oferta eminentemente lidtrelétrica. Entretanto na estaçäo de secs a oferta depende muito de termoeletricidade e portanto os custos são altos (356\% a mais cm valores ile pouta).

A pressão dos organismos intermacionais de crédito sobre os paises, terminurá eliminando os subsidios dos encrgéticos e thes colocará nos mercados concorrenciais com preşos resis.

A tendência de continuar usando os mesmos tipos de equipanento em IP nāo vai mudar caso não exista um programa de uso eficientc de energia.

A potência mérlia adicional instalada por ano durante o periodo 1993 a 1997 para o setor de IP, será de $3.422 \mathrm{~kW}$ equivalente en encrgia a $15 \mathrm{GWh} / \mathrm{mon}$.

A potência tota! instalada to setor de IP foi calculada em $89.940 \mathrm{~kW}$ para 1995 (Capítulo 11), usando os dados de demanda de luminárias pesquisados pela CEBCA, a potência será $93.419 \mathrm{~kW}$ para $1996 \mathrm{e} 97,096 \mathrm{~kW}$ para 1997.

Existe gramde oferta de lurminárins no Equador onde a capacidade de produçăo é 395,800 luminárias/ano, cuyuanto a demanda média é de 16.832 luminárias/ano; alèm disso, a lumisária não ó testada nem dispōe de etiquelagem (controle de qualidade). 
A maior vantagem dos programas de uso eficiente de energia no setor de IP, implica que aqueles podem ser implantados pela imposiçăo ou decisâo de poucas pessoas ao úvel do governo, miuistério. INECEL ou concessionárias, utilizando leis, decretos, resoluçôes ou acordos. Conitrírio aos programas para setores residencial e comercial que precisam de campanhas publicitarias, acompanhamento, informação, marketing c vários atores atuando simultnneamente nos lados da concessionária e dos clientes.

Conforme já citado, o maior problema do Equador é a falta de recursos econômicos para investimentos e uma altemativa para atingir essa eficiência energética, sem investimento inicial, pode ser o alugucl de um novo sistema de IP eficiente ("leasing" similar ao chso do Município de Autofugrasta no (rile).

As concessiotsains do Equador continuam toâ้ serem víayeis econônica e finatceirameace, e necessitam transferências do orçamento nacional.

Na América Iatina existem paises que começaram implantando programas de uso eficicnte de etargia no setor de IP, caso da Colômbia, do Brasil e do Chile, com bons resultados até o presente. Nos scus planejamentos os programas estaส̃ c cıminados num prazo entre um e três anos.

Observa-se dúvidas nas decisð̄es do sctor elétrico equatoriano onde os executivos nāo querem tomar decisōes sólidas, esperando a aprovaçâno da nova lei. Alúm clisso, os recursos financciros do setor são limitados pela suspensño de créditos extemos. O setor atualmente encontra-se uuma elapa critica: racionamentos de energia pela baixa hidrologia, empreendimentos de graude porte suspensos, insatisfação dos clientes, etc. 


\section{CAPITULO IV}

\section{AVALIACÃO TICNICA, RCONÔMICA E FINANCEIRA DO USO EFICIENTE DE ENERGGA NO SETOR DE IL,UMINAÇÃO PÚBLICA (IP) DO EQUADOR}

Uma das partes centrais da questão atual está associada à cxploração e ao uso dos recursos naturis, no que se refere tanto an sel estoque quanto i redacilo dos impactos atnhientais, que ocorrem en toda a cadein energćtica, da produçŭn ao consumo.

Além desta dimensāo ligada no tema dos recursos naturais, a energia, por ser um insumo básico para u utividade econômica, pur demandar pesados investimentos com longos prazos de maturaçãa e por ser um indutor que alavanca outras atividades produtivas, repercute de forma inpostanie sobre o estilo de desenvolvimento.

A conservaçäı c o uso eficieste de energia, por kua vez, têm um papel decisino no tratamento de tados estes assuntos, tanto dentro do próprio setor energético comin cm todas as fonnas de sua vinculaçro com a sociedade.

Ao ser considerada em sua plenitude, a conservaçầo de energia contribui para a construçio da sociedade e a redução das desigualdades socinis, a minimizaçŭo dos impactos anbientis, a melhoria da produtividade, o aumento da competitividade $e$, comsenjientemeste, para o alcance do desenvohimento sustentável (PROCEL, 1994).

A entergia pode ser conservada de muitas manciras, mas uma delas o "sncrificio" (desligar os equipamentos) nāo é examinadła nestc estudo de caso pur se considerar contraria aos critirios de deccuvolvimento sustentavel e porque não se enนuatra na

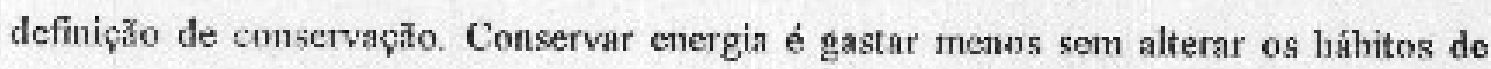
consumo. 
A conservaçăo do cnergia pode ser feita trocando equipamentos de uso convencional de energia por equipamentos eficientes ao nível de uso final, portanto programas de troca de equipamentos podem contribuir para a reduçâo da demnnda máxima nos sistema elétricos; além disso, pode-se implementar medidas de gerenciamento da demanda. Esses programas implicam en um significativo desembolso de investimentos por parte das concessionárias ou organismos encarregados da eletrificaç̆o que analisariam essas opções de mantira competitiva com os tradicionais investimentos na expansăo do parque de geraçĩo de energia.

Um excmplo de investimentos refere-se aos programas de eficiência energética de empuesas norte-smericanas. Um levantamento renlizado em 1990 entre as maiores concessionárias de eletricidade indien que com um total de investituentos de US\$ 1,2 billhöes foran economizados 17 TWh/ano e evitados $24 \mathrm{GW}$ no período de ponta nos Fstados Unidos (Junuzzi, 1993)

A reduçño do coasumo de energia por conservaçăo não sonente vai diminuir o consumo de combustiveis na geração de eletricidade, mas também pode diminuir o consumo de encrgia na pouta, refletindlo-se na reduçăo da capacidade instalada. Os programas de conservaçîio de encrgin têm escopo de reduzir o consumo de enetgia, enquanto as medidas de gercnciameuto da demanda tamhém alteram o perfil da curva de demanda.

Tểm sido descenvolvidos métodos para determinar a eficiência econômica dos iavestimentos cun conservaçăo; un deles é a técniça de análise da energia for usos finais para provisĩo de energia no custo mítimo; isto é, comparar os custos e beneficios produzidos pela implementaçăo de programas de uso eficiente de energia, assim como tarmbém obter os beneficios da rechuçāo de demanda. Muitas alternativas propostas reduzem o consunu de encrgia e proporcionum iguais característicàs de confonto que com tecnologia convencional. Isto se chama medidas de conservaçño de cnergia ao nível de uso fillal (Dutt, 1993) 
A conservação de energia e o gerenciamento da demanda podem ter diferentes impactos econômicos the sociedade, dependendo somente da perspectiva que sejam vistos, do usuário, da concessionária ou da sociedade.

Há outras maneirns de se produzir conservação de energia, como a mudança na estrutura econômica do país e especificamente politicas de tarifnção, cuja consequiência será a otimização dus processos produtivos, melhorin nos processos industriais, planejamento urbano, aproveitamento da comunicação para reduzir o transporte, etc.; tais mudanças afetam o constumo de energia produzindo a sua reduçăo. Incrementos significativos nos preços de conbustiveis, pode ter como resposta diminuiçāo do consurno desses combustiveis que serão trocados por outras fontes de energia (o ótimo seria usar fontes renovíveis) e produzir incremento no consumo de outros combustívcis.

Nāo sc acredita que melhorias de eficiência entergética ocorram espontaneamente a partir de iniciativas dos consumidores. A larga experiência intemacional nn questro, nostra que sem a participação das concessionárias, do govento e das próprias industrias de equipamentos, a crinçâo de $\mathrm{um}$ mercado para esse produtos mais elicientes nั̆o se viabiliza de maneira significativa.

\subsection{PREMISSAS CONSIDERADAS NA ANÁLISE ECONÔMICA}

\subsubsection{WAXA DE DESCONTO}

A análise ecnuòmica da eficiência energética requer uma taxa para avaliar as alternativas energéticas no presente o determinar os beneficios no futuro; portanto, o valor que permite trazer os valores (iuvestimentos) futuros até o presente chama-se taxa de desconto. $\Lambda$ taxa de desconto tomn a forma de uma taxa de juros, expressida como fração e não como porcentirgem. A taxa de desconto depende da taxs de inflaçióo an prútica também da taxa de juros. O setor elétrico usa tipicamente taxas de desconto baixas, por exempio, $6 \%$ nos Fustados Unidos, $12 \%$ na Suécia, $12 \%$ na Tailândia, Brasil c Jamaica. 
Neste estudo de caso, a avaliaçăo econômica e financeirn será feíta com a taxa de descouto de $12 \%$ e o motivo deve-se a que os projetos de conservaçăo de energia no Equador podem ser feitos com o concurso externo de recursos, fundamentalmente pelo alto montante do investimento inicial. Por outro lado, a taxa stual de captaçăo de tecursos extemos pelo INECEL para empreendimentos é igual ao valor acimn proposto.

\subsubsection{PRECOS DA ELETRICIDADE PARA ILUMINAÇC̄O PÚBLICA (IP)}

O cálculo do preço marginal para consumo de IP é feito da scguinte maneira: segundo os dados apresentados na TABFLA 3.5 (Capítulo III) e considerando características próprias de funcionamento dia IP, tais como: ligada durante 3 lorad dia na ponta e 9 liorasidia forn da ponta (tempo de funcionamento diario 12 horas); 5 meses conespouden ì estaçăo de seca e 7 meses à estaçīo úmida. Aplicando estes conceitos, calcula-se o valor médio marginal de longo prazo ao nível de tede secundíria, que é igual para IP, em 82,9 USS/MWh próximo a 83 US\$MWh.

O prep̧o narginai de longo prazo de 83 USSMWWh, será usado no cálculo das figuras de mérito a seguir; no entanto, também usar-5e-á os valores referenciais previstos pelo INECDI. para venda de energih deste organismo às costcescionárias e cujo preço é 56 US\$/MWh (em 1996), alćm do preço de venda das concessionárias repassado aos seus usuários que ơ 76 US.ศ/MWh.

\subsubsection{PRECCOS DOS EQUIPAMENTOS}

Na TABELA 4.1 apresenta-se os preços de equipamentos para IP; luminárias, lâmpadas, reatores, ignitores e acessórios para a instalaçăo de luminárias de vapor de mercúrio e sódio alta pressĩo. Os dados foram recolhidos pelo Departamento de Compras da Empresa Edétsica Regional do Sul S.A., quem tem atualizado todos os preças de materiais para obras elétricas que estāo em concotrência. Neste caso, a lista de preços foi da Philips Equasur porejue tinha quase todos os acessórios e além disso a diferença de preços com outros distribuidores era mínima. 
Alén đisso, no ANEXO D há outros materiais ptóprios para a instalação de Jumintúrias (chamados "outros - vários", e dentre eles estāo: o parafuso, condutor de cobre isolado, conectores). O preço total destes materinis mais o preço do braço de sustentação para instalaç̧o de uma luminária é US\$13,5 para luminírias até potências 175 W, e USS 14,5 para luminárias de maior potência desde $175 \mathrm{~W}$ até $400 \mathrm{~W}$.

TADELA 4.1: PRECOS DOS MATERJAIS PARA ILUMINACÅO PÜBLICA (IP) ЛU-95

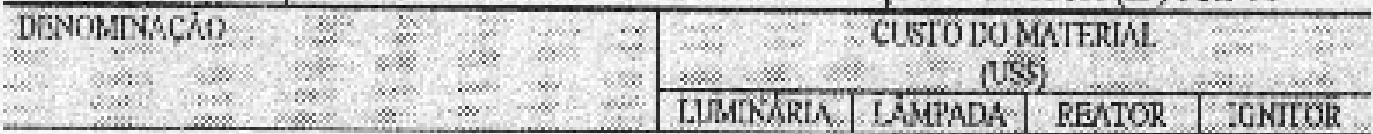

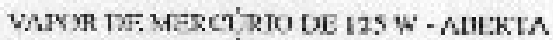

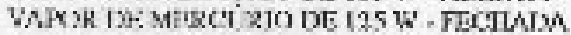

VATYR DEMERCIRTO DE ITS W - AHEHTA

VATOR DE MUECLIRIO DF iTS W - FFCINAM

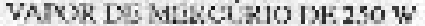

VMTRT TE MIBRCLRJO DE $400 \mathrm{~W}$

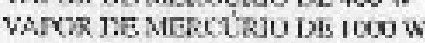

VATOR LES Sxnmes Ius sil $w$

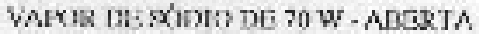

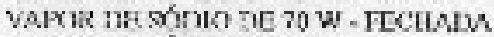

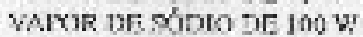

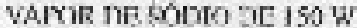

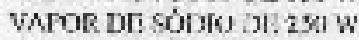

VAFUR IJE SUOUE : 가: 400 w

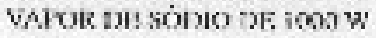

67.4

7000

786

110,9

173,9

189,1

3006

L.IZ. MIST ist

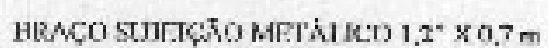

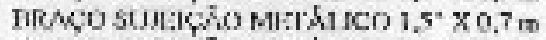
nRACO SUDC,

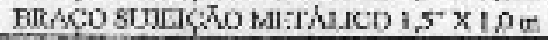

FONTE. DEPARTAMENTO DE ILUMINAÇ̄o PHILIPS EQUADOR C.A.

NOTA: Os preşos foram quotadhs em sterres ${ }^{\text {is }}$ pelo Departamento da Plilips, e foram conventidos à mocda forte pelo autor.

Para o cílculo do custo de instalaçйo c transporte, tomou-se os custos e rendimentos referenciais que possui a Empresa Elétrica Regional do Sul S.A. (Loja-Equador) para licitaçäo de obras. O preço médio de um grupo de trabalho com transporte é USS 22,9 por hora. Fste vafor inclui todos os bencficios econômicos da lei para os trahallıadores. Considerou-se diferente o rendimento dos grupos de trabalho, seguado sua ativilade, um para instalaçfo e outro para troca e manutenção de luminátias.

Com extes antecedentes pode-se apresentar o custo total de uma luminária instalada que sāo os seguintes(ver TABELA 4.2):

\footnotetext{
${ }^{15}$ Moeda equatoriana que no mês de junhom5 o seu valor em relaçăo an dólar dos Estados Unidos de
} América do Norte fos 2.30 s sucres/dólar. 


\begin{tabular}{|c|c|c|}
\hline TRODCLLRARKRIA & coDites & $\begin{array}{l}\text { CUSTO } \\
\text { (LB) }\end{array}$ \\
\hline YAPUR DE ME IPCITIO DR $125 \mathrm{~W}$ & $H G-125 \mathrm{~W}$ & 88.5 \\
\hline VACOI DE MERCLIRLODE ITS W & $116.175 w$ & 93,8 \\
\hline VAPOR DE MEXCUURO IX 250 W & HO-250 W & 197,6 \\
\hline WAYOR DI MERCTITIO DF dW WW & $\mathrm{HC}-400 \mathrm{~W}$ & $212, \mathrm{~B}$ \\
\hline WU2 MOSIA DE IS: W & $\mathrm{MQ}-160 \mathrm{~W}$ & 64,6 \\
\hline WMOR DE MIZRCIRIO DE $50 \mathrm{~W}$ & NA. $-50 \mathrm{~W}$ & 99.4 \\
\hline YAK:R DE SODID DE $70 \mathrm{~W}$ & Nh. $70 \mathrm{~W}$ & 1008 \\
\hline VAPCR DS SODLO DH $19 \mathrm{~W}$ & Nh-100w & 1429 \\
\hline WARIR DE SOODLO DR 150 W & NA-150 W & 151,6 \\
\hline YATOR DE SODOR DT 250 W & NA-2SOW & 223.7 \\
\hline WAFOI DE SUODIO DE 350 W & Nhyow & 219,3 \\
\hline VAFUR DLE SODIO DE $400 \mathrm{~W}$ & $\mathrm{MA}+100 \mathrm{~W}$ & 234,5 \\
\hline
\end{tabular}

FONTE: CALCULOS FETTOS PE1O AUTOR

\subsubsection{VIDA RFAL E ESTIMADA DOS EQUIPAMENTOS}

A tarefa de pespuisar a vida útil dos equipamentos nas concessionárias foi muito dilicil, porque nesthuma delas tínha o comtrole para estimat a vila útil dos equipamentos de IP. Porém, a metorlologia usada para determinar esces daclos neste cstudo de caso é pelo métudo indireto. Utilizou-se a quantidade de lâmpadas compradas pela Enupresa Elótricn Regional do Sul S.A. nos anos 1991 até 1994, com a caracteristica que a concessionária compron esses equipamentos somente para manutençân. Além disso, foi ncecssário obter o dado da quanticlade total de humivárias em funcionamento no ano 1994. A quantidade de luminárias em funcionamento durante os anos 1991 a 1993 foram calculadas (a concessionária năo tinhà essa informaçăo), basenda nos dados de consumo de energia faturado nesses mestros anos. A premissa ascumida fô que após " $x$ " anos de vida útil, todns as lâmpadas serz̃o trocadas por obsolescéncia. Os resultados foram bons pars as lâtmpadas de mercúrio, porém năo tão bons para as lômpadas de códio, exigindo um дjuste estimativo baseado na experiência e além disso em dados de outra concessionária (Empresa Flétrica Ambato S.A.). Para a avaliação cconômicn, a vida das lîmpaclas foi tomada aquela que apresetila-se na TABELA 4.3, coluna "vida real estimada".

A vida real dos outros aparelhos, simplesmente foram assumidos segundo dados proporcionadus pelos fornecedores Assim, no caso de reatores e iguitores 20.000 horas $(4,6$ nnos) e para carcaça da luminária 43.800 horas ( 10 anos). 
Por outro lado, aualisando os valores da vida da lâmpada MS-160 W é importante notar a diferença entre a vida proposcionada pelo fomecedor $(2,7$ anos) e a vida real $(1,4$ anos), sento este último resultado da experiêncin na Empresa Flétrica regional do Sul S.A.

\begin{tabular}{|c|c|c|c|c|c|}
\hline \multirow[t]{2}{*}{ Q(1)ign } & \multicolumn{2}{|c|}{ पTDA FORWECDTKR } & \multirow{2}{*}{ 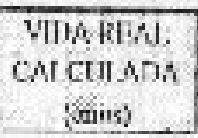 } & \multicolumn{2}{|c|}{ VIDARFA- TSTDARIXA } \\
\hline & (nexs) & (lianal & & (aich) & (bcens) \\
\hline $116: 125 \%$ & 5,5 & 15.006 & 3. & 3.1 & $13.51 \%$ \\
\hline $116-175 \%$ & 3,4 & 15000 & 36 & 3,4 & 15000 \\
\hline $100-259 \mathrm{~W}$ & 3.4 & 15.4100 & 2,3 & 3,4 & $15.00 \%$ \\
\hline nlic. $4001 \%$ & 3,4 & 15000 & & 3,1 & $150 \mathrm{anc}$ \\
\hline MS tho w & 2,3 & 13.006 & & 1,2 & $500 n$ \\
\hline Nn.so w & 1,1 & 18.um: & & 3,6 & 15.700 \\
\hline Wh- $-50 \mathrm{w}$ & 4.1 & 18 cont & 3.6 & 3,6 & 15700 \\
\hline NA. $150 \mathrm{~W}$ & d.1 & 18099 & 7,9 & 36 & 15701 \\
\hline NA $250 \mathrm{~W}$ & 4,1 & 18000 & 2,3 & 4,1 & 18000 \\
\hline An allow is & 4,1 & 18090 & 4,8 & 4.1 & 18000 \\
\hline
\end{tabular}

\subsection{CARÁTERIZACÃO TÉCNICA, ECOVÔMICA F HINANCEIRA DAS TECNOLOGIAS CONVENCIONAIS E RFICIENTES.}

\subsubsection{CARACTERI7AÇAO TÉCNICA}

\subsubsection{CONTINGẼNCIAS NAS LUMINÁRIAS}

O Departamento de IP da Empresa Elétrica Regional do Sul S.A., elaborou o controle mensal dos materiais usados na mamutençōo de $I^{3}$ da cidade de Loja (janciro a julho de 1994) e estes diadus furam usados no cálculo da frequência de contingéncias.

No período entre janeiro e julho de 1994, ocorreram 889 contingências (exuivalente a 127 cuntinģูûcias mensais on 1.524 contingências anuais); a quantidade total de luminárins em funcionamento na cidade de Loja nessa data (setembro-94) foi 6.614. Portanto, o indice de contingências ao ano é $23^{\mathrm{m}} \%$ das luminárias instaladas. $O$ custo médio de contingência para concentar a luminária é US\$ 10,1 (só inclui os materinis). 


$\begin{array}{lr}\text { Lampadas esgotadas } & 63 \% \\ \text { Reatores } & 8 \% \\ \text { Fusiveis e breakers } & 6 \% \\ \text { Relês } & 1 \% \\ \text { Células fodoelètricas } & 3 \% \\ \text { Ignitores } & 3 \% \\ \text { Capacitores } & 3 \% \\ \text { Starters } & 3 \% \\ \text { Porta lâmpada } & 1 \% \\ \text { Conectores } & 5 \% \\ \text { Oultros } & 4 \% \\ & \\ \text { TOTAL } & 100 \%\end{array}$

Estas porcentagens coincident com os valores da Empresa Elćtrica Ambato S.A., portanto corrobora-se os resultados do cálculo.

\subsubsection{ANÁLISE TÉCNICA}

A iluminação de recintos residenciais, comerciais, industriais, etc. proporciona uma gramde flexibilidade quanto ao fhuxo das làmpadas, o vúmero de lâmpadas pot luminária, - número de luminárias por recinto e a distancia entre luminárias. No entauto, a iluruinaçīo de vias motorizadas näo possui esta flcxibilidade. além de exístirem ainda técuicas difurentes para o cálculo e mediçào (humiıâneja e ihuminâncin).

Muitas vezes os cáleulos săo feitus em iluminâncias (lux) e depois convertidos em lumiıñncias $\left(\mathrm{cd} / \mathrm{m}^{2}\right)$. De qualquer maneira o resultado será quase sempre um compromisso entre as características descjadas possiveis.

A diferença entre us fluxos das lâmpadas é grande (um fator 2). 0 numero de tipos de luminátias é restrito. A altura da luminária (poste) é pouco variávcl e geralmente padronizada (estre 7 a $9 \mathrm{~m}$ ). O espaçamento é pouco variável e de 30 a $40 \mathrm{~m}$.

A própria recomendaçân da CIE (Comissão Intemacional de Iluminação), restringe a luminåncia da pista n três faixas: $2 \mathrm{~cd} / \mathrm{m}^{2}, 1 \mathrm{~cd} / \mathrm{m}^{2}$ e $0,5 \mathrm{~cd} / \mathrm{m}^{2}$, reconbecendo que o projetisia deverí poder julgar qual o mellor compromisso. Nesse aspecto a uniformidade terá influencia no resultado. Una boa uuiformidade podeá compensar uma luminancia 
média menos: A faixa de toleråncia do Ofuscamento $(G)^{17}$ e lacretucnto Limiar (IL) ${ }^{18}$ é igualınente importante.

No Equador os padrões e regulamentaçĩes de IP sân poucos, dentre o principal e mais usado é a "Normas para Sistemas de Distribuiçĩo" da E.E. Quito S.A, na qual apresenta-se certos critérios gerais sobre condiçĩes e características de iluminaç̆o em ruas e rodovins. Na TABELA 4.4 observa-se o resumo dos niveis mituimos de ilumiuaçî̀ e fatores de uniformidade, segundo o padrão da E.E. Quito S.A., que devem ter as ruas e rodovins. Sob estes parâmetros de planejamento serão consideradas as altemativas de trocs,

\section{TABELA 4.4: NIVEIS DE ILUMINACAOO E UNIFORMTDADE PARA CALCADAS}

\begin{tabular}{|c|c|c|c|c|}
\hline $\begin{array}{l}\text { THPOISE } \\
\text { VAN: }\end{array}$ & TuhNSTO & 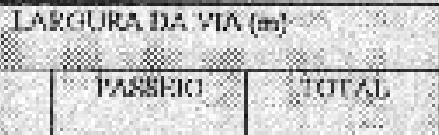 & $\begin{array}{l}\text { ofive } \\
\text { sfirmo } \\
\text { sitoro } \\
\text { ituxi }\end{array}$ & 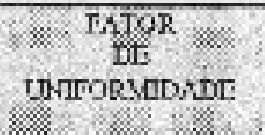 \\
\hline
\end{tabular}

\begin{tabular}{|c|c|c|c|c|c|c|}
\hline 1 & PH.DESIRA & - & - & 6.00 & 10 & 0,20 \\
\hline 2 & VHICTIZ AR & $5, n 0$ & 1.50 & 8.120 & 21. & 0.25 \\
\hline 3 & SFICIIn An & 7.00 & 1.50 & 10,00 & 25 & 0.39 \\
\hline 4 & VEICULSR & 8,40 & 2.311 & $13 \mathrm{nI}$ & 35 & 0.30 \\
\hline 5. & VEICULAR & 1II.KO & 2,60 & 16,00 & 35 & 0,70 \\
\hline
\end{tabular}

FONTE: NORMAS PARA SISTEMAS DE DISTRIBUICAAO - PARTE A - E.E. QUTTO

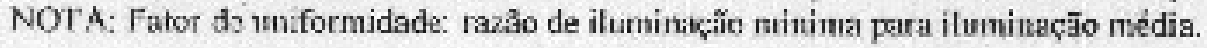

Neste estudo deve-5e assumir certas condições, premissas on caracteristicas exclusivamente técnicas que sĩo expresşs a seguir.

Considera-se que o programa de troca de lmminárias năo implica modificaçồes na topologia da rede secundária de distribuiçiono ou modificaçôes físicus de seus contjonentes; em consequicencia assume-se que a altura de postes, espaçamento de postes, niveis de iluminação, quala de tensão sāo no momento adequados e estão dentre os paliōes e regulamentaçōes. Na FIGURA 4.I apreserıta-se as earacterísticas e nome das dimensīes usadas na IP.

1' Medida de Oáuscamento Desconfortável (G) è o nimero que indira o grau do qus esta controlado o

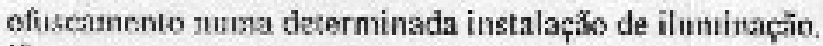

"F Incremento Limiar é o número que indica o limite da dinimuiçazo de contraste, provocado pela luminânciu veladora cu o gran do que esta limitada uma luminária do ofuscanento. 


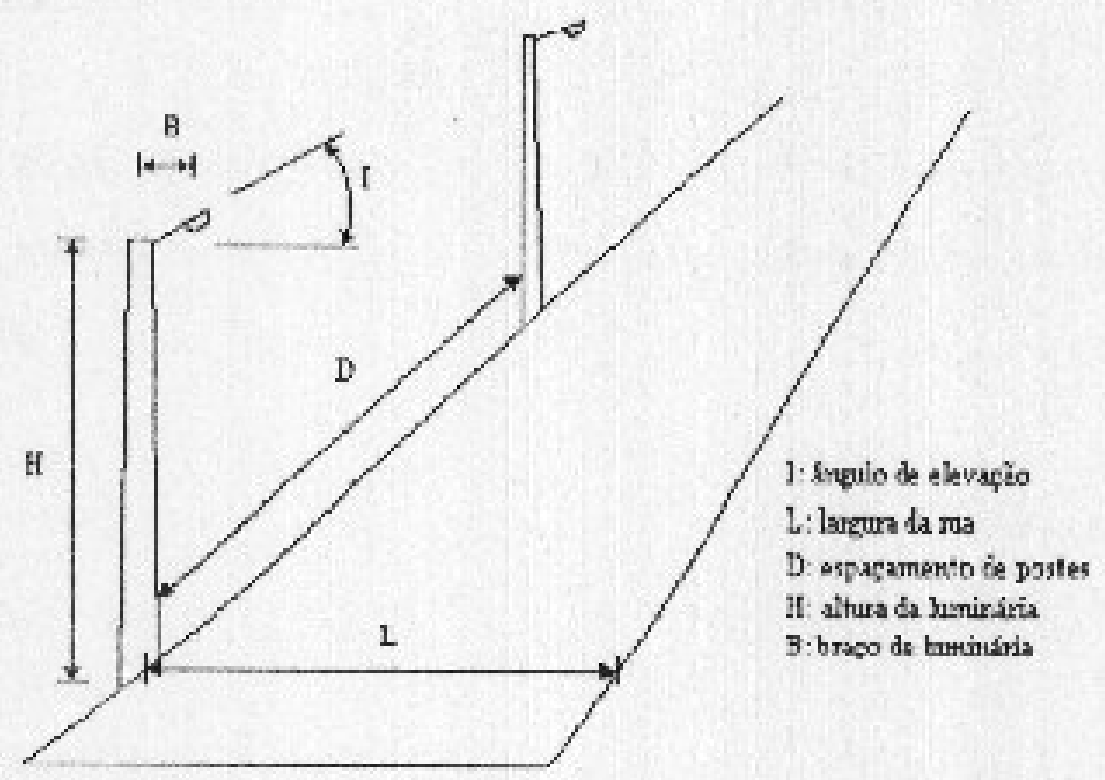

Sabemos que as lîrmpadas de vapor de sódio não proporcionam boa reproduçâo de cores, poufanto as trocas propostas năo podem ser consideradias nos lugares que precisnrem de bon indice de reprodução de cores; năo obstante, estima-se que no programa de troca serūo poucos os cosos desta natureza.

0 processo de aperfeiçoamento tecuológico estí baseado no principio de retirar a lumiuária convejucional (vapor de mercírio) e substitui-la com outra luminária eficiente (vapor de sídio), ficando pelo menos igual ou ainda melhor o nivel de iluminaçăo.

Identificado o potemeial de conservaçān (no Equador usa-se principalmente luminárias de vapor de mercúrio de $125 \mathrm{~W}, 175 \mathrm{~W}, 250 \mathrm{~W}$ e $400 \mathrm{~W}$, e luz mista de $160 \mathrm{~W}$ ), busca-se uma luminária eficiente pura cada tipo de convencional, considerando $\mathrm{cm}$ primeiro lugar que o fluxo luminoso da lumiıária eficiente seja igunl ou maior à convencional. Assim, obteve-se as alternativas de troca que são apresentadas un TABELA 4.5. Além dissn, com ajuds de softuyare proporcimado pela Philips Equador, calculou-se as varacterísticas técıicas de ifuminaçāo (luminância e ilumiuância), sob as premissas de manter jguais dimensōes físicas (largura da calçada. altura de postes, espaçamktnto de pastes, etc.), segundo já foi dito e cujos resultados também são apresentados na TABFL A 4.5. 
Na altcraativa T-1 (HG-125 W por NA-70 W), a potência diminui em $55 \mathrm{~W}(-44 \%)$, o fluxo luminoso também diminui de $6,3 \mathrm{klm}$ a $5,8 \mathrm{klm}(-8 \%)$, não obstante o nivel de luminância cresce de $1,0 \mathrm{~cd} / \mathrm{m}^{2}$ para $1,1 \mathrm{~cd}^{2} \mathrm{~m}^{2}$ (+ $\left.10 \%\right)$, bem como o nfvel de ihminŝncia aumenta de 10 lux para 11 lux $(+10 \%)$, emborn se tenha menor fator de unifonnidade.

\begin{tabular}{|c|c|c|c|c|c|c|c|c|c|c|c|}
\hline \multirow{2}{*}{ TROL } & \multirow{2}{*}{$\begin{array}{l}\text { Covina } \\
\text { cionst }\end{array}$} & \multirow{2}{*}{$\begin{array}{l}\text { ETEENTE } \\
\\
\end{array}$} & s. & \multicolumn{4}{|c|}{ 1OMINGNCW } & \multicolumn{4}{|c|}{ IIUMTNKKCN } \\
\hline & & & $\begin{array}{l}\text { MEDIO } \\
\text { (calins) }\end{array}$ & IL(G) & $\mathrm{G}$ & Us & 17 & $\begin{array}{l}\text { Meplo } 0 \\
\text { duxi }\end{array}$ & Minúx & Minkay & (t)inin) \\
\hline$T-1$ & $\mathrm{H}(\mathrm{i}-12 \mathrm{sW \textrm {W }}$ & & 1,0 & 5,3 & 6.6 & 0,40 & 0.25 & 10 & 0,08 & 0.22 & 6.3 \\
\hline $\mathrm{T}-2$ & [50-175W & & 1,1 & 43 & 70 & 0,47 & 0.98 & 12 & 0.14 & 034 & B, 5 \\
\hline$T-3$ & DG $135 \mathrm{~N}$ & & 1,1 & 43 & $7 \not 0$ & 0,47 & 0.38 & 12 & 0,14 & 0.34 & 8,6 \\
\hline $\mathrm{T}-1$ & {$[16-250 \mathrm{~W}$} & & 1.9 & 42 & 68 & 0,12 & 0,39 & $2 n$ & 0.12 & 0,32 & 13.5 \\
\hline $\mathrm{T}-5$ & [DG-1000, & & 2,4 & 58 & 65 & 0,13 & 0,40 & 24 & 0,12 & 0,32 & 23,0 \\
\hline $\mathrm{T}-6$ & $\mathrm{M}-1 \mathrm{~S}-1,002$ & & 0,7 & 3.1 & 8.7 & 0.24 & 0.21 & 7 & Dos & 0,13 & 3.2 \\
\hline$T-1$ & & Nh-Tow & 1,1 & 4.8 & 8.4 & 0.17 & 0.15 & 11 & 0.03 & $0,0 \mathrm{~g}$ & 58 \\
\hline $\mathrm{T}-2$ & & WA-100W & 15 & 9.2 & 7.7 & 0.38 & 0,45 & 15 & 0.112 & 0,21 & 9,5 \\
\hline$T-3$ & & M $150 \mathrm{~W}$ & 2,1 & 3,6 & 6,9 & 0,0 & 0,37 & 21 & 0.12 & $0,3,7$ & 13,5 \\
\hline$T-4$ & & $\mathrm{NA}-1.50 \mathrm{~W}$ & 2.1 & 3.6 & 6.9 & 0.16 & 0,39 & $2 t$ & 11,12 & 0.30 & 135 \\
\hline$T: 5$ & & NA-250W & 2.8 & 4.7 & 6,0 & 0.13 & 01,32 & 29 & 0,03 & 0,27 & 25,0 \\
\hline$I-6$ & & $\mathrm{MA}-5 \mathrm{CON}$ & 0,7 & 3,1 & 8,7 & 0,24 & 0,31 & $\tau$ & 0.05 & 0,13 & 35 \\
\hline
\end{tabular}

FONFE: CALCULOS FEITOS PELO AUTOR

NOTA: Os cálcuios form feitos sob a prennissa de trocar toda a luminária de vapor de metcúrín por vapor de sódio.

II. $(\%)=$ increntento limiar

$\mathrm{G}$ - índios sis controle de ofuscamento

Uo $=$ uniformidade ylobalizeda

$\mathrm{LT}=$ uniformidade longitudingl

Em T-2 (IIG-175 W por NA-100 W), a potêncis dimintui em $75 \mathrm{~W}(-43 \%)$, of fluxo luminoso cresce de $8,6 \mathrm{~km}$ para $9,5 \mathrm{kmm}(+10 \%)$, enquanto o nivel de luminância tambén cresce de 1,1 at/m $\mathrm{m}^{2}$ para $1,5 \mathrm{~cd} / \mathrm{m}^{2}$ ( $136 \%$ ), o nivel de jluminância de 12 lux a 16 lux $(+37 \%)$, embora $\propto$ tenln diminuiçẫo dos fatores de uniformidade. Na alternativa T-3 (HG-175 W por NA-150 W), complemento da altemativa $\mathrm{T}-2$, a potência diminui em $25 \mathrm{~W}(-14 \%)$, o fluxo luminoso incrementa significativamente de $8,6 \mathrm{klm}$ para 13,5 $\mathrm{klm}(+57 \%)$, de igual mansira o nivel de luminåncir cresce de $t, 1 \mathrm{~cd} / \mathrm{m}^{2}$ para $2,1 \mathrm{~cd} / \mathrm{m}^{2}$ $(+91 \%)$, o nivel de iluminância de 12 lux para 21 lux (+75\%); cmbora a couservação de potêntia scja somente $25 \mathrm{~W}$, porérn sob a ótica técnica a proposth é muita boa. Na altenativa $\mathrm{T}-4$ (HG-250 W por NA-150 W), a potêtıcia diminui eu $100 \mathrm{~W}(-40 \%)$, os fluxos lumimosos das tecnologias săo iguais o sen valor é $13,5 \mathrm{klm}$, no critanto o valor de 
lumintancia cresce de $1,9 \mathrm{cl} / \mathrm{m}^{2}$ para $2,1 \mathrm{~cd} / \mathrm{m}^{2}(11 \%)$ e o valor de iluminância de 20 lux para 21 lax $(+5 \%)$.

$\mathrm{Na}$ altemativa T-5 (HG-400 W por NA-250 W), a potência diminui $150 \mathrm{~W}(-38 \%)$, o fluxo luminoso incrementa de $23 \mathrm{klm}$ para $25 \mathrm{klm}(+9 \%)$, o nível de luminância também cresce de $2,4 \mathrm{cdim}^{2}$ para $2,8 \mathrm{~cd} / \mathrm{m}^{2}(+17 \%)$, de igual maneira o wivel de iluminância de 24 lux a 29 lix $(+21 \%)$, no entanto diminuem os fatores de uniformidade por um pequeno valor. Finalmente na alternativa T-6 (MS- $160 \mathrm{~W}$ por NA-50 W), a potência diminut em $110 \mathrm{~W}(-69 \%)$, o fluxo luminoso cresce de $3,2 \mathrm{klm}$ para $3,5 \mathrm{klm}(+9 \%)$, o tivel de iuminâucia mantém-se no mesmo valor de $0,7 \mathrm{~cd}^{2}{ }^{2}$, da mesma formı que o nivel de iluminânciin em 7 lux, porém tem dimisuiçiơ substancisl de potência, $110 \mathrm{~W}$ ($69 \%)$

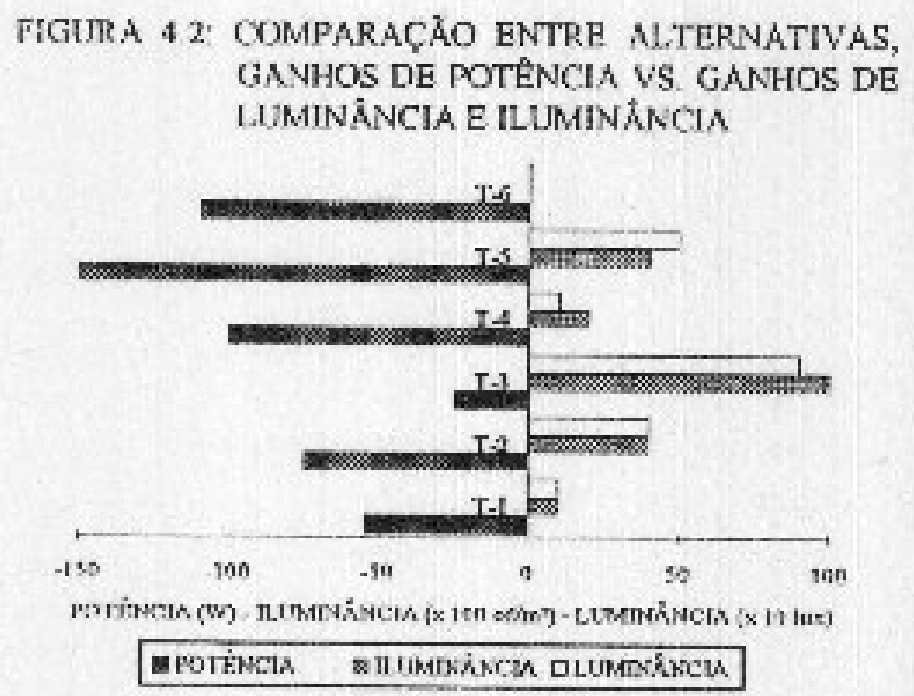

Na FIGURA 4.2 apresenta-se os ganhos de potência pula troca de lumintárias no lado esquerdo do eixo " $y$ ", enquanto no lado dircito os ganhos ent luminância expressos em $100 \mathrm{~cd} / \mathrm{m}^{2}$ e iluminância expressos em 10 lux. Sob ótica de ganhos do potência, a melhor altemativa é T-5, cuquanto en luminància e iluminância é $\mathbf{T}-3$. 


\subsubsection{EXPERIÊNCIA E RESULTADOS LUMINOSOS COM A TROCA DE LUIMINÁRIAS NA COLÔMIIA}

A Empresa de Energia de Bogotá com o objetivo de determinar a conveniêncis dos níveis luminosos da substituição de luminárins e/on lâmpadas de vapor de mercúrio de $125 \mathrm{~W}$ por vapor de sódio de $70 \mathrm{~W}$ fez uma pesquisa de campo. Trocou luminárias num bairro da cidade de Bogotá (vapor de mercúrio de 125 W por vapor de sódio de $70 \mathrm{~W}$ sum lugar e, por vapor de sódio de $50 \mathrm{~W}$ em outro lugar) das seguintes caracteristicas (Miristério de Mintas e Energia đa Colômbia, 1995):

- luminárias NA-50 W tijo "nova geração" (fecluadas, com refiator prismático, lâmpad tubular clara)

- luthinárias NA-70 W tipo "hova geração" (fecladas, com refrator prismático, lâmpada tubular clara)

- huminárias NA-70 W tipo convencional (montadas na Empresa com varcạ̧ de $\mathrm{HG}-125$ W, lâmpada tubular clara)

Os resultados foram os scguintes:

- a luminância média da luminária HG-125 W encontra-se $80 \%$ menor do que o valor padrào $\left(0,5 \mathrm{~cd} / \mathrm{m}^{2}\right)$.

- a luminância média da huminária NA-70 W (nova geraçāo) aitinge um valor $70 \%$ maior do que o valor padrīo $\left(0,5 \mathrm{~cd} / \mathrm{m}^{2}\right)$.

- a lumintincia média da huminária NA-50 W (nova geraçāo) atinge un valor $10 \%$ maior do que o valor padrăo $\left(0,5 \mathrm{~cd} / \mathrm{m}^{2}\right)$.

- a luminância média da luminśria NA-70 W (convencional) encontra-se 8\% menor do que o valor padråo $\left(0,5 \mathrm{~cd} / \mathrm{m}^{2}\right)$.

O valor da unifomidade globalizada (Uo) para HG-125 W foi $75 \%$ menor do que o patlrāo $(0,4)$, estretanto para NA-70 W (nuva geraçīo) foi $10 \%$ menor do que o padräo, porém estimam que este valor pode ser corrigido palo angulo de elevação. Para as 
luminárias NA-50 W (nova geraçăo) e NA-70 W (convencional) dizetn que os valores são mniores do que o padrão.

0 valor da unifornidade longitudinal (UI) para HG- $125 \mathrm{~W}$ foi $80 \%$ menor do que o padrăo $(0,5)$, entretanto para NA-70 W (nova geraçăo) foi $24 \%$ maior do que o padrão. Para as luminárias NA-50 W (nova geraçăo) e NA-70 W (convencional) n uniformidade longitudinal foi t\% e $40 \%$ respectivamente maior do que o padrão.

Portanto concluem que, é víivel usnr n luminária NA-70 W (novn geraçõo) em substituiçäo da luıninária HG-125 W, e, usar a lumintáia NA-70 W (convencional) com Lâmpada tubular clara em substituição da luminária HG-125 W só para espaçamentos entre postes menores do quc $24 \mathrm{~m}$

Deve-se notar que a luminária NA-70 $\mathrm{W}$ tipo convencional, a sua carcaça foi de uma lunainária HG-125 W e o projeto ótice para lànupada tipo ovóide.

\subsubsection{CARACTERIZAÇ̃o ECONÔMICA E FINANCEIRA - FIGURAS DE MÉRTTO}

O custo efetivo dos investimentos $\mathrm{cm}$ eficiêncin energética ou gercuciamento da demanda, pode ser avaliado de difercntes perspectivas. $O$ consumidor de energia vé o beneficio através da redução dos pagamentos produzidos pela reduçăo do conısumo dc energia e a pussivei reduçào de demanda. A análise econômica considera os custos e beneficios para o usuário e as suas perspectivas.

Os investimentos en eficiência energética ou reduçăo (gerenciamento) de demanda, podem dimimir as necessidates adicionais em empreendimentos para geraçāo de encrgias; além disso, reduzem o consumo de combustiveis em usinas tćrmicas, reduzem as perdas em linhas de transmissāo e sistemas de distribuiçāo e, reduzem os impactos atabientais associados com geraçăo e transmissåo de eletricilade; portanto, o conjunto destes beneficios redundam no beneficio econômico do país ou região. 
A análise ceonônica está baseada na comparaçăo entre custos e beneficios de imvestimentos envolvidos na questão de conservação de energia, levados às perspectivas da sociedade, donde por "sociedade" define-se os usuários do serviço elétrico, concessionárias e govemantes. Em uutrns cnsos dever-se-ia também considerar àquelas pessoas que não dispòem do serviço elétrico. As perspectivas individunis e coletivas no campo energéticn sĩo diferentes, principalıente porque as tarifas nก̃o são exatamente iguais aos custos de produção.

$O \mathrm{kWh}$ conservado ou $\mathrm{kW}$ de demanda redusido permite diminuir a energia e pontência gerada pela usina cujo custo de produção é maior; neste caso, o custo unitários conservado chama-se "custo marginal conservado". O custo marginal geralınente é maior que o custo médio, portanto os programas de conservaçăo de energia e reduçân da demanda, produzem beneficio social, que superam os beneficios individuais. Além disso, os custos ambientais e extemos (extemalidades) produzidos pelos impactos ambientnis na geraç̄̄o de eletricidade, năo estน̃o inseridos nas tarifà, portauto a pupulaçño paga aquilo indiretamente através da despesa mídica. dimimuiçño do tenpo de trabalho ou diminnição da expectativa de vida (Iutt. 1993).

Os preços das tarifas do tipo Inonômia, a qual contemsplu somento o uso de um preço para energia cuนsumidn, nâo necesșriamente mudarâo em altas porcentagens os valores da demanda máxima (ponta) dos sistemas elétricos, porént, podem ser o postapé inicial para a eliciêncin energética; no entanto, os subsidios inseridos nas tarifas podem ter aho conterído socint.

Ievabdo-se em conta os investimentos iniciais adicionais necessários para melhorin da eficiência energética por parte das concessionárias, um aspecto que influi notavelmente na aquisiç̧̃o de equipamentos eficientes, é o custo inicial superior dessas tecnologias en relação is tectologins convencionais, espuecendo as vantugens posteriores dessa tecuologia altemativa; assim, por exempio para o caso do Equador, a luminária eficiente NA-70 W tem preço maior em $17^{\mathrm{m}}$ a sus simular convencional $\mathrm{HG}-125 \mathrm{~W}$; a luminária eficiente NA-100 W maior cm 52\% à IIG-175 W; a lutrinánia eficiente NA-150 W maior

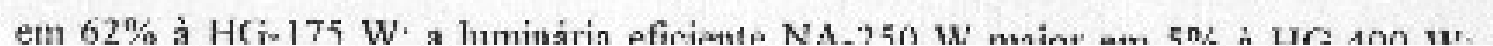


lumiıária eficiente NA-50 W maior em 54\% à MS-160 W; uma exceçåa é a luminária convencional IIG-250 W cujo preço é maior em $30 \%$ a sua similar $\mathrm{N} / \mathrm{A}-150 \mathrm{~W}$.

\section{FIGURAS DE MÉRITO}

\section{a) FATOR DE RECUPERACÃO DO CAPITAL (TRC)}

Para amulizar o custo do investimento deve-se multiplicar o investimento inicial pelo Fator de Recuperaçăo do Capital (FRC); isto é, calcula-se o equivalente ao investimento que seria gasto durante um ano, considerando determinada taxa de desconto.

OFRC é dado pela seguinte expressâo:

$$
\begin{aligned}
\operatorname{FRC}(d, N) & =\frac{1}{\sum_{n=1}^{N}(1+d)^{-n}}=\frac{d}{1-(1+d)^{-N}} \\
A & =P * \operatorname{FRC}(d, N)
\end{aligned}
$$

onde:

d - taxa de descouto (decimal)

$\mathrm{N}=$ numero de períodos

$\Lambda=$ valor anualizado dos iuvestimentos

$\mathrm{P}$ - valor presente dos investimentos

\section{b) TEMPO SIMPI JS DE RETORNO (TSR)}

V'́rios critérios econômicos săo usados para nvaliar a efetividade dos investimentos cm eficiência energúticn. O Tempo Simples de Retorno (TSR) é um deles, e define-se como a relação entre o investimento inicial adicional para conservaçño e v custo de energia conservada no primeiro ano. Representa o tempo simples onde se vai recuperar o valor do investimento inicial em conservaçĩo de energia. 


$$
T S R=\frac{(C E-C C)}{\operatorname{PE}(F C-E E)}
$$

onde:

$\mathrm{CE}=$ é o custo (investimento inicial) da tecuologia eficiente

$\mathrm{CC}=$ custo da tecnologia convencional

$P \mathrm{E}=$ preęo unitátio de energia

EE - consumo anual de energia com tecnologia eficiente

EC = cotsumo anual de energia com tecnologia convencional

\section{c) TAXA INTERNA DE RETORNO (TTR)}

A Taxa Interua de Retomo (TTR) define-se como a taxa de desconto na qual duas altemativns de investimento têm igual valor presente. $\Lambda$ soluçäo da scguinte equaçåo (4.4) dá o valor d que é a TIR:

$$
\mathrm{CC}+\mathrm{PE} * \mathrm{EC} \sum_{k=1}^{n} \frac{1}{(1+\mathrm{d})^{k}}=\mathrm{CE}+\mathrm{PE}+\mathrm{EE} \sum_{k=1}^{n} \frac{1}{(1+d)^{k}}
$$

Uma das características mais irmportantes da análise econômico financcira ć a taxa interna de retorno (TIR), especialmente quando deve-se tomar decisōes sobre várias altemativas de projetos

\section{d) CUSTO DE ENERGIA CONSERVADA (CEC)}

O Custo de Euergia Conservada (CEC) é uma medida desenvolvida especialmente para análise de investimentos em conservação de energia. CEC define-se como o custo efetivo do investimento, e é expresso como o custo equivalente desse investimento por unidade de energia conscrvada. O CEC toma em conta a taxa de desconto e a vida útil dars investimentos; assim, é calculado pela relação anualizada dos investimevtos adicionais cm conservação de energia e pela energia auual conservada. 


$$
\mathrm{CEC}=\mathrm{FRC}(\mathrm{d}, \mathrm{u}) * \frac{\mathrm{CE}-\mathrm{CC}}{\mathrm{EC}-\mathrm{EE}}
$$

onde:

FRC $(d, n)$ - fator de recuperaçâo de capital para taxa de desconto de múmero de anos a

\section{e) CUSTO DURANTE A VDA (CDV)}

Custo Durante a Vida (CDV) de uma altenativa energéticn é o valor presente de todas as receitas a deşesis relacionadas com essa alternativa. Inclui-se o investimento inicial, os custos de operaçĩo e manutençũo e, o custo pelo consumo de energia e instalaçũo.

$$
\operatorname{CDV}-\mathrm{C}+\frac{\operatorname{PE} * \mathbf{E}}{\operatorname{FRC}(d, n)}+\frac{\operatorname{COM}}{\operatorname{FRC}(d, n)}-\frac{V_{r}}{(1+d)^{N}}
$$

onde:

$\mathrm{C}=\quad$ ensto ou investimento inicial da alternativa

$\mathbf{E}=\quad$ consuno amual de cnergia para a alternativa

COM = custo de operaç̃̃o e manutençăo anual da slternativa

$\mathrm{Vr}=\quad$ valor residual (valor restante no final de periodo - proporcional à vida restante)

$\mathrm{N}=\quad$ múmero de períodos

\section{f) CUSTO DURANTE A VTDA ANUALIZADO (CDVA)}

O Custo Durante a Vila Anualizado (CDVA) é a soma anualizada do seguinte: investimento inicial, consumo de energia elétrica, instalą̧āo 6 , operação e manutençŭo.

$$
\text { CDVA }=\mathrm{C} * \mathrm{FRC}(\mathrm{d}, 11)+\mathrm{PE} * \mathrm{E}+\mathrm{COM}
$$

ou também 


$$
\mathrm{CDVA}=\mathrm{CDV} * \operatorname{FRC}(\mathrm{d}, \mathrm{n})
$$

\section{g) CLSTO DO LÚMEN-HORA}

O fluxo luminoso é a energia capaz de sensibilizar o olho humano, emitida por un determinada fonte de luz. Como resultado de um longo processo ele é produto de uma série de feuômenos, frequientemente não perceptíveis imediatamente, como a eficiência, as perdas entergéticas nos componentes, a depreciação luminosn e outros. Aliando a esses fitores alguns elementos de custo de implantaçăo e forma de utilizaçăo, operaçăo e mantutcrção de um determinado conjunto de ilumiuaçăo, obtemos o chamado custo do himen-Lora (USS/Mim-h).

$$
\text { USs i Mlm-h }-\frac{C * F R C(d, n)+P E * E+C O M}{()^{*} b_{1} / d * d / \text { ano }}
$$

onde:

Ф - fluxo luminoso emitido pela lâmpada em Mlúmen

by'd = uso de horas diárias da luminária

d/ano - $\quad$ uso de dias ao ano da lumimária

\subsection{ANÁlISE ECONÔMICO FINANCEIRA DE ALTERNATIVAS PARA ILUMTNACÃO PÚBLCA (IP)}

Todas as alternativas de troca propostas no item 4.2 , serão analísadas sob a ótica das principais técnicas de usos finais utilizadas na determinaçăo das vantagens em uso eficiente e conservaçăo de cnergia. Estes critérios foram expressos como figuras de mérito.

\subsubsection{TEMPO SIMPLES DE RETORNO (TSR)}

Observa-se na TABELA 4.6 a seguir, que o menor tempo pertence à troca $T-6$, isto fo souncute 2,8 anos såo necessátios para recuperar o investimento inicial; eutretauto, para a 
altenutiva $T-3$, o tempo de retomo é muito longo, 22 anos. As outras alternativas apresentam valores intermediários. No entanto, esta figura de mérilo não é caracteristica determinística na tortıada de decisōes.

\begin{tabular}{cccc} 
TABELA 4.6: TEMPO SIMPLES DE RETORNOTSR) & \\
\hline TROCA & ATUAL & PROJETADA & TSR (anos) \\
\hline T-1 & HG-125 W & NA-70 W & 5,3 \\
T-2 & HG-175 W & NA-100 W & 5,4 \\
T-3 & HG-175 W & NA-150 W & 22,0 \\
T-4 & HG-250 W & NA-150 W & 4,3 \\
T-5 & IIG-400 W & NA-250 W & 4,1 \\
T-6 & MS-160 W & NA-50 W & 2,8 \\
\hline
\end{tabular}

FONTE: CALCULOS FEITOS PELOO AUTOR

\subsubsection{TAXA INTERNA DE RETORNO (TIR)}

No $A N E X O D$ apresenta-se os fluxos de caixa para todas as alternativas propostas neste estudo de oaso; nõo obstante, a seguir -como cxemplo- encontra-se o quadro para a alternativa ']'-1 (troca te luminánia de vapor de mercúrio de $125 \mathrm{~W}$ pela luminária de vapor de sódio de 70 W) (ver TABELA 4.7), cujo resultado proporciona a taxa interna de retorno de $125,8 \%$

Neste exemplo, o investimento inicial da lumiuária NA-70 W émior em $17 \% \mathrm{em}$ relaçăo à lumitı́nia $\mathrm{HG}-125 \mathrm{~W}$, porém, o consumo anual de energia desta ultima é maior cm $65 \%$; além dissn, ห̀ vida útil da lâmpada de sódio é maior em $16 \%$ à vida útil do lâınpada de mercúrío.

0 tempo estabelecido para análise das allemativas é 10 anos ${ }^{10}$ e assume-se que todos os fluxos de caixa ocorrem no fiou de cada anto. $O$ cálculo inclui o valor residual da lâmpada e do realor an final do periodo, quando, ao final do décimo ano ainda existe remanescente (residuo) do vida útil da lâtmpada e do reator. $\mathrm{A}$ seguir se estabelece o

\footnotetext{
19 este tempo foi excolhidu arbitrariamente para todas as alternativas, pois a vida útil das luminárias sh̆o

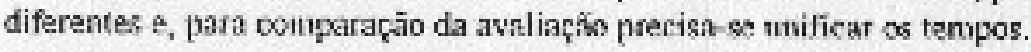


balanço entre os fluxos de caixa da tecnologia convencional e eficiente, obtendo-se assim a taxa intema de retorno da alternativa.

Para o restante das alternativas veja o ANEXO D.

TABELA 4.7: EXEMPLO DE FLLXO DE CAIXA PARA T-I

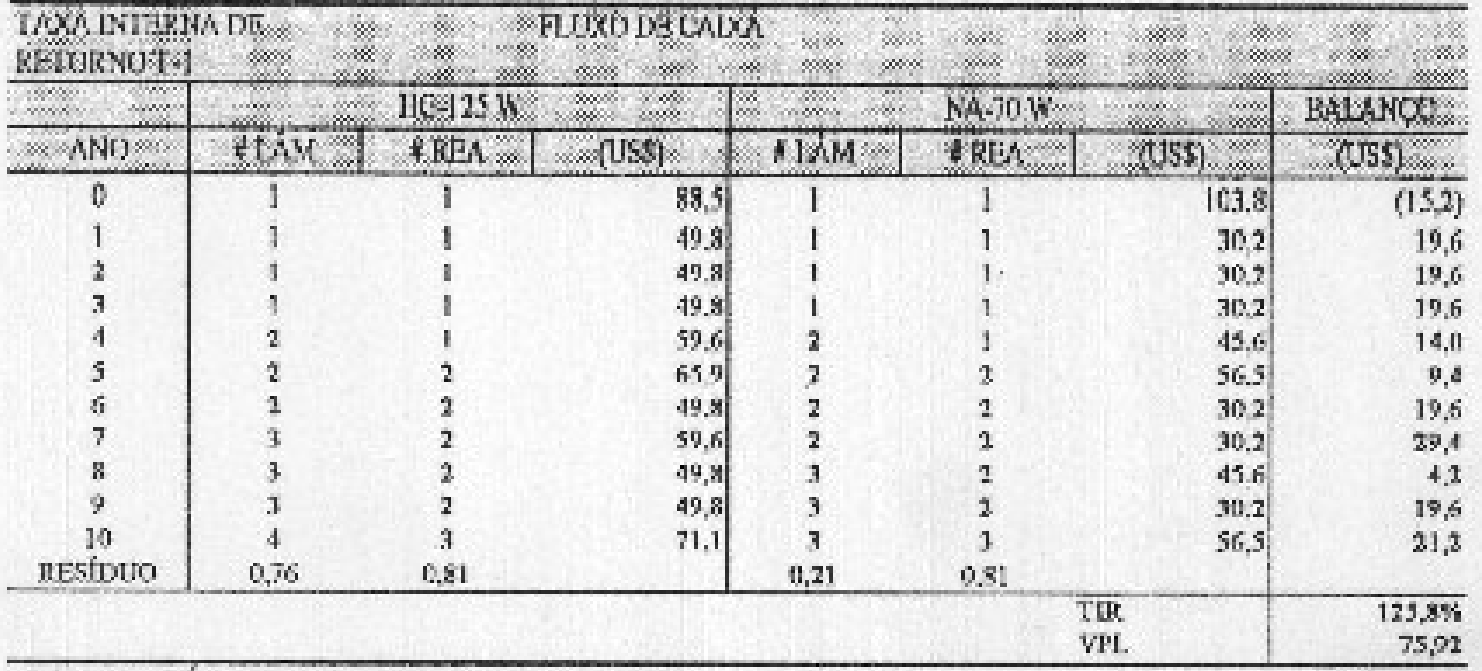

FONTE: CALCLLOS FEITOS PELO ALTOR

Os dados apresentados na TABEIA 4.7 foram desenhados na FIGURA 4.3, cujo oljetivo é dar a idéia de grandeza dos mesmos.

Conforme já dito, a taxa interna de retomo para $\mathrm{T}-1$ é $126 \%$, no entanto, o maior valor dentre as allemativas comresponde a $\mathrm{T}-4$ (ver TABELA 4.8), cuja porcentagem é infinita, isto ć o seu resultado de investimento é superior aos demais. Igual conclusāo para as altemativas $\mathrm{T}-2, \mathrm{~T}-5$ e $\mathrm{T} 6$, devido às suas porcentngens serem muito maiores que a taxa de desuuato (12\%), o que não ocorre para o caso da alternativa $\mathrm{T}-3$, cuja porcentagem ainda é negrativa, $-5 \%$. Portanto, a alternativa T-3 fica fora do programa,

\begin{tabular}{|c|c|c|c|c|c|}
\hline TROCA & ATIIAI : & PROJE IADA & 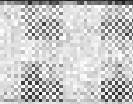 & $\operatorname{TIR}(\%)$ & , \\
\hline $\mathrm{T}-1$ & HG-125 W & $\mathrm{NA}-70 \mathrm{~W}$ & & 126 & \\
\hline $\mathrm{T}-2$ & $\mathrm{HG}-175 \mathrm{~W}$ & $\mathrm{NA}-100 \mathrm{~W}$ & & 50 & \\
\hline $\mathrm{T}-3$ & $\mathrm{HG}-175 \mathrm{~W}$ & NA- $150 \mathrm{~W}$ & & -5 & \\
\hline $\mathrm{T}-4$ & HGG-250 W & $\mathrm{NA}-150 \mathrm{~W}$ & & $+\infty$ & \\
\hline T. 5 & HG-400 W & $\mathrm{NA}-250 \mathrm{~W}$ & & 502 & \\
\hline T-6 & MS- $160 \mathrm{~W}$ & $\mathrm{~N} A-50 \mathrm{~W}$ & & 111 & \\
\hline
\end{tabular}


FIGURA 4.3: FLUXOS DE CAIXA PARA TROCA (T-1) HG-125 W POR NA-70 $\mathrm{w}$

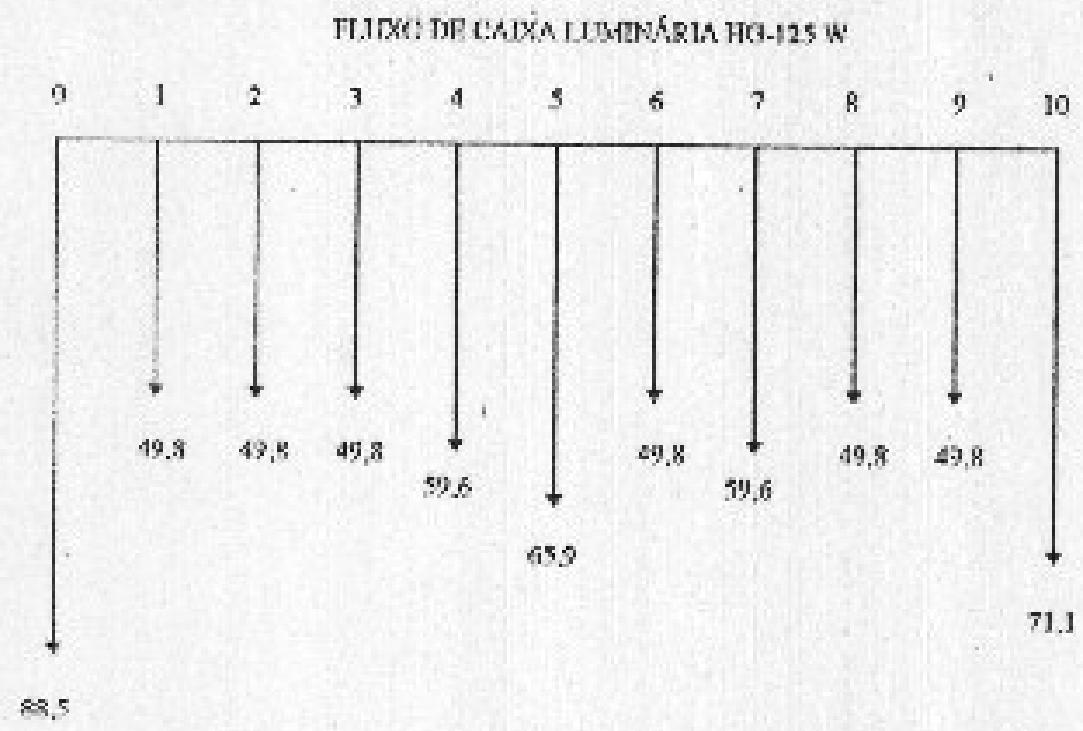

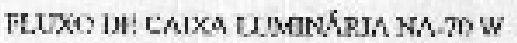

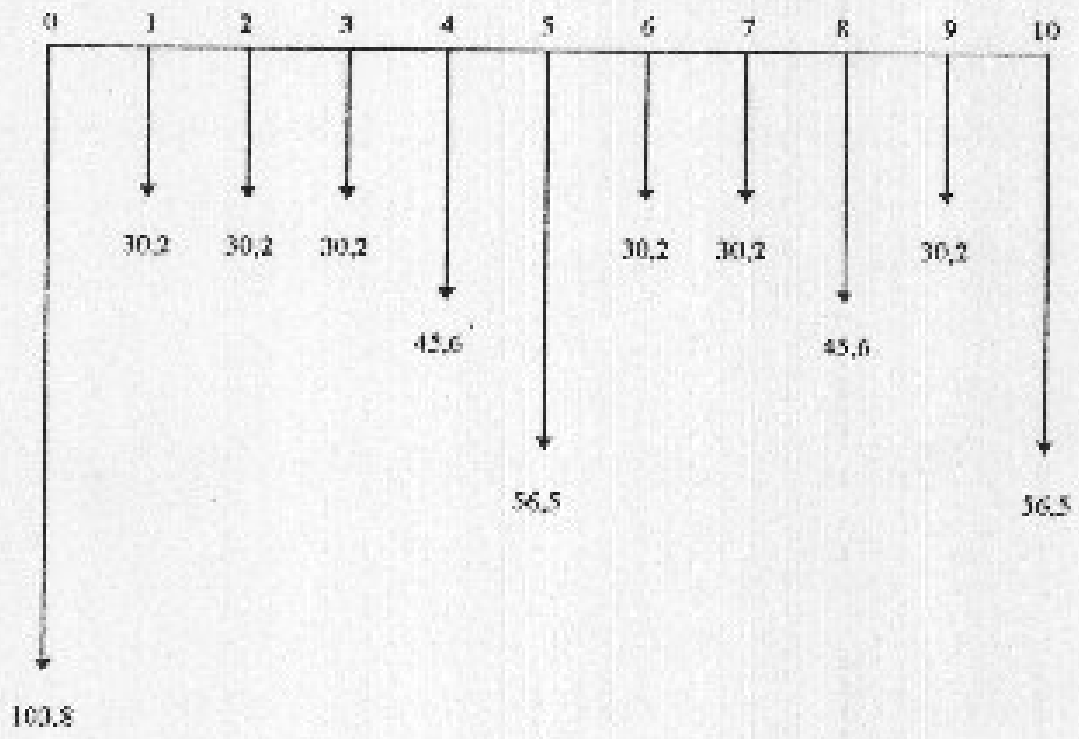

\subsubsection{CUSTO DE ENERGLA CONSERVADA (CEC)}

O Custo de Encrgin Conservada (CEC) é comparsda com o custo de energía produzida na géração; ueste estudo de caso, o preço marginal médio de energia ao nivel de rede secundátio (o preço também é igual para IP') é 83 USSMMWh (dado expresso no item 4.1.2.). 
Observa-se 123 TABELA 4.9 que todos os valores de CFC sằ menores do que 83 USS/MWh, exceção da alternativa T-3. Isto quer dizer que nas altemativas T-1, T-2, T4, T-5 e T-6, o custo de couservar energia é mais barato que gerar.

A seguir, o ordenamento das alternativas de troca segundo sen beneficio econtomico do CEC: T-4, T-5, T-6, T-1 e T-2. O ordenamento assinalado deveria ser aquele implementado sa troca de luminárias do programa de uso eficiente de entergia; não obstante, no seguiate capitulo (Capítulo V) determina-se com exatidão este requerimento.

$A$ altermativa $\mathrm{T}-2$ apresentn alto valor do CEC (US\$/MWh 25,6 ), porém é menor do que 0 custo marginal.

O sinal negativo das allemativas $\mathrm{T}-4$ e T-5, deve-se ao preço meuor do investimento inicial da tecuologin eficiente em relaçăo a sua correspondente convćaciovial, ou seja sua implementação é por đemais lógica e necessita de pouck análise.

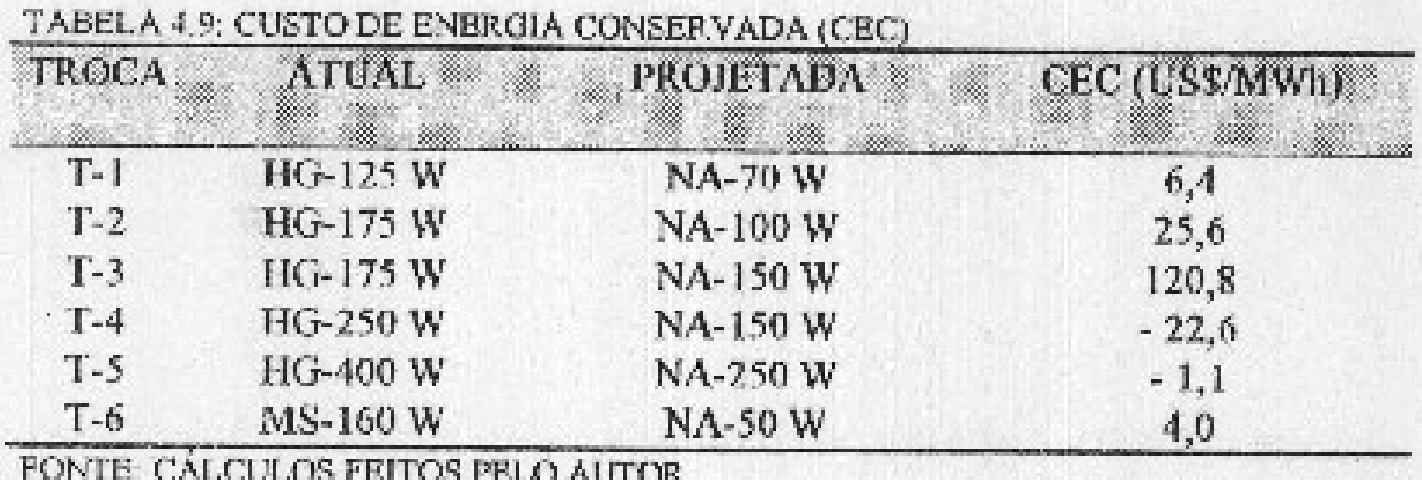

\subsubsection{CUSTO DA POTENNCIA CONSERVADA (CPC)}

O Custo ta Potência Conservada (CPC) nāo se encontra, normalmente, nas figuras de mérito; no enianto, t́ importante tê-lo presentc na análise. $O$ cálculo é fieito pela relaçåo entre o acréscino de custo por mudar de tecnologia, e a sobra de potêacia. 
Observa-se na TABELA 4.10 os valores do $\mathrm{CPC}$; a ordem segundo a sua eficiência é $\mathrm{T}$ 4, T-5, T-6 e T-1, que concorrem favoravelmente com os custos unitarios em investimento para construção de usimas elétricis no Equador (o menor valor do Plano de Equipamento do SNI -ver TABELA 2,4, Capitulo II- es 398 USS:kW para a usina de gás natural de $30 \mathrm{MW}$ ). T-2 compete com usinas térnicas a gás e serão outras figuras de mérito as decisorias. T-3 não concorte com uenhuma das usinas.

Na TABELA 3.5 (Capitulo III) apresentou-se o custo marginal de potência ao nível de rede secundária (o valor é igual para IP), cujo valor é 235,2 USS $\mathrm{kW}$-ano, todos os valores de CPC-ANUALIZADO e apresentados na TABELA 4.10 sāo menores que o custo marginal exceto T-3; portanto, essas aiteruativas concorrem com o custo marginal. inclusive $\mathrm{T}-2$ que antes era superior no CPC.

TABELA 4.10: CUSTO DE POTÉNCLA CONSERVADA (CPC)

\begin{tabular}{|c|c|c|c|c|}
\hline TROCA & ATUAL & PROIETADA & $\begin{array}{l}\text { CPC - ANUAL } \\
\text { (US\$ } \mathrm{kW} \text {-ano) }\end{array}$ & $\begin{array}{c}\mathrm{CPC} \\
\text { (US\$RW) }\end{array}$ \\
\hline T-1 & $\mathrm{HG}-125 \mathrm{~W}$ & $\mathrm{NA}-70 \mathrm{~W}$ & 28 & 159 \\
\hline T-2 & $\mathrm{HG}-175 \mathrm{~W}$ & $\mathrm{NA}-100 \mathrm{~W}$ & 112 & 634 \\
\hline$T-3$ & HG- $175 \mathrm{~W}$ & $\mathrm{NA}-150 \mathrm{~W}$ & 529 & 2,988 \\
\hline$T-4$ & $\mathrm{HG}-250 \mathrm{~W}$ & $\mathrm{NA} \cdot 150 \mathrm{~W}$ & -99 & -558 \\
\hline$T-5$ & $\mathrm{HG} \cdot 400 \mathrm{~W}$ & $\mathrm{NA}-250 \mathrm{~W}$ & -5 & -27 \\
\hline$T-6$ & $\mathrm{MS}-160 \mathrm{~W}$ & NA-50 W & 18 & 100 \\
\hline
\end{tabular}

\subsubsection{CUSTO DURANTE A VIDA (CDV)}

O Custo Durante a Vida (CDV) segundo foi definido como o custo total em valor prescnte devido à despesa em investimento inicial, operação, manutenção, instalą̧ão e consumo de energia: portanto, pode-se comparar a sua eficiẻncia entre duas alternativas, pela relaçào expressa em porcentagem:

$$
\% \text { eficiencia }=\frac{\text { CDV convencional }- \text { CDV eficiente }}{\text { CDV convencional }}
$$


Os valores de CDV correspondem ao período da análise de 10 anos e foram obtidos do cálculo do ANEXO D.

Na TABELA 4.11 observa-se as "eficiências" calculadas, das quais a maior porcentagem e $44 \%$ na alternativa T-6; isto indica que cla é a melhor alternativa porque de USS 436 para a luminána MS-160 W diminui até USS 244 para a luminária NA-50 W. 0 ganho pelo uso de tecnologia eficiente em valores absulutos ó USS 192 . Menor vantagem tem a alternativa T-3; isto se deve que o CDV convencional (HG-175 W) de USS 513 é menor que o CDV eficiente (NA-150 W) de USS 530; portanto, esta alternativa tăo d recomendável. Analisando a alternativa T-2, a tecnologia convencional custa US\$ 513 e sua correspondente eficiente US\$ 409 , obtendo vantagem expressa em porventagem de $20 \%$ e em valores ahsolutos de US\$ 104. As alternativas T-1, T-2, T-4 e T-5 rêm porcentigens semulhantes, sendo a média $26 \%$; no entanto há diferença nos valores absolutos. Os ganhos em valores absolutos das alternativas T-1 e T-2 são similares, ao contrario de outras alternativas que sino diferentes.

Sob esta figura de mérito, conclui-se que as alternativas T-1, T-2, T-4, T-5 e T-6 sāo recomendáveis para implemeutaçāo.

TABELA 4.11: CUSTO DLRAVTE A VTDA (CDV)

\begin{tabular}{|c|c|c|c|c|c|c|}
\hline \multirow[t]{2}{*}{ Trocs } & \multicolumn{2}{|c|}{ ATCW } & \multicolumn{2}{|c|}{ PROJITAI) } & \multirow{2}{*}{ \% eficiürac } & \multirow{2}{*}{$\begin{array}{c}\text { CDFona-covefie } \\
\text { cuss }\end{array}$} \\
\hline & corokio & $\begin{array}{c}\text { C15Nari } \\
\text { (105) }\end{array}$ & Cobroo & $\begin{array}{c}\text { LDV uis } \\
\text { (USS) }\end{array}$ & & \\
\hline$T-1$ & HG-125 w & 396 & NA-70 W & 294 & 26 & 102 \\
\hline$T-2$ & $11 \mathrm{G}-175 \mathrm{~W}$ & $5: 3$ & Nh.100 w & 409 & 20 & $10-1$ \\
\hline$T-3$ & $170.175 W$ & $5: 3$ & She150\% & $53: 1$ & -3 & -17 \\
\hline$T-4$ & Iti. $2512 \mathrm{~W}$ & 281 & Nh-15n' & 530 & 32 & 251 \\
\hline $\mathrm{T}-5$ & $H \mathrm{r} i \rightarrow 00 \mathrm{~W}$ & 1.135 & $\mathrm{NA}-250 \mathrm{~B}$ & $\$ 23$ & 27 & 312 \\
\hline $1-6$ & $\mathrm{MS}-160 \mathrm{~W}$ & 436 & NA-50W & 244 & 44 & $1 \%$ \\
\hline
\end{tabular}

NOTA: O valor de CDV corresponde às despesas (investimento inicial, operaçäo, manutençäo e instalıçāo) diarante o periodo da análise de 10 ancs.

Os valores obtidos no cáleulo de CDV estăo ilustrados na FIGURA 4.4, tanto para tecnologia convencional quanto para eficiente.

Na FIGURA 4.4, observa-se o comportamento parabólico dos custos no que se refere as

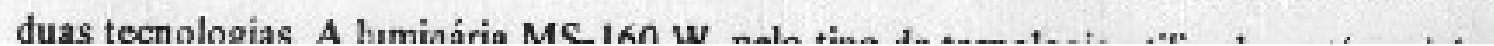


e não tem comparaçāo (no Equador usa-se tecnologia de hz mista só em potência de $160 \mathrm{~W})$.

\section{FIGURA 4.4: CLSTO DURANTE A VIDA (CDV) POR TIPO DE LUMINÁRIA}

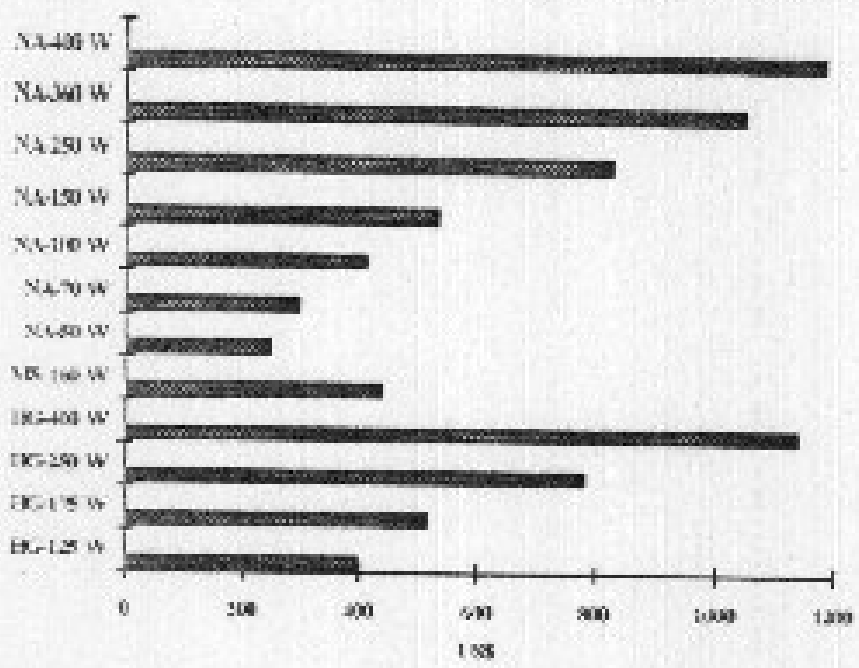

\subsubsection{CUSTO DURANTE A VIDA ANUALIZADO (CDVA)}

O Custo Durante a Vida Anualizado (CDVA) proporciona parâmetros de comparaçăo para equipamentos quando as suas vidas úteis sào diferentes e além disso para análises feitas para periodos diferentes. Neste estudo de caso, o periodo de análise das alternativas é 10 anos, entìo, o valor CDVA é diretamente proporcional ao valor CDV do ponto anterior; portanto, as conclusōes são as exatamente iguais.

Na TABEI.A 4.I2 apresenta-se os resultados da comparação entre tecnologias, onde a "eficiència" é expressa em porcentagem, assim também a diferença de CDVA em valor absoluto.

TARELA 4.12: CUSTO DURANTE A VIDA ANUALIZADO (CDVA)

\begin{tabular}{|c|c|c|c|c|c|c|}
\hline \multirow[t]{2}{*}{$\mathrm{ROCA}$} & \multicolumn{2}{|c|}{ ATtWL } & \multicolumn{2}{|c|}{ PRODETADA } & \multirow[t]{2}{*}{ * tficidocia } & \multirow{2}{*}{$\begin{array}{l}\text { CDVAami - } \\
\text { CI)vadie } \\
\text { (U55) }\end{array}$} \\
\hline & CODLIG & $\begin{array}{l}\text { CDVA arav } \\
\text { (NSS) }\end{array}$ & CXIDOO & $\begin{array}{l}\text { CIWVA iffe } \\
\text { (IXs) }\end{array}$ & & \\
\hline $\mathrm{T} \cdot \mathrm{I}$ & HICi-125 W & 70 & $\mathrm{NA}-70 \mathrm{~W}$ & st & 26 & 18 \\
\hline$T \cdot 2$ & $\mathrm{HG}-175 \mathrm{~W}$ & פI & NA-1 $100 \mathrm{~W}$ & 72 & 21 & 19 \\
\hline $\mathrm{T}-3$ & $\pi G-175 \mathrm{~W}$ & 91 & NA-ISO W & 24 & -3 & -3 \\
\hline $\begin{array}{l}\text { I. } 4 \\
\text { T: }\end{array}$ & $\mathrm{H}(\mathrm{i}-250 \mathrm{~W}$ & $\begin{array}{l}138 \\
-n .\end{array}$ & NA $150 \mathrm{~W}$ & 94 & 32 & +4 \\
\hline
\end{tabular}


Segundo foi dito, a FIGURA 4.5 confirma a proporcionalidade dos valores CDV e CDVA, o fator responsaivel desta proporcionalidade é o $\operatorname{FRC}(12 \%, 10 \mathrm{a})(0,177)$.

\section{FIGURA 4.5: CUSTO DLRANTE A VIDA ANUALIZADO (CDVA) POR TIPO DE LUMINARIA}

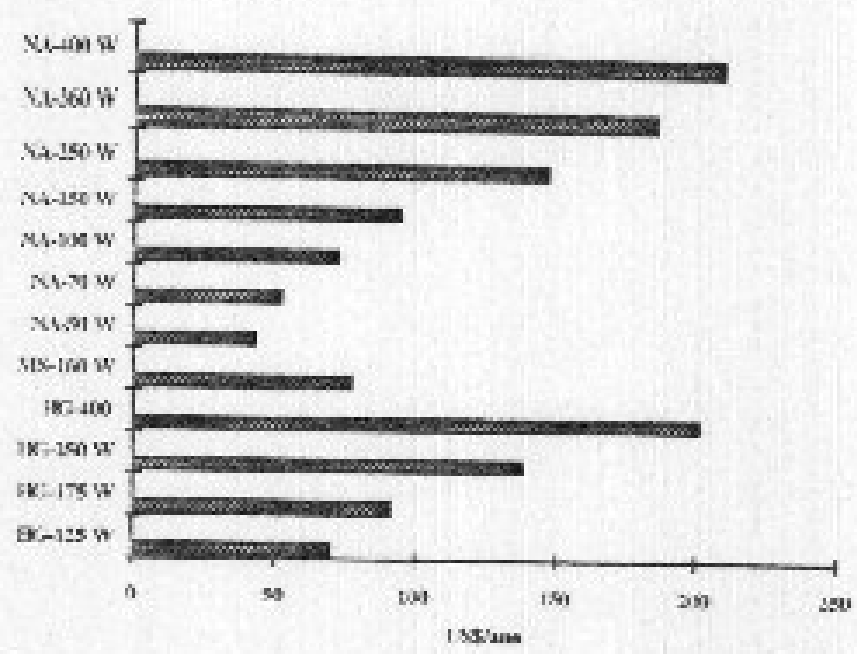

\subsubsection{CUSTO DURANTE A VIDA ANUALIZADO NÃO ENERGÉTICO (CDVINE)}

O valor de CDVANE representa o custo total anualizado da luminária exceto o custo pelo consumo de energia elétrica; isto ć, custo do investimento inicial, operaçāo, manutençã̀o e instalaçà̃o.

Na TABELA 4. 13 pode-se observar os valores de CDVANE expresso em porcentagents, segundo a definiçāo enunciada na förmula (4.10). Aqueles valores com indicaçăo negativa, assimalam que o custo da tecnologia convencional é menor à tecnologia eficiente; sucesso contrario ao indicado na TABELA 4.11. Esta caracteristica deve-se ao alto custo de investimento inicial da tecnologia eficiente (luminária de vapor te sódio); năo obstante, o scu custo operacional é baixo.

Dentro dos resultados obtidos, T-4 e T-5 têm "eficiência" cotn indicaçẫo positiva, portanto o custo da fecnologia convencional é maior a tecnologia eficiente. 
Baseados nas porcentagens de T-1, T-2, T-3 e T-6, conchi-se que sem considerar o custo de consumo de energia, a tecuologia eticiente é mis cara que a tecnologia couvencional numa porcentagem de $19 \%$, sobre tudo pelos altos custos do investimento inicial.

\begin{tabular}{|c|c|c|c|c|c|c|}
\hline \multirow[t]{2}{*}{ IROCA } & \multicolumn{2}{|c|}{ ACIAL } & \multicolumn{2}{|c|}{ ROEIADA } & \multirow[t]{2}{*}{ S. ficuncia } & \multirow{2}{*}{$\begin{array}{c}\text { CDWANE an: } \\
\text { CDWMNE orie } \\
\text { ussi }\end{array}$} \\
\hline & Critco & $\begin{array}{l}\text { GJVANE CEN } \\
\text { USS }\end{array}$ & CODIG) & $\begin{array}{c}\text { CDVNWt die } \\
\text { (CSS) }\end{array}$ & & \\
\hline T.t & $H(1-125 \%$ & 203 & $N=-70 w$ & 21,8 & -7 & -1.2 \\
\hline $\mathrm{T} 2$ & HC-175W & $221)$ & Nateo w & 30,2 & -37 & $-k 2$ \\
\hline $1-3$ & $\mathrm{HO}-175 \mathrm{~W}$ & 22,10 & Nh.150: & 32,1 & -46 & $-10,1$ \\
\hline$T^{1-4}$ & $110-250 \mathrm{~W}$ & 41,5 & $\mathrm{NA}-150 \mathrm{~W}$ & 52,1 & 23 & 9,4 \\
\hline T- & $716-100 \mathrm{~W}$ & 46.4 & $\mathrm{~N}-2 \operatorname{sen} \mathrm{W}$ & 45,7 & $z$ & 0.7 \\
\hline$I-6$ & $\mathrm{Ms}-160 \mathrm{~W}$ & 18.9 & $\mathrm{NA} .5 \mathrm{~W}$ & $2 n 7$ & .9 & 1,8 \\
\hline
\end{tabular}

A FIGURA 4.6 ilustra os valores calculados do CDVANE por tipo de luminária e observa-se mudança $\mathrm{em}$ relação às figuras anteriores. A característica parabólica antes observada agora mudou, embora forma-se grupos de dois ou trés luminárias de valores similares. Os custos das luminárias de vapor de sódio de $250 \mathrm{~W}, 360 \mathrm{~W}$ e $400 \mathrm{~W}$ estão perto e formam um grupo; de igual maneira as luminárias de vapor de sodio de $100 \mathrm{~W}$ e $150 \mathrm{~W}$ estão formando outro grapo, e assim a seguir. vapor de súdio de $50 \mathrm{~W}$ e $70 \mathrm{~W}$; vapor de mercúrio de $250 \mathrm{~W}$ e $400 \mathrm{~W}$; vapor de mercúrio de $125 \mathrm{~W}$ e $175 \mathrm{~W}$.

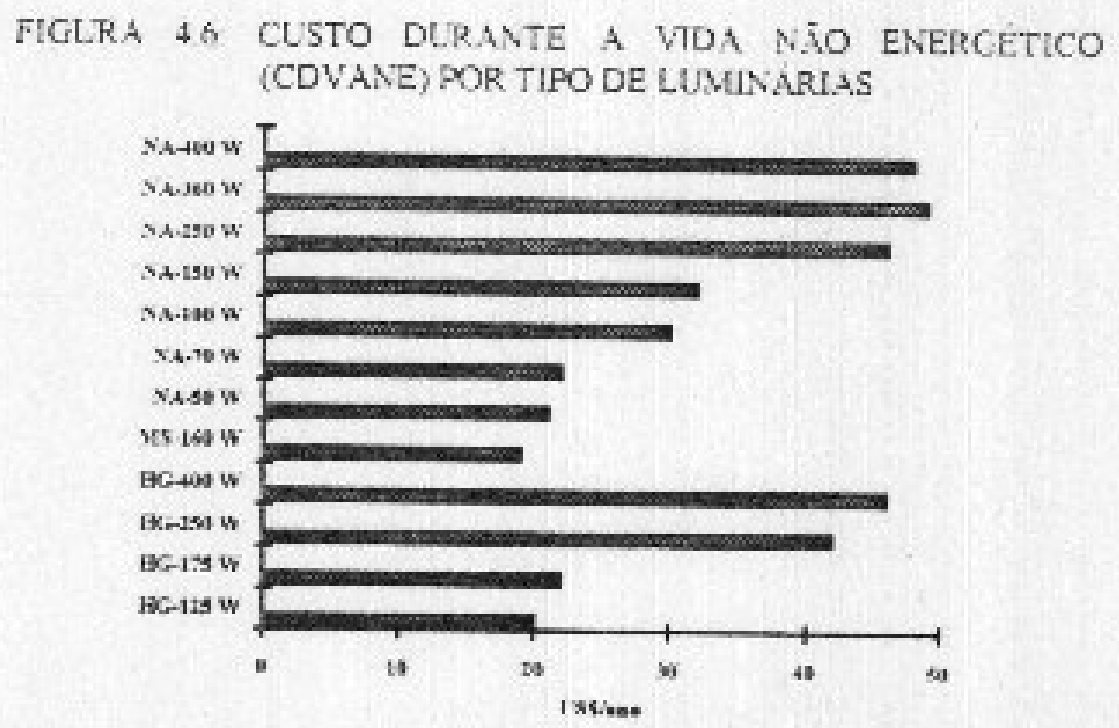




\section{3,8. CUSTO DO LÚMEN-HORA}

O custo do lúmen-hora foi calculado para todos os tipos de luminárias usadas no estudo de caso (usadas no Equador), sob as premissas indicadas anteriorneate. Os valores são os seguintes:

$\begin{array}{lc}\text { CODIGO } & \text { US\$N1m-h } \\ \text { HG-12S W } & 2,5 \\ \text { HG-17S W } & 2,4 \\ \text { HG-250 W } & 2,3 \\ \text { HG-400 W } & 2,0 \\ \text { MS-160 W } & 5,6 \\ \text { NA-50 W } & 2,8 \\ \text { NA-70 W } & 2,0 \\ \text { NA-100 W } & 1.7 \\ \text { NA- } 150 W & 1.6 \\ \text { NA-250 W } & 1.3 \\ \text { NA-360 W } & 1,2 \\ \text { NA-400W } & 1,0\end{array}$

Estes dados são ilustralos na FIGURA 4.7 onde observa-se um decréscimo quase linear dos custos (exceto a luminária de luz mista de $160 \mathrm{~W}$ ) enquanto produz-se melhoria da tecnologia e aumento de potencia na luminária. Assim, o fluxo luninoso emitido pela luminária de vapor de sódio de $400 \mathrm{~W}$ é mais barata que todas as analisadlas.

FIGLRA 47 : CISTO DO LIMEN-HORA POR TIPO DE LLMINARIAS

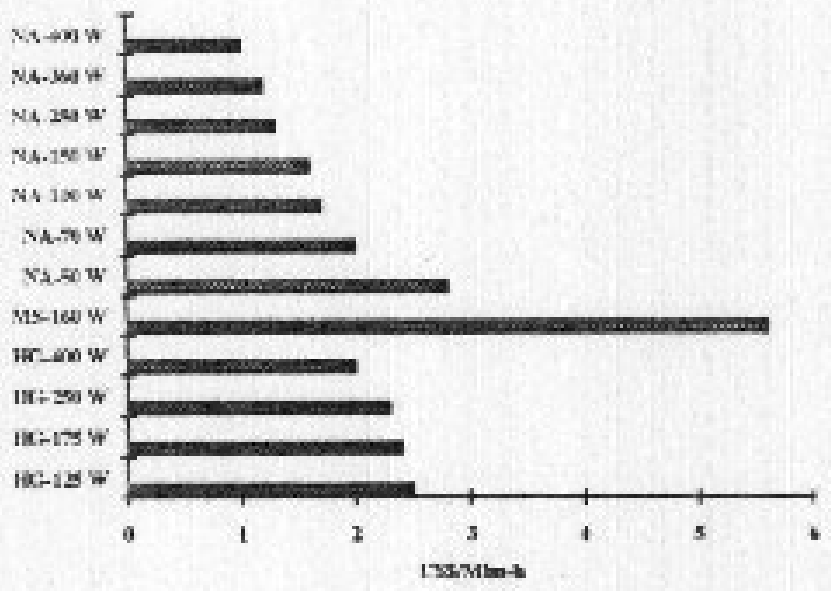


lâmpada incandescente tem custo dúmen-hora em 15 US\$/Mlm-h (para funcionamento superior a 3 horas diárias), a lumisờia fluorescente convencional 9,8 USS/Mim-h (com 6 horas diárias de funcionamento), brinária fluorescente compacta 8,5 US\$MMm-h (com 14 horas diárias de funcionamento $A$ taxa de desconto usada pelos autores do artigo foi $12 \%$, as premissas foram aplicadassa fömula 4.9 (Cauvilla e Sauer, 1992).

Contudo, os custos do lumen-hosepara luminárias de vapor de mercúrio usadas em IP curn 12 horas diárias de funcionanento mostram uma média de 2,3 USS MMlm-h, e para vapor de sódio de 1,7 US\$/Mlm-k Só a luminária de luz mista está muito longe destes valores com 5,6 US\$/Mm-h.

Analisando os dados de custo lúien-hora, conclui-se que a tecnologia de sódio é mais barata em $29 \%$ do que a tecnolọ de mercúrio. No entanto, a seguir spresenta-se a vantagem expressa em porcentagen, da tecnologia eficiente sobre a convencional para cada alternativa de troca propostaser TABELA 4.14).

\begin{tabular}{|c|c|c|c|}
\hline TROCA & ATUAL & PROJETADA & $\begin{array}{l}\text { US\$:Mlm-h (conv'efic) } \\
(\%)\end{array}$ \\
\hline$T-1$ & $\mathrm{HG}-125 \mathrm{~W}$ & NA.70 W & 20 \\
\hline $\mathrm{T}-2$ & HG-175 W & NA-100 W & 29 \\
\hline$T-3$ & $\mathrm{HG}-175 \mathrm{~W}$ & NA- $150 \mathrm{~W}$ & 33 \\
\hline $\mathrm{T}-4$ & $11 \mathrm{G}-250 \mathrm{~W}$ & NA- $150 \mathrm{~W}$ & 30 \\
\hline T-S & HIG-400 W & NA-250 W & 34 \\
\hline $\mathrm{T}-6$ & MS- $160 \mathrm{~W}$ & NA-50 W & 50 \\
\hline
\end{tabular}

Analisando a TABELA 4, 14, obsesa-se que T- 6 tem a maior porcentagem $50 \%$ devido fundamentalmente à alta eficiênć na melhoria proposta, o custo do lúmen-hora na luminária MS- $160 \mathrm{~W}$ ó 5,6 US\$/7m-h frente à luminária NA-50 W cujo custo è 2,8 US\$MMlm-h. A alteruativa T-1 tm o menor valor da tabelı, a sua explicaçăo fica contrária a T-6; năo obstante, é boalternativa considerando-se outras figuras de mérito.

A figura de merito do lúmen-hos năo é usada fundamentalmente para determinar a conveniència de alternativas de tach, mas seu uso esta restrito em proporcionar uma 
ideia de grandeza dos custos totais (investimento, operação, manutenção e consumo de energia) por unidade de fluxo luminoso.

Um parìmetro importante no cálculo do custo himen-hora (US\$IMlm-h) é o tempo de uso diário da luminiria; no entanto, neste estudo de caso o valor é fixo e igual a 12 horas diárias. Existe também outro parâmetro importante tal como a taxa de desconto ( $12 \%$ para o estudo de caso).

\subsection{ANÁIISE DE SENSIBILIDADE}

\subsubsection{PRECO DA ELETRICIDADE}

Segundo foi dito anteriormente (no Capitulo III, item 3.2), o escopo do INECEL o subir as tarifas de energia elétrica em todos os níveis de consumo. O INECEL subiria as tarifas às concessionárias e estas por sua vez ìs repassariam aos usuários, segundo o planejado oo "Plan Maestro de Electrificaciono..3n?

O preço médio de energia elétrica vendido pelo INECEL em 1995 is concessionárias foi 46 USS/MWh, e das concessionárias repassado aos usuários 64 USS/MWh; no entanto, o custo marginal situa-se em 83 US\$/MWh; assim também, segundo o planejado os preços médios em 1996 subirão a 56 USS/MWh e 76 US\$/MWh respectivamente no ano 1996, perto do custo marginal.

Todas as concessionárias do Equador faturam o consumo em IP no preço de 52 US\$ $/ \mathrm{MWh}^{21}$ (a partir de maio 1993).

Sob estes antecedentes, é necessário fazer uma análise de sensibilidade para determinar a conveniência dos programas de conservaçào de energia a partir de várias óticas segundo os preços de energia apresentados. Portanto, usou-se as principais figuras de mérito na

${ }^{23}$ Os jornais do Equador dَ̄o um 
análise de sensibilidade, formando uma faixa de variação de preços entre 40 e 100 US\$MWh.

As figuras de mérito usadas na simulaçăo de sensibilidade foram TSR, TIR, CEC, lúmenhora.

Observa-se na FIGURA 4.8, o TSR será metor para altos preços da tarifa de energia elétrica. O valor de TSR mantém-se alto para preços baixos de energia, isto é o investimento inicial será recuperado em muitos anos; sob csta ótica o caso da alternativa T-3 é eritico no regime de 40 USS MWh.

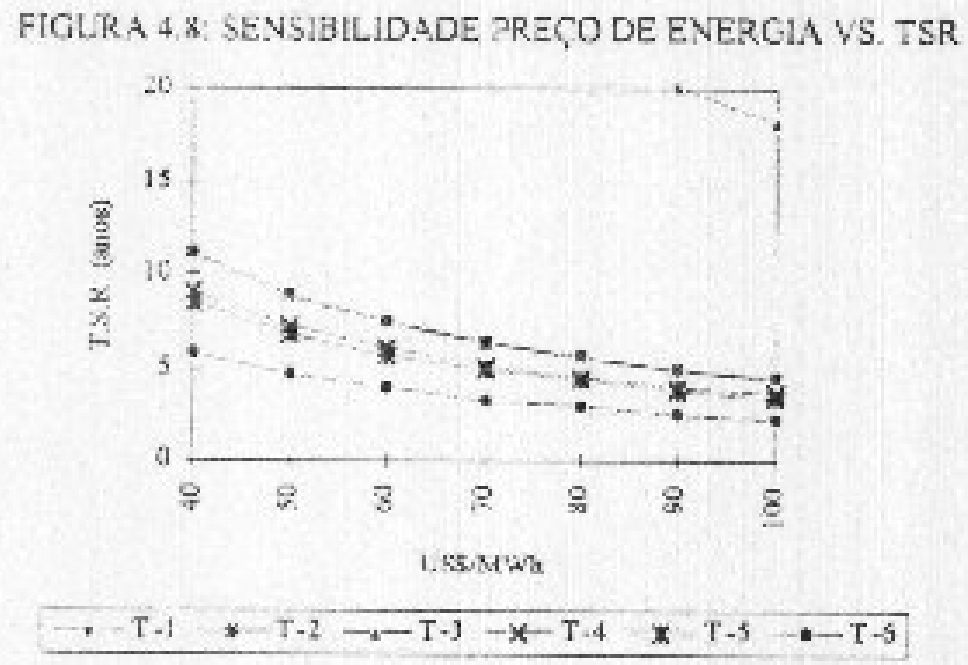

Analisando a sensibilidade do preço vs. TIR (ver FIGURA 4.9), as alternativas de troca T-I, T-2, T-4, T-5 e T-6 tèm valores de TIR maiores que a taxa de desconto (12\%) para qualquer regime dentro da faixa de análise; porém para preços de eletricidade maiores as alternativas de troca continuariam sendo melhores. Portanto, couclui-se a conveniência do programa de uso eficiente de energia em todas as alternativas -exceto T-3garantindo-se bom resultado econômico para qualquer regime de preços de energia elétrica situados dentro da faixa indicada. 
FIGURA 4.9: SENSIBIL.IDADE PREÇO DE ENERGIA VS.TIR

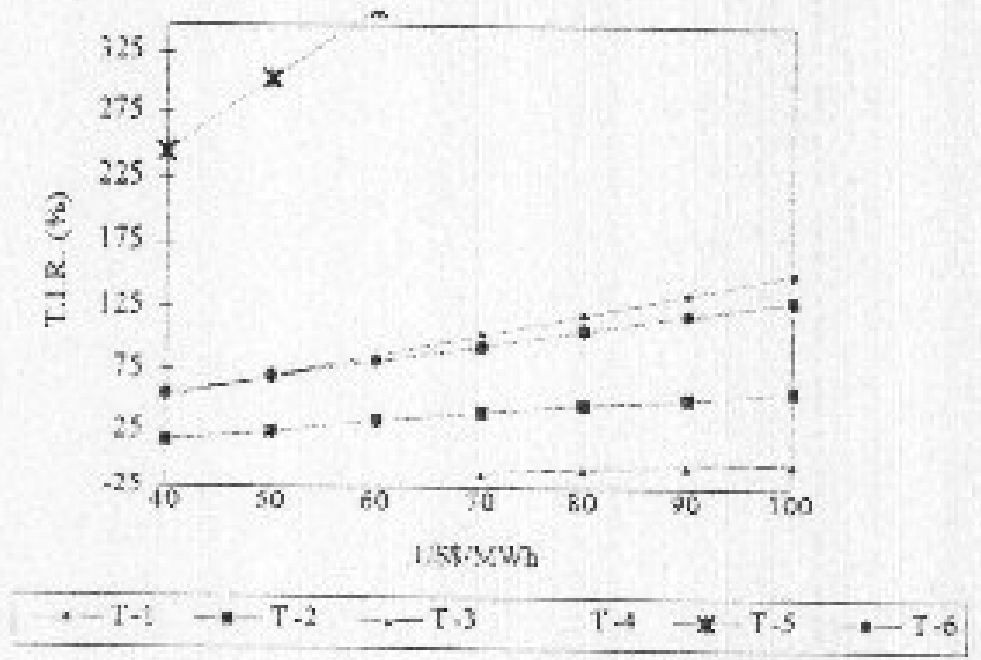

Analisando a serı sibilidade preço de energia vs. CEC, observa-se (ver FICIURA 4.10) que os valores para cada uma das altemativas șo consiantes, independentes do preço da energia. Us valores de T-1, T-2, T-4, T-5 e T-6 estäo enubaixo do preço marginal médio, só T-3 está sobre o preço marginal. T-3 estí maior do que o valor padrāo e portanto esta altemativa será eliminada dos programas segundo já foi dito. T-4 e $1-5$ são altemativas convenientes em toula a faixa, além disso sãu programas hans do pouto de vista de conservaçào de energia pelo reduzido valor do CEC. T-6, T-1 e T-2 nesta ordem sào convenientes, portanto encontram-se dentre as perspectivas de conservaçào de cnergia e è recomendável sua aplicaçào.

A conclusào teste item é que o preço da entergia nāo influi no valor CEC.

FIGURA 4.10: SENSIBILIDADE PRECO DE ENERGIA VS CEC $118 \times 56$

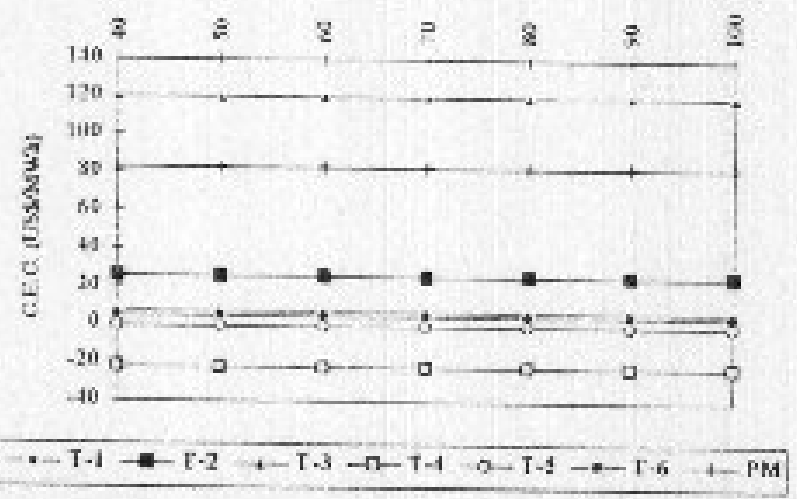


Da mesma maneira, com o objetivo de comparat as alternativas baseadas nos fluxos luminosos, estabeleceu-se porcentagens de relaçăo entre tecuologias convencionais e eficientes. A conclusão foi que com actéscimos do preço de energia, tambèm há acréscimos nas porcentagens de fluxo, isto é, quando o preço cresce o beneficio ainda é maior (ver FIGURA 4.11).

As altemativas T-3, T-4 e T-5 tèm curvas semellhantes; as altemativas T-1 e T-2, estāo em baixo, com vantagens menores. A alternativa T-6 situa-se acima e encuntra-se com meihores vautagens.

\section{FIOLRA 4.11: SENSIBLLIDADE FREÇO DE ENERGIA VS. \% FLUXO LUMINOSO}

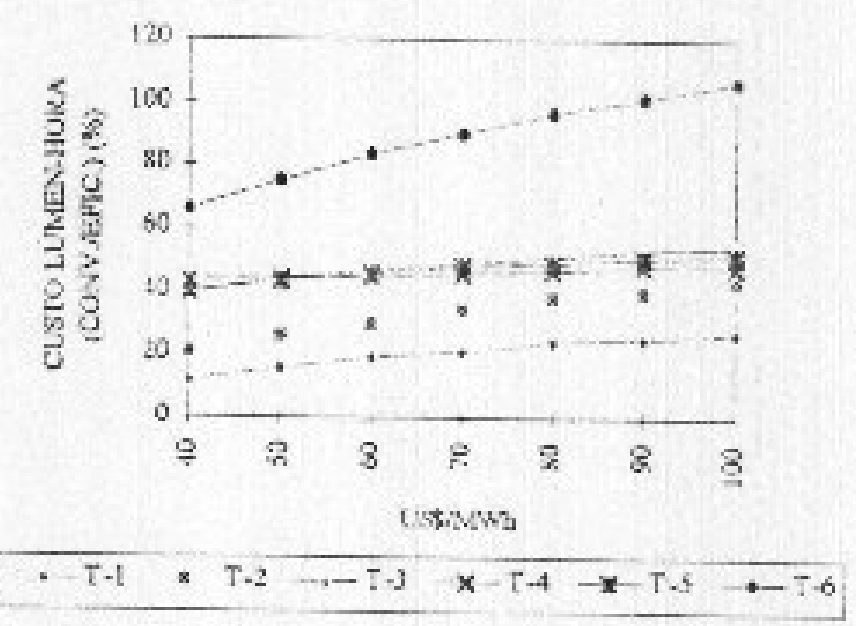

\subsubsection{HORAS DE FUNCIONAMENTO}

Segundo foi expresso cm irens anteriores o tempo de funcionamento do sistema de IP do Equador é aproximadamente 12 horas diárias, porém, em funçào da estaçầo (invemo ou verăo) este valor pode diminuir para 11,5 horas diárias. Outro fator que pode produzir variaçăo no tempo de funcionamento é a regulaçăo do aparelho para cuntrole automático ("cèlula fotvelétrica"); não obstante, dita variaçăo será de poucos minutos no acendimento ou desligamento.

As concessionárias do Equador usam dois sistemas nara n controle do [D. . A 
Com o objetivo de determinar as alteraçōes nas figuras de mérito quando produz-se variaçào do tempo de funcionamento das luminárias, faz-se uma análise de seusibilidade.

A seguir apresenta-se a FIGUIRA 4.12 resultado da análise de sensibilidade entre horas de funcionamento (entre 10 e 13 horas) vs. TSR. Observa-se pequenas variações de TSR para a faixa mais provavel de ovorrer ( 11,5 a 12,5 horasidia). Para tempos menores de funcionamentos o valor de TSR aureata.

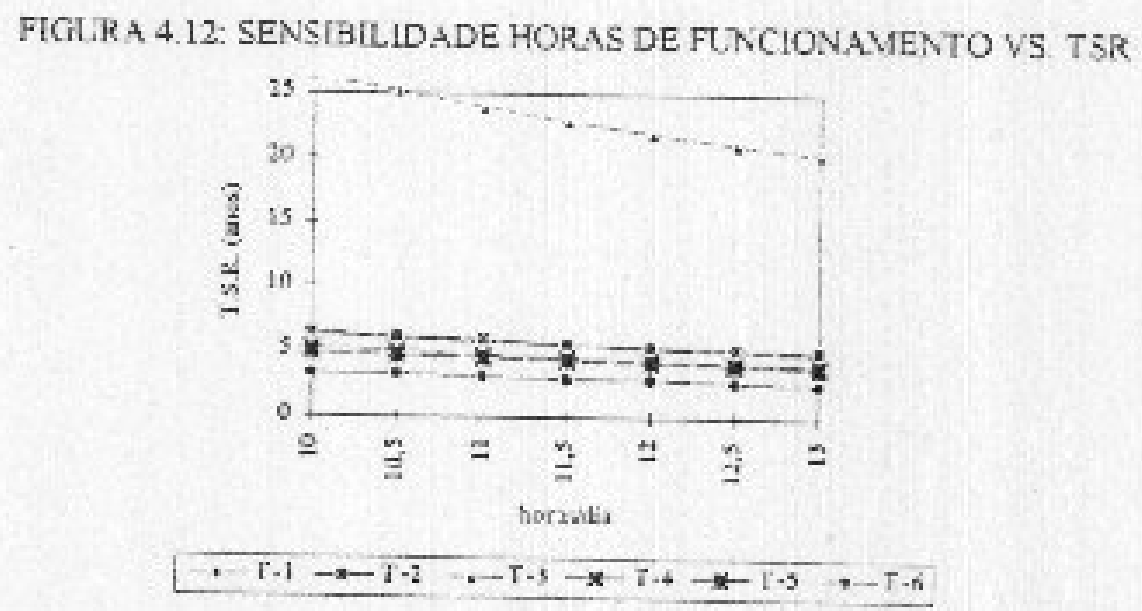

Na FIGURA 4.13 observa-se a tendência de aumentat a TIR cuquanto aumenta o tempo de funcionamento das lusninárias, porém em pequenas porcentagens, exceto T-5 que apresenta melhores vantagens.

FIGURA 4. 13: SENSIBILIDADE HORAS DE FUNCIONAMENTO VS. TTR

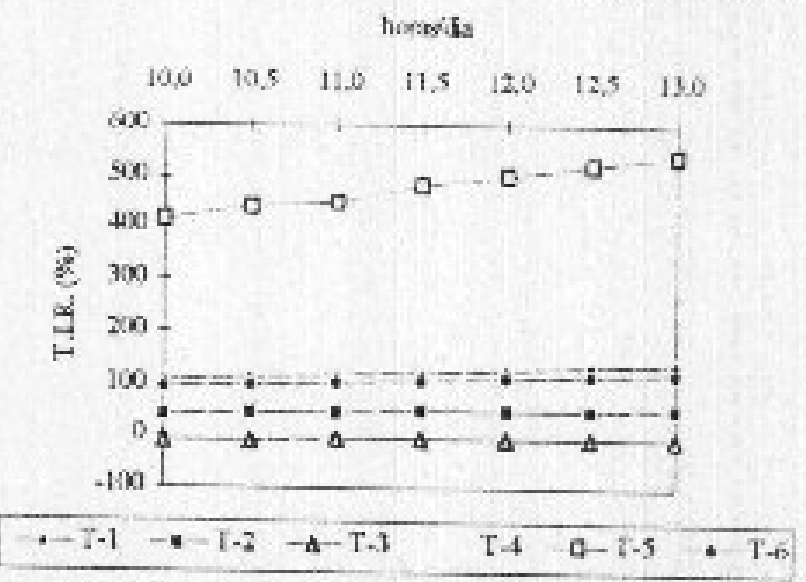


Na FIGURA 4.14 observa-se a tendência de se dirigir o CEC para o eixo " $x$ " enquanto produz-se aumento do tempo de funcionamento, ou seja a vantagem é maior para mais horas de funcionamento. T-3 mantem-se sempre sobre o custo marginal, entretanto as outras altemativas encontram-se perto do eixo " $x$ ".

FIGURA 4.14: SENSIBILIDADE HORAS DE FUNCIONAMENTO VS. CEC

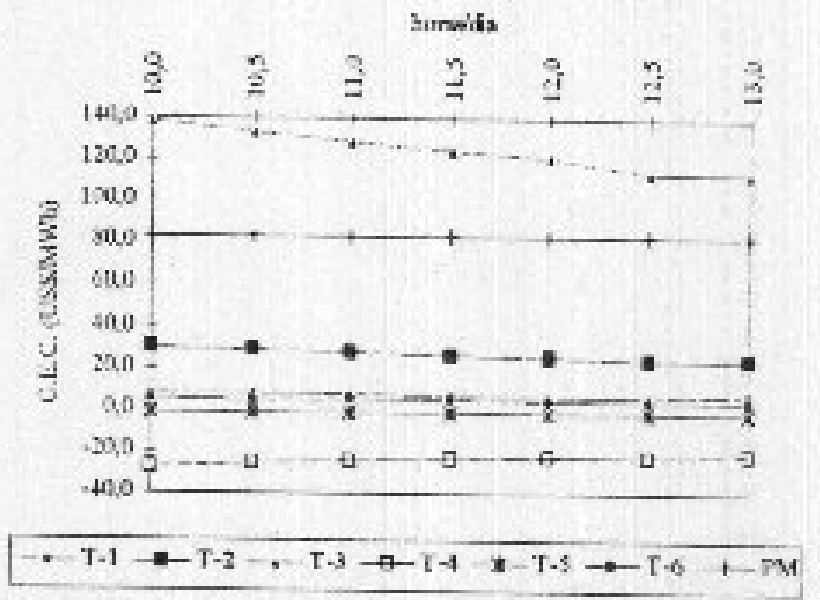

Fïnalmente, observa-se na FIGURA 4.15 a tendência de aumentas o valor de CPC enquanto aumenta o tempo de funcionamento. Estes aumcntos sâo pequenos especialmente ua faixa consideradá provável de ocorrer $\{11,5$ a 12,5 horasidia). Neste caso ha desvantagem com o aumento do tempo de fumcionamento.

FIGURA 4.15: SENSIBILIDADE HORAS DE FUNCIONAMENTO VS CPC

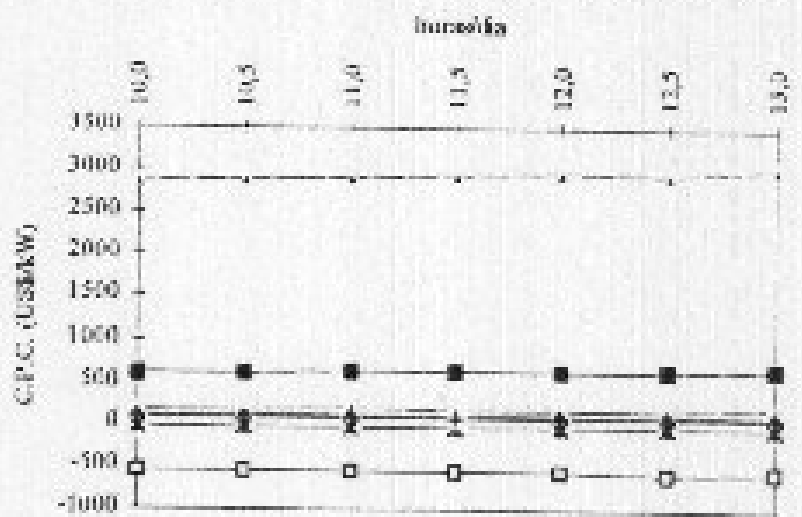

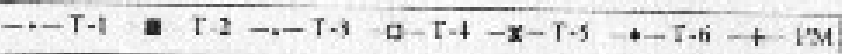


Concluindo este item, o tempo de funcionamento da IP na faixa provável de ocorrer, não afeta os resultados das figuras de mérito. Para 12 horas diárias de funcionamento a energia do sistema de IP foi calculada em 394 GWh/ano, considerando 11,5 horas diárias a energia diminui para $378 \mathrm{GWh} /$ ano, equivalente à diminuiçāo de $4 \%$.

\subsection{CONSERVACĊO DE ENERGIA MEDIANTE REDUÇÄO DE TENSÃO}

Ocorre que, embora os niveis de iluminamento recomendados para os liversos tipos de vias variem com os tráfegos de pedestres e veiculos, o sistema de IP equatoriano estabelece um nivel de iluminamento constante, desde o instante do seu acendimento até o seu apagamento. $O$ pior desta situação é que o dimensionamento é feito em funçào do tráfego mais intenso, Fato que é recomendável para as primeiras horas da noite mas que representa um desperdicio considerável para os periodos da madrugada.

Assim sendo, pode-se utilizar tal caracteristica, a fim de se propiciar uma economia de energia, sem prejuizos sociais, uma vez que é possivel através de equipamentos específicos, a obtenção de ajustes que permitam adequar os niveis de iluminação às necessidades, variando-os no decorrer da noite, bastando apenas dois ou très niveis de iluminação as longo de cada periodo noturno.

O equipamento enfocado tem a linalidade de propiciar as facilidades anteriormente expostas a custos competitivos e viáveis economicamente, e de forma suficientemente flexivel, permitir uma adequabilidade as necessidades, em funçāo dos recursos cnergéticos, atendendo assín aos requisitos de economia a cada época.

As luminárias utilizadas en IP apresentam características similares, no que diz respeito á potência consumida e huminosidade em relaçào à tensăo de alimentação. Assim, para tcnsōes nominais tẻm-se valores nominais de potência e fluxo luminoso em cada uma delas. Variando-sc as tensões, variam também, no mesmo sentido, a potência e o fluxo luminoso. A reduçāo da tensão de $15 \%$ provoca uma reduçăo no índice de iluminamento 
da tensāo de $25 \%$ provoca uma redução no indice de ifuminamento em $65 \%$, tendo-se uma redução de potência consumida de $50 \%$ (Moreira, 1989).

Assumindo instalado um aparcho de reduçăo de tensão, o nivel de tensão de fornecimento às làmpadis seria $100^{\circ}$ para o periodo na pouta pelo tempo de 3 horas diárias (18:30 às $21: 30$ ) e a reduçĩo de tensão $\mathrm{em} 15 \%$ para o período fora da ponta pelo tempo de 9 horas diárias ( $21: 30$ às 06:30), a seguir apresenta-se em detalhe os resultados do cálculo usando estas premissas (assume-se inicialmente I kW instalado em IP) (ver TABELA 4.15):

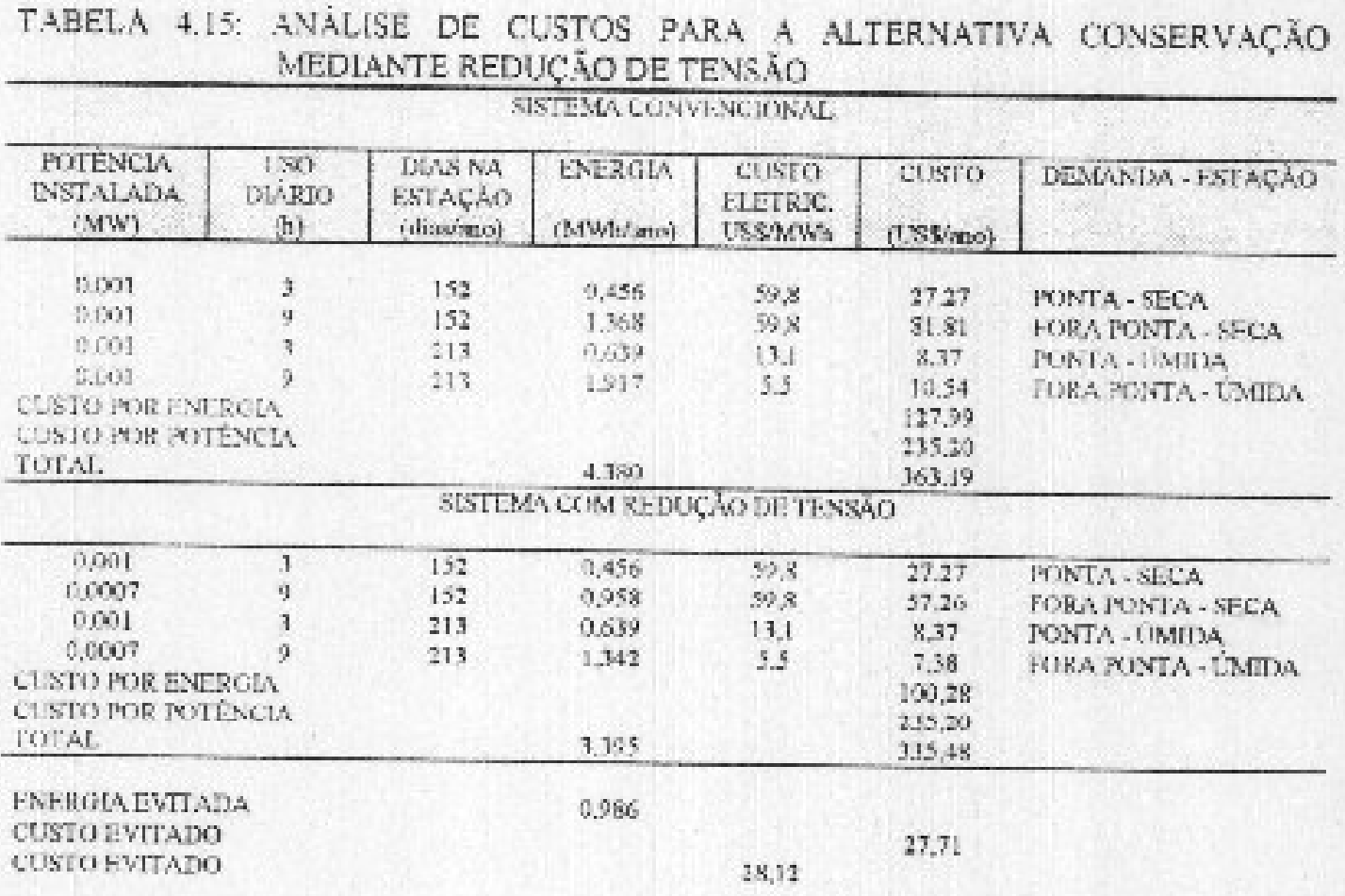

\footnotetext{
FONTE: Cálculos feitus pelo autor

NOTA: Os custos unitirios de eletricidade foram tomados da TABELA 3.5 do Capitulo III "Custos Marrginais de Longo Prazo para o Setor Elétrico Equatoriano" Assume-se 3 horas de fincionamento diário na ponta e 9 horas fora da ponta Assume-se que 5 meses (152 dias) por ano correspondem à estaçio seca e 7 meses (213 dias) por atto à cstaç̄ö ümida.

Assume-se tigado $1 \mathrm{~kW}$ de potência cm IP em condiçées normais (100\% da tenstio). Assume-se ligado $0.7 \mathrm{~kW}$ ( $30 \%$ de reduçäo) de potência em IP exn condiçöes de tensũo reduzida $(15 \%$ de reduç̦īo).
}

Analisando os resultados da TABELA 4.15, o custo da conta por consumo de energia diminui em $7 \%$, a potència diminui em $30 \%$, o consumo de entergia diminui em $22 \%$ e, 
couchui-se que o CEC da anva tecnologia basendo no preço do aparelho (para redução de tensāo) deveria ser igusl ou menor do que o "custo de cnergia evitada" de 28,1 US.̧̧MWh, para que o sistema seja economicamente víivel. Esta comparaçâo é féita devido que o aparelto ainda năo é comercializadu c portanto nสัo existe preço.

O aparelho que regula a tensão basicamente esta associado de um "timer" progıamável com um elemento redutor de tensĩo. O dispisitivo utiliza, como filosofia básica de funcionamento. \& reduçâo automática de sun tensãa de saida, após períodos predefinidos, estabelecidos a partir do instante de seu acionamento.

Havendo brixa luminosidade, o circuito é fechado e rencio plena aplionda, sobre o aparelho, proporcionamdo, internamente, a excitaçio do "timer programível" e a permissŭo, pelo circuito retutor de tensĩon, de saída de tensũo plena às lampadas (ver FIGIIRA 4, 16).

\section{FIGURA 4 16. ALTERNATIVA PARA CONSERVACุÃO DF. ENERGIA, VARIACAO DE TENSĀO}

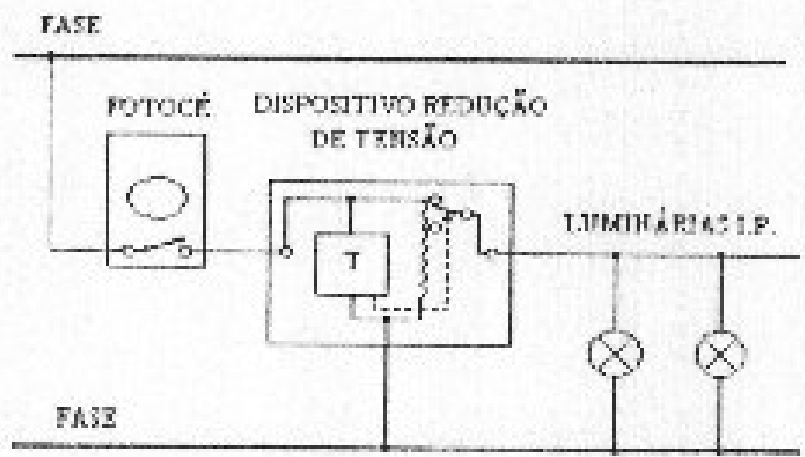

Após a extinção do tempo pró-ajustado no "Limer", há uma redução de tensāo de saída para ns lânp̣odas, havendo a partir deste instante, a redução tanto da luminosidade (a níveis aceitáveis\} quanto no consumo de energia na IP.

Há que ressalta que sendo o "tinner" programável, este ciclo de "lumirosidade normalihuminosidade redurida" poderá se efetuar em mais de uma vez, dando, entäo, flexibilidade operativa para a adequaçâo da luminocidade com us necssidades das várins lases da noite. 


\subsection{CONCLUSŌES}

No sistema elétrico equatoriano, as perdas técnicas ${ }^{23}$ de entergja elétrica $\mathrm{cm}$ toda a cadeia de transporte, da geração às redes de distribuição secundarias ou sistema de IP, são grandes e atingem $10,5 \%$. No Brasil o valor está próximo a $14 \%$, na maioria dos países da América Latina é de aproximadamente $20 \%$, e, de $7 \%$ nos paises deservolvidos Além disco, as perdas de potência no Equador pelo mestmo couceito para máxima demanda somam $15,9 \%$.

Camo o custo marginal de energia elétrica ao nivel de rede secundária é 83 US\$MWh, o escopo, do INECEL, para 1996 é elevar o preço de venda de cnergia aos usuários finais até 76 US\$MWh. Então. cntende-se que nos próximos anos este valor ainda crescerá até atingir o custo margirial,

Os preços dos equipamentos podem variar em moeda equatoriana "sucres" segundo o tipo de câmbio do dolar; no eatanto, os preços em dólares serào quase constantes pois a industria de produção de luminárias no Equador usa insumos importados.

As concessionarias do Equador devem realizar programas de tomada de dados dos sistemas de IP, com o objetivo de planejar a expansão de seus sistemas, a manutençăo e a operaçño. Algumas das concessionárias se esqueceram desta area de distribuiçaio e inclusive nāo tẻm conhecimento da quantidade de luminárias instaladas uos seus sistemas.

O Equador necessita de padrōes e regulamentaçōes para o desenvolvimento do setor elétrico, especialmente este estudo de caso, recomenda a expedição de padrōes para os sistemas de IP. $O$ úntico padrão existente pertence à E.E. Quito $S . \Lambda$, o qual foi elaborado no ano 1979 e ainda seu conteúdo fala das características dos sistemas de iluminação em forma geral. 
Todas as altemativas de troca propostas, a partir do ponto de vista técnico săo viáveis e além disso convenientes pela melhoria nos niveis de iluminação. Os niveis de huminancia e iluminância crescem em todas as alternativas, exceto na úlima $T-6$, onde se mantém iguais.

A experiência de troca obtida pela Empresa de Energia de Bogota demostra a viabilidade técnica -begundo os niveis luminosos- de usar luminárias NA-70 W em substituição de HG-125 W; no entanto, porleria ser trocada somente a lämpada de sodio de 70 W por mercúrio de $125 \mathrm{~W}$ (além do reator) enquanto o espayantuento entre postes seja menor do que $24 \mathrm{~m}$. Porém, analisando os valores calculados c apresentados na TABELA $4.5 \mathrm{com}$ os valores medidos na experięnecia, nota-se que existe diferença entre eles devido fundamentalmente às diferentes caracteristicas óticas de cada luminária, no entanto, as cunclusōes sobre a viabilidade de troca sào iguais tanto para o cálculo quanto para a experičncia. Sob csta premissa, as conclusöes fazem-se extensivas para as outras altemativas de troca.

O Fquador deveria realizar uma pesquisa de campo direcionada para obter valores de luminosidade reais para cada uma das alternativas, antes de empreender os programa de uso eficiente de energia, especialmente considerando as luminárias de maior penetraçào segundo as suas caracteristicas construtivas.

Usando as figuras de mérito para determinar a convenićncia ecunômica de troca de luminarias, conclui-se que as alternativas T-1 (HG-125 W por NA-70 W), T-2 (HG-175 W por NA- 100 W), T-4 (HG-250 W por NA-150 W), T-5 (HG-400 W por NA-250 W) e T-6 (MS-160 W por NA-50 W), sāo viáveis do ponto de vista econômico, porque proporcionam as características minimas exigidas na análise. $A$ alternativa $\mathrm{T}-3$ (HG-175 W por NA-150 W) Dão é reccomendável porque năo atende os requisitos mínimos das figuras de mérito (exemplo a TIR, CEC).

A alternativa T-2 encontra-se wa margem de conveniência, porém, recomenda-se sua 
A anilise econòmica foi feita a partir da premissa de avaliar duas alternativas de iluminaçāo, a primeira usando lumimária convencional e a segunda usando lumintária eficiente onde assumiu-se que os equipamentos usados nas duas alternativas seriam novos. Este caso vai acoutecer nas concessionárias somente quando o custo da luminária convencional tenha sido depreciado e o seu valor seja zero (0); além disso, assume-se que vai coincidir con o término da vida útil. Caso contrario, deveria ser avaliado o residuo (segundo depreciação) da tuminária convencional, embora também poderia ser vendido por esse resíduo, fazendo em que a avaliaçāo econômica tenha dois parâmetros adicionais.

A alternativa técnica, reduçảo de tensão fornecida às huminárias, somente será viável quando o custo de investimento no aparelho em relaçāo aos valores evitados, seja menor do que 92,4 US\$/kW de potència evitada, ou menor do que 28,1 US\$ $/ \mathrm{MWh}$ de energia evitada. $O$ preço desses equipamentos não se encontra disponível no mercado, portanto não é possivel avaliar, porém expressa-se os custos máximos unitários que eles devem ter.

Segundo a análise de sensibilidade preço de cletricidade, a variaçăo dos preços na faixa de 40 a 83 USSiMWh não afeta os resultados económicos das figuras de mérito $\mathrm{c}$ portanto qualquer preço a partir de qualquer ótica (INECEL, concessionária ou usuário) nāo afetará a recomendaç̧̃o feita anteriormente sobre a troca das luminárias.

Finalmente, segundo a análise de sensibilidade horas de funcionamento diário, a variaçào do tempo de funcionamento na faixa provável de ocorrer ( 11,5 horas/dia e 12,5 horasidia) uão afeta os resultados cconômicos das figuras de mérito e portanto qualquer tempo de funcionamento nessa faixa não afetará as recoréndaçōes da análise. 


\section{CAPítulov}

\section{AVALIACCIO INTEGRADA DE ALTERNATIVAS DE OFERTA E ISO EFICIENTE DE ENERGLA NO SETOR DE ILUMINAĊ̃o PÚBLICA (IP).}

A concepção do planejamento come um processo de formulaçäo de rketas $\mathrm{e}$ análise de opçỏes deverá se tomar um principio fundamental de um sistema que atua inserido em um processo sócio-econômico complexo, onde as decisìes serāo tomadas pela sociedade atrayés de seus órgàos de representação, cabendo às entidades cncarregadas da condução das politicas setoriais a responsabilidade de informar os dados relevantes, as trajetórias possiveis e as implieaçōes de decisões especificas (Eletrobrás, 1994).

O Planejamento integrado de Recursos (PIR) constitui-se num novo enfoque de planejamento, que esta sendo utilizado por empresas do setor elétrico de vários países em deseuvolvimento que possuem restriçōes tinancciras para expandir seu sistema, e alguns deles, limitaçòes de recursos primários disponíveis para geraçào de eletricidade.

O Plancjamento Integrado de Recursos (PIR), consiste na formulação e na seleçào da expansão da oferta de encrgia elétrica através de processos que avaliem todo um conjunto de altemativas que iscluem, uäo somente, o aumento da capacidade instalada, como também a conservaçāo e a eficiència energética, autoproduçāo e fontcs renováveis. de modo de garantir que os ustários do sistema recebam uma energia com confiabilidade e de boa qualidade, da mellsor forma possivel, considerados os aspectos técticos, cconòmicos-financeiros e sócio-ambientais. Em uma formulação mais ampla, considerando todo o espectro energético, o resultado indicaria a aplicaçāo da energua para um desenvolvimento sustentado. 
contradiçōes, questōes näo resolvidas, etc., tais como: os altos custos das novas usinas; as possibilidades de repotenciamento das usiaas paradas, os problemas causados ao meio ambiente, a participação da sociedade, os modelos administrativos inchados e vegetativos, as possibilidades de redução nas perdas da transmissão e distribuiçào e de reconfiguraçào da rede atual, as necessidades de mantejo efetivo da carga, os programas de conservação de energia, a regulamentação vigente, as novas tecnologias, a busca da eficiência energética tanto no oferta quinto nos usos finais, as novas fontes acessiveis, os recursos alternativos, a busca de um planejamento pelo minimo custo, as próprias caracteristicas do setor. Estes aspectos, dentre outros elementos da realidade do setor elétrico, levarn à busca da implantação de um planejamento, que näo é apenas uma metodologia, mas um processo integrado de recursos, onde os recursos constitucm-se em todas as formas factiveis de responder às necessidades da energia elćtrica, an menor custo possivel tanto para o consumidor quanto para o supridor, e com ampla aceitação da sociedade com a consideração ambiental (CEDEE, 1994).

A introduçāo desta nova metodologia de planejamento, permitira uma busca da melhor soluçàn, considerando $\mathrm{em}$ seu contexto a influência das diversas contradiçōes, dúvidas, tetudências, pressũes, ctc., não incorporadas no planejamento tradicional, e listadas a seguir, considerando os lados da carga, do suprimento e, dos usos finais.

\subsection{CENÁRIOS}

A previsäo de energia e potência (ponta) è em última análise o ponto te partida para o planejamento integrado de recursos, sendo vital para este objetivo.

Várias técnicas tém sido utilizadas para a previsäo de mercado ou carga, sendo que elas podem ser agrupadas dependendo de seu fim $\mathrm{em}$ :

- Previsões de curtíssimo prazo.

Previsōes de longo prazo ( 10 a 20 anos) e médio prazo ( 2 a 5 anos). 
No primeiro tipo de categoria cncontram-se as previsòes com o objetivo de operação do sistema elétrico em tempo real.

As previsões de médio e longo prazo visam determinar a energia c a poténcia da carga anual. Evidentemente estas previsīes dependem de fatores extemos às concessionárias, como por exemplo: o crescimento da Nação, erises mundiais ou continentais, desejos e exigèneias da sociedads.

Além disso, existem metodologias para determinar as previsōes da demanda. Duas vertentes de previsão de médio e longo prazo podem ser constatadas:

- Processo economćtrico (convencional ou tradicional)

- Processo baseado no "uso final" da energia

O processo econométrico baseai-se no histórico passado (cnergia e potência) e procura definir os futuros valores com base tm certas variáveis como o PIB - Produto interno Bruto - o preço dos combustiveis, a cvoluçào da renda familiar, etc,

A segunda vertente procura estahelecer para que fim serve a cnergia (iluminaçào, aquecirnento, acionamento mecinico, etc.). Para tanto bascia-se em modelo "orientado pela engenharia", onde precisam ser determinados a posse (extmpio: quantos cluveiros existem cm uma casa) e o uso (quantos banhos, a que hora) dos cquipamentos de cousumo de energia. Desta forna a energia total é decomposta em sua aplicação.

A energia cousumida é calculada somando o consumo de todos os equipamentos:

$$
E_{\text {umal }}=\sum_{i} E_{\text {cqupaurata i }}
$$

$E_{\text {eqpentante }}=S \mathrm{~N} \mathrm{PH}$

onde: 


\section{$\mathrm{N}=$ numero (consumidores $\mathrm{x}$ equipamentosiconsumidor) \\ $\mathrm{P}=$ potència do aparelho \\ $\mathrm{H}=$ horas de utilização}

Em alguns casos, substitui-se $\mathrm{PH}=\mathrm{C}$, onde $\mathrm{C}$ é o consumo médio do equipamento.

Existem casos onde índices sảo usados para estimar o consumo. Por exemplo para aquecinento do ambiente em regiōes de inverno rigoroso, pode-se calcular o consumo por $\mathrm{E}=\mathrm{U} \mathrm{Q}$, onde $\mathrm{U}$ ć o consumo por $\mathrm{m}^{2}$ de habitaçào $\mathrm{e} \mathrm{Q}$ área de labitaçào.

Pode-se também, com base na metoduloggia descrita, avaliar o efeito da mudança de políticas de gerenciamento da demanda, como, por exenplo, substituir a aquecimento de água feita com eletricidade por gás.

Verifica-se, portanto, que com o modelo da segunda vertente, tem-se uma forma mais tlexivel de avaliar a projeç̧̄o da carga.

Neste contexto podem ser verificados os impactos tecnologicos de equipamentos mais eficientes energeticamente Neste caso os consumos médios tendem a cair.

Como o sistema de energia, no qual está incluido o sistema elétrico, precisa ser planejado e construído, costuma-se definir "cenários" de evoluçào prevendo as correspondentes cargas, depois aplicando uma técnica de análise perante incertezas para a tomada de decisāo (CEDEE, 1994).

Segundo Araújo (Araújo, 1994), "cenário" é uma projeçāo condicional da evolução de um sistema; seu pressuposto de base é que existem vários futuros víaveis e qualitativamente distintos, segundo opęcées políticas do decisor e segundo fatores que escapam so seu controle. 
Um estudo de cenários procura pois organizar a incerteza, de maneira a a) investigar alternativas de políticas em distintos contextos, e/ou b) avaliar sstratégias ern contexto incerto. Ambas fítalidades sảo importantes, seja qual for o sentido da prospectiva.

Com a definiçāo acima, distinguem-se num cenário as hipóteses de base e as conseqüências daquelas hipóteses, ambas configurando o cenário. Por outro lado, as lipóleses de base podem referir-se a elementos sob o controle do decisor, ou a elementos contextuais e fora de seu controle. É possivel assim visualizar num cenário três componentes:

- uma politica (coujurto de hipóteses sob controle do decisor).

- um contexto (conjunto de hipóteses fora do controle do decisor)

- as consequînncias de uma política agindo num contexto dado.

Com estes antecedeutes, o estudo de caso esta centralizado no estabelecimento de cenarios, que considerem o modo como é utilizada a caergia nos usos finais e que promova um desenvolvimento baseado no uso eficiente da energia.

\subsubsection{CENÁRIO EFICIÉNCIA CONGELADA}

A projeçăo pelo Cenário de Eficiência Congelada, considera que a eficiència ( $\mathrm{t} / \mathrm{W}$ ) dos equipamentos utilizados no ano projetado seja a mesma dos equipamentos do ano base: além dissa, considera-se os mesmos padrōes (consumos específicos) de comportamento do sistema de IP no ano base e no futuro. O consumo projetado por este cenário formece um extremo superior.

A premissa usada em todos os cenários, baseia-se na determinação do "consumo especifico" que resulta da razão potência instalada em IP por cada habitante com serviço elétrico (W/habitante atendido); a desagregação é feita para o setor urbano e nural e para cada concessionária. No entanto, poderia se usar outros métodos como por exemplo 
huminarias $(\mathrm{m} / \mathrm{W})$. Simplesmente, em ambos os casos, aplicaram-se porcentagens de evolução.

As projeçǒes em todos os cenários foi feita para os anos 1995, 1996, 1997, 1998, 2000 e 2005.

Mediante a aplicação dos dados estatísticos proporcionados pelo Instituto Nacional de Estatisticas e Censos do Equador - INEC (INEC, 1994) subre a população e o número de moralias, e, com o número de clientes proporcionados pelas concessionáríns, determinou-se o indice de atendimento do pais. $O$ índice de atendimento do nível nacional para o ano 1993 foi $78,3 \%$, descomposto assim: $95 \%$ para o setor urbano, $5.3 .3 \%$ para o setor rural (porcentagens similares aos apresentados na introduçào do Capitulo I).

Porem, dentro deste cenário estabelecc-se duas altemativas com diferentes premissas que șio indicalas a seguir:

\section{FFICLENNCIA CONGELADA MAIOR:}

- indice de atcudimento no ano horizonte: $98 \%$ para o setor urbano e $65 \%$ para o setor rural (indices iguais aos usados pelo INECEL nas projeçòes e que foram indicados no item 2.2.3);

- ineremento nos niveis de IP dos centros urbanos en $10 \%$ até o ano borizonte;

- igual eficiència dos equipamentos; e,

- igual consumo especifico no periodo.

FFICIÊNCLA CONGELADA MENOR:

- indice de atendimento no ano horizonte: igual do ano base, isto é $95 \%$ 
- os níveis de IP são iguais no ano base e no ano horizonte;

- igual eficiência dos equipamentos; e,

- igual consumo especifico no periodo.

Os resultados dos cenários sĩo apresentadus em detaihes no ANEXO E; não obstante, a seguir apresenta-se o resumo desses resultados (ver TABELA 5.1):

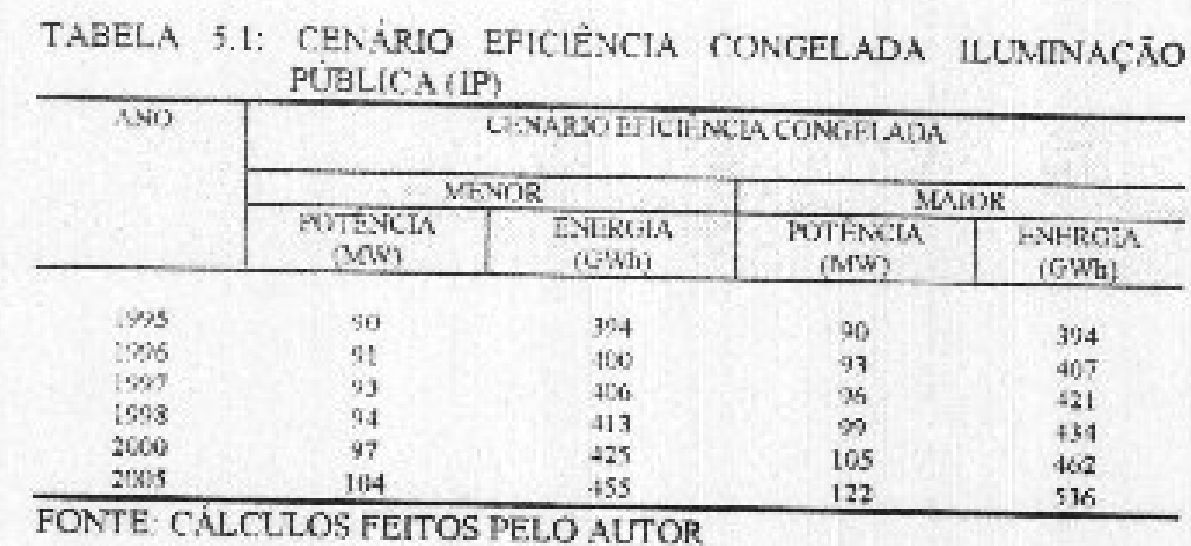

A taxa média anual de meremento para o cenirio menor é $1,4 \%$ e para o cenário maior $3.1 \%$. Estes valores ș̄o menores do que os projetados pelo INECEL cujos valores são $4,2 \%$ para o cenário menor e $5,4 \%$ para o cenário maior, os messmos que foram calculados por métodos econométricos usando a variúvel PIB.

\subsubsection{CENARIO EFICIENTE OI: POTENCLAL TÉCNICO}

O cenário Eficiente ou Potencial Técnico assume o uso de equiparnentos mais eficientes disponiveis em cada ano para substituiçào daqueles que terminaram a sua vida útil e além disso considera-se o crescimento vegetativo do número de huminárias. 0 consumo projetado por este cenário fornece um extremo inferior.

De igual maneira que o cenário do item 5.1.1. estabelece-se duas alternativas com diferentes premissas, sob definição do cenário cficiente ou técnico potencial e, que sào as seguintes: 


\section{EFICIENTE MAIOR:}

- indice de atendimento no ano horizonte: $98 \%$ para o setor urbano e $65 \%$ para o setor rural;

- nào existe incremento nos uíveis de IP dos centros urbanos;

- ganhos de eficiència nos equipamentos de $30 \%$, segundo cstimą̧ŏes de "Iluminating Enginecring Society of North America"(Iluninating Engincering Society of North America, 1993);

- igual consumo especifico no periodo; $\mathrm{e}$,

- existe programas de uso eficiente de energia segundo aqueles propostos neste estulo de caso.

\section{EFICIENTE MENOR:}

- indice de atendimento no ano horizonte; igual do ano base, isto $\leq 55 \%$ para o setor urbano e $53,3 \%$ para o setor nural.

- os niveis de IP săo izuais no ano base e no ano horizonte.

- ganhos de eficiència nos equipamentos de $30 \%$;

- igual consumo especificon no periodo; e,

- existe programis de uso eficiente de energia segundo aqueles propostos neste estudo de caso.

Por outro lado, assume-se que o programa de uso eficiente ocorre no ano 1995. Os equipamentos trocados atendem os critérios dos resultados da análise econòmicafinanceira do Capitulo anterior (Capitulo IV). Isto é:

TROCA

T-1

$T-2$

T. 4

ANTERIOR

TEC. CONVENCIONAL

HG - $125 \mathrm{~W}$

HG - 175 w

HG $-250 \mathrm{~W}$
PROPOSTA

TEC. EFICIENTE 
Observa-se que não se encontra a alternativa $\mathrm{T}-3$ ( $\mathrm{HG}-175 \mathrm{~W}$ por NA-150 W) devido aos resultados negativos da análise.

Na TABELA 5.2 observa-se os valores calculados tanto de potência quanto de energia para as alternativas indioudas.

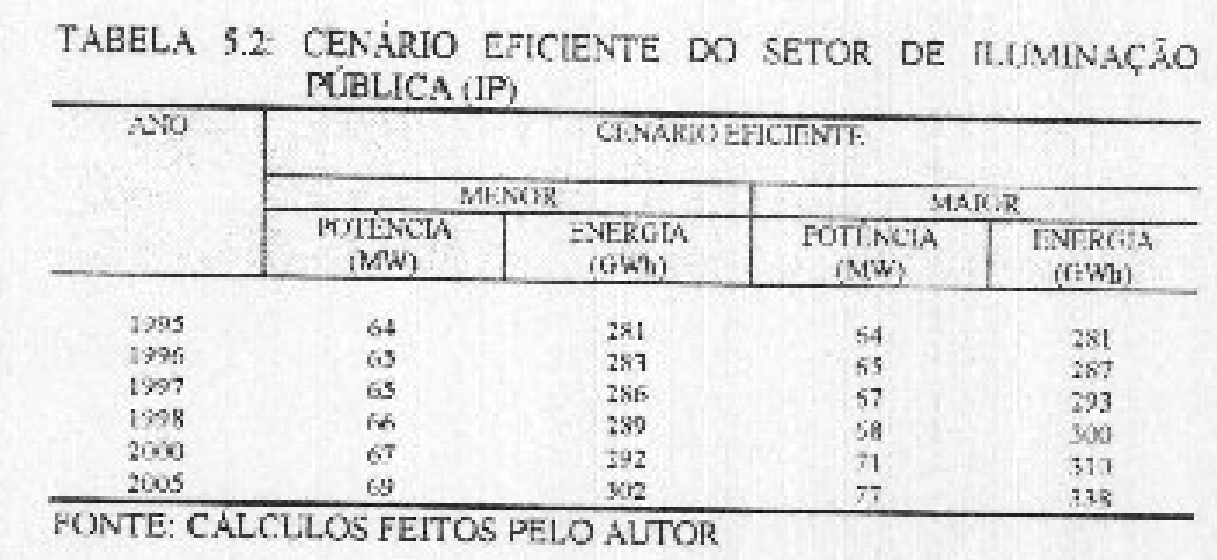

A potêtucia do sistema de IP no ano 1995 é 90 MW, o cousumo de energia de 394 GWh/ano; trocando todas as luminárias convencionais pelas respectivas cficientes, segundo este cenário, a potência dimimui para $64 \mathrm{MW}$ e, a encrgia diminui para 281 GWh/ano, ou scja a diminuição é de $29 \%$ tanto em potência quanto em energia.

A taxa média anual de incremento, devido ao crescimento vegetativo do número de Luminárias, para o cenário menor é $0,7 \%$ e para o cenário maior $1,9 \%$, valores menores do que as porcentagens de incremento calculadas no cenário de eficiència congclada (item 5.1.1) e, ainda menores que os calculados pelo INECEI.,

\subsubsection{CENÁRIO TENDENCLAL}

No cenário Tendencial considera-se um aumento da eficácia natural e de uma evolução tecnológica dentro das expectativas. Assim, o aumento da cficiência é considerado natural, decorrente de uma evoluçào tecnológica natural dos equipamentos colocados no mercado. $\mathrm{O}$ aumento na penetração das tecnologias mais eficientes se deve às mudanças

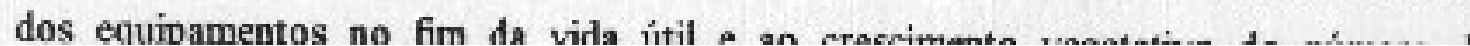


tnergia. A projeção estará compreendida entre o máximo superior (cenário eficiência congelada maior) e o minimo inferior (cenário eficiente ou potencial técuico menor).

De igual maneira que o cenário do item 5.1.1. estabelece-se duas altemativas com diferentes premissas, sob definição do ctmário tendencial e, que são as seguintes:

TENDENCIAL MAIOR:

- indice de atendimento no ano horizonte: $98 \%$ para o setor urbano e $65 \%$ para o sctor rural;

- aão existe incremento nos níveis de IP dos centros urbanos;

- ganhos de eficiência natural nos equipamentos de $10 \%$;

- igual consumo especifico no periodo;, ,

- não existe programas de uso eficiente de energia.

TENDENCIAI. MENOR:

- indice de atendimento no ano horizonte: igual do ano base, isto e $95 \%$ para o setor urbano e $53,3 \%$ para o setor mural.

- os níveis de IP são iguais no ano basc e no ano horizonte.

- ganhos de eficiència natural nos equipamentos de $10 \%$,

- igual consumo especifico no periodo; e,

- não cxiste programas de uso eficiente de energia.

A vida útil média das lâmpadas de vapor de mercúrio ou vapor de sódio é aproximadamente 3,3 anos (ver TABELA 4,3) o que significa que cada ano devem ser trocadas por efititos de manutençào $30 \%$ das lânpadas por suas correspondentes; portanto, esta é a freqüència para mudança de tecnologia segundo ganhos de eficiência natural. 
TABELA 5.3: CENARIO TENDENCIAL DO SETOR DE ILUMINAC̨ĀO PUBLICA IIP)

\begin{tabular}{|c|c|c|c|c|}
\hline \multirow[t]{3}{*}{ ANO } & \multicolumn{4}{|c|}{ CENIRIO TENIENCLI. } \\
\hline & \multicolumn{2}{|c|}{ MENOR } & \multicolumn{2}{|c|}{ MATOR } \\
\hline & $\begin{array}{c}\text { FOTENCIA } \\
\text { MAI }\end{array}$ & $\begin{array}{c}\text { ENERGiL } \\
\text { (GWh) }\end{array}$ & $\begin{array}{l}\text { FOTENCLA } \\
\text { GNM }\end{array}$ & $\begin{array}{c}\text { ENER } 604 \\
\text { (jWh }\end{array}$ \\
\hline 1945 & 90 & 304 & 90 & 34 \\
\hline 1996 & 91 & 309 & 73 & 404 \\
\hline 1997 & 12 & $+1 / 4$ & 95 & 414 \\
\hline 1998 & 93 & $k B$ & 97 & 425 \\
\hline 2000 & 26 & 419 & 201 & 445 \\
\hline sines & 101 & +12 & $\$ 13$ & tos \\
\hline
\end{tabular}

Com o objetivo de visaalizar os dados calculados nos très cenários, a seguir obsirva-se a FIGURA 5.1.
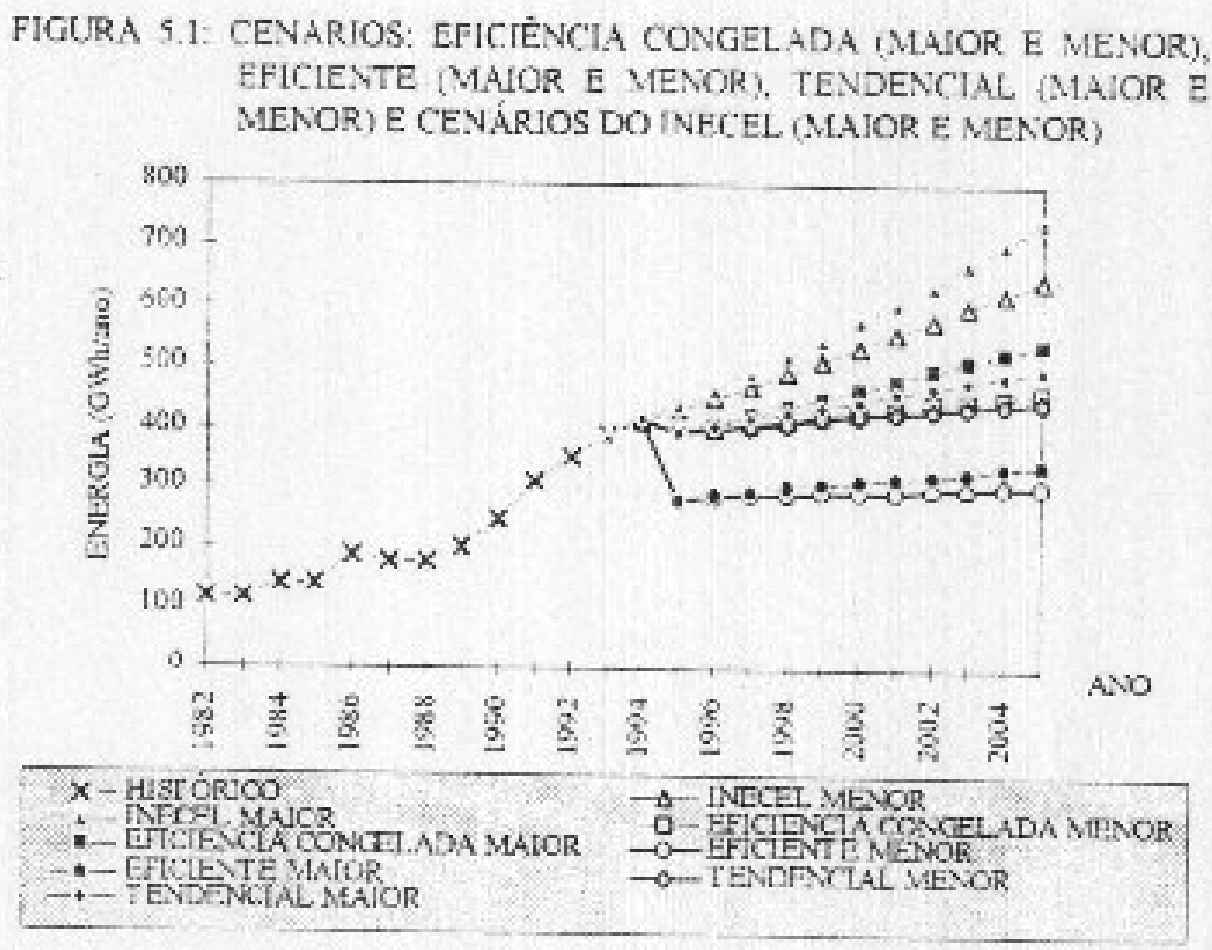

\subsection{ALTERNATIVAS DE TROCA DE LUMINÁRLAS E/OU LÂMPADAS.}

Existem duas alternativas viáveis para serem trocadas as luminárias: a primeira consiste cm obter todo o financiamento para a implantaçāo de um programa de troca imediata c, a segunda consiste em parcelar os investimentos em três anos, trocando as huminárias 
A premissa estabelecida para estas duas alternativas é que faz-se a troca total do aparelho (luminária), isto é: lâmpada, reator, porta lâmpada, carcaça, braço, parafusos e acessórios; no entanto, na prática polb-se apresentar situaçōes de troca de somente lâmpada, reator e ignitor, dependendo basicamente da condiçāo fisica da luminária convencional Sob esta premissa assegura-se o investimento míximo a ser feito e os resultados minimos ecunùmico-financeiros a serem obtidos.

0 Custo Durante a Vida (CDV) ${ }^{23}$ do coujuato de luminarias instaladas atualmente no sistema de IP do Equador (exceto as luminárias incandescentes, fluorescentes e vapor de sódio de $175 \mathrm{~W}, 199 \mathrm{~W}$ e $215 \mathrm{~W}$ ) atinge USS 246 milhões (investimento inicial e despesa operacional), este valor anualizado (CDVA) atinge USS 43,6 milhỏes e, o valor anualizado não energetico (CDVANE) atinge US\$ 11,6 milhōes.

A despesa anual por consumo de energia inchuido as luminárias incandescentes, fluorescentes e vapor de sódio antes excluidas atinge US\$ 32.7 millhões.

O potencial de cunservação è de $66,1 \mathrm{MW}$ e o maior potencial encontra-se nas luminarias de vapor de mercúrio de $175 \mathrm{~W}$ com $35,1 \mathrm{MW}(53 \%)$, depois estāo as luminarias de vapor de mercurio de $125 \mathrm{~W}$ com $18,7 \mathrm{MW}(28 \%)$, enquaato os outros potenciais são menores (ver TABELA 5.4).

TABELA 5.4 RESLMO DE POTÉNCIA E ENERGIA DAS ALTERNATIVAS PROPOSTAS (1995)

\begin{tabular}{|c|c|c|c|c|c|c|c|}
\hline \multirow[t]{2}{*}{ TKtX:A } & \multirow[t]{2}{*}{ ATUA } & \multirow[t]{2}{*}{ PRADFFA,ALA } & \multirow{2}{*}{$\begin{array}{c}\text { QWWNTDADE } \\
\text { (6) }\end{array}$} & \multicolumn{2}{|c|}{ DOIEप्रCIA } & \multicolumn{2}{|c|}{ FNHRGIA } \\
\hline & & & & $\begin{array}{l}\text { ATTWL } \\
\text { MN }\end{array}$ & $\begin{array}{c}\text { PRos.rFTanA } \\
\text { (MW) }\end{array}$ & $\begin{array}{l}\text { Arur. } \\
\text { (Gwhing }\end{array}$ & 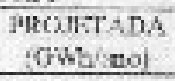 \\
\hline$t-1$ & $3 G-125 W$ & NA. $70 \mathrm{w}$ & 176,573 & 18,7 & 11.3 & 82.0 & 49.7 \\
\hline$\tau-2$ & $\pi t G r-175 \mathrm{~W}$ & $\mathrm{NA}-100 \mathrm{~W}$ & 185.706 & 35.1 & 21,5 & 153.7 & 94.4 \\
\hline$I-6$ & $\mathrm{HCr}-250 \mathrm{~W}$ & $\mathrm{NS}=1.50 \mathrm{~W}$ & 25.924 & 69 & 4,4 & 30,2 & 193 \\
\hline T. 5 & $\mathrm{HCr}-4 \mathrm{CO}) \mathrm{W}$ & $\mathrm{NX}-250 \mathrm{~W}$ & 8.179 & 3.5 & 2,2 & 19.2 & 99 \\
\hline$T \cdot$ & $M, s-160 \mathrm{~W}$ & $\mathrm{NA}-50 \mathrm{~W}$ & 12.045 & 29 & 0,7 & 8,4 & 3.3 \\
\hline TOTAL & & & $36 k 427$ & 66.1 & 40,1 & 289.5 & 176.6 \\
\hline Ioras s & 15: MA IIUS & $\operatorname{sicho}$ & 449019 & 829 & 64,1 & 3940 & $2 \sqrt[90.8]{8}$ \\
\hline
\end{tabular}


A seguir será feita uma análise das duas alternativas propostas, onde os dados de energia, potĉncia, custos operacionais, etc. estão referenciados ao elenco de substituiçôes consideradas vìveis.

\subsubsection{TROCA DE LUMINÁRIAS NO ANO 0}

Esta primeira alternativa consiste na implantação de progarmas imediatos de uso eficiente de energia para as trocas propostas e que resultaram viáveis.

O programa proposto de trocas no ano 0 , produz no sistema de IP os seguintes resultados: o valor de CDV cai de US\$ 246 milhòes para USS 202 milhōes, enquanto os valores anualizados de CDVA cai de US\$ 43,6 milhòes para US\$ 35,7 milhōes e, o CDVANE sobe de US\$ 11,6 milhões para USS 13,1 millı̌es (ver TABEI.A F 13 do ANEXO E).

Além disso, cousiderando somente o clenco de substiruiçües, o valor de CDV cai de US\$ 184 milhöes para USS 139 milhöes, enquanto os valores anualizados de CDVA cai de US\$ 32,6 milhões para USS 24,7 milhòes, o CDVANE sobe de US\$ 8,5 milhões para USS 10,0 milhōes e, a despesa por consumo de energia cai de USS 24,0 milhōes para USS 14,6 milhũes, O equivalente pela dirttinuição do consumo de energ̨ia é de USS 9.4 milhōes, dos quais US\$ 6,1 são por potência (baseado no custo marginal de potência 235,2 USS $/ \mathrm{kW}$ que inclui custos de geração, transmissĩo e distribuiçāo) e US\$ 3,3 por energia (ver TABELA E. 13 do ANEXO E).

A seguir analisa-se duas figuras de mérito que serāo decisónias na determinaçào da viabilidade do programa.

\section{a) TAXA INTERNA DE RETORNO}

Com objetivo de obter a taxa interna de retorno do investimento em eficiência 


\begin{tabular}{|c|c|c|c|}
\hline$\overline{A Y O}$ & $\begin{array}{c}\text { TECNOICGIA } \\
\text { CONVENCTONAL. } \\
\text { (mill.ISS) }\end{array}$ & $\begin{array}{c}\text { TECANOLOGIA } \\
\text { EFICasTE } \\
\text { (miluss) }\end{array}$ & $\begin{array}{l}\text { BALANÇO } \\
\text { (millss) }\end{array}$ \\
\hline a & 0 & 47.661 & -47.661 \\
\hline 1 & 32.581 & 14.644 & 17.937 \\
\hline 2 & 32.581 & 14,644 & 17,937 \\
\hline 3 & 32.581 & 14644 & 17.937 \\
\hline 4 & 32.581 & 21129 & 11. 452 \\
\hline 5 & 32.581 & 25.747 & 6.834 \\
\hline 6 & 32.581 & 24.644 & 17937 \\
\hline 7 & 32581 & 14.644 & 17937 \\
\hline 8 & 32581 & 21.129 & 11.452 \\
\hline 9 & 32.581 & 14.843 & 12.797 \\
\hline 10 & $12.4 x 1$ & 11.258 & 21.323 \\
\hline & & $\bar{R}$ & $31 \ldots \%$ \\
\hline
\end{tabular}

Analisando os valores do fluxo, para o ano 0 , considera-se o valor do investimento inicial de USS 47,7 milhỏes (terceira coluna) para comprar luminárias eficientes, entretanto, para a tecnologia convencional (segunda coluna) näo se considera nenhum valor inicial. Para os seguintes anos considera-se o valor respectivo do CDVA para tecnologia convencional, enquanto para tecnologia eficiente considera-se os custos de consumo de energia e quando seja do caso, manutenção e instalaçẫo de lámopadas, reatores e ignitores. Sob estes antecedentes, a taxa intema de retomo TIR é $31,6 \%$, superior à taxa de desconto $(12 \%)$.

\section{b) CUSTO DE ENERGIA E POTÊNCIA CONSERVADA}

Aplica-se o conceito de custo de energia conservada CEC (item 4.3.3.) para calcular o valor equivalente do conjunto de luminárias:

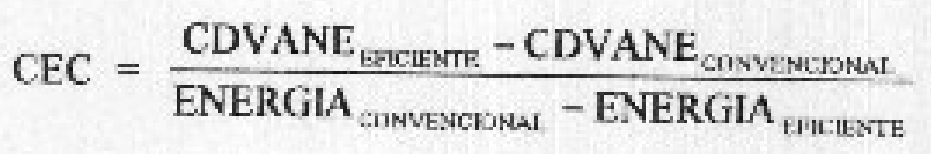

Substituindo os valores respectivamente, o resultado de CEC para esta altemativa de investimento e 13,2 USS/MWh, valor inferior ao custo marginal médio de energia de 83 US\$/MWh. 
De maneira similar, calcula-se o valor do custo de potência conservada CPC, cujo resultado $\& 328$ US\$ $\mathrm{kW}$, valor inferior que qualquer alternativa de oferta de energia.

\subsubsection{TROCA DE LUMINÁRIAS NOS ANOS 1,2 e 3}

O sscopo desta altemativa é trocar as luminárias quando termine a vida útil da sua lâmpada, on seja $33 \%$ das luminárias serāo trocadas cada ano (lembra-se que a vicla útil média é 3 anos aproximadamente), terminando o programa no final do terceiro ano. Sob estes antccedentes observa-sc a TABELA 5.6 a evoluç̣̄o da potência e energia.

\begin{tabular}{|c|c|c|c|c|c|c|}
\hline \multirow{2}{*}{ SISTH.MA } & \multirow{2}{*}{ 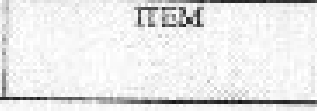 } & \multirow{2}{*}{ TNIDXDF } & \multicolumn{4}{|c|}{ ANO } \\
\hline & & & 0 & 1 & 2 & 3 \\
\hline CONVEACLUNAL. & $\begin{array}{l}\text { POTLECLA } \\
\text { ENEROLA }\end{array}$ & $\begin{array}{c}(M W) \\
(G W / 2 \ln )\end{array}$ & $\begin{array}{r}90 \\
304\end{array}$ & & & \\
\hline EFCANETE & $\begin{array}{l}\text { BOTFULIA } \\
\text { BARETIA }\end{array}$ & $\begin{array}{c}\text { (MW) } \\
\text { (FWhivo) }\end{array}$ & & $\begin{array}{r}81 \\
385\end{array}$ & $\begin{array}{r}73 \\
3 i 9\end{array}$ & $\begin{array}{r}64 \\
28 \mathrm{t}\end{array}$ \\
\hline & DFSPESA EM ICVIIRGTA & (1006 uss) & 32.7 & 295 & 26.4 & 25,3 \\
\hline & DVESTIMT-NTO & (11\%G USE) & & 159 & 15.9 & 159 \\
\hline
\end{tabular}

No terceiro ano atinge-se a eficiéncia total, igual ao caso da alternativa anterior no ano 0 (item 5.2.1).

De maneira similar, com o objetivo de obter a taxa interna de retorno TIR do investimento, apresenta-se a seguir os fluxos de caixa da evoluçāo do sistema convencional ao eficiente (ver TABELA 5,7): 


\section{TABELA S 7. FLUXO DE CALXA INVESTMENTO ANO 1,2 e 3

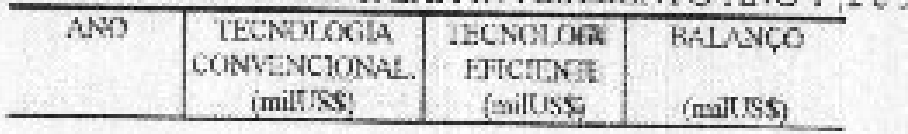

\begin{tabular}{|c|c|c|c|}
\hline 0 & E. & 0 & 0 \\
\hline 1 & 52.581 & 4380 & -9.968 \\
\hline 2 & 32.581 & 3510 & -3929 \\
\hline 3 & 32.581 & 3931 & 2050 \\
\hline 4 & 32581 & $21 \geq 0$ & 11.552 \\
\hline 5 & 12 $\$ \$ 1$ & 257 & $5 \times 34$ \\
\hline 5 & 32.581 & RAS & 17.937 \\
\hline 7 & $12.5 \times 1$ & 1544 & 17937 \\
\hline$x$ & 32.581 & 2629 & 11452 \\
\hline 9 & 32.581 & 1243 & 17.737 \\
\hline 10 & 17481 & $189 y$ & $15.5 \times 2$ \\
\hline \multicolumn{3}{|c|}{ TIK } & 45.725 \\
\hline
\end{tabular}

Analisando o fluxo de crixa, no ano 0 , não existe dspesa para as duas alternativas, a partir daqui começa a implantaçăo do programa de tras, atingindo no primeiro ano $33 \%$ do objetivo. Nota-se que os irvestimentos durante ogrimeiro ano, são passados ao final desse periodo, isso é feito também paru os anos seguitus.

Assimh, no final do primeiro ano, na coluna da tecnògia eficiente, o valor total é USS 42,5 milhōes, parcelado em US\$ 15,9 trithōes de invosimento inicial para comprar $33 \%$ do equipamento da nova tecnologia, USS 21,7 milos pelos custos operacionais da tecnologia convencional e USS 4,9 milhöes peloconsumo de energia dos novos equipamentos.

Para o segundo ano, o valor do investimento inicial żigual do que o anterior US\$ 15,9 milhōes, somado os valores de USS 10,9 milhōes pelecustos operacionais da tecnologia convencional ainda existente mais USS 9,7 milhöespor consumo de energia da nova tecnologia, o resultado disto é USS 36,5 milhòes. Now-se que este uiltimo valor é menor do que o seu similar anterior, devido à maior penetraj̄o da tecnologia eficiente.

Para o terceiro ano, o valor do investimento continuzigual USS 15,9 milhǒes somado o valor de US\$ 14,6 milhỏes por consumo de energia dmova tecnologia, o resultado disto ¿́ US\$ 30,5 milhōes. Nota-se que ainda este ultimo alor é menor do que o seu similar anterior, devido que atimgiu-se o escopo de troca bs luminárias, portanto, daqui em 
Por outro lado, para o décimo ano, jí que a vida util das luminárias é 10 anos considerase os valores residuais das liminarias instaladas no segundo e terceiro ano.

Entretanto, a segunda coluna que è a tecnologia convencional, a partir do ano I contén os custos parcelados de investimento da tecnologia convencional somado os custos пperacionais (manutenção e cousumo de energin) e, além disso todos os valores sĩo igaลis uos 10 anos.

A taxa interua de retorno TIR desta alcernativa ed de $46,7 \%$ superion do gue a alternativa anterior (item 5.2.1) e também maior do que a taxa de desconto $(12 \%)$.

Os custos de energia e potência conservada (CEC e CPC) sào ligciramente menores queles calculados no ifem anteriur (5.2.1).

\subsection{DISCRIMINACÄO DA CURVA INTEGRADA DF RECURSOS RASEADA EM CRITÉRIO DE MINIMO CUSTO.}

Para que se possa alcançar um bom plano integrado de recursos, é essencial que se proceda uma análise sobre diversas condiçōes fituras aceitáveis, correlacionadas as opçñes de recursos disponívis. Técnicas comer: análise de cenários, análise de sensililidarle, análises probabilísticas, análise de easos extremos (condições mais desfavaráveis), etc., são possiveis enfoques que podem ser utilizadas para analisar os impactos das incertezas do plancjamento.

Segundo a análise do item anterior (item 5.2), a potência conservada na IP pode atingir (no ano 1995) 26 MW. Com o objetioo de se ter uma idéia de grandeza daquele valor para o Equador, ele é comparável demanda maxima do sistena clétrico da concessioniria E.E. Regional do Sul S. A. é equivalerte a $17 \%$ da capacidade instalada da usina hidrelétrica Agoyín ou $39 \%$ da usina hidrelétrica Pisayambo ${ }^{24}$. A energia conservada poderia atingir $113 \mathrm{GWh} /$ ano.

24 on nrdan nala ixvênria ineralar 


\subsubsection{CURVA DE ENERGIA CONSERVADA BASEADA EM CRITÉRIO DE MíNIMo Custo}

Através da análise do consumo de energia nos diversos tipos de tecnologias de uso final, verifica-se qual a incidência de cada tecnologia no pico dn sistema e no consumo de energia para determinar com quais tecnologias podemos reduzir o pico do sistema e conservar a maior quantidade de energia possivel, e, a partir dai. propor a troca destas por outras mais eficientcs.

A curva de encrgia conservada basea da no critério de minino custo. ć uma função do custo unitário de energia conservada (USS:MWh) vs. a diminuiçàto de energia anual por uso cficiente (GWh/ano). A curva é construida da seguinte maneira:

- a primeira alternativa a ser introduzida nos programas é aquela que comesponde a altemativa mais baratz (menor custo do $\mathrm{CEC}$ );

- o passo scguitite corresponde a alterativa com custo (CEC) imediato maior do que o anterior;

- a altura do passo corresponde proporcionalmente ao valor do CF.C para essa alteruativa;

- a largura do passo conesponde à diminuiçāo de encrgia por uso eficiente dessa alternativa; e depois,

- continua-se o processo cumulativo até abranger todas as alteruativas

assim, é construida passo a passo a curva (Dutt, 199.3)

Na TABELA 5.8 observa-se em ordem ascendente, segundo o valos de $\mathrm{CrC}$, as altemativas de troca c além disso os valores de energia conservada para cada uma das alternativas e o valor acurnulado que atinge $113 \mathrm{GWh} /$ ano segundo já foi dito.

O investimento neccssário para adquirir o conjunto de luminárias eficientes do programa de uso eficiente de cnergia atinge USS 47,7 milhoes. 
TABELA 5.8 INVESTIMENTO INICIAL, CUSTOS E ENERGIA CONSERVADA PARA 1995 (SEGUNDA ORDEM ASCENDENTE)

\begin{tabular}{|c|c|c|c|c|c|c|}
\hline \multirow{2}{*}{$\begin{array}{l}120 \mathrm{CA} \\
4 \\
\end{array}$} & \multirow{2}{*}{ ATUK } & \multirow{2}{*}{ Fom } & \multirow{2}{*}{ 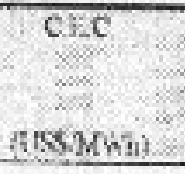 } & \multicolumn{2}{|c|}{ ENE:RGIK CONESE WDA } & \multirow{2}{*}{ 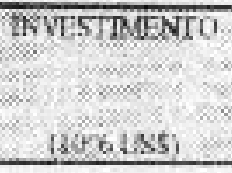 } \\
\hline & & & & $\begin{array}{l}\text { INDFinik? } \\
\text { fithbiary }\end{array}$ & 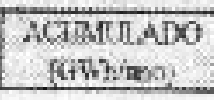 & \\
\hline It & $\mathrm{HKi}-25) \mathrm{W}$ & $\mathrm{NA}$ & -22.6 & 10,9 & 10 & 3,9 \\
\hline $7-5$ & $\mathrm{H}_{1-4}$ & M & -1.1 & 5,3 & & 1. \\
\hline 14 & $0 \mathrm{w}$ & $\mathrm{NA}$ & 4.0 & 5,1 & 2 & 1,2 \\
\hline T.1 & $\mathrm{HO}-125 \mathrm{~W}$ & NA. & 6.4 & 32 & & $\hat{2}$ \\
\hline 1.2 & $\mathrm{BG} \cdot 175 \mathrm{~W}$ & $\mathrm{NA}-100 \mathrm{~W}$ & $25, f$ & 59,3 & 112.9 & 26,5 \\
\hline WIAL: & & & & 1129 & $1[2.9$ & 475 \\
\hline
\end{tabular}

NOTA: As alternativas foram orderadas en ordeno asvendente segundo o valor de CEC (Custo de Energia Corenada)

Os valores de CEC foram: tomados do Ceppitule IV, item 4.3 .3

A ordem de priorização dos programas de uso eficiente de energia está em função do menor valor de CEC; no entanto, também poder-se-ià considera-la em funçăo do potencial de conservação de energia.

A seguir apresenta-ke a F1GURA 5.2 que permite visualizer os resultados da 1 ABELA 5.8 para o ano $1995 \mathrm{e}$ gire foi concruida beseada no processo indicadi. Fsta curva vem a ser uma representaçio ideal do que seria o supsimento da energia conservada (megawall-hora), permitindo visualizar a alocaçăo cumulativa das opçōes de conscrvaçào e seus custos correspondentes, an mesmo tempo comparando-ás cum a faixa do custo marginal de geração ( 83 USS:MWh).

FIGURA 5.2: CLRVA DE ENERGIL CONSERVADA BASEADA NO CRITFRIO DE MINIMO CLSTO PARA O ANO 1905.

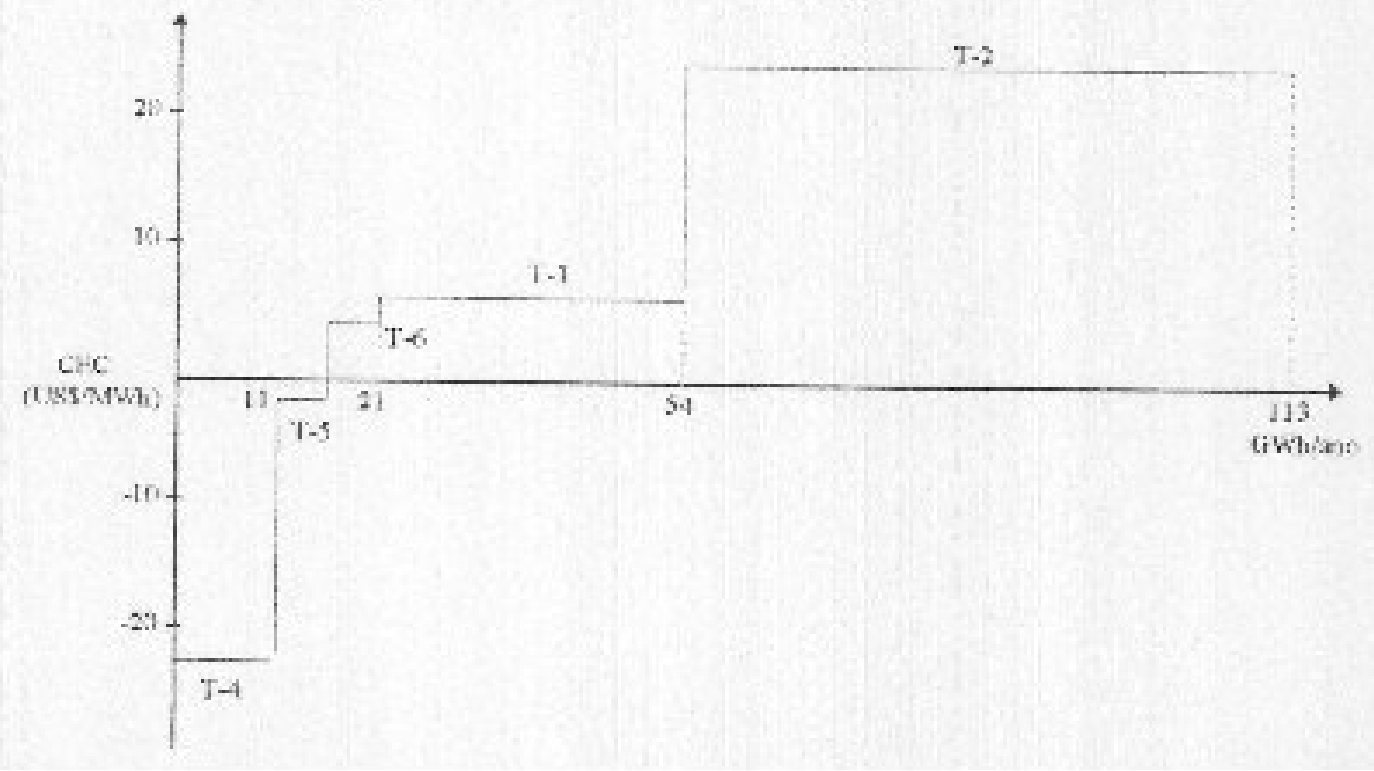




\subsubsection{CURVAS do CUSTO UNITÁRIO dE GERAÇÃo ElÉTRICA PARA USINAS A SEREM INSTALADAS NO PERIODO 1995-2005}

Muitas tecnologias de conservaçào e uso eficiente de energia que são introduzidas para o uso final são mços custosas que o custo médio de fomecimento de cletricidade; além disso, existe graude diferença de custo de fomecimento de eletricidade entre diferentes tipos de usinas de gerą̧ão. Com o objetivo de obter otimizaçào global pela via de uinimo custe e satisfazer as necessidades encrgèticas dos usos fimais de eletricidade, é necessário una metodologin que permita comparaçôes entre alguns tipos de formecimentos pelo lado da ofera com alternstivas de eficiência pelo lado da demanda.

Antes de continuar é necessúrio definir novos conceitos tais como:

- Fator de Carga da Planta ou Fator de Capacidade; é a razào entre a poténcia média anunl geradu c a potência máxima gerada.

- Fator de Carga de Conservação: é a razāo entre a carga conservada média amual e a carga conservada na pouta; onde a "carga conservada média atual" ć a conservaçào esperada num ano medida $\mathrm{em} \mathrm{hWh}$ coniservados, c, a "carga conservada na ponta" é a energia total conservada no tempo útil da demanda máxima.

A comparaçào econōtnica das opę̧es de geraçăo c conservaçằ pode ser feita de forma integrada utilizando uma figura que compare as diferentes opçòes através do casto do LW gerado (economizado) em fusçào do fator de capacidade (fator de carga de conservaçāo) (Sauer, 1994). O fator de carge de conservaçào é análogo ao fator de capacidade ou fator de carga da planta, portanto os programas de conservaçũo podem ser sobrepostos na figura de "Varią̧î́ dos custos unitários antualizados de potência em função do fator de carga de conservação e o fator de capacilude". 
A seguir, na FlGURA 5.3 aprescnta-se as curvas das diversas usinas de geração que serâo construidas no Equadot segundo o plano de eletrificaçăo do SNI e que tinhas sido indicado na TABELA 2.4 do item 2.1.2.1.

FIGURA 5.3: VARIAÇÃO DOS CUSTOS UNTTÁRIOS ANUALIZADOS DE POTENCIA EM FUNÇÃO DO FATOR DE CARGA DE CONSERVAÇÃO E O FATOR DE CAPACIDADE PARA O PLANO DE INST ALACCÃO DE USINAS 1995-2005.

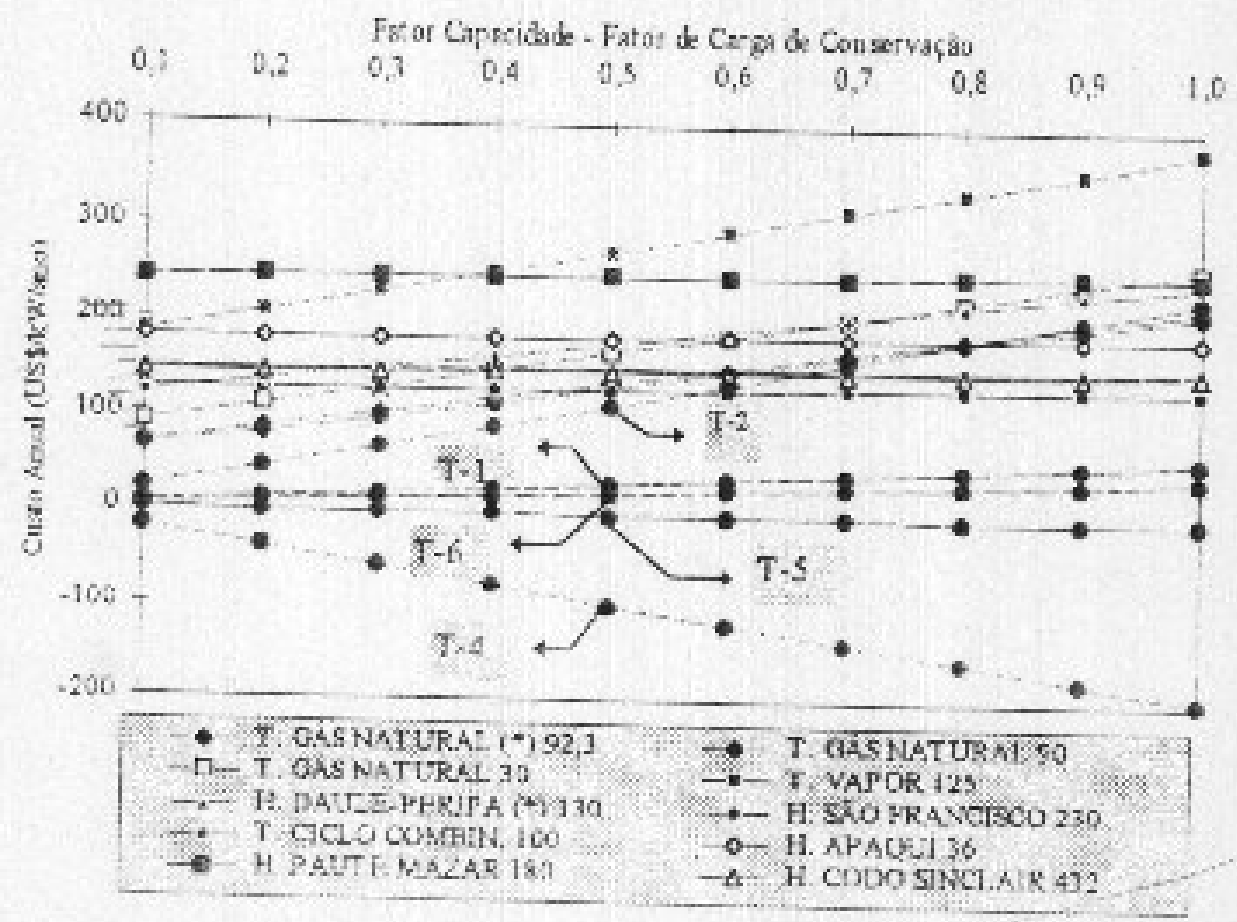

\subsubsection{INTEGRAC̆̃O OFEKTA-DEMANDA E ANÁLISE DOS IMPACTOS F.CONÔMICOS.}

Na FIGIRA 5.3 alem de se indicar as curvas das usinas de geraçăo, tambèm se indicam as curvas das alternativas de uso eficiente de energia propostas neste estudo de caso, isto é os custos unitarios (USS/kWiano) em funçào do fator de carga de conservaçâo (faixa entre 0,1 ( 1,0 ).

O fator de carga de couservação para o casu da IP corresponde ao valor 0.5 , devido que a poténcia mantem-se coustante durante todo o periodo de funcionamento de 12 horas por dia inclusive no mornento de demandy míxims do sistema elétrico. 


\begin{abstract}
Através da FIGURA 5.3 podemos fazer uma análise comparativa entre as opcōes de geração e as opçòes de conservação que dependem da trocu de luminárias. Como o fator de carga de conservaçio para todas as altemativas é 0,5 , conservar $1 \mathrm{~kW}$ de potência é mais atrativo do yue gerar com qualquer altemativa de geração. Isto é válido para todas as alternativas.
\end{abstract}

Asalisando a FIGURA 5.3, observa-se que para qualquer fator de carga de conservação, o custo unitário das altemativas sempre é menor do que gerar, exceto para a altemativa T-2 que só compete com a geraçño para fatores de carga de conservação na faixa entre $0.1 . e 0,6$.

Na TABELA 5.9 apresenta-se o cálculo dos impactos das opsōes de uso cficiente de energia pelo lado da oferta e da demanda.

Define-se como Fator de Ffetividade de Custo (FEC) ì razỹo cntre o custo de potência comservada (CPC) anualizado de certa altenativa de uso eficiente e o minimo ensto anualizado de potência no lado da oferta que suprirá essa carga e, além disso deve-se considerar para um valor do fator de carga de conservação igual ao fator de capacidade $(0,5$ neste estudo de caso). Este fator definido é apresentado na TABELA 5.9 .

Buscados nos cálculos obtidos e apresentados nas TABELAS 5.8 e 5.9 pode-se visualizar na seguinte figura (ver FIGLRA 5.4 para o ano 1995) os potenciais de conservaçũo cumulativos em ordem segundo o fator de efetividade de custo (FFC) e o custo de energia conservada (CEC) Esta fugura dá uma visão geral integrada dos recursos de geraçà̀ e uso final atraves da relaçân entre os custos da polência conservada (CPC) e o custo da potência instalada (conservadaigerada). Além disso, esta figura mostra através do fator de efetividade de custo (FEC) em ordem cresvente (expressa em porcuntngeus), quais as tecuologias viáveis a serem implantadas, e ao mestno tempo, indica quanto custa conservar com cada tecnologia. 
TABELA 5.9: CÁLCULO DOS IMPACTOS DOS PROGRAMAS DE CONSERVAÇÃO DE ENERGIA

\begin{tabular}{|c|c|c|c|c|c|c|}
\hline $\begin{array}{l}\text { TROCA } \\
\text { TECNOLOGIA ATUAL. } \\
\text { TICCNDLOCIA EJTCIINTE }\end{array}$ & \begin{tabular}{|c|}
$\mathrm{T}-\mathrm{t}$ \\
$\mathrm{H} \mathrm{i}-\mathrm{-} 2 \mathrm{WW}$ \\
$\mathrm{N}+-70 \mathrm{~W}$
\end{tabular} & $\begin{array}{c}\mathrm{T}-2 \\
\mathrm{HG-175} \mathrm{W} \\
\mathrm{N}-10 \mathrm{~W}\end{array}$ & 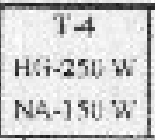 & $\begin{array}{c}\text { T-5 } \\
\text { NG- } 100 \text { w } \\
\text { N-250 }\end{array}$ & $\begin{array}{c}7 \leqslant 6 \\
M S-100 \mathrm{~W} \\
\text { NA-50 W }\end{array}$ & TUIALI. \\
\hline \multicolumn{7}{|c|}{ ANRLIST NTI THLA TITMINARA } \\
\hline CI.SIU ENERGIA CONSER (USSMWH) & 64 & 25,6 & $22 \%$ & -11 & 4,0 & \\
\hline REDUçio FNHKGIA (kWh/ans) & 236,5 & $3: 9.3$ & 4205 & 657,0 & $42 y, 2$ & \\
\hline RDDLCAOISEMANDU PONIA (W) & 54,0 & 230 & 96,8 & 159,9 & 58,0 & \\
\hline RFIOKCAOO DZUANISA MËDM (W) & $27, a$ & 36,5 & $48 . n$ & 75,0 & 490 & \\
\hline FATOR THE CAILOA DE CONK-R VACAZO & 0,5 & 0.5 & 0.5 & os & 0.5 & \\
\hline F.R.C. & 0,17 & 8.177 & 0,177 & $0.17 \%$ & 10.17 & \\
\hline CLSTOROTENCKLONS. MSSRky & 150 & 634 & .558 & .27 & 100 & \\
\hline CUSTO ZOTENCIA CONS.IIASS WIOOO) & 28 & 112 & -9 & 5 & ts & \\
\hline 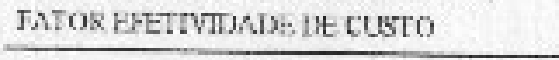 & 0.22 & 0,87 & 0,77 & $+\sqrt{n} 4$ & $\mathrm{c}, 14$ & \\
\hline \multicolumn{7}{|c|}{ ANO 1995} \\
\hline 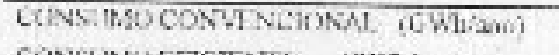 & 82 & 154 & it & 15 & 8 & $2 \%$ \\
\hline CONSUMUEICIFNT (GWh/as) & st & 54 & is & 10 & 3 & 126 \\
\hline F.K X(ila (XONSIE VAl) (NoWbian) & 32 & s2 & 11 & 5 & 5 & 113 \\
\hline RIDITÇÄ) DEMANDAR FUNTA OMN] & 7 & 14 & 2 & 1 & 1 & $2 t$ \\
\hline N. L1BMNAYIAS CONULNCIONA & $1,1,5873$ & $185 \%$ & $29: 124$ & 8174 & 12014 & 36827 \\
\hline 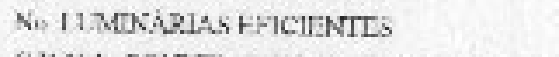 & 1749 & it & 101546 & 31900 & $a$ & 4211 \\
\hline CIIVA CONVENCIONAL (1043LSS) & $957 \mathrm{~K}$ & 16847 & 3584 & $36+3$ & Yiy & 32581 \\
\hline 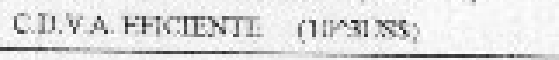 & 2100 & 13445 & 2033 & 2192 & 520 & $24 c 05 x$ \\
\hline \multicolumn{7}{|c|}{ Av02005 } \\
\hline 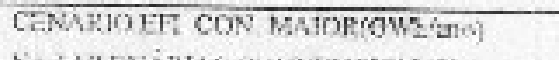 & 112 & 20 & $c_{2}$ & 7 & in & $45 \mathrm{Y}$ \\
\hline NotUWRNAUAS CORVINCWXNAS & 183941 & $252 \times 35$ & dsais & 1113 & 10.364 & S: $: 0 \%$ \\
\hline No. LtMANGRLASETCHENTES & 2381 & 22 & 14358 & 2343: & 0 & 60192 \\
\hline 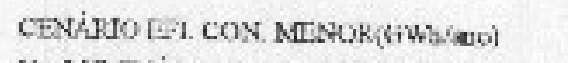 & 95 & 178 & 4.4 & 62 & 10 & 385 \\
\hline N: LUMNẊk2AS COSVINCIONATS & 1.57442 & 214626 & $29 \% \leqslant 1$ & 9453 & $13: 21$ & 45500 \\
\hline No 1EMTNARLASHFTIENTES & 2021 & 18 & 12188 & $1 \cos 69$ & 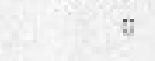 & $\sin 05$ \\
\hline 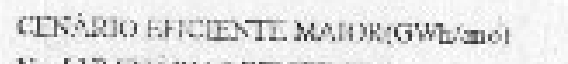 & $\theta 0$ & 113 & 3. & 58 & 4 & $26 \%$ \\
\hline No LUMNAKLAS ZJICEVIIS & 216273 & 2901795 & $5702:$ & 6262 & 18525 & 645183 \\
\hline RFDEKAO DEMANDA FUNIA (NWW & 12 & 22 & 4 & 3 & : & 43 \\
\hline 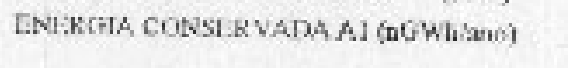 & 52 & 96 & 30 & 15 & $s$ & 188 \\
\hline CENAB1O FFCINAN MENOR(GWhians) & 52 & 102 & 20 & 52 & 4 & 249 \\
\hline No LUMINÁLAS LULZNNIFS & $1935 \%$ & 25092.1 & sruac: & $\operatorname{sen} 60$ & 1685 & 577453 \\
\hline HFTXCAOHWMANDAR KONIA (BN) & 0 & 17 & 3 & 2 & $t$ & 14 \\
\hline ENERE LA COVSER VACA $A Z$ (nitwe/no) & 4) & Th & 15 & 14: & $t$ & 148 \\
\hline \multicolumn{7}{|c|}{ 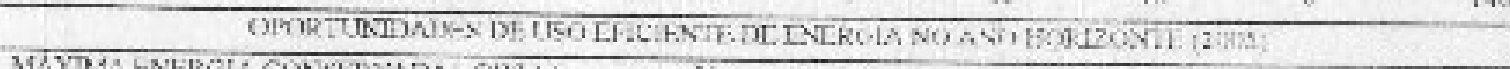 } \\
\hline 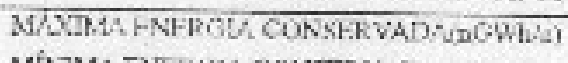 & 52 & 96 & 19 & 19 & 8 & $\overline{1 \times 0}$ \\
\hline 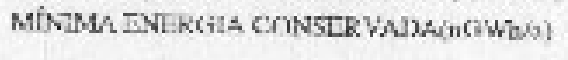 & 41 & 76 & 15 & 30 & fi & $14 \%$ \\
\hline KFIYTCAODEMANIJA MONTA (MW) & 12 & 22 & 4 & 3 & 2 & 23 \\
\hline REIIXIC:AOD DEMNNDA KONTA (MW) & 9 & 17 & 3 & 2 & 1 & 34 \\
\hline
\end{tabular}

FONTE CALCULOS FEITOS PELO AITTOR

NOTA: vGWh = nega GWh - energia efetivamente conservada

As quantidades de luminarias instaladas no ano 1995 foraut tiradas da pesquisa de campo cujo resultado for apresentado no Capitulo II,

As quantidades de luminárias projelades para o ano 2005 foram calculadas eu. basz dos cenarios apresentados no item 5.1 (potência total projetada e poténcia unitária das. luminárias). 
FIGLRA 5.4 ENERGIA CONSERVADA ACUMLLADA POR ALTERNATIVA EM FUNÇ̄̇O DO FATOR DE EFETIVIDADE DE CUSTO (19D5)

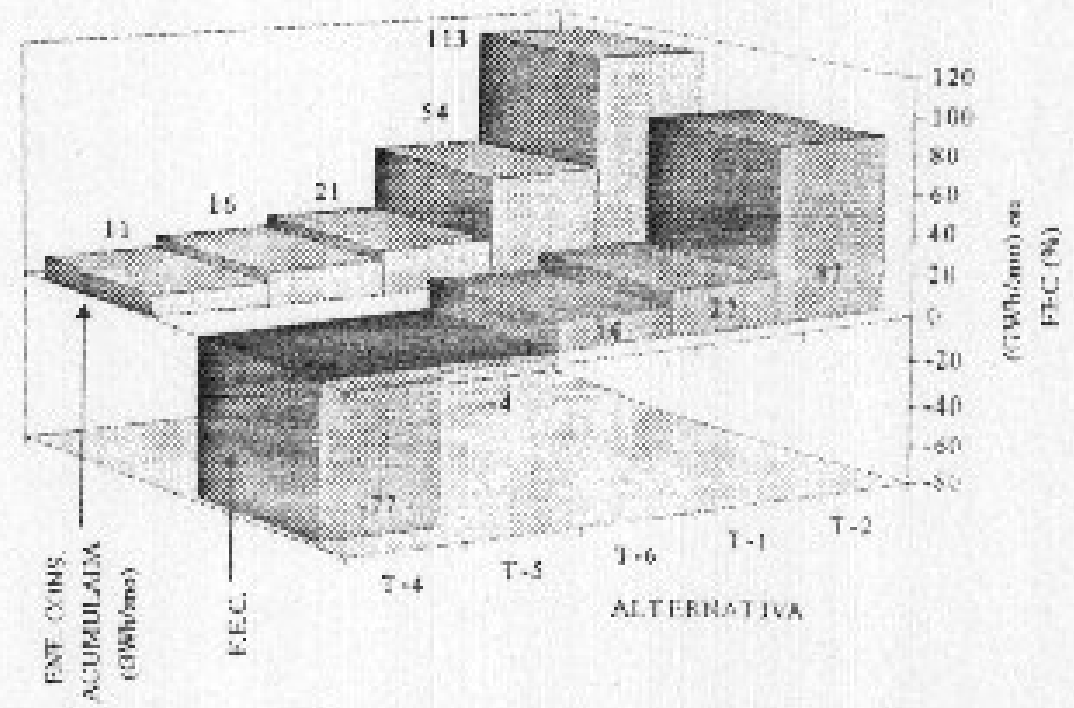

NOTA: Os valores de energia conservada acumulada estäc expressos en GWhano, as valores da FEC estão expressos ens porcentagem:

No presente estudo de casu, a maior reduçồo de energia por uso eficienie produz-se na alteruativa T-2 cujo valor é 59,3 GWh/ano ( $53 \%$ do total) correspondendo-lhe o major valor do CEC 25,6 US\$ MWL; não obstante, set este último valor o maiur das alternativas a sua implantaşa é desejável porçue analisando outras figuras de mérito obtém os seguintes resultados:

- CEC, o custo para comservar 1 MWh de energia é USS 25,6, menor do que o custo marginal de produção 83 USSMWh;

- CPC. o custo para conservar $1 \mathrm{~kW}$ de potêcia é 122 USSiano, entretanto, o menor custo prata produzir I kW de potêscia no ano horizonte considerando um fatos de capacidade 0,5 jgual que o fator de carga de conservação é 140 US\$ $\mathrm{kW} /$ ano (fator de efetrividade de custo 0,87 ). portanto conservar no ano horizonte é menor que gerar; e,

- TIR, a porcentagem es $50 \%$ segundo foi indicada no item 4.3.2. 
Depois, em segundo lugar encontra-se a altemativa T-1 que produz reduçāo de 32,3 GWh/ano ( $29 \%$ do total), o CEC é bastante redurido 6,4 US\$/MWh, o CPC também é reduzido 28 US\$ $/ \mathrm{kW} /$ ano motivo pclo qual o seu FEC c 0,22 .

As alternativas T-6, T-5 e T-4 emn ordem, não admitem discusş̂, já que proporcionam bons resultados de uso eficiente de energia c os FEC săo 0,$14 ;-0,04 ;-0,77$, respectivamente.

\subsubsection{EVOLUCÃO DA CAPACIDADT. DE CONSERVAÇĀO PARA O ANO HORLZONTE (2005)}

Com has nos estudos feitos anteriormente parte deles sintetizados na TABELA 5.9, segue-se uma nova proposta de planejamento para o ano horizonte.

Amatisundo of cenarios expressos no item S1 para n amo borizonte 2005, o cenário eticiêncis congelada maior prevè uma poténcia instalada de $122 \mathrm{MW}$ e uma energia do $536 \mathrm{GWh} / a n o$; tutretanto, o cenário eficiente maior prevê uma poténcia de $77 \mathrm{MW}$ e uma energia de 338 GWh/asto; a difcreaça telatisa entre estes cenários è $37 \%$. A diferenç̧a de poténcia em valores absolutos, ou sçja a poténcia conservadia poderia ser 45 MW c a energia conservada $198 \mathrm{GWh} /$ ano.

No mesmo ano 2005. O cerrário eficiência congelada menor prevé uma potència instaladia de $164 \mathrm{MW}$ e uma energia de 455 ( $\mathrm{WWh} /$ ano; entrelanto, o conário eficiente menor prevê uma patencia de 69 MW e una encrgia de 302 GWhano, a diferença relatisa de potència e energia cntre estes cenários é $34 \%$. A diferença te poténcia em valores alsolutos, ou seja a potência consetvads, scria $35 \mathrm{MW}$ e a energia conservada $153 \mathrm{GWh} / \mathrm{ano}$.

Contiuumos a analise, tho mesmo ano 2005 , pata os cenários do extremo superior e inferior observa-se que: s) o extremo superior corresponde ao ccnário eficiência congelada maior fomecendo valores de poténcia de $122 \mathrm{MW}$ e de energia de 536 (WWh/ano e, b) o extremo inferior corrcsponde ao ccnário eficiente menor fomecendo 
valores de potência de $69 \mathrm{MW}$ e de energia $302 \mathrm{GWh} /$ ano, a diferença relativa entre estes cenários tanto em potĉncia quanto em encrgia corresponde a $34 \%$.

A capacidade de conservação em potência e energia para o ano horizonte considerando somente us alternativas de troca propostas (T-1, T-2, T-4, T-5 e T-6), são menores do que os valores antes indicados. Assim, com o objetivo de construir as curvas de conservaçũo de ettergia baseadas no critério de mínimo custo, deline-se um novo cenário chamado "CONSERVACÀO MAIOR AI" que corresponde à diferença entre o cenário eficiência congelada maior e o cenário eficiente maior, cujo valor acumulado é 189 GWh/ano.

De maneira similar, detine-se o cenário de "CONSERVAÇÃO MENOR $A 2$ " que corresponde à diferença entre o cenário eficiêucia congelada menor e o cenário eficiente menor onde o valor acumulado è 148 GWhiano. As curvas de energia conservada basendas em critério de mínimo custo correspondentes à estes novos cenários podem ser mostradas nas FIGITRAS 5.5 e 5.6. 
FIGURA 5.5: CURVA DE ENERGIA CONSERVADA BASEADA NO CRITÉRIO DE MINIMO CUSTO PARA O ANO 2005 - CONSERVAÇĀOMAIOR A1

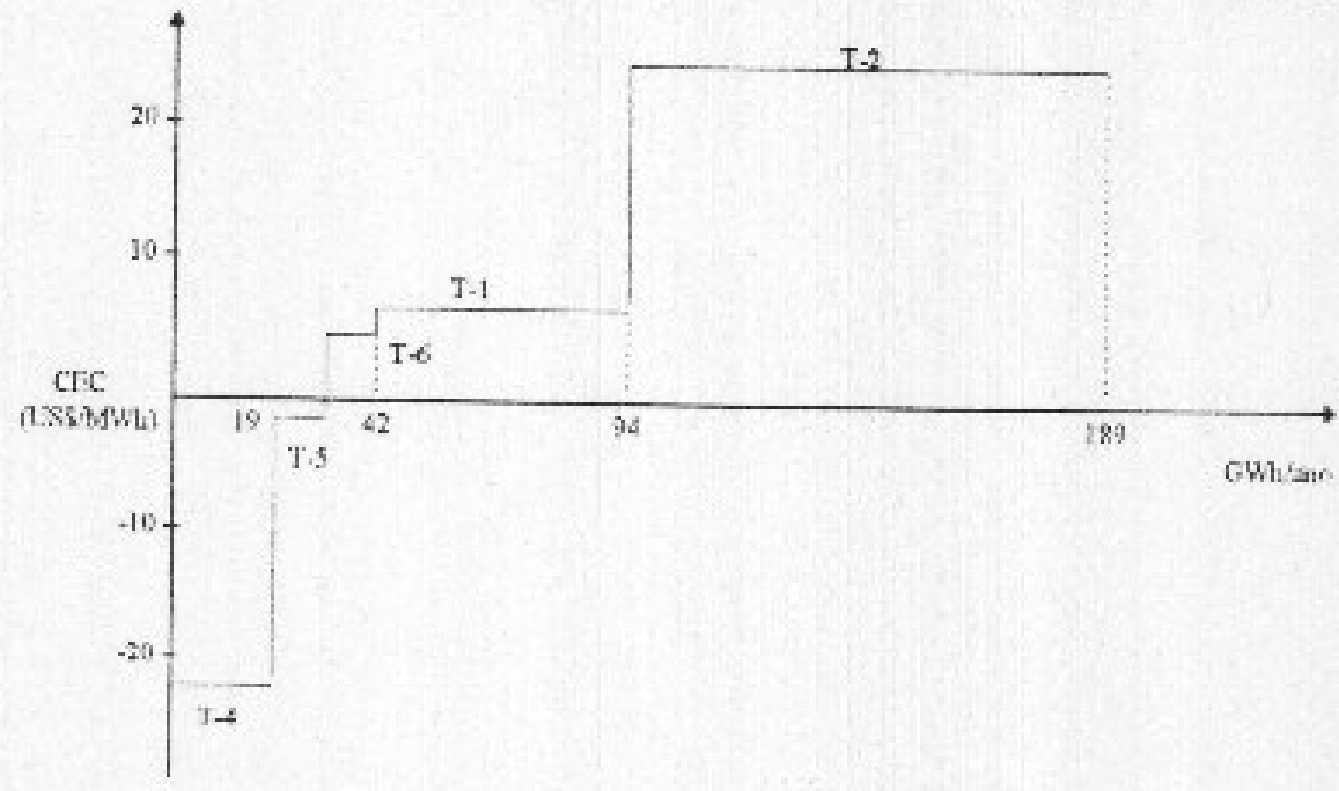

FIGURA 5.6: CURVA DE ENFRGIA CONSER VADA BASEADA NO CRTTERIO DE MINIMO CLSTO PARA O ANO 2005 - CONSER VAC̨ĀO MENOR AZ2.

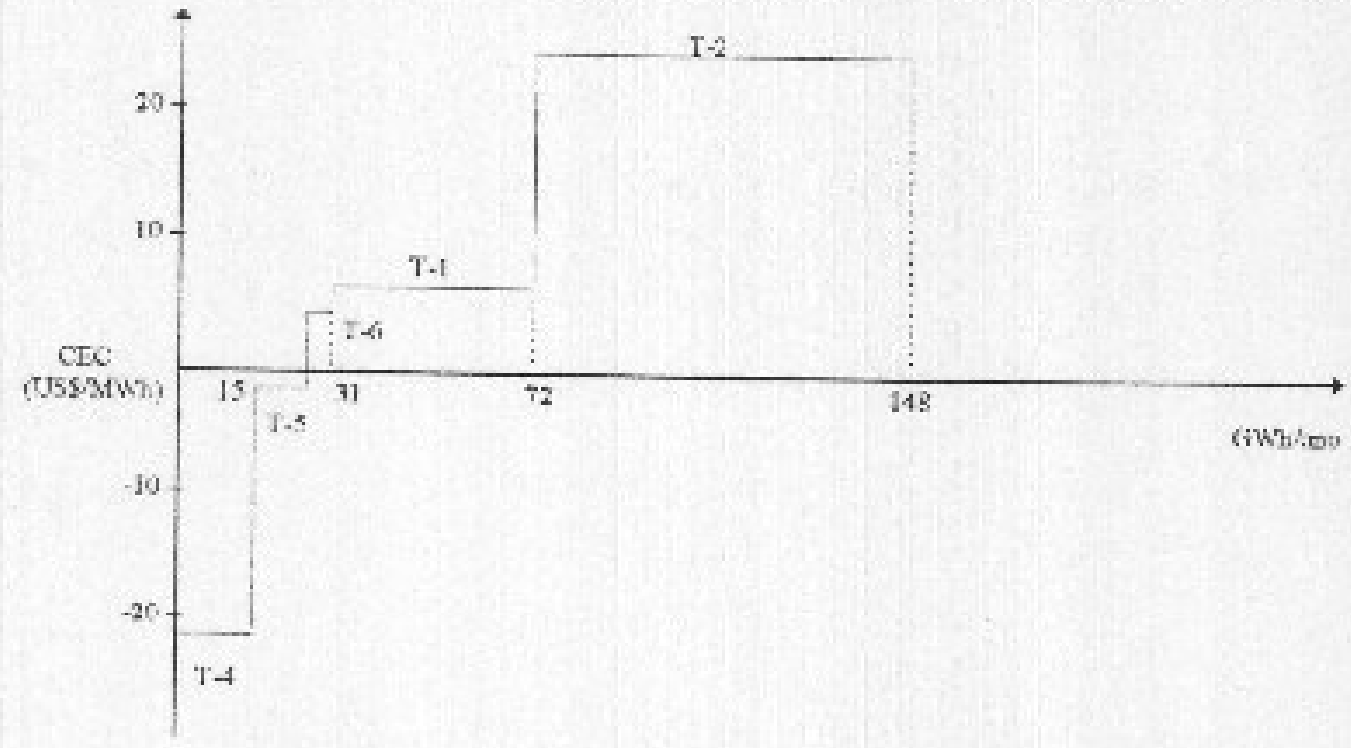

Os cenários de conservação MAIOR c MENOR fomecem uma faixa provável de conservação no ano horizonte. Esta faixa de conservaçâo prevê-se que estaria entre 148 GWh/ano e $189 \mathrm{GWh} /$ ano (potência conservada entre $34 \mathrm{MW}$ c $43 \mathrm{MW}$ ), equivalente à reduçẫo relativa de poténcia e encrgia entre $38 \%$ e $41 \%$. As oportunidades de couservaçào de energia para o ano atual e, os múximo c mínimo para o ano horizonte, visualiza-se na FIGURA 5,7 . 


\section{FIGURA 5.7: OPORTUNIDADES DE CONSERVACุÃO PARA O ANO ATUAL E HORIZONTE}

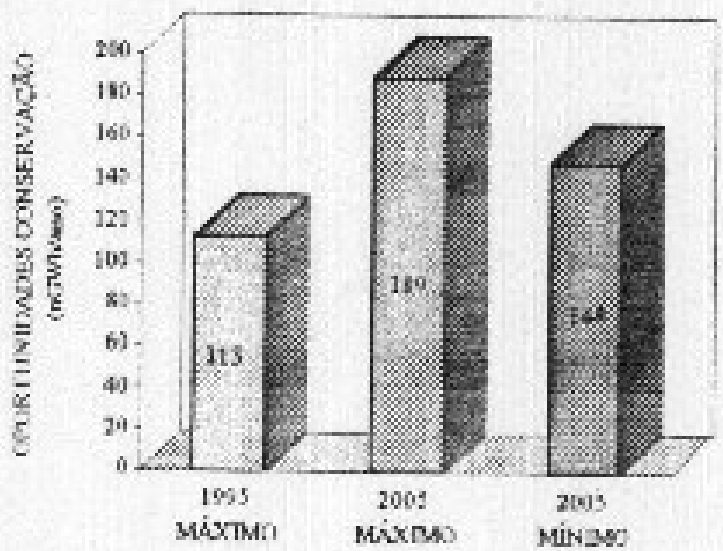

Baseados nos cálculos obtidos e apresentsdos nas TABELAS 5.8 e 5.9 pode-se visualizar na seguinte figura (ver FIGURA 5.8 para $n$ ano horizonte 2005) os potenciais de conservação cumulativos em ordem segundo of fator de efetividade de custo (FEC) e o custo de energia conservada (C.FC), tanto para o cenário de conservaçīo maior quanto para o cenário de conservação menor. Esta figura dá uma višăo geral integrada dos recursos de geraçāo e uso final através da relação entre os custos da potência conservada (CPC) e o custo da potência instalada (conservada/gerada). Além disso, esta figura mostru através do fator de efetividade de custo (FEC) em ordem crescente (cxpressa em porcentugens), quais as tecuologias viśveis a serem implantadas, e ao mesmo tempo. indica quanto custa conservar com cada tectnologia. 


\section{FIGURA 5.8: ENERGIA CONSERVADA ACUMULADA POR ALTERNATIVA DE CONSERVAÇĀO EM FUNÇẢO DO FATOR DE EFETIVIDADE DE CUSTO PARA CENÁRIO CONSERVAÇÃO MAIOR E MENOR (2005)}
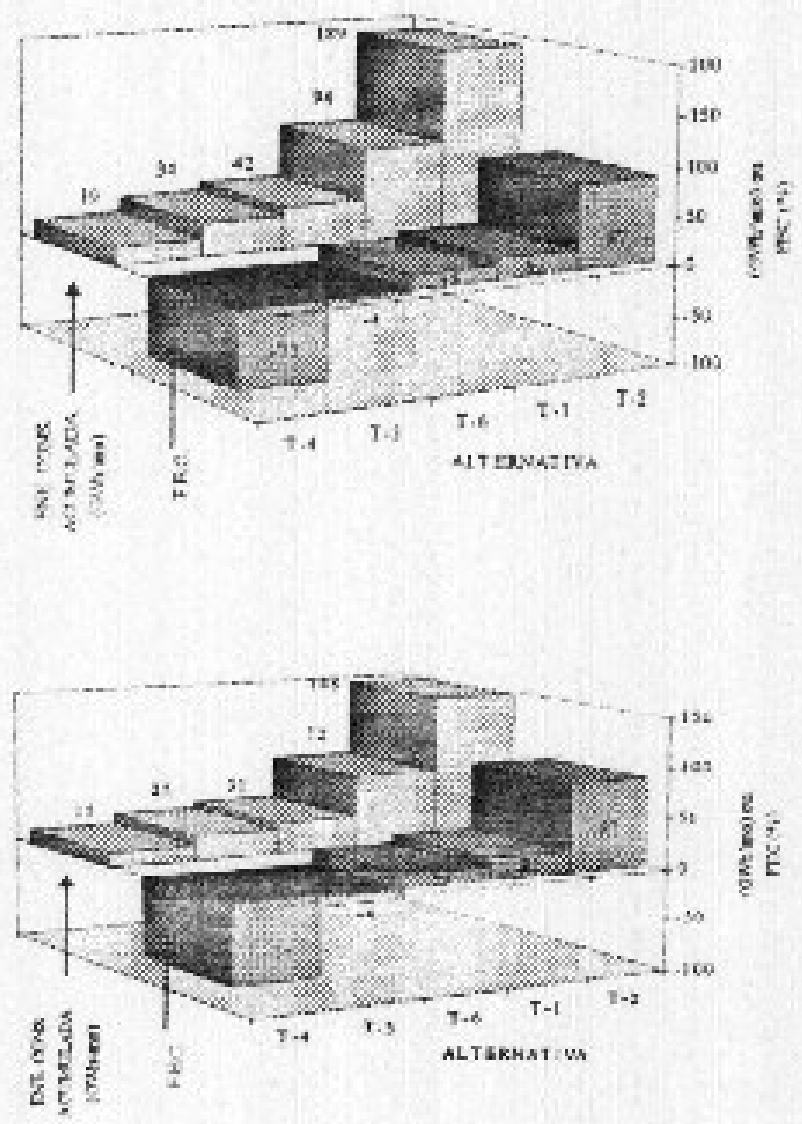

\subsubsection{POTENCIAS I ENERGIAS TRANSFERIDAS AO LADO DA CARGA AO LADO DA GERAÇÄO}

Tolu sistema elétrico tem perdas de potência e energia devido principalmente ao efeito Joule no transporte dessa energia a partir da geração até os usos finsis. Os valores anteriormente determinados foram calculados para o lado da demanda.

Segundo a TADELA 3.5 du Capítulo III, o sistems elétrico equatoriano apresenta perdas de potência na ordem de $15,9 \%$ ( $\mathrm{cm}$ demanda máxima), cntretanto as perdas de energia sũo de $10,5 \%$. 
Na TABELA 5.10 observa-se os valores de poténcia e energia transferidos do lado da demanda (baixa tensão na rede de distribuição) para o lado da geração (alta tensāo) das ahternativas de troca viảveis. A máxima potência que poderia ser conservada no ano (1995) -segundo as caracteristicas deste estudo de caso- atinge 30,9 MW (na hora de ponta ou denanda máxima), entretanto a energia conservada atinge 127 GWhiano.

No ano horizonte (2005), a energia conservada poderia situar-se dentro du faixa entre 167 e $211 \mathrm{GWh} /$ ano e o valor equivalente de potência na ponta entre 40,4 e 51,3 MW: Isto significa que o deslocamento de investimentos em geração no ano horizonte cstará na faixa entre 40,4 e 51,3 MW. comparando estes valores com a terceira (scgundo seu porte) usina hidrelétrica do Equador -a usina Pisayambo- representa porcentagens entre $58 \%$ e $74 \%$ da capacidade instalada.

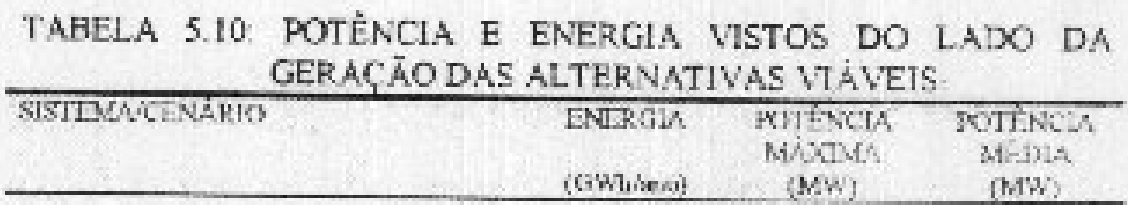

\begin{tabular}{|c|c|c|c|}
\hline CONVHINCTONAI ATILAI. & & & \\
\hline EFTCIENTE ATTIAL & $19 ?$ & 47.8 & 44.5 \\
\hline FOTLRCLAL CONSERVACX̄O & 127 & 30,9 & 25,1 \\
\hline ANO Dok17astE 2005 : & & & \\
\hline ETICIE:NEIA OXNOE NDA MAICIZ & $\$ 12$ & 124,3 & 116.8 \\
\hline FHICIENCLA CONGII ADA MENOR & 435 & 105,6 & 99,2 \\
\hline EEICIENTI: MAIC SR & $30 !$ & 73,0 & 64.9 \\
\hline EHCIIIE:MENOK. & $26: 8$ & 65.2 & 61.2 \\
\hline CONSEK VAÇÖO MHIOR & 211 & 51,3 & 48,1 \\
\hline CONSFIE VASAO MIENUL: & $16 ?$ & 40,4 & 38,0 \\
\hline
\end{tabular}

\subsection{ESTRATÉGIAS PARA USO EFICIENTE DE ENERGIA NO SETOR DE LLUMINAÇÃo PÚBLICA (IP) DO EQUADOR}

Em alguns casos pode ser preferivel, do ponto de vista da economia de investimento, a concessiotı́xia de energia elétrica subsidiar o consumidor para substituir um cquipamento por outro que economize energia. Assim, a concessionária deixa de investir na expansão da geraçâa, da transtrissão $\mathrm{e}$ da distribuiçāo a parcela correspondente à energia economizada. Essa é uma decisão de intercsse social que contraria a lógica nomal da concessionária de ampliar sua venda de energia. As empresas cstatais devem 
ser orientadas para seguir essa linha, o que nāo tem ocorrido, com poucas exceções. Devera haver algum tipo de regulamentação ou estimulo do Estado para esse fim (Pinguelli, 1993).

Nào se acredita que melhorias de eficiéncia no uso de encrgia ocorram espontaneamente a partir de iniciativas dos consumidores. A larga cxperiência intervacional no assunto mostra que sem a participaçāo das companhias de energia, do govemo e das próprias industrias de equipamentos, a criação de um mercado para csses produtos mais eficientes nào se viabiliza de maneira significativa. Uma atuação maỉ agressiva nessa direção deverá estar amparada en avaliaçôes do tipo que pretendemos ihustrar neste trabalho, bem como de acompanhamento c mensuraçōes para verificar a atratividade econômica dos programas (Jannzzi, 1993).

No Equador observa-se que importantes consumidores de energia como o proprio setor elétrico que controla a IP e o governo nảo consideram o desempenho energético como critério de compra de equipamentos para consumo próprio, ou mesmo especificaçôes para construções das suas instalaçỏes e'ou edificios que proporcionem menores requisitos durante a vida útil desses empreendimentos.

Programas de eficièncir energética podem set importantes elementos de geraçào de novos empregos tamhém, Eles criam uma demanda por serviços técnicos especializados para a realizaçāo de auditorias, consultores para elaboração de projetos, desenvolvinento de softwares nacionais para auxiliar nas especificaçoes de projetos c. técnicos para manutençåo de equipamentos (Jantıużi. 1993).

Sob condiçồcs de transiçẫo do setor clétrico, cumo atualmente se encontra o Equador, as dificuldades ainda serāo maiores para a implantaçāo de programas de uso eficiente de energia no setor de IP segundo o escopo deste estudo de casa, devido fundametitalmente à falta de decisōes na ordem administrativa e de recursos económicos; no entanto, existem outros mecanismos para obter esses recursos, um daqueles é a concessân mediante licitação para venda dos "negawatt-hora" e outro mecanismo poderia ser a compra dos equipamentos via "leasing". 
De qualquer maneira, existe a sugestão da intervenção do capital privado no novo processo de modemização do setor elétrico no setor da IP.

A estratégia téenica conveniente, segundo resultados da análise deste Capitulo, deverá proceder imediatamente com a implantação do programa. Portanto, o trabalho de retirar c instalar as novas luminárias poderia ser parcelado e executado por contratação com companhias privadas nacionais que trabalham na área de engenharia elétrica. As auditorias e fiscalizaçào podem ficar sob a responsabilidade do INFCFL e as concessionárias, ou ainda, também, poderia ser licitada para intervenção privada.

$\mathrm{Na}$ ordem política, se deverá prover todas as leis e regulamentos que facilitem o desenvolvimento dos programas, especialmente se adota-se a via mediante a participaçâo privada.

\subsection{Concuusóes}

Os cenários proporcionam os seguintcs valores de energia para o setor de IP do Equador no ano horizonte 2005:

- Eficiêncin Congeladu maior: $536 \mathrm{GWh} / 4 n 0$

- Eficiência Congelada menor: $455 \mathrm{GWh} /$ ano

- Eficiente maior: $337 \mathrm{GWh} / a n o$

- Eficiente menor: $302 \mathrm{GWh} /$ ano

- Tendencial maior $496 \mathrm{GWh} / \mathrm{ano}$

- Tendencial menot $442 \mathrm{GWh} / \mathrm{ano}$

Portanto, a faixa de potencial de conservaçăo de energia no ano horizonte (2005) para todas as tecnologias do setor de IP do Equador situa-se entre $153 \mathrm{GWh} / \mathrm{gmo}$ e 199 GWh/ano. Valores próximos sos potenciais de conservação correspondentes as altemativas propostas e consideradas vínveis neste estudo de caso (T-1, T-2, T-4, T-5 e T-6) e que atinge a faixa entre $148 \mathrm{GWh} /$ ano e $189 \mathrm{GWh} / \mathrm{ano}$. 
$\mathrm{Da}$ análise das duas alternativas para troca de luminárias a) no ano $0 \mathrm{e}, \mathrm{b}$ ) nos anos $1,2 \mathrm{e}$ 3. determinou-se as TIR para cada caso, sendo maior o segundo caso com o valor de $46,7 \%$ frente a $31,6 \%$ do primeiro caso; portanto, a conveniência está đirigida à troca de luminárias no periodo de trề anos. No entanto, as TIR situam-se superiores à taxa de desconto (12\%). Por outro lado, este cálculo considera a substituição total da huminária, na prática poder-se-ia apresentar situaçòes diferentes, jú que em funçăo do estado da luminária, em certos casos só seria necessário a troca da lâmpada, reator e iguitor, dimiauindo assim o investimento imicial e aumentando ainda mais a porcentagem da TIR.

A despesa do setor de IP atualmente atinge o valor USS 43,6 mithöes por ano (considera-se o valor de CDVA que inclui investimento c despesa operacional). Mediante a implantaçào dos programas de uso eficiente, este valor pode diminuir para USS 35,7 milhŏes, poupando USS 7,9 milhōes por ano, cquivalente à diminuição de $18 \%$ da despesa por ano. Além disso, considerando somente o elenco de substituições (T-1, T-2, T-4, T-S e T-6), o valor de CDV cai de USS 184 milhôes para US\$ 139 mithôes, encquanto os valores anualizados de CDVA cai de US\$ 32,6 milhōes para US\$ 24,7 milhōes, o CDVANE sobe de US\$ 8,5 milhōes para US\$10,0 milhōes e, a despesa por consumo de energia cai de US\$ 24,0 millhôes para US\$ 14,6 milhōes. O equivalente pcla diminuiç̧̄o do consumo de energia é de US\$ 9,4 milhôes, dos quais US\$ 6,1 săo por potĉncia (baseado no custo marginal de potencis 235.2 US\$ $\mathrm{kW}$ que inclui custos de geraçî̀, transmisș̆o e distrihuiçāo) e US\$ 3,3 por energia.

O investimento inicial para comprar o conjunto de luminarias de vapor de sódio para o programa de uso eficiente de energia atinge USS 47,7 milhōes; nào obstante, este valor de investimento inicial é ficticio, já que para o cálculo do valor real deve-se considerar a despess que vormalmente deveria se realizar no sistema convencional (USS 32,6 millañes). Portanto, o valor liquido do investimento inicial diminui para USS 15,1 milhỏes, valor que ć absorvito pela diminuiçào do consumo de cnergia. No entanto, seguado já foi dito, na prática o investimento imicial poderia ser ainda menor se snmente for trocado certos elementos como a låmpada, reator $\mathrm{c}$ iguitor. Este cstudo de caso, por nào ter informaçảo do estado atual das huminárias, considera a troca total da luminária, e 
os resultados obtidos garantem desde qualquer ponto de vista a conveniência dos programas.

Os valores do $\mathrm{CEC}$ e $\mathrm{CPC}$, mantêm-se constantes nas altemativas analisadas e, os seus valores para o elenco de substituiçôes atinge 13,2 US\$iMWh e 328 USS/kW respectivameute. Estes valores correspondem às "figuras de mérito" e podem-se conferir respectivamente com os preços da eletricidade (o custo marginal para IP é 83 USSMWh) e os custos de instalaçâo de usinas (o mais baixo para uma usima de gás natural é de 398 USS:kW); além disso, os valores são decisórios na determinação da conveniència da implartą̧ão dos programas de uso eficiente de energia. O CEC é scmente $16 \%$ do custo marginal da eletricidade e o $\mathrm{CPC}$ é $82 \%$ do menor custo para imstalação de usinas.

Os FEC para todas as alternativas propostas no ano horizonte 2005 são menores que 1.0, isto garanta que os investimentos emr programas de conservação até essa data são viaveis e que é melhor conservar que gerar. No entanto, quando se considera as perdas por transmissāo o FEC é ainda melhor.

A oportunidade de conservaçầ no ano 1995, considerando somente as alternativas viáveis (T-1, T-2, T-4, T-5 c T-6), atinge o valor em cuergia de 113 GWh/ans (ern potência $26 \mathrm{MW}$ ). Em termos econômicos considerando o custo marginal de potência de 235,2 US\$:kW/ano pela instalação da geração, transtrissāo e distribuição, o deslocamento dos recursos por uso eficiente de encrgia eqüiivale a US\$ 6,1 milhōes por ano ou LS\$ 34,4 milhâes no periodo de 10 anos que é o tempo da análise.

As oportunidades de conservaçẫo para o ano horizonte 2005, considerando as alternativas viáveis, situam-se na faixa de encrgia entre 148 e 189 GWhiano (potência entre 34 e $43 \mathrm{MW}$ ).

A oporturidade de conservação no ano 1995 para o lado da geração (considerando perdas por transporte e alternativas viáveis) atinge $127 \mathrm{GWh} / \mathrm{ano}$ (30,9 MW na hora de demanda máxima). 
As oportunidades de conservaçào no ano horizonte 2005 para o lado da geraçảo (considerando perdas por transporte e alternativas viáveis), situam-se na faixa de energia entre 167 e $211 \mathrm{GWh} /$ ano (potência entre 40,4 e 51,3 MW na hora de demanda múxima).

O uso eficiente de energia em IP dentro do contexto elétrico equatoriano para 0 ano 1995, representa urna dimisuição do consumo de energia de $1,8 \%$, enquanto em relação ao consurno do sistema de $\mathrm{PP}$ a diminuiçāo é de $26 \%$.

O uso eficiente de encrgia em IP dentro do contexto clétrico equatoriano pнтr o sno horizonte 2005 , representaria uma diminuição de necessidade de energia de $1,5 \%$ etn média e cm relação ao consumo do sistema de IP uma diminuiçâo de $35 \%$. 


\section{CAPITULO VI}

\section{CONCLUSÖES E RECOMENDACÕES}

Do mareo governamental, legal e institucional

Segundo o Decreto Lei de criaçùo do INECEL, é da competência deste organismo a elahoraçùo de diretrizes para a atuaçâo do Setor Elétrico, em consonância com a politica energética governamental, a coordenaçâo do plancjamento da operaçāo e da expansão dos sistemas elétricos, tanto na àrea técnica quanto na área financeira: alêtn disso, coordenar as atividades das concessionárias nas árcas técuica, financeira e administrativa. Desta maneira, desenvolve-se o setor clétrico equatoriano, isolado das outras atividsdes

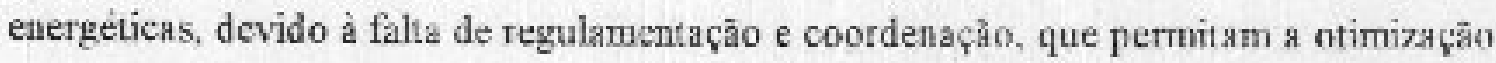
dos recursos energéticos. A regulamentação existente c velha c obsoleta. Pelas experiências de outros paises tem-se demostrado que o plancjamento energético deve ser intcgral, jí que todos os atores encontram-se atuando dentro de uma matriz energética com possibilidades de mudar -dentro dela- de um lugar para outro, quer dizer. acréscimos energéticos de um setor pode ser decréscimos para outro setor.

Sob estc antecedente, o Equador precisa das leis $c$ regulamentações que permitam a coordcnaçäo dos organismos encarregados da questão energética tais como Irstituto Nacional de Energia (INE), Instituto Equatoriano de Eletrificação (INECEL), Petroequador, etc, sob as diretrizes do Ministério de Euergia e Minas.

A atuação do INECEL e das concessionárias deve estar encaminhtada com o escopo de compatibilizar os interesses lockis e rcgionais das concessionárias com aqueles do Pais e 
do Setor Elétrico, no seu conjunto, assegurando o atendimento ao mercado consumidor com padrôes elevados de confiabilidade e baixo custo.

No Equador é marcante a falta de desenvolvimento tecnológico de interesse do setor elétrico, assim, não existe apoío para as universidades com este fim, à criaçăo de laboratórios de pesquisa e imdustrias, à mobilização de empresas de engenharia, etc.

o Equador precisa das leis e regulamentos que permitam e garantam a participaçāo privada no setor elétrico, sob condį̧ōes especificas e caracteristicas próprias do pais.

\section{Do marco financeiro}

O setor elétrico equatoriano encontra-se atravessatio a pior crise energética da sua história, marcada fundamentalmente pela falta de recursos financeiros para a expansio da oferla de energia. lsto se deve à falta de autofinanciamento do setor, à gestão dos govemos na questão tarifäria que sempre esteve conduzida coun fins demagógicos, até chegar ao controle politico das tarifas que não cobrem o serviço de atendimento nem permitem a sua expansão. Existe racionamento diário de energia elétrica (entre 4 e 8 horas na estaçầ seca), o que afeta todos os setores produtivos do P'aís.

Os recursos financeiros que o Equador esteve acostumado a receber como emprestimo dos organismos e bancos internacionais para a sua expansâo do sistema elétrico, não chegarão até que o governo privatize e modemizc o setor, segundo atitude demostrada por esses organismos $\mathrm{em}$ capítulos anteriores. Outra exigência desses organismos é a implementação de tarifas reais baseadas em valores de custo marginal, portanto, o prę̧o médio de venda de energia dos consumidores subirá para 76 US\$/MWh cm 1996; no entanto, o custo médio situa-se em 67 US\$iMWL (o custo marginal para IP é 83 USS/MWh). 


\section{Da confiabilidade da geração elétrica}

Segundo foi dito a capacidade instalada em geração hidrelétrica atinge $65 \%$,portanto, a geração elétrica é majoritariamente hidrelétrica e depende do fator hidrológico, sendo crítico para a estação sech (periodo cntre outubro e fevereiro), mais ainda quando as usinas de grande porte (Paute, $\Lambda$ goyán e Pisayambo) encontram-se siruadas na mesma margem da corditheira oriental Além disso, pelos motivos financeiros indicados, existe atrasu no cronograma do plano de expanșio da oferta.

Das experiências internacionais

Alguns países no âmbitu mundial encontram-se implantando programas de uso cficiente de energia, especialmente para os setores residencial e comercial. Na América Latina há alguns paises que iniciaram estes programas inclusive na década passada. O setor da ihuminação pública tem sido esquecido na implantaçāo de programas e talvez o motivo deve-se que a porcentagem do consumo desle setor em relação ao consumo total de energia é pequeno ( $7 \%$ para o caso equatoriano, $3,5 \%$ para o Brasil, $3 \%$ para o Chile); no entanto, existem países na América Latina que já iniciaram programas neste setor com sucerso, caso especifico da Colómbia, do Brasil c do Chile.

\section{Do potencial de uso eficiente no setor de IP do Equador}

O potencial encontra-se identificado: a) no uso de luminárias de vapor de mercúrio cuja porcentagem de participaçāo na pottencia total instalada atinge $72 \%$ e, b) no uso de huminária: incandescentes, fluorescentes c luz misł com participaçāo de $2,5 \%$. Dentro do elenco de luminárias de vapor de mercurio, a luminária de HG-175 W tem a maior penetração com 55\%. Em segundo lugar encontra-se a huminária de HG-125 W com uma penetraçāo de $29 \%$, sendo estes dois tipos mais importantes. Em valores absolutos o 
potencial de conservação das tecnologias de mercúrio e de luz mista atingem $66 \mathrm{MW}$ de un total instalado de $90 \mathrm{MW}$ do sistema de IP do Equador.

\section{Das propostas de substituição de luminárias ou lâmpadas}

Fotam propostas seis altemativas de substituição de luminárias: T-1 (HG- 125 W por NA-70 W); T-2 (HG-175 W por NA-100 W); T-3 (HG-175 W por NA-150 W); T-4 (HG-250 W por NA-150 W); T-5 (HG-400 W por NA-250 W); e, T-6 (MS-160 W por $\mathrm{NA}-50 \mathrm{~W}$ ), depois de realizar em primeiro lugar uma análise técnica na qual se verificou melhoria dos indices de lumiaància e iluminància para tudas as alternativas; $\mathrm{e} \mathrm{cm} \mathrm{segundo}$ lugar. uma análise econômica baseada em "figuras de mérito" na qual se verificou converièncio para todas as altemativas exceto T-3; portanto, recomenda-se a implantaçẫo de programas de uso eficiente de energia nas alternativas T-1, T-2, T-4, T-5 e T-6,

Estes resultados de substituiç̧ơ foratn obtidos para o caso mais critico, isto é para a substituiçăo total da tuminária (lâmpađa, carcaça, reator, ignitor, braço, etc.), sob a premissa que não existe conpatibilidade entre os elementos a serem substituidos, devido as diferentes caracteristicas construtivas das luminárias segundo os fabricantes c além dissu, não há certeza do estado das luminárias.

Por outro lado, todas as luminárias recomendadas são do tipo de vapor de sódio de alta pression, que apresentam como característica uma boa reprodução las cores. $\dot{\mathbf{E}}$ recomendada a substituição por luminárias de vajor de sódio de baixa pressão somente para lug̣ares onde esta característica não é importante, 


\section{Dos resultados da análise econômica individualizada}

A análise econômica indrvidual de luminárias baseada nas "figuras de mérito" proporcionou resultados satisfatórios para todas as altenıativas exceto T-3. As TIR são superiores à taxa de desconto ( $12 \%)$, os CEC sào menores do que o custo marginal para a IP (83 USS/MWh), os CPC são menores do que os custos unitários para instalação de usinas de geraçāo, o CDV dos equipamentos eficientes são menores do que os convencionais, o custo do lümen-hora para equipameutos eficientes é menor do que para equipamentos convencionais, portanto, os resultados da análise económica justificam a instalaçào e troca dos equipamentos por tecnologia de vapor de sódio de alta pressão, para as alternativas T-1, T-2, T-4, T-5 e T-6.

Da análise de sensibilidade

Os programas de uso eficiente contimuam sendo viáveis para preços da energia na faixa entre 40 e 83 US\$ $/$ MWh, ou seja a partir de qualquer ponto de vista (clientes, concessionárias ou INECEL) os resultados econômicos e as recomendaçōes ธāo as mesmas. De maneira igual com a variaçầ do tempo de funcionamento da IP. na faixa mais provavel de ocorret entrc 11,5 e 12,5 horas diárias, as recomendaçốc continuam inalterávcis; no entanto. observa-sc que ainda cstas variaçôes são menores do que o caso anterior.

Da análike do eleneo de substituiçōes

O imvestimcnto para o programa de uso eficiente de energia em todo o elenco de substituiçōes propostas e que resultaram viàveis atinge US\$ 47,7 milhôes; nāo obstante, este valor de investimento inicial é fictício, já que para o cálculo do valor real deve-se considerar a despesa que normalmente deveria se realizar no sistema convencional (US\$ 32,6 milhōes). Portanto, o valor liquido do investimento micial diminui para US\$15,1 
milhòes, valor que $\mathfrak{e}$ absorvido pela diminuiçào do consumo de energia nos anos seguintes. No entanto, segundo já foi dito, na prática o investimento inicial poderia ser aibda menor se somente for trocado certos elementos como a làmpada, rcator e ignitor. Este estudo de caso, por não ter informaçào do estado atual das lumimárias, considera a troca total da huminária, e os resultados obtidos garantem desde qualquer ponto de vista a conveniêtucia dos programas.

A ordenaçāo dos programas de substituição em fumçâo do CEC é a seguinte: T-4, T-5, T-6, T-1 e T-2, porém, a análise econômica do elenco de substituiçôes determinou como mellor forma a implantaçäo dos programas no periodo de três anos, já que desta maneira a TIR do investimento será $46,7 \%$ maior do que a implantação imediata cuja TIR é de $31,6 \%$.

A oportunidade de conservação do sistema de TP no ano de 1995, cumsiderando somente as alternativas viáveis (T-1, T-2, T-4, T-5 e T-6), atinge o valor em energia de 113 GWh/ano equivalente $\mathrm{cm}$ potência de $26 \mathrm{MW}$.

As oportunidades de conservação para o ano horizonte 2005, considerando as alternativas viáveis, situam-se na faixa de energia cntre 148 e 189 GWh/ano equivalente em potência entre 34 e $43 \mathrm{MW}$, respectivamente. Estes valores foram obtidos do resultado da unálise dos cenários.

- cenário "cficiềucia congelada maior" prevê o consumo de energia para o ano hotizonte $2005 \mathrm{em} 536 \mathrm{GWh} /$ ano;

- cenário "cficiência congelada menor" em $455 \mathrm{GWh} / \mathrm{ano}$;

- cenário "tendencial maior" em $496 \mathrm{GWh} / \mathrm{ano}$;

- cenírio "tendencial menor" em $\mathbf{4 4 2}$ GWhiano;

- cenário "eficiente ou potencial técrico maior "em $338 \mathrm{GWh} / \mathrm{ano}$; e,

- cenário "eficiente ou potencial técnico menor" $\mathrm{cm} 302 \mathrm{GWh} / a n o$. 
No entauto, as projeções do INECEL sào:

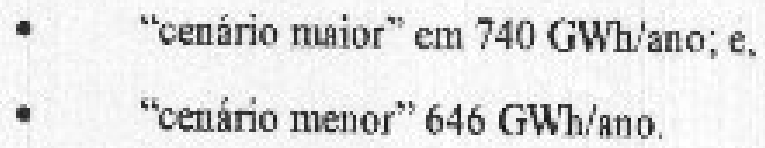

Os resultados deste estudo de caso foram obtidos usando metodologias deservolvidas para usos finais, entretanto o INFCEL usou métodos econométricos (variáveis PIB e taxa de incremento da população).

Além disso, verificou-se, que as caracteristicas das "figuras de mérito" ohtidas para o ano base permanecem inalteráveis no ano horizontc 2005

\section{Do financiamento para os programas de substituiçẵo}

O maior problema atual do Equador é a falte de recursos financeiros pars o setor elétrico, segundo já foi dito, no entanto, este estudo de caso apresenta outras alternativas baseadas na experiência intenaacional.

- execução dos programas via "leasing" (aluguel dos equipamentos com opçåa de compra):

- licitação e venda dos "negawatts" mediante concessāo às companhias privadas

Assim, o Equador vôo realizará investimentos, não aumentหrá a divida exterrı, cumprirá com as exigências dos organismos internacionais sobre a prrticipąão privalla, produzirí uma ótima alocaçăo dos recursos (uso eficiente da energia, conservando $\mathrm{cm}$ hugar de gerar) e terá maior disponibilidade da capacidade instalada no lado da oferta. 


\section{Das vantagens econômicas e financeiras}

Os programas propostos de uso eficiente de energia sob qualificação de viáveis produzem poupança de US\$ 9,4 milhôes por ano pela diminuiçào de potência e energia. Por este motivo, o deslocamento dos investimentos nas áreas de geração, transmissão e distribuiçâo atinge o valor de US\$ 6,1 mithôes por ano (considerando a vida útil das haminírias em 10 anos e a taxa de desconto de $12 \%$; esta quatidade -em valor presenteé igual que produzir deslocamento na instalação de uma usina de geração cujo custo inicial scja US\$ 33,9 milhỏes). A poupança pela diminuiçāo do consumo de energia atinge US\$ 3,3 milhôes por ano. No entanto, o valot de CDVANE (inclui custos operacionais, exceto o consumo de energia elétrica) para o elenco de substituiçôes aumenta de USS 8,5 milhòes para USS 10,0 milhōes, obtendo um saldo negativo deste viltimo caso de US\$ 1,5 milhòes por ano. Portanto, o balanço abrangente de perdas e ganhos pela implantaçõo dos programas de uso eficiente de energia proporciona resultado com saldo positivo de USS 7,9 milhốes por ano (o valor presente é USS 44,6 milaỏes\}).

A TIR dos investimentos para uso eficiente de energia segundo as caracteristicas expressas situa-se ern $46,7 \%$. sendo uma porcentagem atrativa para qualquer investidor.

Do preço médio de energia para consumo de IP

Em outubro de 1995 a tarifa para IP situava-sc em 50 US\$/MWli. Nor tntanto, o custo marginal da energin encontra-se em 83 US\$MWh. Alem disso, se adicionamos os custos operacionais, a tarifa real deveria se situar em 110,7 USS MWh, portanto o pagamento só cubre $45 \%$ das despesas c o resto é subsidiado pelo governo. Com a implantaçăo dos programas de uso eficiente, o preço médio sobe para 127,2 USSMWL, porém, a vantagem encontra-se na dimimuiçấo da despesa total (pela diminuição de consumo de 
energia) do sistema de IP e portanto na diminuição do pagamento individual dos chientes. Lembra-se que o pagamento do consumo da IP é feita pelos usuários do serviço elétrico.

\section{Das oportunidade e barreiras}

A maior vantagem dos programas de uso eficiente de energia no setor de IP, implica que aqueles podem ser implantados pela imposiçào ou decisão de poucas pessoas ao nivel do goveno, ministério, INECEL ou concessionárias, utilizando leis, decretos, resoluçòes, acordos. Contrário aos programas para setores residencial e comercial que precisam de campantlas publicitarias, acompanhamento, informação, marketing e vários atores atuando simultaneamente nos lados da concessionária e dos clientes.

Outra vantagem dos programas de IP é que pode-se atingir altas taxas de penetraçầ no uso da nova tecuologia, assim, por exemplo, uma estimativa para o caso equatoriano situa-se $\mathrm{cm} 98 \%$.

\section{Dos impactos ambientais}

O setor elétrico e especificamente as usinas de geraçào térnica do Equador emitem $\mathrm{cm}$ média ao meio ambiente $0,77 \mathrm{kt}$ entre $\mathrm{SO}, \mathrm{NOx}, \mathrm{HC}, \mathrm{CO}$ e $\mathrm{CO} 2$ por cada MWh gerado e, além disso este sctor é responsável pela $5 \%$ das emissões totais (OLADE-SIEE, 1993). Com a implantaçáo dos programas de uso eficiente de encrgia propostos neste cstudo de caso, as ervissōes diminuirăo em $87 \mathrm{Mt}$ 'ano, se considera-se a IP produzida exclusivamente por gerą̧ão térmica. 
ANEXOA

MAPAS GEOGRÁFICO E DO SISTEMA ELÉTRICO EQUATORIANO 


\title{
ANEXO A
}

\author{
FIGURA A.1
}

\section{MAPA GEOGRÁFICO DO EQUADOR}

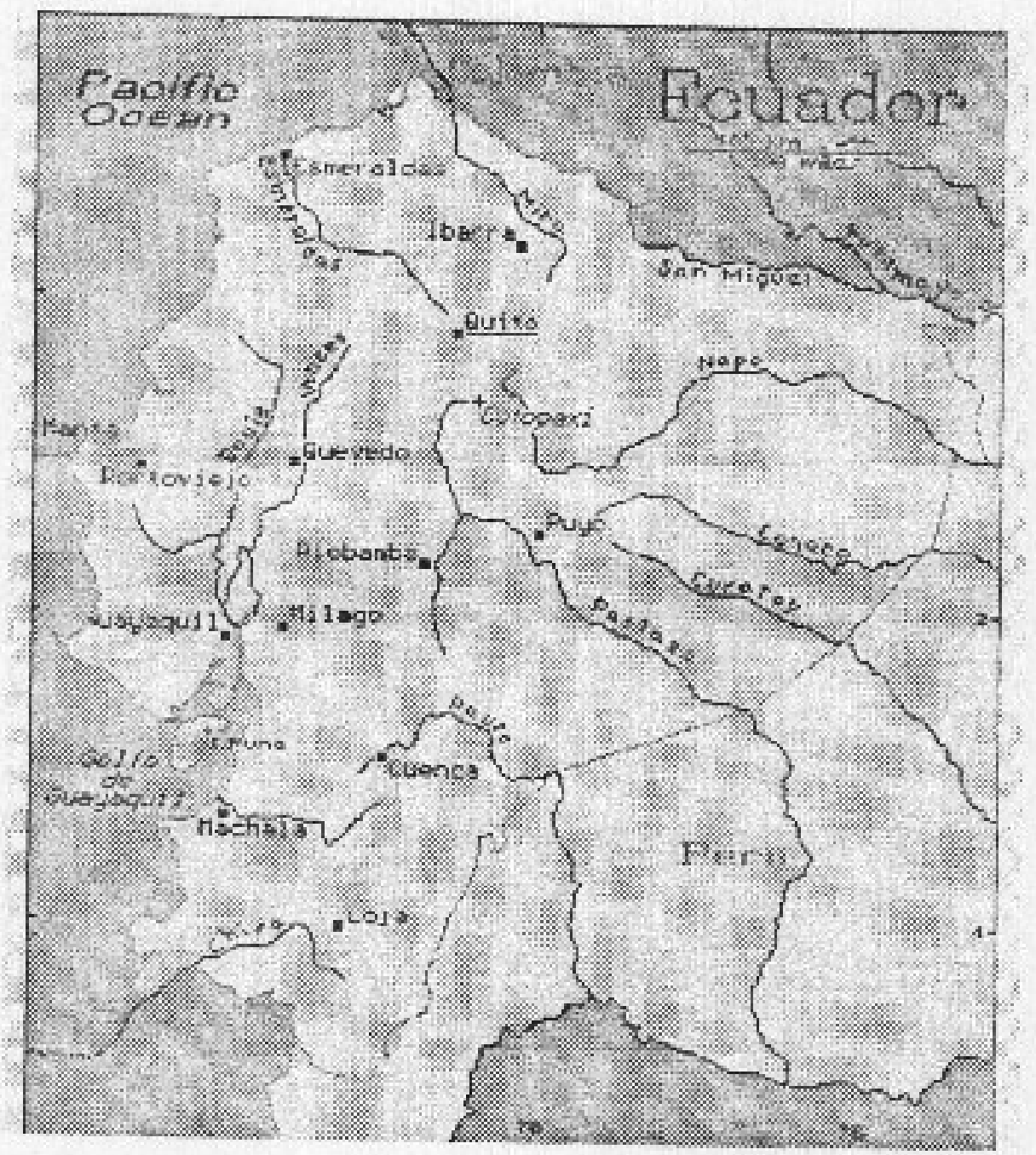




\section{ANEXO B \\ CARACTERISTICAS DA OFERTA E DA DEMANDA DE ENERGLA NO SETOR ELÉTRICO DO EQUADOR: O SETOR DE ILUMINAC̆ÃO PIBLICA (IP). \\ TABELAS}




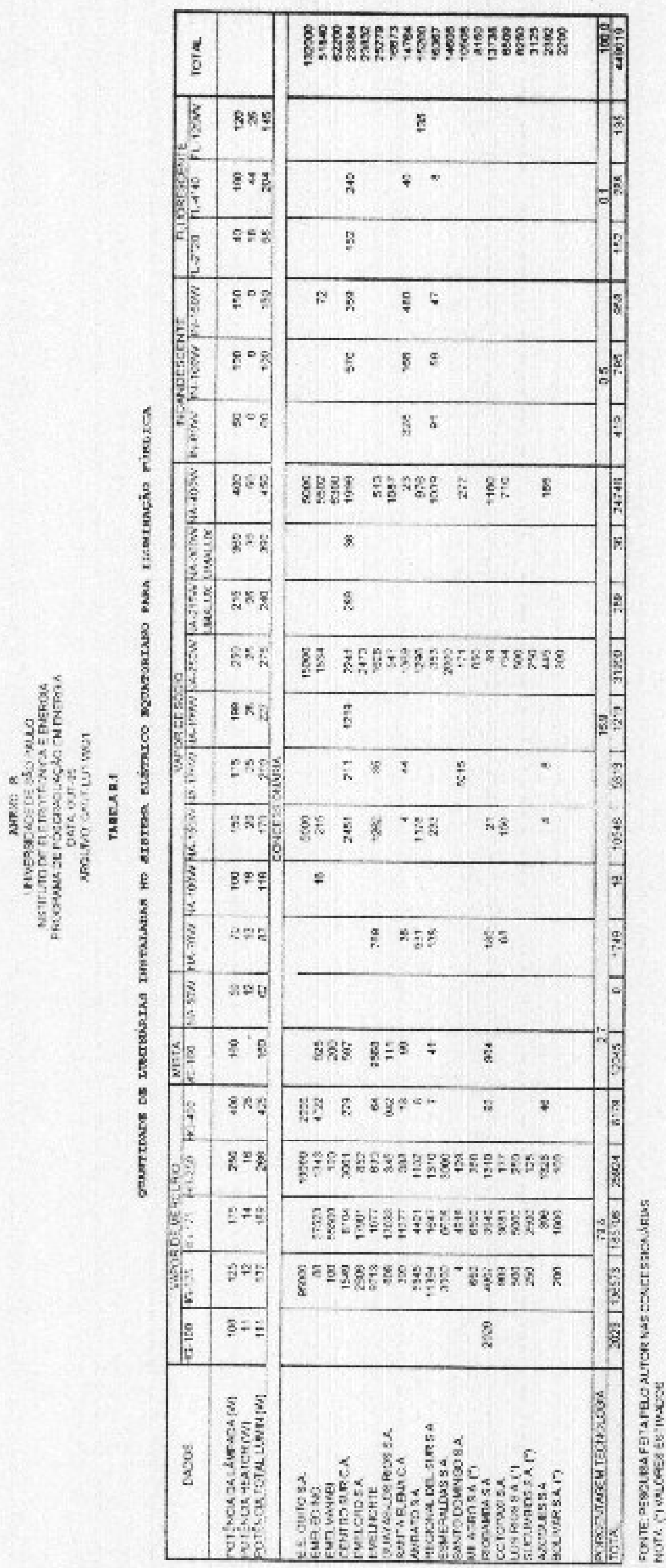




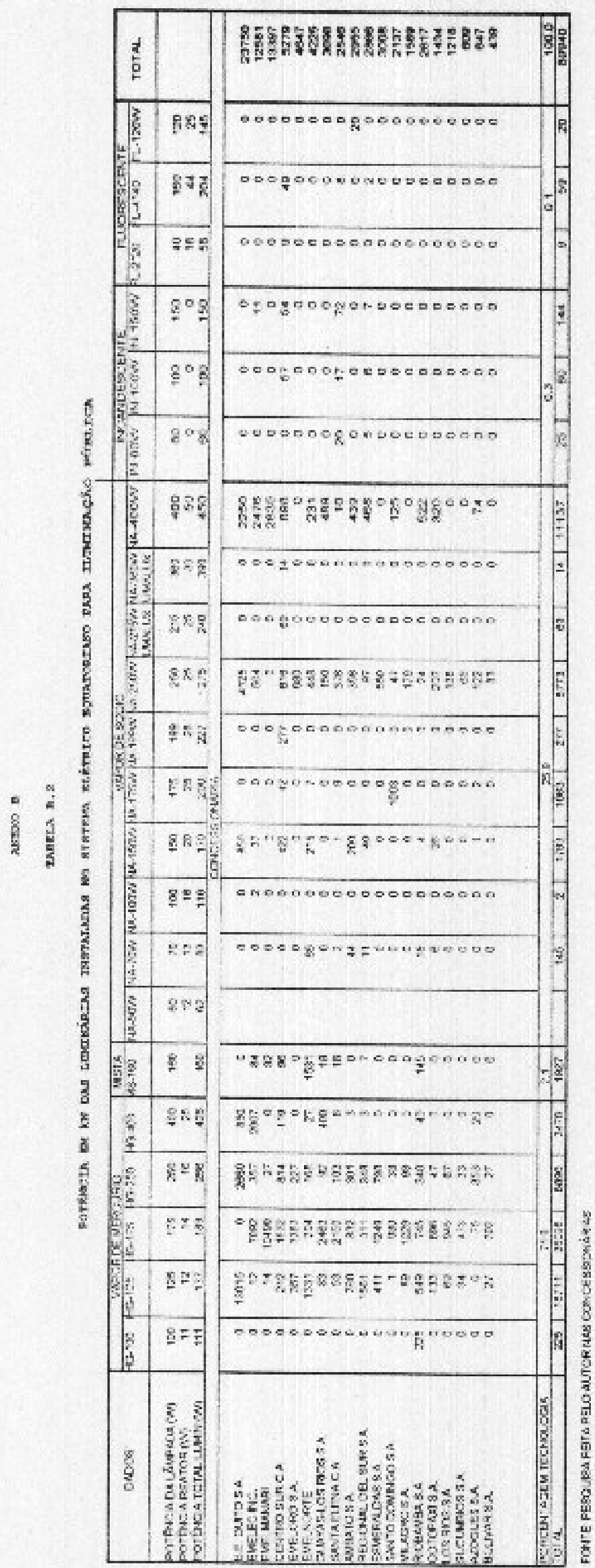




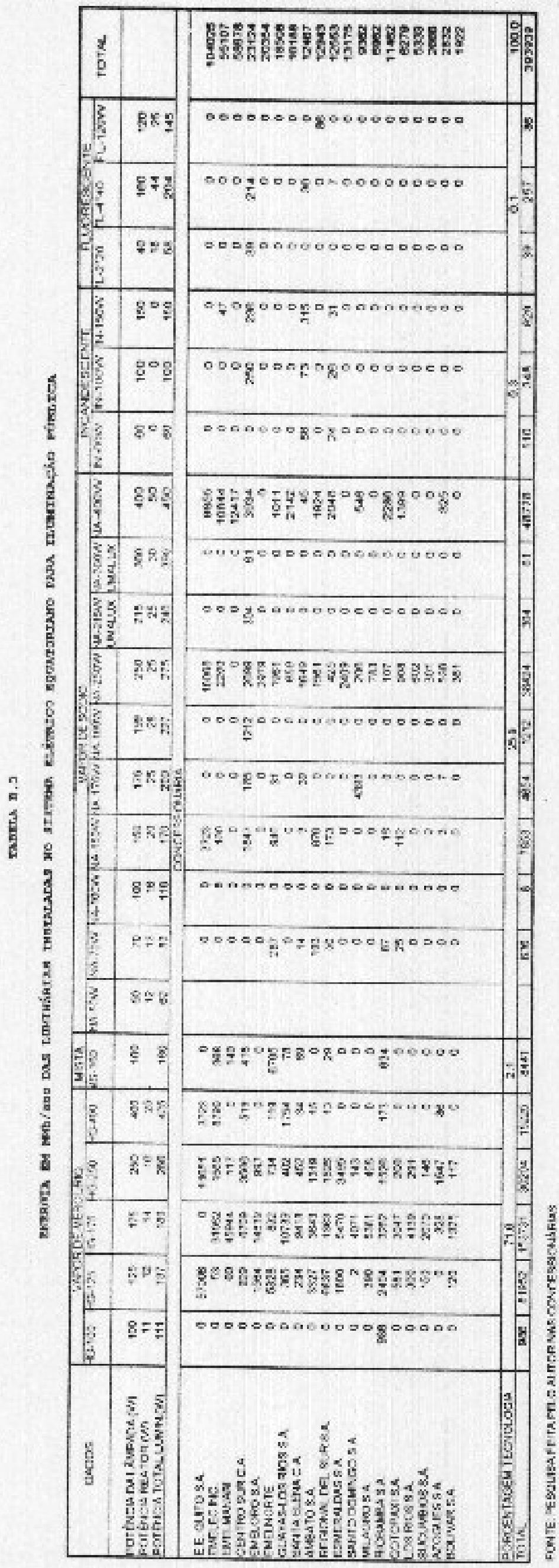




\section{ANEXO B}

\section{TABELAB.A}

\begin{tabular}{|c|c|c|c|c|c|c|c|}
\hline HORA & $\begin{array}{l}\text { V. NECEEI } \\
\text { GUANGOP. }\end{array}$ & $\begin{array}{l}\text { HIDREIETR. } \\
\text { CONCESSI. }\end{array}$ & $\begin{array}{c}\text { AGOYAW } \\
\text { PISAYAMBO }\end{array}$ & $\begin{array}{l}\text { VAPOR } \\
\text { CONCESSI. }\end{array}$ & $\begin{array}{c}\text { OUTRAS } \\
\text { TERAICAS }\end{array}$ & PAUTE & TOTAL \\
\hline 0.00 & 26 & 47 & 156 & 38 & 14 & 498 & 779 \\
\hline 100 & 26 & 43 & 156 & 37 & 14 & 446 & 722 \\
\hline 2.00 & 26 & 43 & 156 & 37 & 14 & 446 & 722 \\
\hline $3 ; 00$ & 26 & 42 & 156 & 38 & 13 & 421 & $\infty$ \\
\hline 4:D0 & 26 & 42 & 155 & 38 & 13 & 421 & 695 \\
\hline $5: 00$ & 26 & 54 & 156 & 38 & 13 & 432 & 719 \\
\hline 6:00 & 26 & 63 & 156 & 38 & 13 & 480 & 776 \\
\hline $7: 00$ & 26 & 66 & 156 & 38 & 13 & 549 & 848 \\
\hline $8: 00$ & 26 & 67 & 225 & 30 & 12 & 521 & 890 \\
\hline $9: 00$ & 26 & 74 & 226 & 37 & 12 & 617 & 92 \\
\hline $10: 00$ & 25 & 73 & 226 & 30 & 12 & 647 & 1022 \\
\hline 11.00 & 26 & 74 & 225 & 38 & 12 & 654 & 10000 \\
\hline 12,00 & 26 & 73 & 220 & 55 & 12 & 051 & 1043 \\
\hline 1300 & 26 & 71 & 228 & 55 & 13 & 600 & 99 \\
\hline 1400 & 26 & (x) & 223 & 50 & 15 & $\infty \propto 5$ & 906 \\
\hline $15: 00$ & 26 & 64 & 226 & 55 & 24 & 605 & 1000 \\
\hline $18: 00$ & 28 & 63 & 2260 & 55 & 21 & 622 & 1013 \\
\hline $17: 00$ & 26 & $\oplus$ & 226 & 55 & 30 & 502 & 907 \\
\hline $18: 00$ & 37 & 70 & 226 & 55 & 30 & 580 & $\infty 0$ \\
\hline $19: 00$ & $\pi$ & 124 & 230 & 77 & 101 & 830 & 1441 \\
\hline $20: 00$ & 73 & 116 & 230 & $\pi$ & 103 & 820 & 1425 \\
\hline $21 ; 00$ & 79 & 105 & 230 & 77 & 97 & 751 & 1300 \\
\hline $22: 00$ & 72 & 76 & 228 & 57 & $3 t$ & 706 & 1168 \\
\hline 23.00 & 26 & 61 & 156 & 0 & 11 & $\mathrm{CrG}$ & 873 \\
\hline $24: 00$ & 25 & 60 & 156 & 0 & 14 & 475 & 731 \\
\hline $\begin{array}{l}\text { ENERGIA } \\
\text { APROXIMANA } \\
\text { (MAW }\end{array}$ & 840 & 1062 & 4806 & 1068 & 636 & 14005 & 23127 \\
\hline
\end{tabular}

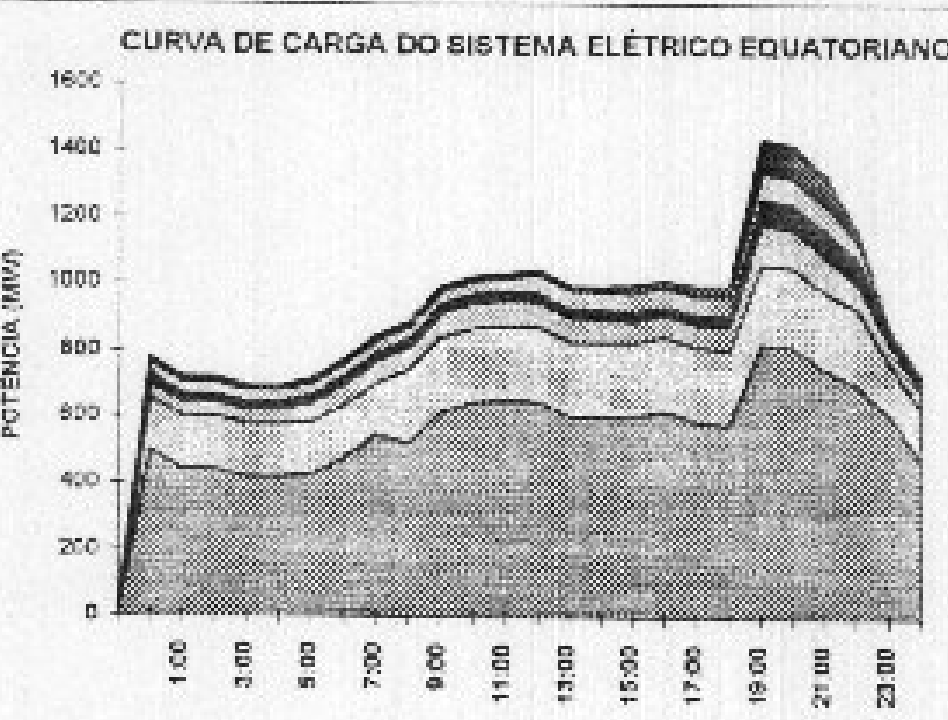

HORA

\begin{tabular}{|c|c|c|}
\hline DPAUTE & CACOYKN PITAYAMEO & DHIDRELETR CONCESS. \\
\hline nv. INFCEL GUANGOP & Q VAFOR COWCEESI & DOUTRAS TEKUICAS \\
\hline
\end{tabular}




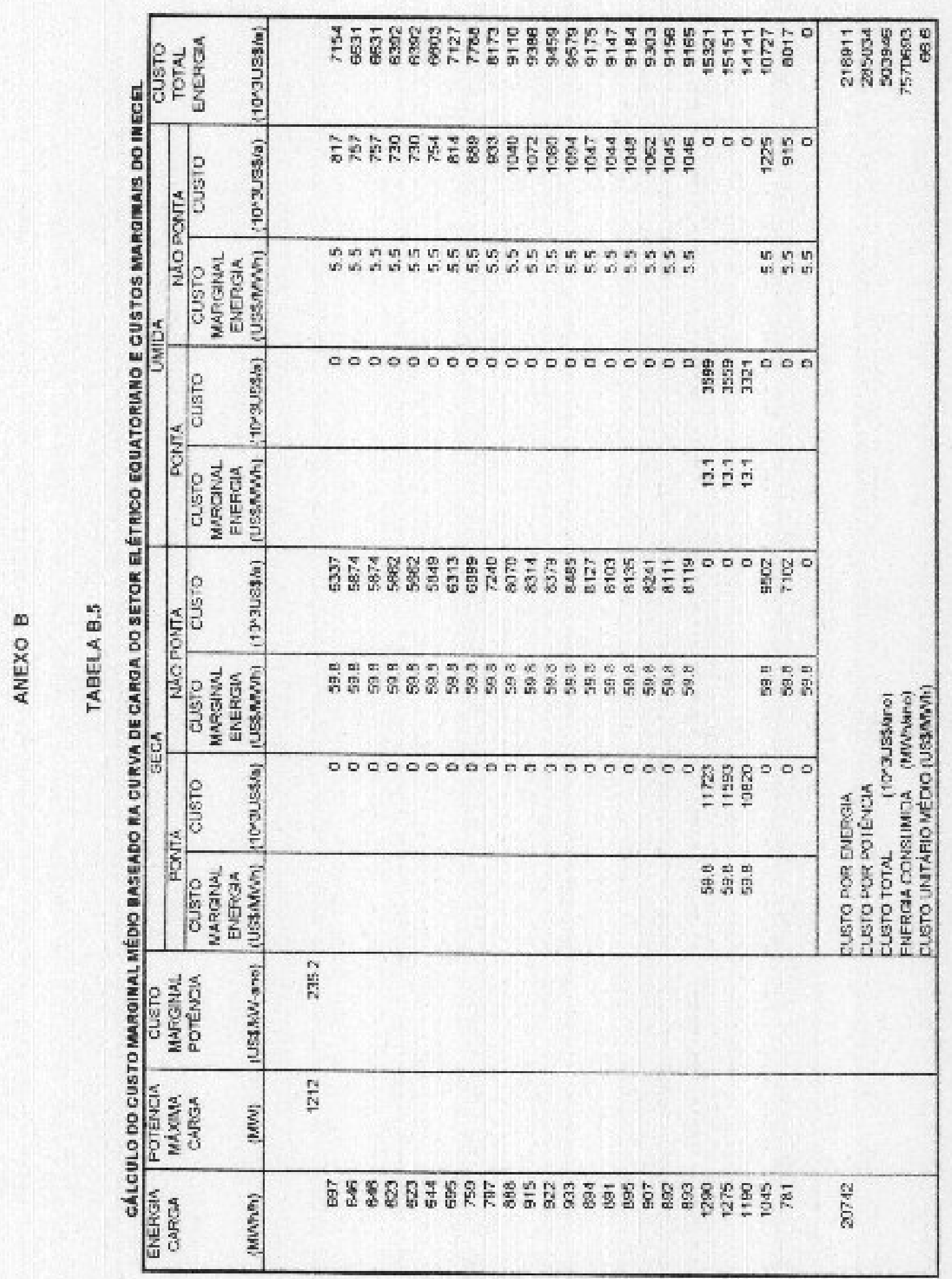




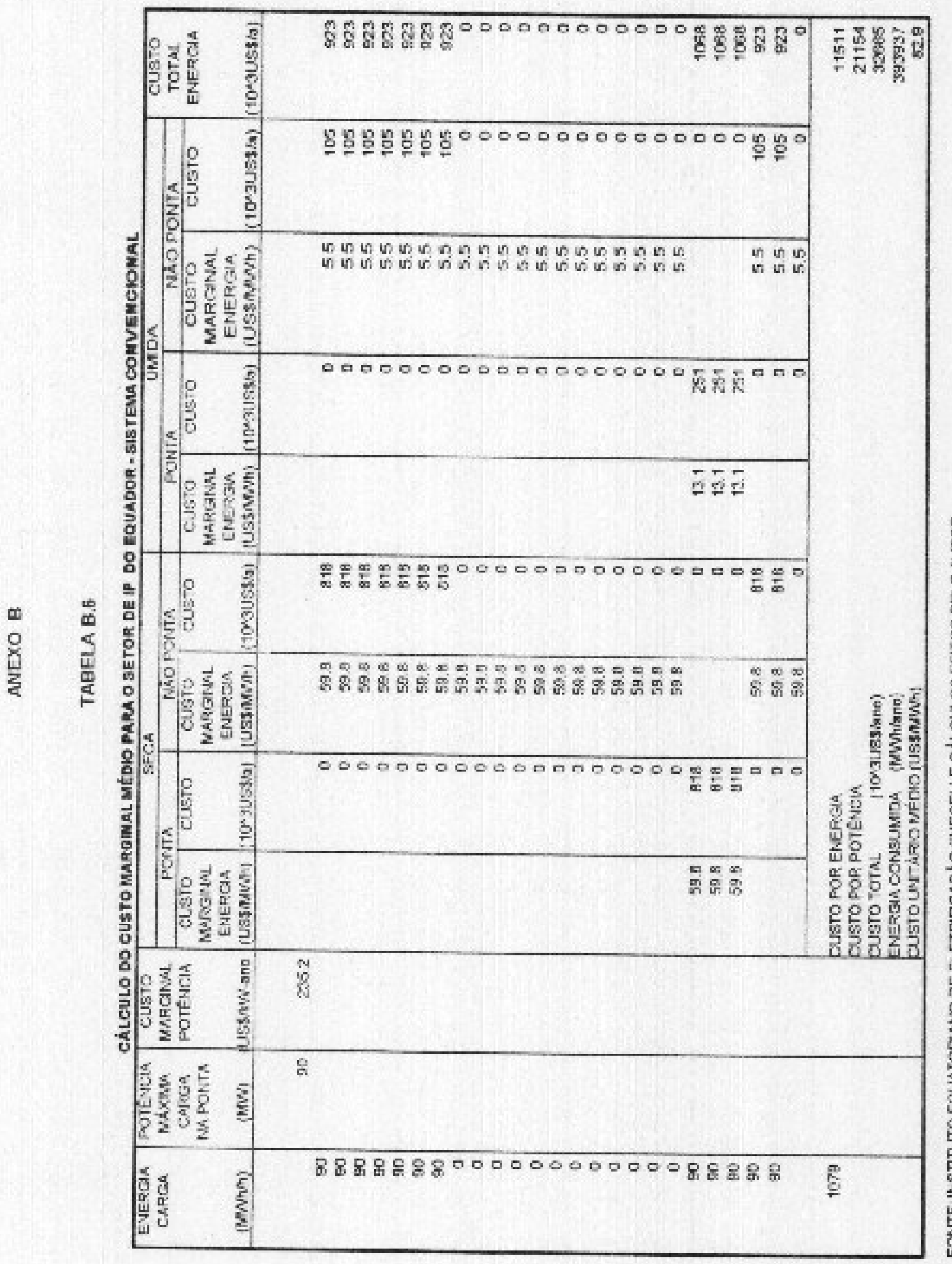




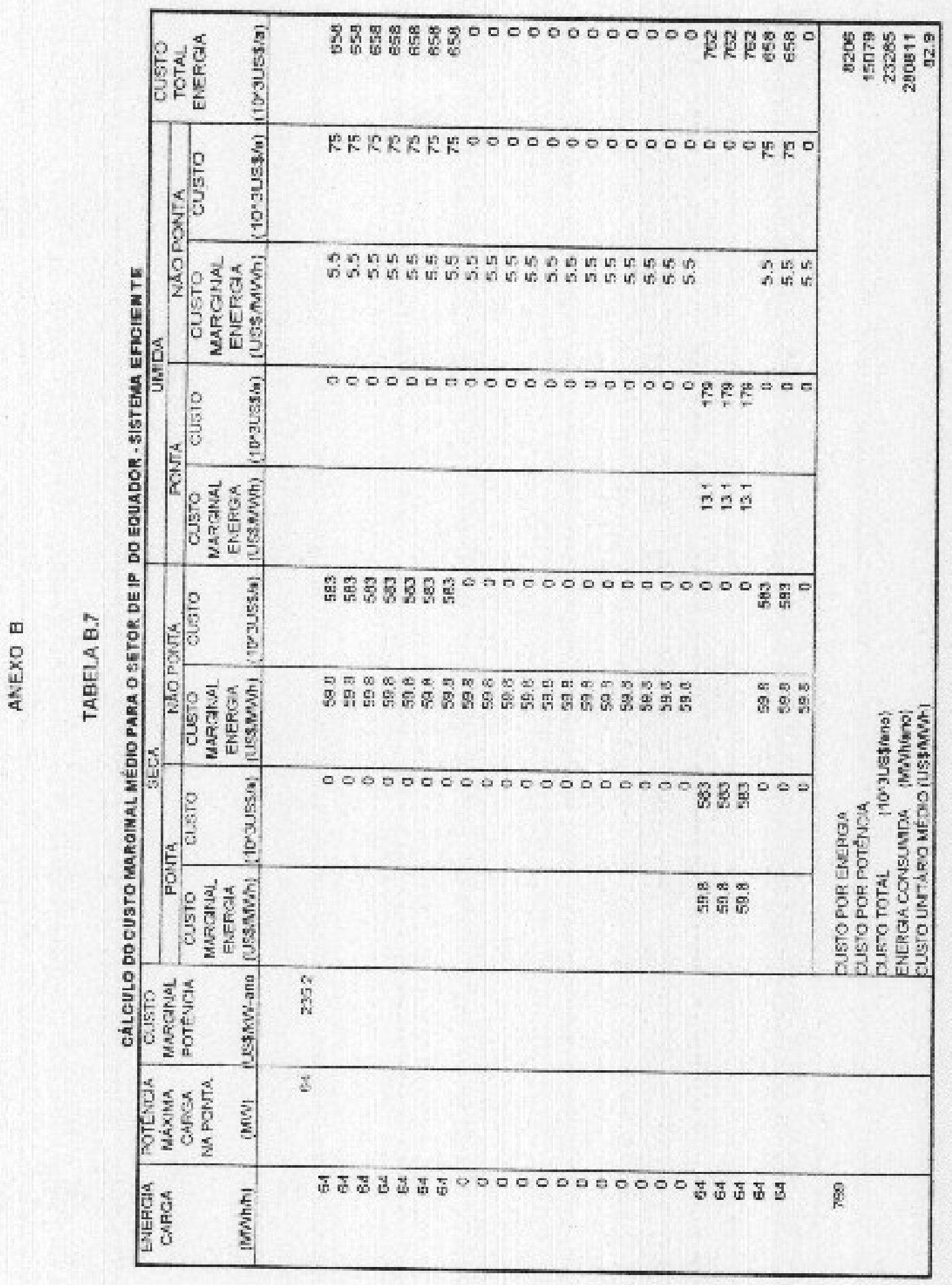




\section{ANEXO C}

CARACTERÍSTICAS DE DESENVOLVTMIFNTO DO SETOR ELÉTRICO EQUATORIANO (ILUMINAÇĀO PÚBLICA-IP).

TABELAS 


\section{ANEXO C}

SISTEMA TARIFÁRIO DA EMPRESA ELÉTRTCA REGIONAL DO SUL S,A, (EERSSA) (JUNHOMS)

\begin{tabular}{|c|c|c|}
\hline $\begin{array}{l}\text { TTPI JE SERVICO } \\
\text { FADS CONSLMC) }\end{array}$ & $\begin{array}{c}\text { PHEQXUNT RRIO } \\
\text { SI CRESA.Wb }\end{array}$ & $\begin{array}{c}\text { PRECO UNIThRH } \\
\text { IISSMNW }\end{array}$ \\
\hline \multicolumn{3}{|l|}{ Reailimativ } \\
\hline $0-20$ & 150 & 0,06 \\
\hline 21.53 & 15 & 6 \\
\hline $51-9$ & 25 & JII \\
\hline 81.100 & 45 & 18 \\
\hline $107 \cdot 120$ & 60 & 24 \\
\hline 121.150 & 75 & 33 \\
\hline 151.2140 & 90 & 36 \\
\hline $201-3: K 1$ & 145 & 58 \\
\hline $301-500$ & 150 & 60 \\
\hline $501-3000$ & 170 & 68 \\
\hline $1001-1500$ & 243 & 96 \\
\hline Ixucessin & 243 & 96 \\
\hline \multicolumn{3}{|l|}{ Coctarcos! } \\
\hline $0-20$ & 725 & 0.29 \\
\hline $21-90$ & 75 & 30 \\
\hline $81-150$ & 100 & 64 \\
\hline 15:-5IX: & $200 ?$ & Kil \\
\hline $5111-11 \times x$ & 220 & $\mathrm{BR}$ \\
\hline Encrsoas & 240 & 96 \\
\hline \multicolumn{3}{|l|}{ Edatist Antosmio } \\
\hline $0-150$ & $8 \times 00$ & 3,201 \\
\hline $101-5.20$ & 155 & 62 \\
\hline $501+1000$ & $2: 15$ & 82 \\
\hline Tixcessai & 280 & 96 \\
\hline \multicolumn{3}{|l|}{ Intidsdes L Misiai } \\
\hline 0.20 & 725 & 0.29 \\
\hline $21-92$ & 75 & 30 \\
\hline $8:-150$ & 155 & 62 \\
\hline $151-500$ & 190 & 36 \\
\hline $501-1000$ & 210 & 81 \\
\hline Fuaseas & 225 & 90 \\
\hline \multicolumn{3}{|l|}{ 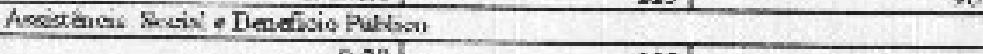 } \\
\hline$\alpha-20$ & 105 & 0,04 \\
\hline $21-50$ & 10.5 & 4,2 \\
\hline $51-80$ & 17,5 & 7,0 \\
\hline $81-100$ & 31,5 & 12,6 \\
\hline 101.120 & 42,11 & 16,8 \\
\hline $121+150$ & 52,3 & 21,1 \\
\hline $15 \cdot 200$ & $6,3,0$ & 25,2 \\
\hline $20:-300$ & 101,5 & 10,6 \\
\hline $301-\sin 0$ & 1050 & $42 \pi$ \\
\hline $501-1(K K)$ & 1290 & 476 \\
\hline tonn-2(k.k:) & 1680 & 672 \\
\hline Foursess! & $168 \mathrm{C}$ & 672 \\
\hline \multicolumn{3}{|l|}{ Fumios glo Hulvist } \\
\hline & $13 \mathrm{C}$ & 52 \\
\hline \multicolumn{3}{|c|}{ TARTAS CXMADEMANDA } \\
\hline \multicolumn{3}{|l|}{ Ciengrial } \\
\hline Xs'ructosstw & S.,KK: & 2 \\
\hline & 165 & 65 \\
\hline \multicolumn{3}{|l|}{ Exidals f Pliving } \\
\hline S.W ou USS2W & 4,750 & 1,9 \\
\hline & 155 & 62 \\
\hline \multicolumn{3}{|l|}{ Inductrial } \\
\hline D-2xki & 165 & 66 \\
\hline $201-4(K)$ & 150 & 60 \\
\hline Excoss: & 140 & 56 \\
\hline s/kW as US\$KW & 5,000 & 2 \\
\hline \multicolumn{3}{|l|}{ Bocchesmeran Agua } \\
\hline Saw wiss.w & $4,75 ! 1$ & 1.1 \\
\hline & 130 & 52 \\
\hline
\end{tabular}


ANEXO D

AVALIAX̃̃O TÉCNICA-ECONÔMICA-FINANCEIRA DO USO EFICIENTE DE ENEHIA NO SETOR DE ILUMINACÃO PÚBLICA (IP) DO EQUADOR.

TABELAS 


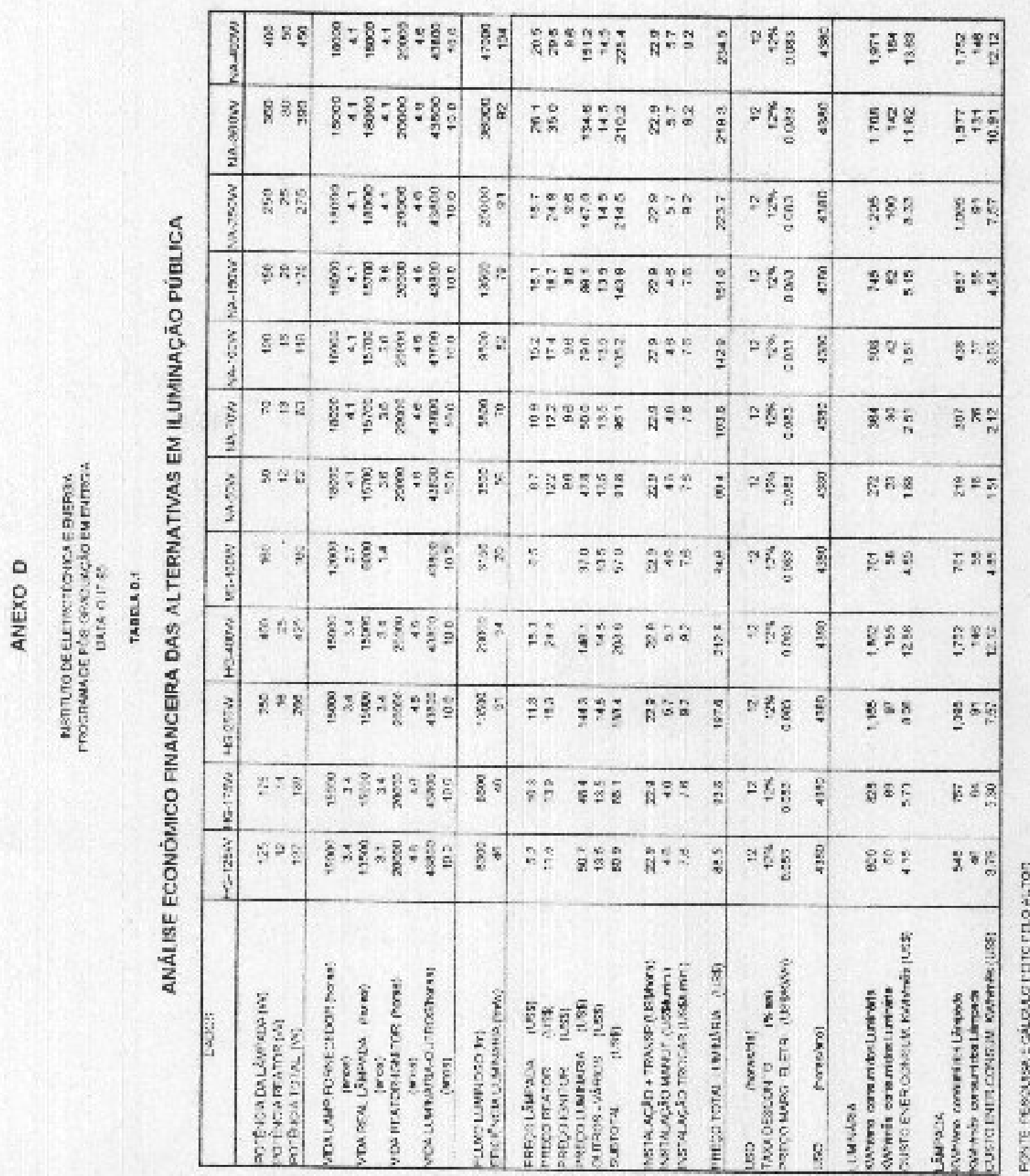




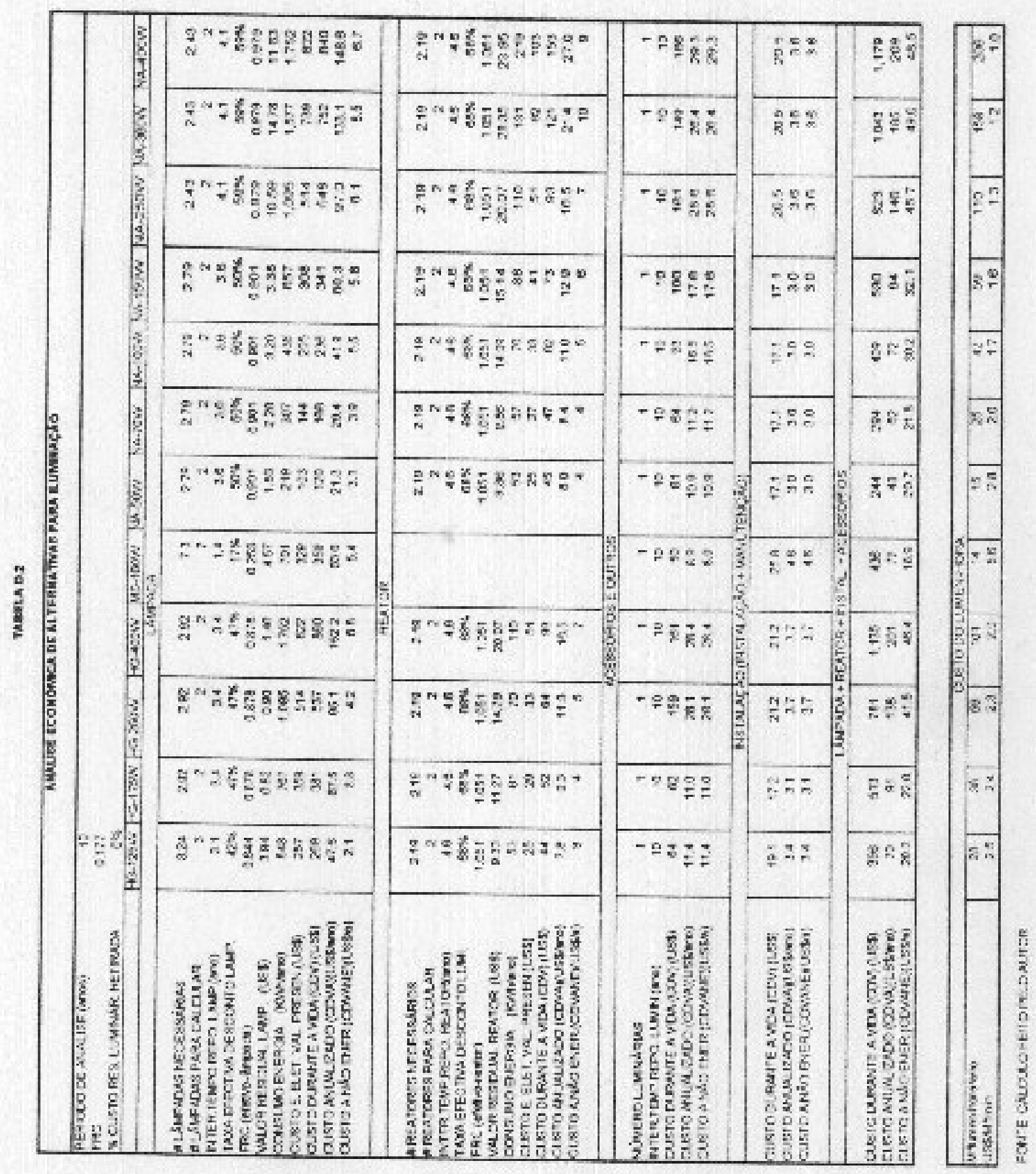


TABELAD.?

RESUMO DE RESJLTADO5

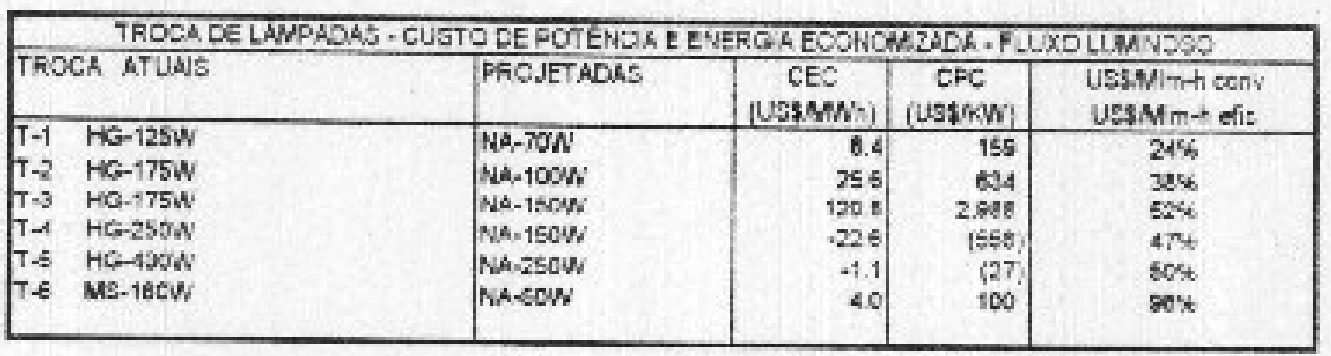

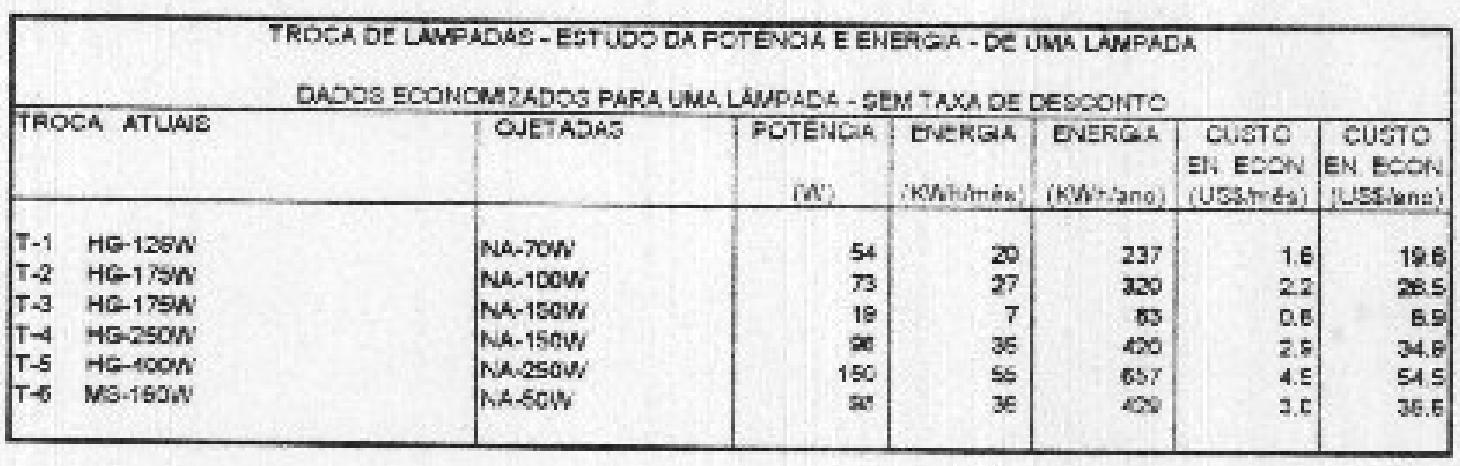

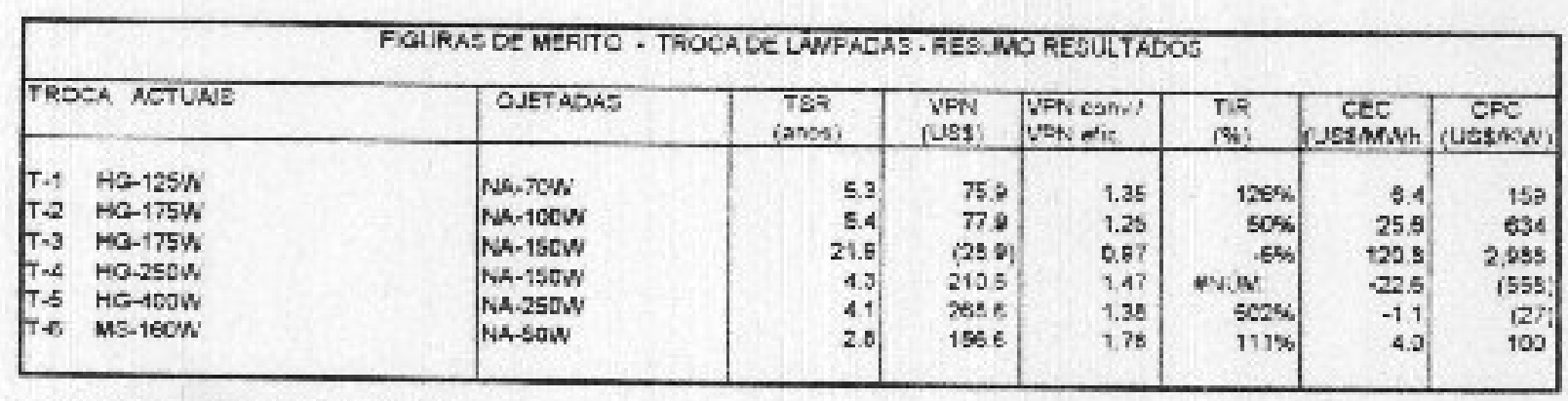

RONTE: CALCULO PETO PELO AUTOR 
TABELA D.4

FLUXOS DE CAIXA PARA ALTERMAATIVAS T-1, T-2 E T-3

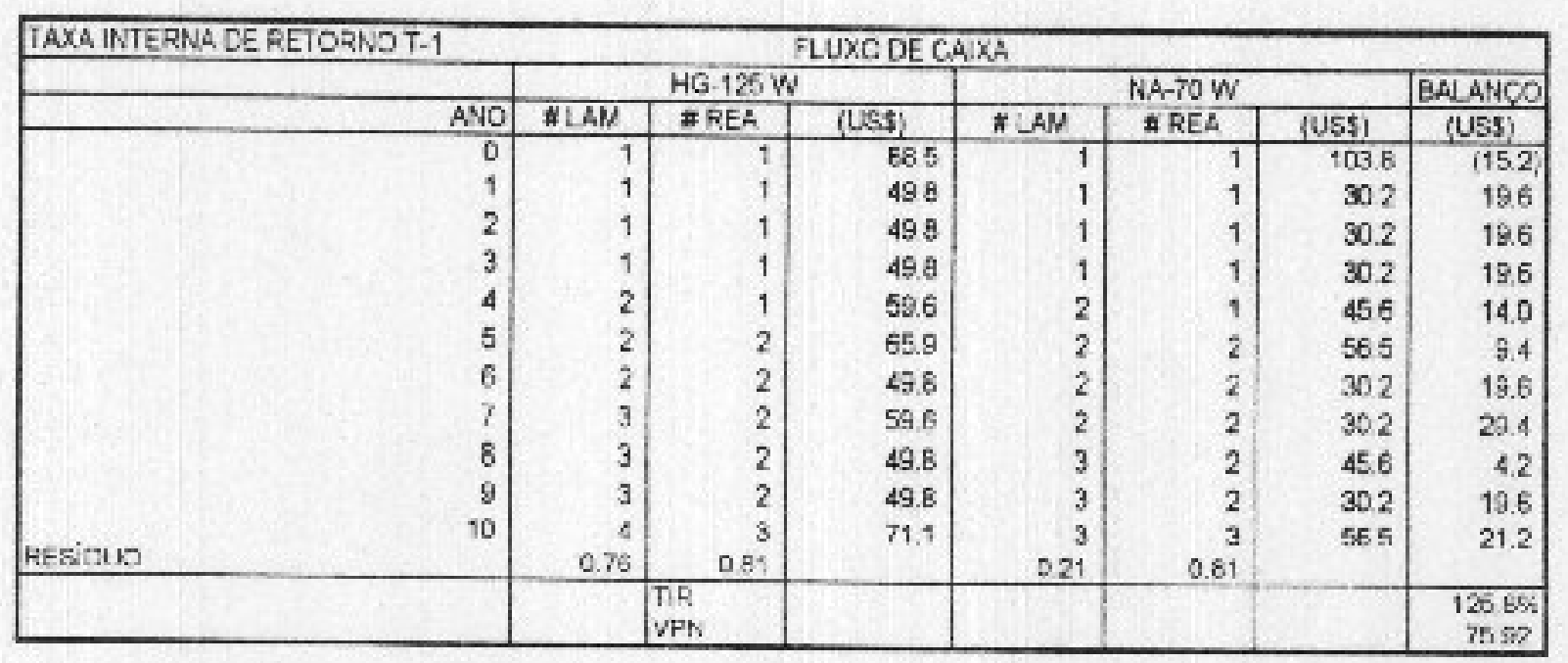

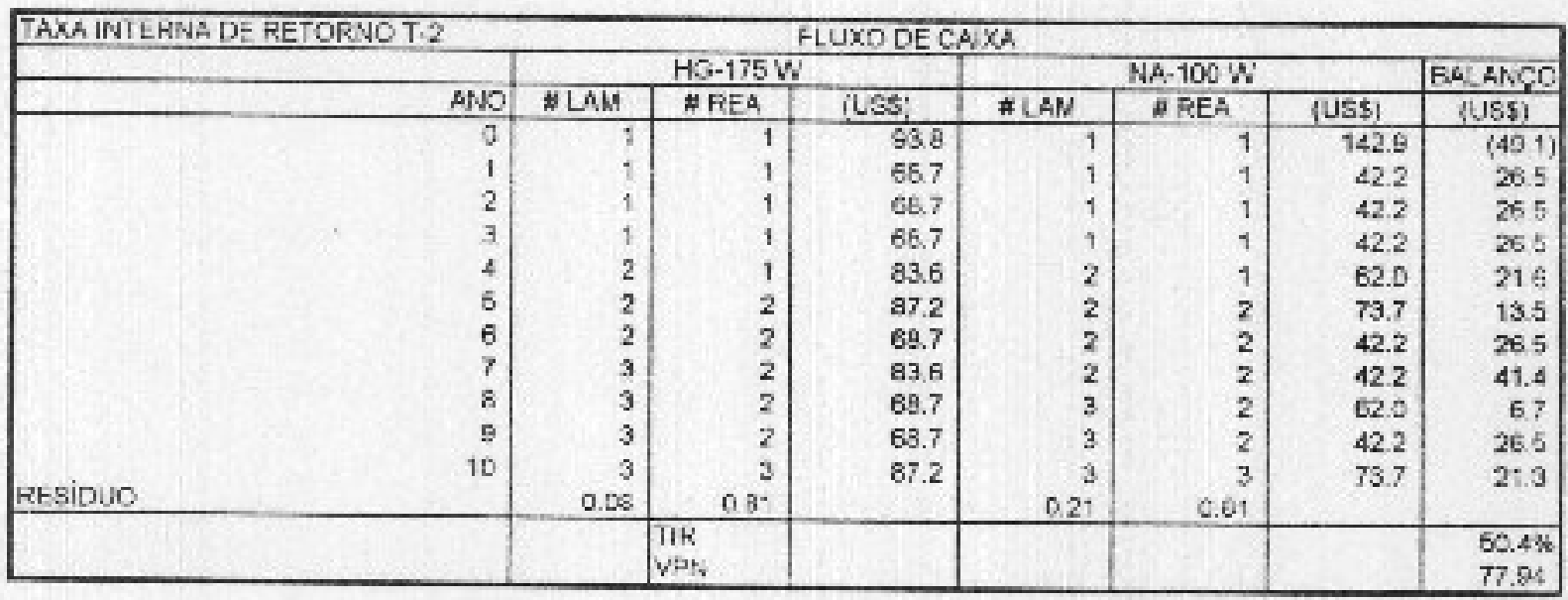

\begin{tabular}{|c|c|c|c|c|c|c|c|c|}
\hline TAXA IMTE & & & & UXODEC & & & & \\
\hline & & & 10.175 & & & $18-150 \mathrm{~W}$ & & BALANCO \\
\hline & ANC & $\# \perp A M$ & HROA & [US\$! & BLAV & \#RFA & [USS! & [USS] \\
\hline & 0 & 1 & 1 & 938 & 1 & 1 & 151.6 & $\{57,8\}$ \\
\hline & 1 & 1 & 1 & 68.7 & 1 & 1 & 61.8 & 6.9 \\
\hline & 2 & 1 & 1 & 68.7 & 1 & 1 & 618 & 6.9 \\
\hline & 3 & 1 & 1 & $6 ! 7$ & 1 & 1 & 61.8 & 6.9 \\
\hline & 1 & 2 & 1 & 89.6 & 2 & 1 & 82.5 & 1.1 \\
\hline & 5 & 2 & 2 & 87.2 & 2 & 2 & 947 & [7.4] \\
\hline & 6 & 2 & 2 & 66.7 & 2 & 2 & 81.8 & 69 \\
\hline & 3 & 3 & 2 & B3.6 & 2 & 2 & 61.8 & 21.8 \\
\hline & B & 3 & 2 & ES.7 & 3 & 2 & 82.5 & $\{13.8\}$ \\
\hline & 9 & 3 & 2 & 58.7 & 3 & 2 & 518 & 6.8 \\
\hline RESIDUO & 10 & 3 & 3 & 67.2 & 2 & 3 & 84.7 & 6.7 \\
\hline & & Wats & 087 & & 0.21 & 0.89 & & 570 \\
\hline & & & VPN & & & & & $\begin{array}{r}-53 \% \\
\text { [2E.87) }\end{array}$ \\
\hline
\end{tabular}

FONTE: CALLULO FEITO FELC AUTOR 
TABELA D.6

FLUXOS DE CADAA PARA ALTERKATNAS T-G,T-6 E TS

\begin{tabular}{|c|c|c|c|c|c|c|c|c|}
\hline TAXA INITE & & & & LXODE & & & & \\
\hline & & & $\mathrm{HC}-25 \mathrm{DV}$ & & & $\sqrt{A-1}-150 \mathrm{~W}$ & & BALATCCCO \\
\hline & AnO & \#LAM & \#REA & (US\$) & \#LAN & \#FEA & (USS) & (US\$) \\
\hline & 0 & 1 & 1 & 197.6 & 1 & 1 & 151.6 & 46.0 \\
\hline & 1 & 1 & 1 & 86.7 & 1 & 1 & 61.8 & 34.9 \\
\hline & 2 & 1 & 1 & 86.7 & 1 & 1 & 61.8 & 34.9 \\
\hline & 3 & 1 & 1 & 96.7 & 1 & 1 & 61.8 & 34.9 \\
\hline & 4 & 2 & ! & 1137 & 2 & 1 & 82.5 & 31,3 \\
\hline & 5 & 2 & 2 & 120.7 & 2 & 2 & 94.7 & 26.0 \\
\hline & 6 & 2 & 2 & 967 & 2 & 2 & 61.8 & 34.9 \\
\hline & 7 & 3 & 2 & 1137 & 2 & 2 & 61.8 & 51.9 \\
\hline & d & 3 & 2 & 86.7 & 3 & 2 & 82.5 & 14.2 \\
\hline & 9 & 3 & 2 & 96.7 & 3 & 2 & 61.8 & 34.9 \\
\hline FESIDUO & 10 & $\begin{array}{r}3 \\
0 \varepsilon^{3}\end{array}$ & $0.81^{3}$ & 120.7 & 3 & 3 & 54.7 & $36 \mathrm{~s}$ \\
\hline & & & & & & & & HUM! \\
\hline & & & FN & & & & & 210.52 \\
\hline
\end{tabular}

\begin{tabular}{|c|c|c|c|c|c|c|c|c|}
\hline \multirow{2}{*}{\multicolumn{2}{|c|}{ TROA INTERNA DE RETORINO T'S }} & \multirow{2}{*}{\multicolumn{6}{|c|}{ FLUXODE CDIXA }} & \multirow{3}{*}{$\frac{\text { BQLANCO }}{\text { (USS) }}$} \\
\hline & & \multirow{2}{*}{\multicolumn{3}{|c|}{$\frac{\mathrm{HG}+\mathrm{COWW}}{\# \mathrm{REA}}$}} & \multicolumn{3}{|c|}{ NA-250W } & \\
\hline & AND & & & & ILAM & " REA & IUSS & \\
\hline \multirow{13}{*}{ FESIDUO } & 9 & 1 & 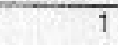 & 2128 & 1 & 1 & 223.7 & $(10.9)$ \\
\hline & 1 & 1 & 1 & 154.5 & 1 & 1 & 100.0 & 54.6 \\
\hline & 2 & 1 & 1 & 154.5 & s & 1 & 100.0 & 54.6 \\
\hline & 3 & 1 & 1 & 154.5 & $=$ & 1 & 100.0 & 54.6 \\
\hline & 4 & 2 & 1 & 1785 & 3 & 1 & 100.0 & 76.5 \\
\hline & $\begin{array}{l}5 \\
6\end{array}$ & 2 & 2 & 185.0 & $?$ & 2 & 168.8 & $2 E .3$ \\
\hline & 6 & 2 & 2 & 154,5 & 2 & 2 & 100.0 & 54.5 \\
\hline & 7 & 3 & 2 & 178.5 & 2 & 2 & 100.0 & 78.5 \\
\hline & B & 3 & 7 & 154.5 & 2 & 2 & 100.0 & 64.6 \\
\hline & 10 & 3 & $=$ & 154,5 & 3 & 2 & 126.4 & $3 c .1$ \\
\hline & & 3 & 3 & 185.0 & 3 & 3 & 140.1 & 61.8 \\
\hline & & & & & & & & $502.4 \%$ \\
\hline & & & Fits & & & & & 26852 \\
\hline
\end{tabular}

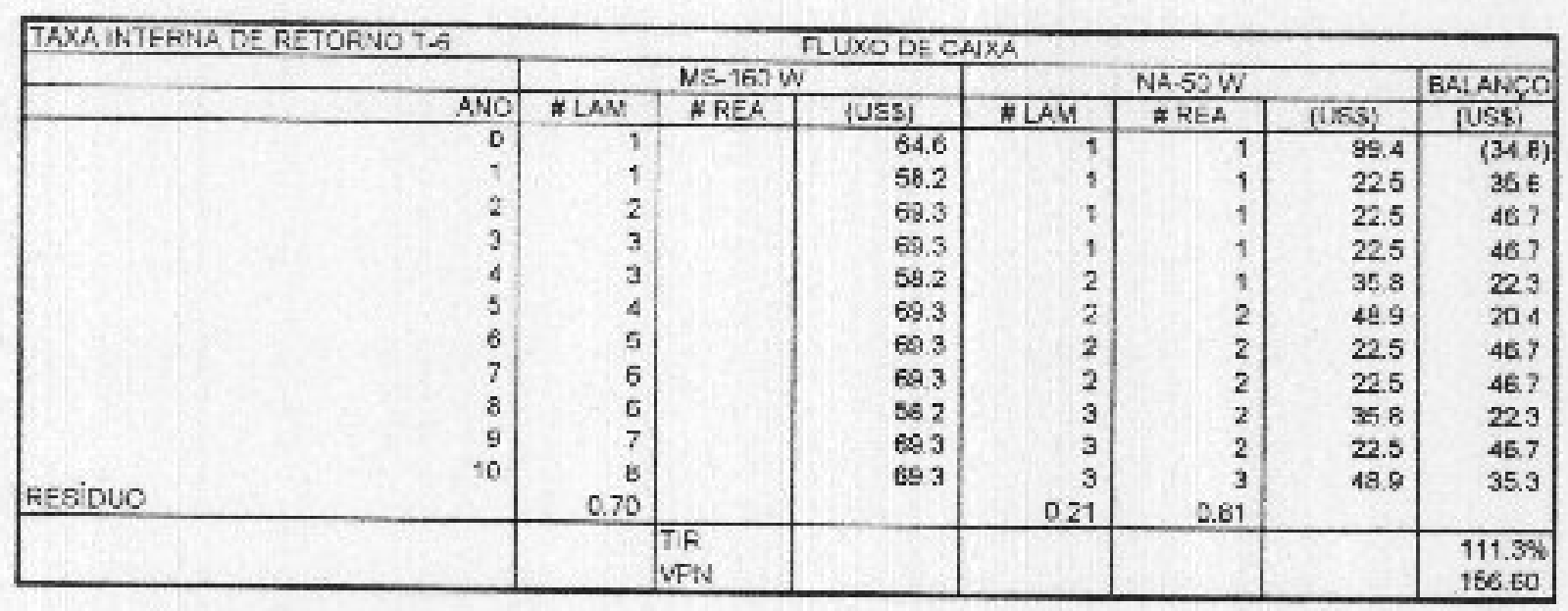

FONTE: CALLCLLO FE TD PELO AUTOR 

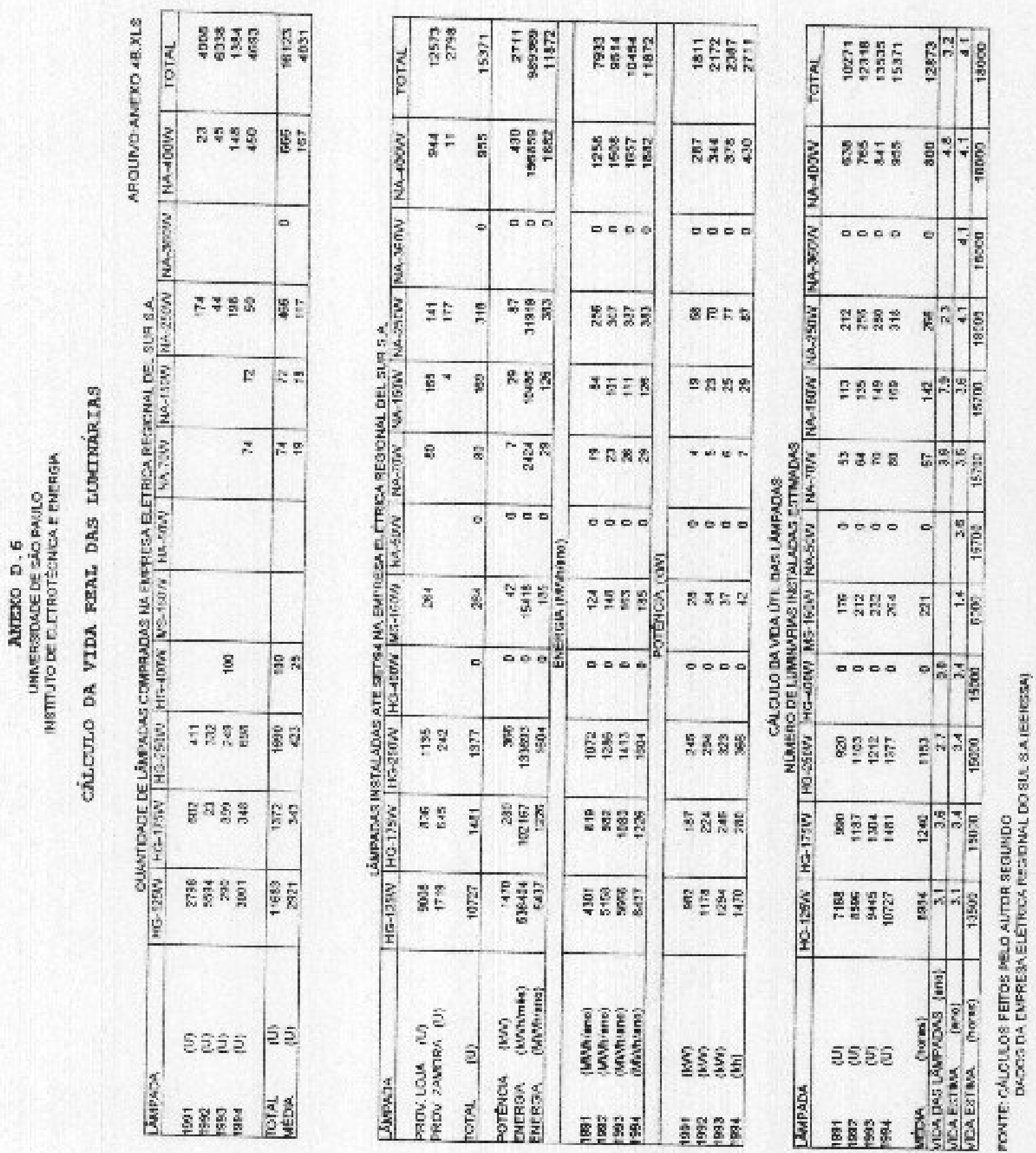
MAXOD

TABELA D.?

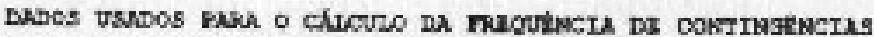
E CUSTOS PAMA MAYUTEHC̆R̃o

\begin{tabular}{|c|c|c|c|c|}
\hline MATERAL & & $\begin{array}{l}\text { conetringe } \\
\text { (ㄴ) }\end{array}$ & $\begin{array}{l}\text { PREECO } \\
\text { UNTAROO } \\
\text { (USS'U) }\end{array}$ & $\begin{array}{l}\text { Custo } \\
\text { jus\$) }\end{array}$ \\
\hline \multirow{4}{*}{ LÖNPRDUS VAFOR MERCLLTHO } & $H G-125 W$ & 284 & 52 & 1477 \\
\hline & \multirow{2}{*}{$\begin{array}{l}H G-175 W \\
H G-250 W\end{array}$} & 27 & 10.3 & $27 \mathrm{C}$ \\
\hline & & 93 & 11.3 & 105 \\
\hline & $H C-000 \mathrm{~W}$ & 38 & 183 & 658 \\
\hline \multirow[t]{2}{*}{ LAMMPADAS VAPOR SODIO } & \multirow{2}{*}{$\begin{array}{l}N A-250 W \\
N A-400 W\end{array}$} & 22 & 187 & 411 \\
\hline & & 93 & 205 & 1907 \\
\hline L.MAPADAS LUZ WISTA & NG-1ED W & 7 & 55 & 45 \\
\hline \multirow[t]{4}{*}{ REATORES } & \multirow{4}{*}{$\begin{array}{l}R-125 W \\
R-175 W \\
R-250 W \\
R-100 W\end{array}$} & 32 & 11.5 & 366 \\
\hline & & 14 & 13.9 & 195 \\
\hline & & 12 & 248 & 225 \\
\hline & & 14 & 29.6 & 414 \\
\hline \multirow[t]{2}{*}{ FUSTVEIS } & $30 A$ & 17 & 20 & 34 \\
\hline & \multirow{2}{*}{$32 \quad A$} & 5 & 20 & 10 \\
\hline RELES & & 12 & 160 & 992 \\
\hline CELLLA FOTDEI ETRICA & & 27 & 170 & 458 \\
\hline IGHITCR & $400 \quad W$ & $\mathbf{s}$ & 96 & 288 \\
\hline \multirow[t]{2}{*}{ CAFACTOR } & $25 \mathrm{meF}$ & 14 & 10.0 & 140 \\
\hline & so mef & 9 & 100 & 90 \\
\hline STARTERS & \multirow{2}{*}{$\sum_{E \rightarrow 0}^{40} \mathbf{E}$} & 25 & 2.5 & 65 \\
\hline PCFTA I I AMPADA & & $\begin{array}{l}3 \\
5\end{array}$ & $\begin{array}{l}6.0 \\
6.0\end{array}$ & $\begin{array}{l}18 \\
30\end{array}$ \\
\hline BRAKEK & \multirow[t]{5}{*}{20} & 19 & 5.0 & es \\
\hline EASE DO BRAKER & & 14 & 15 & 21 \\
\hline CONECTOFES & & 46 & 25 & 120 \\
\hline Dutros & & 35 & E.4 & 306 \\
\hline TOTAL & & 889 & & 85402 \\
\hline \multicolumn{3}{|c|}{ 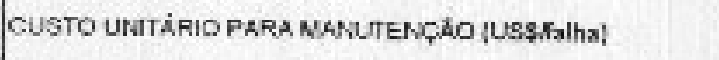 } & & 10. \\
\hline
\end{tabular}

FONIE CALCULO FETO PELO ALTOR BASEADO EM DADOS PROPOFCONIADOS EMPFESA CLETRCA RECOOIIAL DO SULS.A.

NOIR: O PERICO DA ANALLISE CORFESPONDE WHUE RO JULHO-1994 
ANEXC D

TABEIA D.8

PREQUEHCIA DE CONTIWGËNCLAS E CUSTOS DE MANUTENCLO CUSTO TOTA DE WATEAIAIS PARA MANUTEMÇ.

NUNERO DE FNLMAS

CUSTO POR FALHA

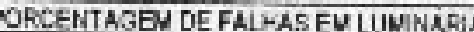

FALHAE EN LIMMPADAS

FALHAS EM FEATCRES

FALHAS EM F USIVEIS E BREAKERS-

FALHAS MOS RE.FS

FALHASNAS FOTOCÉ ULAS

FAL-ASEV ICNITOR

FALLASEV CADACTOR

FA. LUSE EU CEVRDOR

FALHAS EV BJCAL

FALHAS EV COHECTORES

OUTKOS

TOTAL

FONTE: CALCULO FE TO PELO NUTOE NOTA. OS CALCULOS FCRRA FE 7 OS COM BASE NOS DADOS D
TAEEIAD.7 
ANEXO 0

TABELA D.

AMALISE DE SENSIBIUDADE (PREÇO DA ELETPACIDADE)

\begin{tabular}{|c|c|c|c|c|c|c|c|c|c|}
\hline 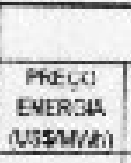 & TRXCA & $A C: L N 3$ & $\begin{array}{l}\text { D. THOCALX } \\
\text { PFOHFLIMS }\end{array}$ & $\begin{array}{c}\text { TSF } \\
\text { (tanos) }\end{array}$ & $\begin{array}{c}\text { WN } \\
\text { BuAnco } \\
\text { nes }\end{array}$ & $\begin{array}{l}\text { VPY cont' } \\
\text { Wh at: }\end{array}$ & $\begin{array}{l}\text { ThP. } \\
\text { Pti }\end{array}$ & $\begin{array}{c}\text { cec } \\
\text { (us\$unt) }\end{array}$ & $\begin{array}{c}\text { CPC } \\
\text { puss5re }\end{array}$ \\
\hline 10 & $\begin{array}{l}7.1 \\
T-2 \\
T-3 \\
T-4 \\
T-5 \\
T-8\end{array}$ & 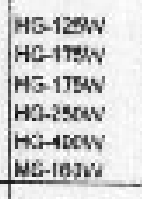 & 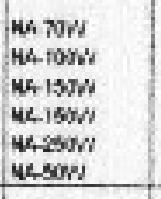 & $\begin{array}{l}11.8 \\
112 \\
45.8 \\
90 \\
8.8 \\
58 \\
\end{array}$ & $\begin{array}{r}24.8 \\
4.8 \\
60.9 \\
110.3 \\
1251 \\
0.5\end{array}$ & $\begin{array}{l}128 \\
1.09 \\
2 \neq 2 \\
1,09 \\
129 \\
1,49 \\
\end{array}$ & $\begin{array}{r}24+4 \\
6 \pi \\
\end{array}$ & $\begin{array}{r}6.4 \\
25.0 \\
120.1 \\
22.2 \\
-1.1 \\
40\end{array}$ & 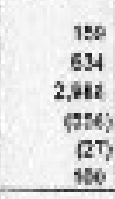 \\
\hline 4 & $\begin{array}{l}T-1 \\
T-2 \\
T-5 \\
T-4 \\
T-5 \\
T E\end{array}$ & $\begin{array}{l}\text { HG. } 125 \mathrm{~W} \\
\mathrm{HB}-175 \mathrm{~W} \\
\mathrm{HG}-175 \mathrm{~W} \\
\mathrm{HG} 25 \mathrm{~W} \\
\mathrm{HG}-40 \mathrm{~W} \\
\mathrm{MS} \cdot 1 \mathrm{BOW}\end{array}$ & 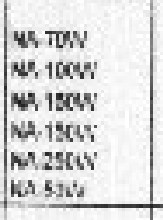 & $\begin{array}{l}2.8 \\
2.7 \\
3.1 \\
7.8 \\
7.4 \\
5.2\end{array}$ & $\begin{array}{r}311 \\
18.2 \\
144.4: \\
112.1 \\
14.2 \\
75.5 \\
\end{array}$ & $\begin{array}{l}1.24 \\
1.12 \\
0.61 \\
1.45 \\
1.31 \\
1.54\end{array}$ & $\begin{array}{c}23 \% \\
64 k\end{array}$ & $\begin{array}{r}64 \\
256 \\
120 A \\
-28 \\
-11 \\
40\end{array}$ & 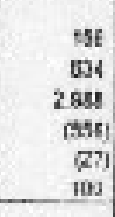 \\
\hline 56 & $\begin{array}{l}T-1 \\
T 2 \\
T S \\
T-1 \\
100 \\
T=0\end{array}$ & 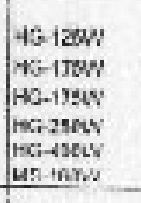 & 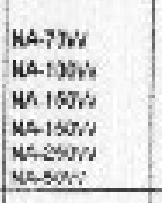 & 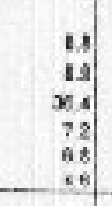 & $\begin{array}{l}36.5 \\
267 \\
162.7 \\
140.5 \\
150.2 \\
63.1\end{array}$ & $\begin{array}{l}1.2 \\
1.14 \\
1.22 \\
4.44 \\
1.22 \\
1.58\end{array}$ & $\begin{array}{l}714 \\
2916\end{array}$ & $\begin{array}{r}B .4 \\
25.6 \\
120 . \\
22.6 \\
-1.7 \\
4.2 \\
\end{array}$ & $\begin{array}{r}153 \\
656 \\
2.153 \\
(582) \\
r 25) \\
100\end{array}$ \\
\hline 53 & $\begin{array}{l}T-1 \\
1-2 \\
T-2 \\
T-2 \\
T E \\
T E\end{array}$ & 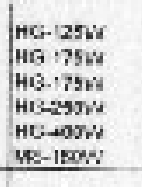 & 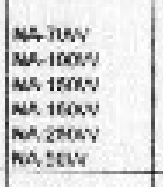 & $\begin{array}{r}7.8 \\
8.0 \\
2.3 \\
0.1 \\
0.1 \\
1.1 \\
\end{array}$ & $\begin{array}{c}43.1 \\
4.4 \\
140.8 \\
5.2 .8 \\
52.1 \\
38.1\end{array}$ & $\begin{array}{l}120 \\
5.17 \\
0.03 \\
1.40 \\
1.35 \\
1.2 \\
\end{array}$ & $\begin{array}{c}615 \\
360 \\
3400 \\
35 \%\end{array}$ & $\begin{array}{r}6.4 \\
22.4 \\
226 . \\
22.1 \\
1.5 \\
40\end{array}$ & $\begin{array}{r}150 \\
604 \\
2.968 \\
(558) \\
527) \\
580 \\
\end{array}$ \\
\hline 66 & $\begin{array}{l}T .1 \\
T .2 \\
T \cdot 3 \\
T-4 \\
T .8 \\
T .8\end{array}$ & 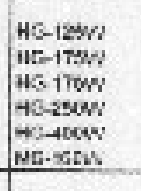 & 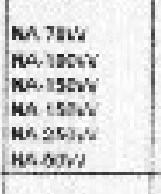 & $\begin{array}{r}7.2 \\
3.4 \\
3.4 \\
t .2 \\
. .7 \\
3.9\end{array}$ & $\begin{array}{r}4.5 \\
42.5 \\
-21.5 \\
16.7 \\
125 . \\
100.5 \\
\end{array}$ & $\begin{array}{l}1.2 \\
1.2 \\
0.6 \\
1.8 \\
1.2 \\
1 .\end{array}$ & $\begin{array}{c}118 \\
24 \% \\
2848 \\
12 \%\end{array}$ & $\begin{array}{r}0.4 \\
29.5 \\
128 . \\
-82 . \\
-5.1 \\
40\end{array}$ & $\begin{array}{c}121 \\
\text { nist } \\
2 \text { Ans } \\
\text { poses } \\
02, \\
10: \\
\end{array}$ \\
\hline Bs & $\begin{array}{l}T-1 \\
1-2 \\
T-2 \\
T-4 \\
T-5 \\
T-6\end{array}$ & 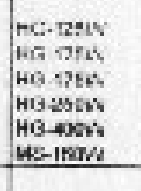 & 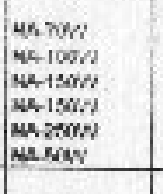 & \begin{tabular}{r|}
6.9 \\
70 \\
25.9 \\
25 \\
9.3 \\
9.9
\end{tabular} & 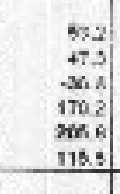 & $\begin{array}{l}1.3 \\
1.2 \\
t .7 \\
1.5 \\
1.2 \\
1.7 \\
\end{array}$ & $\begin{array}{c}\text { ast } \\
378 \\
-12 x \\
30 a s \\
\text { hat }\end{array}$ & \begin{tabular}{r|}
6. \\
258 \\
1206 \\
325 \\
1.1 \\
4.0 \\
\end{tabular} & 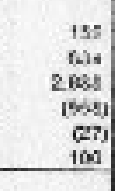 \\
\hline ro & $\begin{array}{l}T-1 \\
T 2 \\
T-2 \\
T-1 \\
T-3 \\
T-1\end{array}$ & 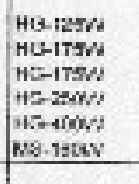 & 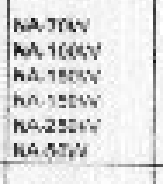 & $\begin{array}{c}\text { E: } \\
\text { n: } \\
\text { xi: } \\
5: 1 \\
4.1 \\
3.1 \\
\end{array}$ & $\begin{array}{c}60.4 \\
5.4 \\
-34.5 \\
132.8 \\
225.5 \\
12 ! .4\end{array}$ & \begin{tabular}{l|}
3.3 \\
12 \\
29 \\
15 \\
1.4 \\
1.7
\end{tabular} & $\begin{array}{c}10 e r s \\
414 \\
105 \\
4045 \\
\text { CEs }\end{array}$ & $\begin{array}{r}6.4 \\
28.5 \\
720.2 \\
22.4 \\
-1.4 \\
4.3 \\
\end{array}$ & 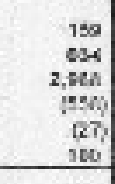 \\
\hline$m$ & $\begin{array}{l}T-1 \\
T-2 \\
T-3 \\
T-4 \\
T-6 \\
T-5 \\
\end{array}$ & 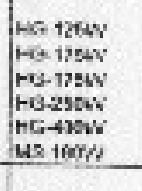 & 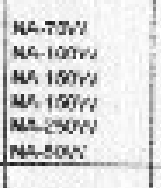 & $\begin{array}{r}0 \\
8 \\
240 \\
47 \\
45 \\
30 \\
0\end{array}$ & $\begin{array}{c}676 \\
067 \\
-318 \\
105 \\
2+5 \\
141\end{array}$ & $\begin{array}{l}1.8 \\
1.2 \\
1.0 \\
1.8 \\
1.4 \\
1.2\end{array}$ & 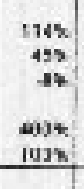 & $\begin{array}{r}61 \\
25.0 \\
1208 \\
20.8 \\
-1.1 \\
40\end{array}$ & $\begin{array}{r}556 \\
634 \\
2.958 \\
65981 \\
67 \\
102\end{array}$ \\
\hline at & $\begin{array}{l}T-1 \\
T-2 \\
T-3 \\
T-1 \\
T-1 \\
T A\end{array}$ & 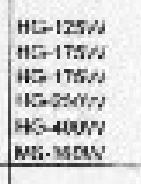 & 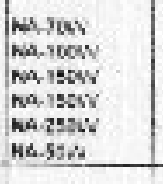 & $\begin{array}{l}58 \\
66 \\
28 \\
48 \\
4 . \\
35\end{array}$ & $\begin{array}{c}\pi .3 \\
n .1 \\
-20.1 \\
25.2 \\
254.3 \\
195.1\end{array}$ & $\begin{array}{l}1.0 \\
13 \\
10 \\
1.5 \\
1.4 \\
10\end{array}$ & 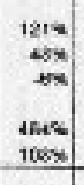 & $\begin{array}{r}5.1 \\
258 \\
120 \\
-22.1 \\
-1.1 \\
4.0\end{array}$ & $\begin{array}{c}158 \\
609 \\
2 \mathrm{ReO} \\
10091 \\
627 \\
100\end{array}$ \\
\hline (8) & $\begin{array}{l}T-1 \\
T / 2 \\
T=3 \\
i-1 \\
T=3 \\
T+5\end{array}$ & 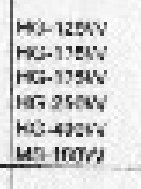 & 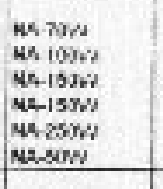 & $\begin{array}{r}5.3 \\
5.4 \\
21.4 \\
4.3 \\
4.4 \\
2.8\end{array}$ & $\begin{array}{l}75 . t \\
72.2 \\
25.2 \\
212.5 \\
268.5 \\
15 i f\end{array}$ & $\begin{array}{l}1.3 \\
1.3 \\
1.0 \\
1.0 \\
1.4 \\
1.8\end{array}$ & $\begin{array}{c}128 / 6 \\
5 / 4 \\
t \% \\
522 \% \\
111 \%\end{array}$ & $\begin{array}{r}6.4 \\
25.9 \\
25.8 \\
22.4 \\
-1.1 \\
4.1 \\
\end{array}$ & $\begin{array}{r}198 \\
634 \\
2.640 \\
158, \\
67 \\
160 \\
\end{array}$ \\
\hline$\omega$ & $\begin{array}{l}T-1 \\
7-2 \\
7-2 \\
1-1 \\
T-3 \\
T-4\end{array}$ & $\begin{array}{l}\text { HE-125W } \\
\text { HE-175W } \\
\text { HE-175W } \\
\text { HS } 260 \% \\
\text { H2-400W } \\
\text { MEI- }\end{array}$ & 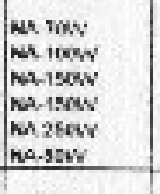 & $\begin{array}{c}49 \\
50 \\
202 \\
40 \\
98 \\
28 \\
\end{array}$ & $\begin{array}{l}20.7 \\
00.2 \\
2 z .9 \\
228.4 \\
211.8 \\
71.8\end{array}$ & $\begin{array}{l}1.4 \\
1.3 \\
1.4 \\
1.4 \\
1.4 \\
1.4\end{array}$ & $\begin{array}{c}-904 \\
55 \% \\
-2 \% \\
545 * \\
1204\end{array}$ & $\begin{array}{r}4.4 \\
21.8 \\
121.1 \\
22.8 \\
-1.1 \\
10\end{array}$ & 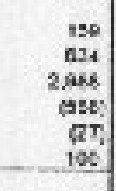 \\
\hline 100 & $\begin{array}{l}T-1 \\
T-2 \\
T-3 \\
T-5 \\
T-6 \\
T-5\end{array}$ & 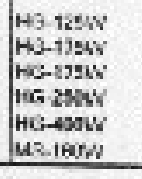 & 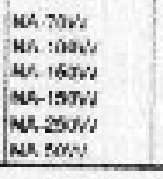 & $\begin{array}{r}4.4 \\
4.9 \\
1.2 . \\
2.4 \\
2.4 \\
2.2 \\
\end{array}$ & $\begin{array}{r}0.2 \\
106.4 \\
22.1 \\
26.6 \\
528.0 \\
180.4\end{array}$ & $\begin{array}{l}1.4 \\
12 \\
10 \\
1.5 \\
14 \\
10\end{array}$ & 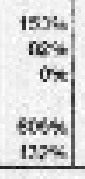 & $\begin{array}{r}6.1 \\
20.8 \\
120.2 \\
22.8 \\
-1.1 \\
4.0\end{array}$ & 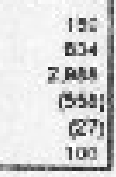 \\
\hline
\end{tabular}


ANEXO D

TABELA D.10

ANALISE DE SENSIBILIDADE (USO DIARIO)

\begin{tabular}{|c|c|c|c|c|c|c|c|c|c|}
\hline & $\overline{F I G}$ & DEME & TROCADE & DSOA & RAC & SFRE & 5 & & \\
\hline $\begin{array}{c}\text { HCRAS } \\
\text { FUNCIDNe } \\
\text { (hidis }\end{array}$ & TROCA & ADTUADS & PAO.ETADRS & $\begin{array}{l}\text { TSR } \\
\text { (anos: }\end{array}$ & $\begin{array}{c}\text { VPV } \\
\text { BALANPO } \\
\text { CUSSI }\end{array}$ & 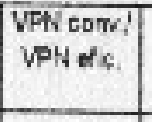 & $\begin{array}{l}\pi R \\
|\$\rangle \mid\end{array}$ & $\begin{array}{c}\text { CEC } \\
\text { (USS } / \mathrm{W} / \mathrm{h})\end{array}$ & $\begin{array}{c}C P C \\
\text { \{USSKW }\end{array}$ \\
\hline 100 & $\begin{array}{l}T-1 \\
T-2 \\
T-9 \\
T-1 \\
T-5 \\
T-8 \\
\end{array}$ & $\begin{array}{l}H G-125 W \\
H G-175 W \\
H G-75 W \\
H G-250 W \\
H G-199 N \\
\text { WS-1ECW }\end{array}$ & 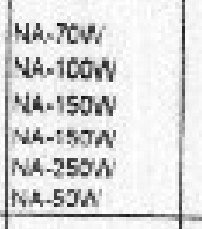 & $\begin{array}{r}6.3 \\
5.5 \\
26.3 \\
5.2 \\
4.8 \\
93 \\
\end{array}$ & & & $\begin{array}{r}100 \% \\
41 \% \\
6 \% 6 \\
418 \% \\
64 \% \\
\end{array}$ & $\begin{array}{r}7.8 \\
25.4 \\
13.5 \\
-27.4 \\
-1.2 \\
5.9\end{array}$ & $\begin{array}{r}162 \\
606 \\
2.856 \\
\langle 588 \\
125 \\
104 \\
\end{array}$ \\
\hline 105 & $\begin{array}{l}T-1 \\
T-2 \\
T-8 \\
T-1 \\
T-5 \\
T-E \\
\end{array}$ & $\begin{array}{l}\text { HG-125W } \\
1-0.175 W \\
H G-175 W \\
H G-250 W \\
H G-400 W \\
\text { MS-100W }\end{array}$ & $\begin{array}{l}\text { NA-roW } \\
\text { HA- } 100 W \\
\text { NA-150W } \\
\text { Na-150W } \\
\text { Nh-2SOW } \\
\text { Na-SOW }\end{array}$ & $\begin{array}{r}6.0 \\
62 \\
251 \\
50 \\
4.7 \\
3.2 \\
\end{array}$ & & 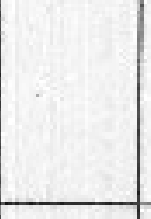 & $\begin{array}{r}113 \% \\
45 \% \\
-7 \% \\
40 \% \\
40 \% \\
906\end{array}$ & $\begin{array}{r}7.0 \\
28.9 \\
1394 \\
-25.0 \\
-1.2 \\
47\end{array}$ & $\begin{array}{r}160 \\
513 \\
2,280 \\
15031 \\
12 \pi) \\
102 \\
\end{array}$ \\
\hline 110 & $\begin{array}{l}T-1 \\
T-2 \\
T-3 \\
T-C \\
T-5 \\
T-6\end{array}$ & $\begin{array}{l}H=125 W \\
H G-175 W \\
H C-175 W \\
H 0-250 W \\
H G-40 C W \\
M E-18 \% N\end{array}$ & 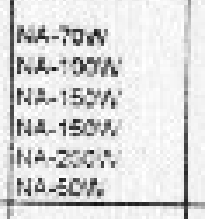 & $\begin{array}{r}5.8 \\
5.7 \\
29.8 \\
4.7 \\
4 . \\
30 \\
\end{array}$ & & & $\begin{array}{r}115 \% \\
45 \% \\
-5 \% \\
41 \% \\
103 \% \\
\end{array}$ & $\begin{array}{r}7.8 \\
27.3 \\
12 t .7 \\
24.8 \\
-1.1 \\
5.1 \\
\end{array}$ & $\begin{array}{r}177 \\
\epsilon 20 \\
2,220 \\
(064) \\
(72) \\
115 \\
\end{array}$ \\
\hline 11.5 & $\begin{array}{l}T-1 \\
T-2 \\
T-3 \\
T-1 \\
T-5 \\
T-6\end{array}$ & $\begin{array}{l}H G-125 W \\
H S-175 W \\
H=175 W \\
H 3-250 N \\
H 3-100 N \\
W=185 W\end{array}$ & $\begin{array}{l}\text { NA-TOW } \\
\text { NA-10OW } \\
\text { NA-150N } \\
\text { NA-15NN } \\
\text { NA-25\%N } \\
\text { NA-5ON }\end{array}$ & \begin{tabular}{r|}
5.5 \\
5.6 \\
28.9 \\
4.5 \\
4.5 \\
2.0 \\
\end{tabular} & & & $\begin{array}{r}120 \% \\
42 \% \\
-6 \% \\
428 \\
107 \%\end{array}$ & $\begin{array}{r}85 \\
264 \\
1245 \\
237 \\
-1.1 \\
4.8\end{array}$ & $\begin{array}{r}154 \\
627 \\
2,866 \\
158 \cdot) \\
129 ! \\
115 \\
\end{array}$ \\
\hline 120 & $\begin{array}{l}T-1 \\
T-2 \\
T-9 \\
T-4 \\
T-5 \\
T-5 \\
\end{array}$ & $\begin{array}{l}H G-125 W \\
H C-175 W \\
H G-175 W \\
H 2-250 W \\
-13-400 W \\
N S-190 W\end{array}$ & $\begin{array}{l}\text { NA-TOW } \\
\text { NA-100W } \\
\text { NA-150W } \\
\text { NA-150W } \\
\text { NA-25\%N } \\
\text { NA. } 55 \mathrm{~W}\end{array}$ & $\begin{array}{r}5.3 \\
5.1 \\
21.5 \\
1.3 \\
1 . \\
2.8\end{array}$ & & & $\begin{array}{r}128 \% \\
50 \% \\
-5 \% \\
5028 \\
1115\end{array}$ & $\begin{array}{r}E .4 \\
2 \leq .8 \\
120.8 \\
22.6 \\
-1.1 \\
40\end{array}$ & $\begin{array}{r}158 \\
634 \\
2.958 \\
(555) \\
(27) \\
100 \\
\end{array}$ \\
\hline 125 & $\begin{array}{l}T-1 \\
T-2 \\
T-3 \\
T-1 \\
T-5 \\
T-6 \\
\end{array}$ & $\begin{array}{l}\text { HG-125W } \\
\text { HG-175W } \\
\text { HO-175W } \\
\text { HG-25DW } \\
\text { HE-400W } \\
\text { NS-1ACW }\end{array}$ & $\begin{array}{l}\text { HA-7OW } \\
\text { raA-10CW } \\
\text { NA-15CW } \\
\text { HA- } 150 W \\
\text { NA-2SOW } \\
\text { NA_SOW }\end{array}$ & $\begin{array}{r}5.1 \\
52 \\
21.1 \\
42 \\
3.8 \\
2.7\end{array}$ & & & $\begin{array}{r}1965 \\
5256 \\
-34 k \\
529 \% \\
115 \%\end{array}$ & $\begin{array}{r}5.3 \\
240 \\
1110 \\
-22.9 \\
-1.5 \\
2.8\end{array}$ & $\begin{array}{r}183 \\
62 C \\
284 C \\
1575) \\
(46) \\
99 \\
\end{array}$ \\
\hline 130 & $\begin{array}{l}T=1 \\
T-2 \\
T=3 \\
T-1 \\
T=5 \\
T=8\end{array}$ & 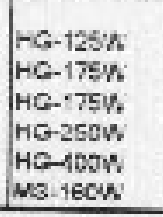 & $\begin{array}{l}\text { WA-75OH } \\
\text { WA-15OW } \\
\text { NA-15OW } \\
\text { NA-1SOW } \\
\text { NA-ASOW } \\
\text { NA-SOW }\end{array}$ & $\begin{array}{r}4.6 \\
5.0 \\
20.5 \\
4.0 \\
3.8 \\
26 \\
\end{array}$ & & & $\begin{array}{r}141 \% \\
55 \% \\
-45 \% \\
5194 \\
1214\end{array}$ & $\begin{array}{r}7.3 \\
24.0 \\
113.4 \\
-20.9 \\
-1.6 \\
4.2\end{array}$ & $\begin{array}{r}145 \\
816 \\
3,042 \\
(560) \\
(43) \\
113 \\
\end{array}$ \\
\hline
\end{tabular}




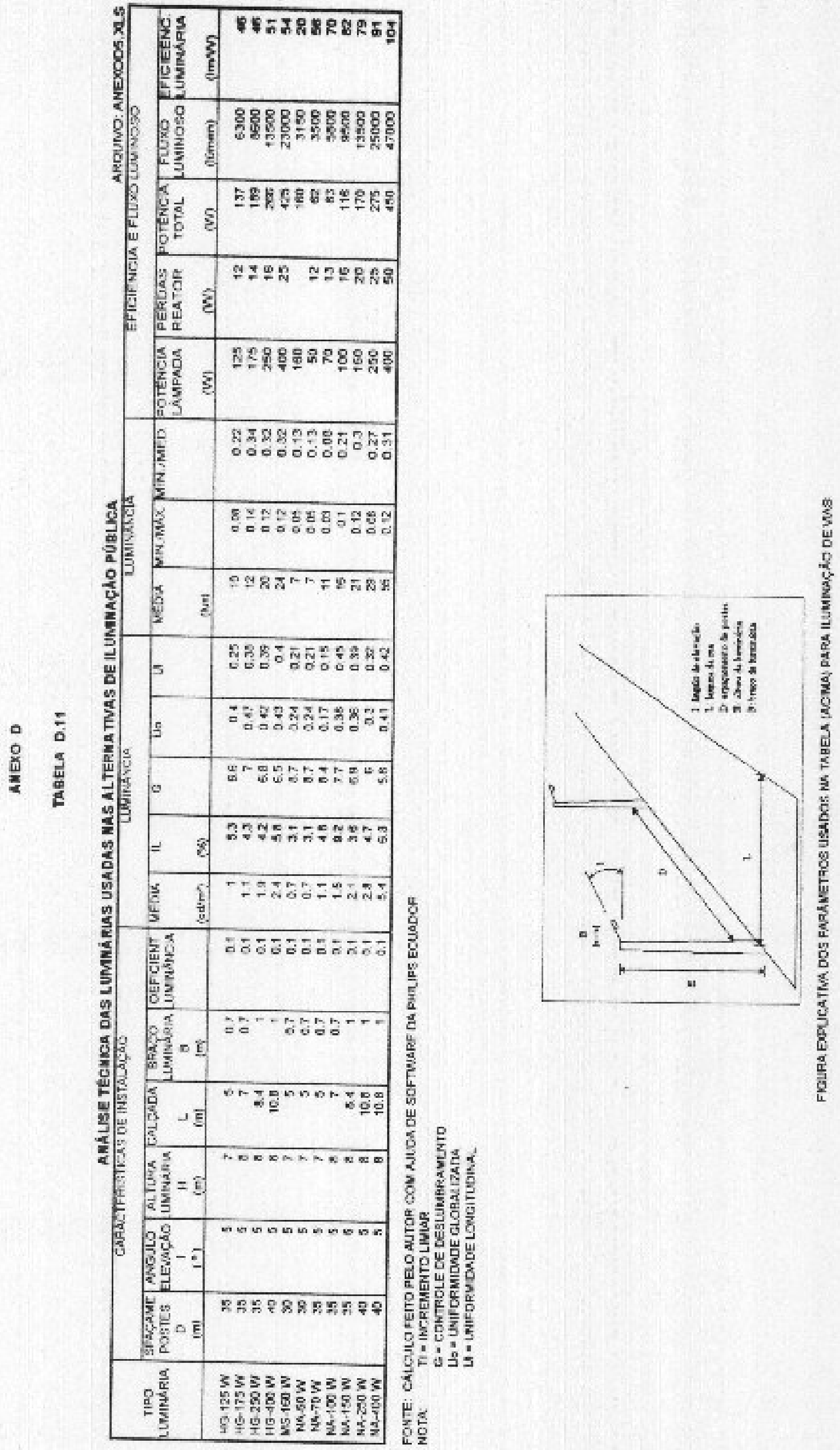


ANEXO E

AVALIAC̄̃O INTEGRADA DE ALTERNATIVAS DE OFERTA E USO EFICIENTE DE ENERGIA NO SETOR DE ILUMINAÇÃO PÚBLICA (IP).

\section{TABELAS}




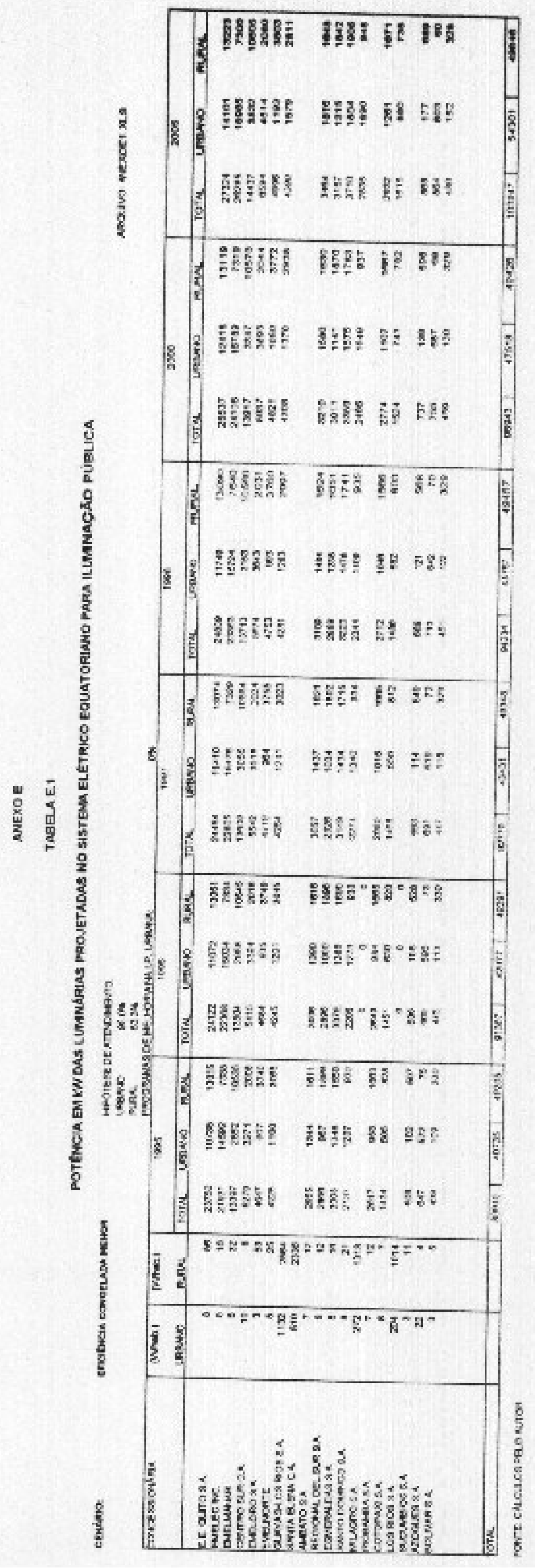




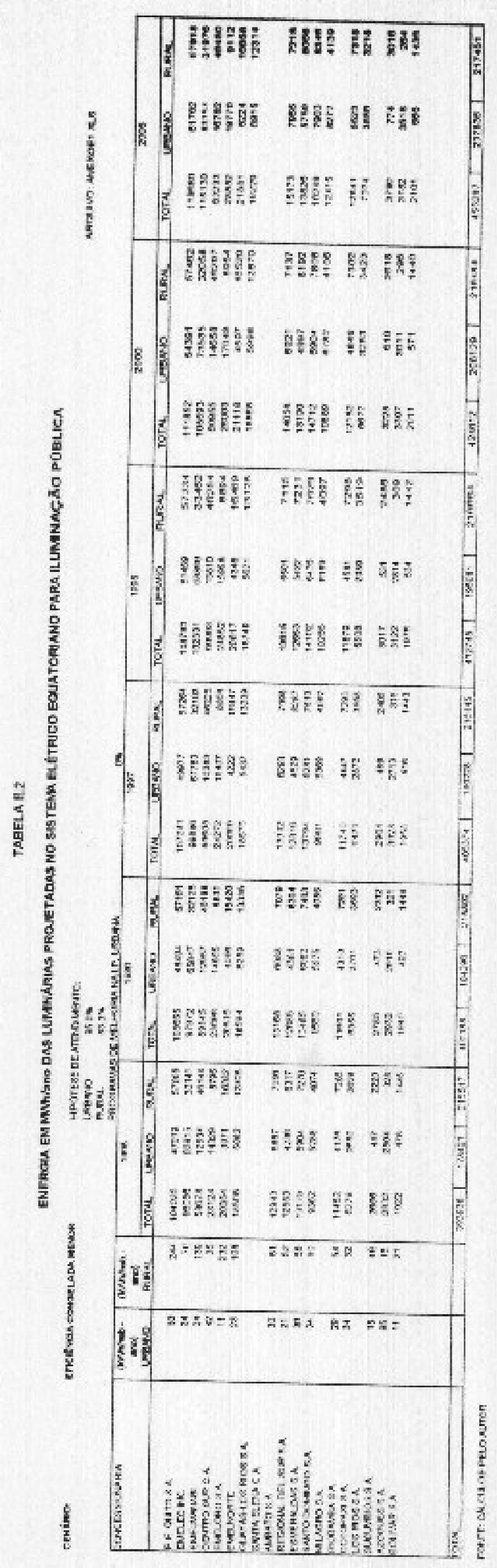




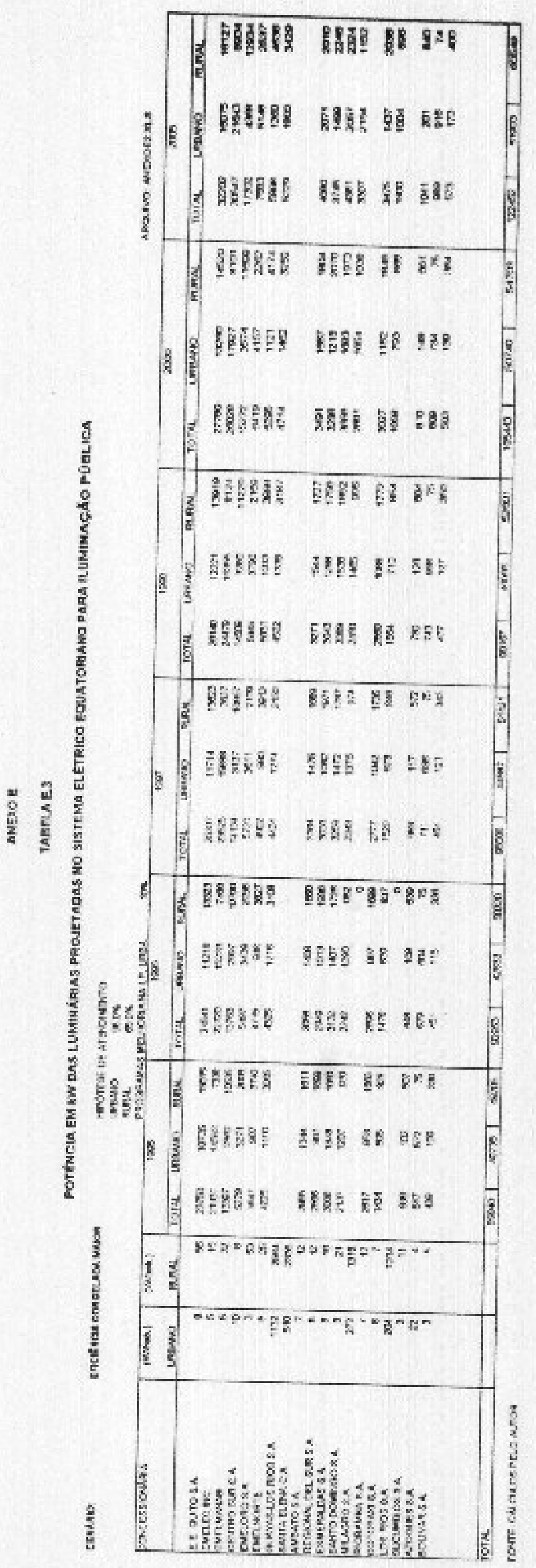




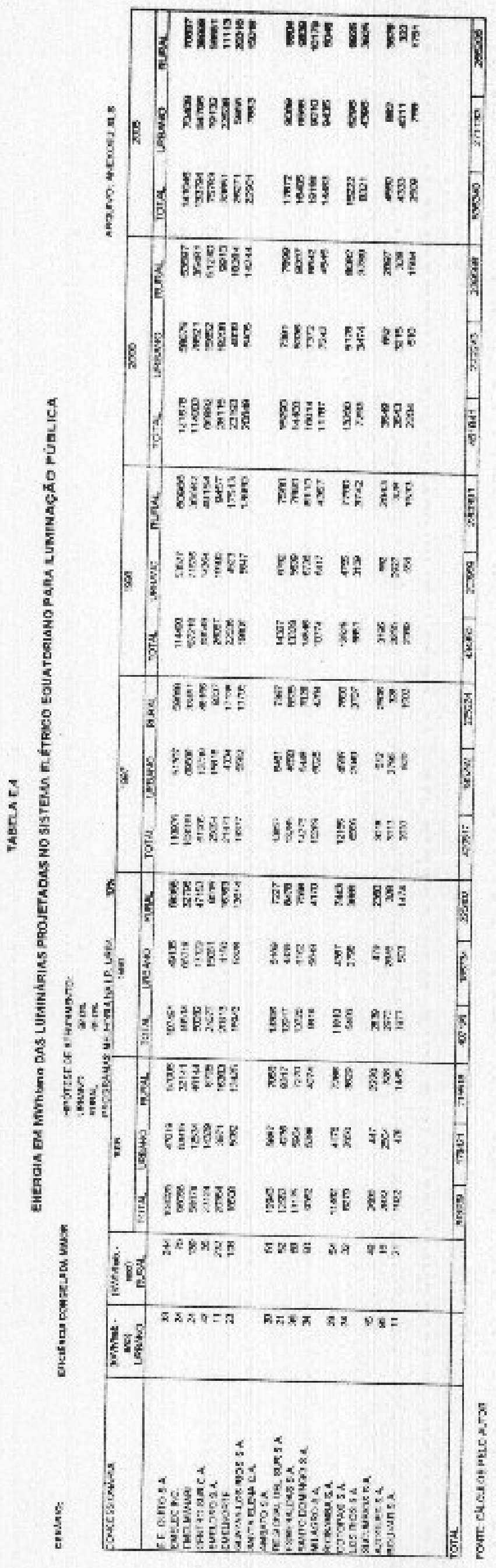




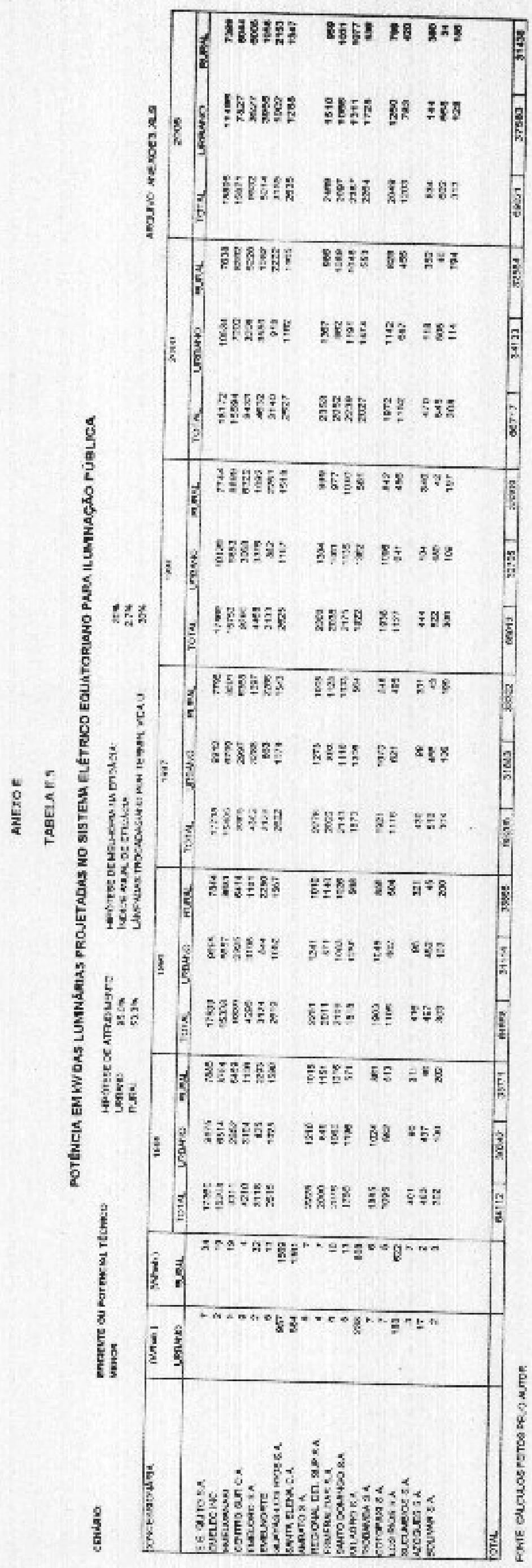




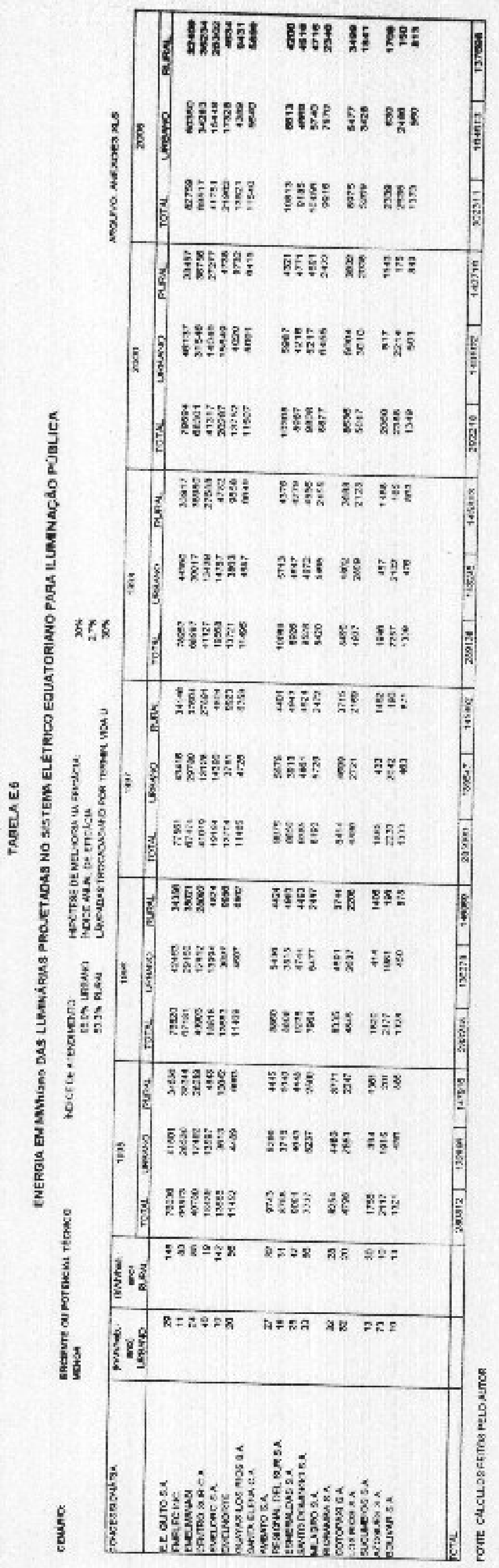




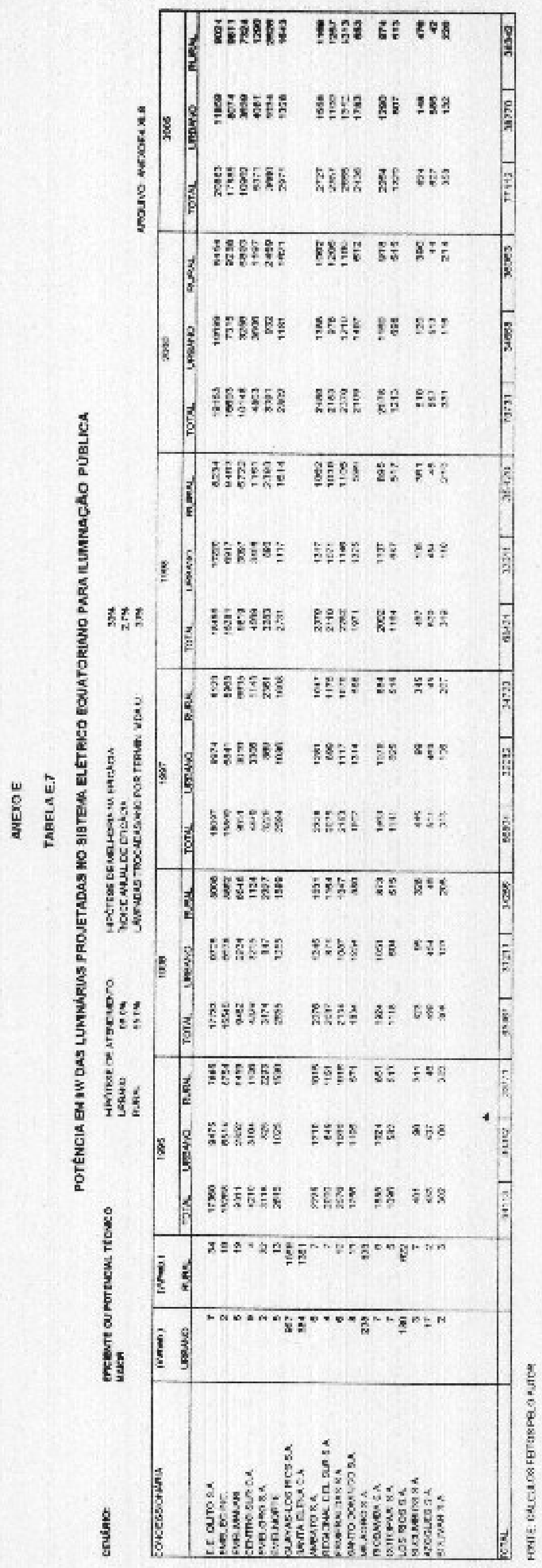




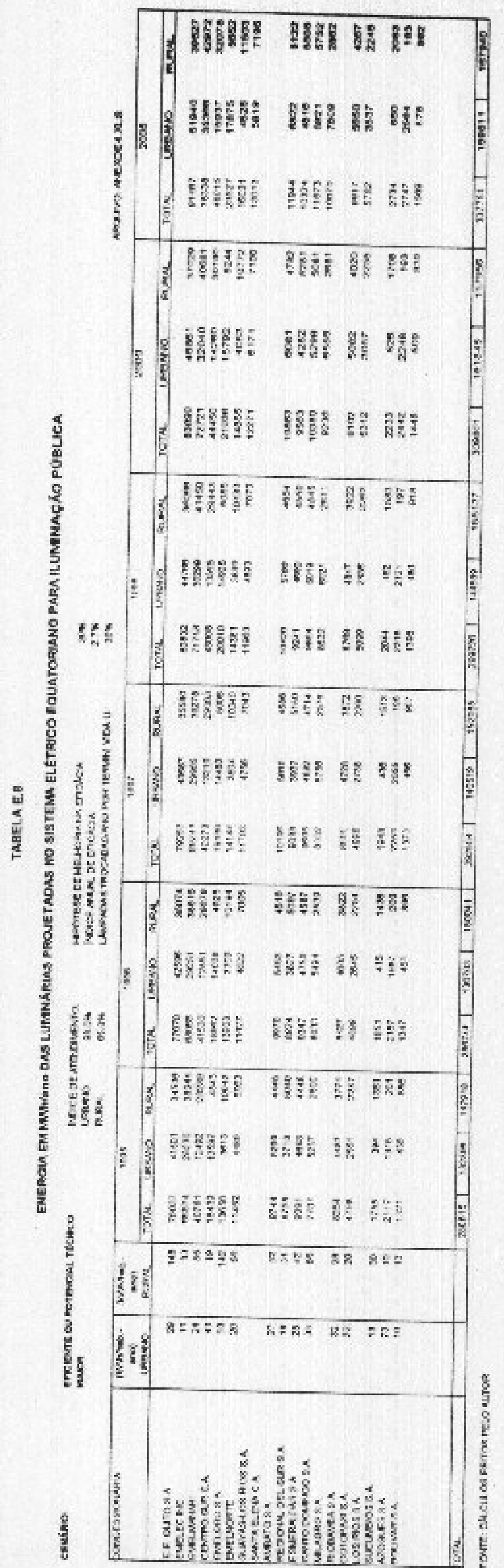




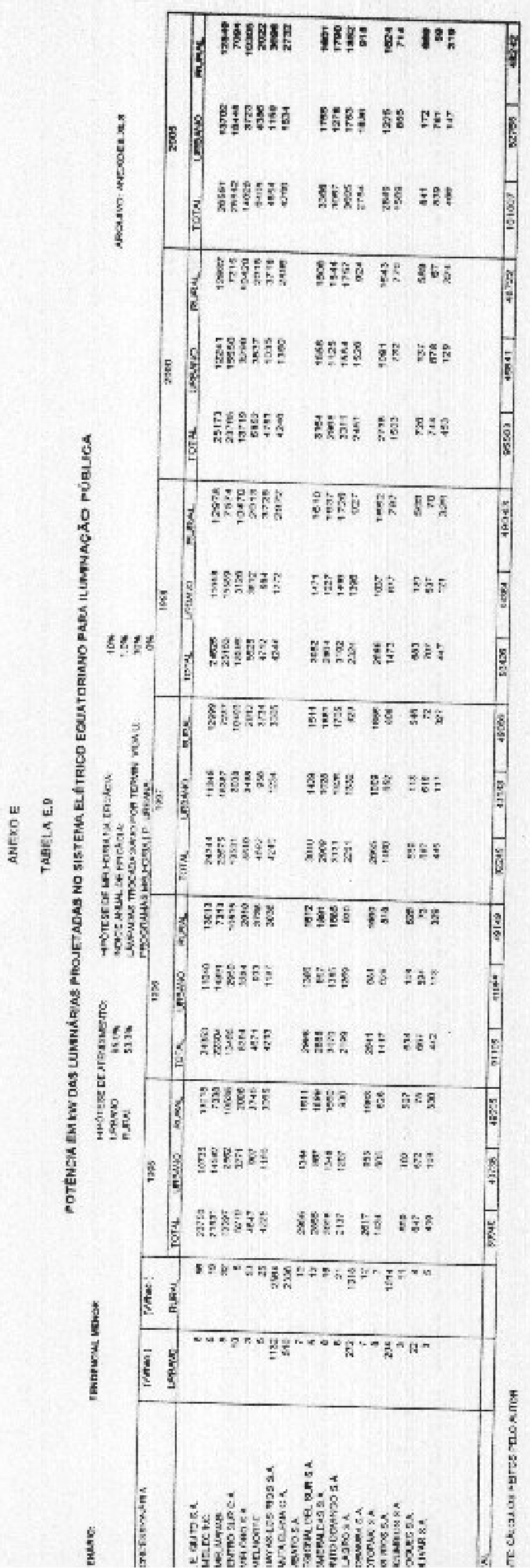




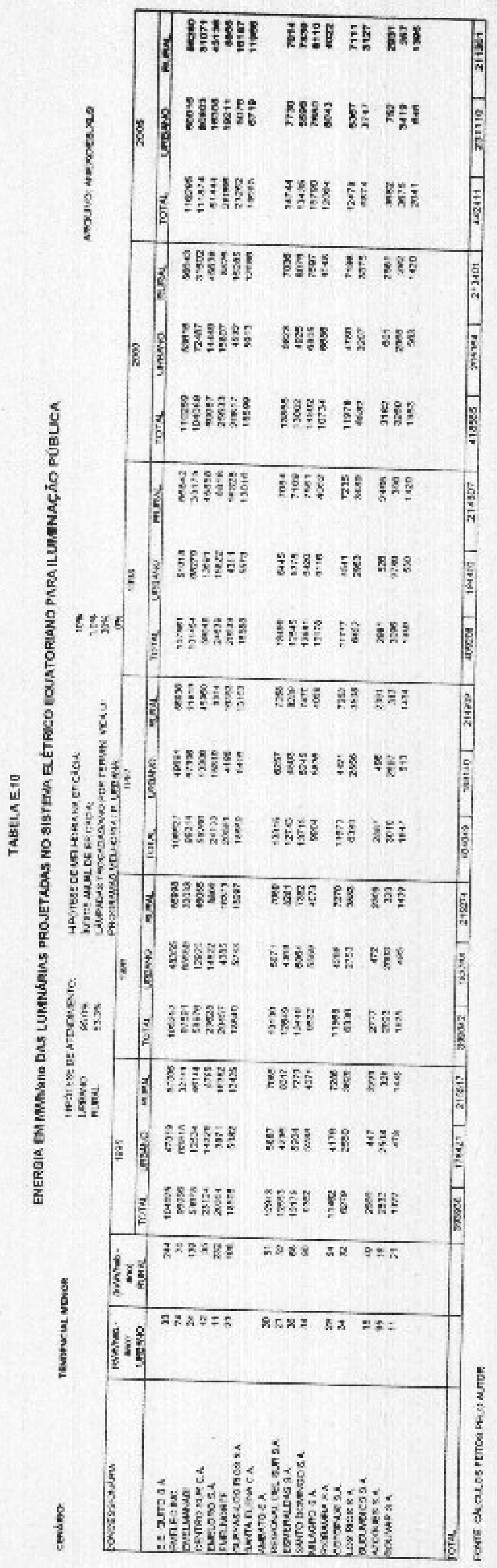




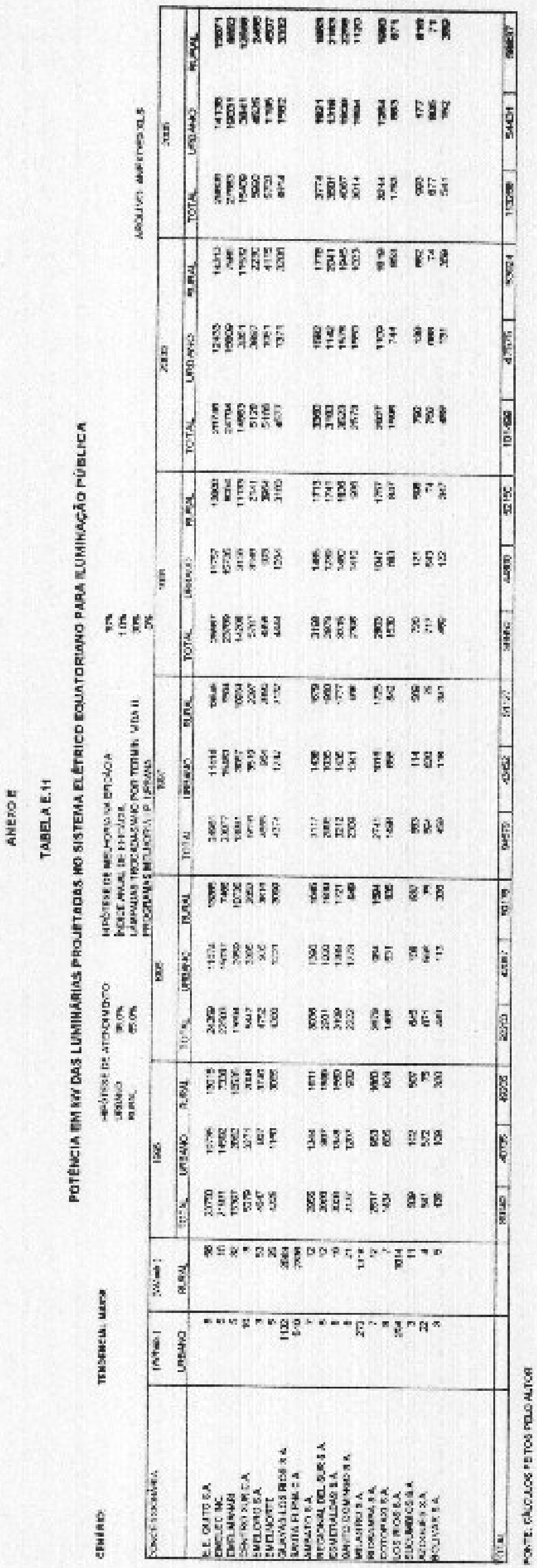




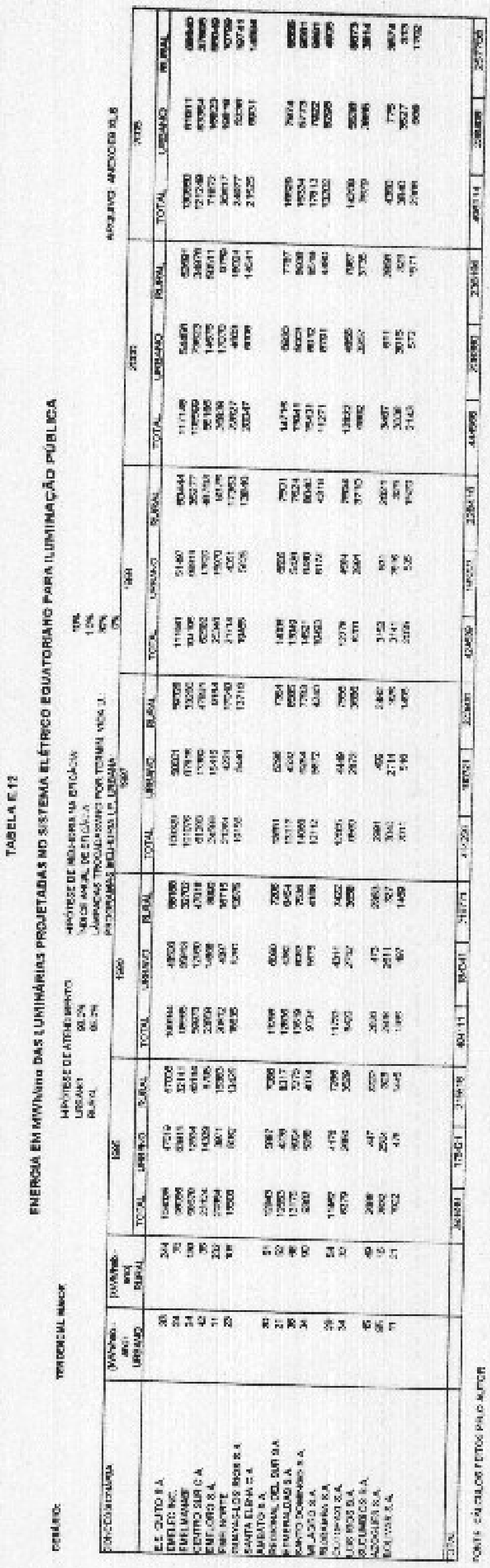




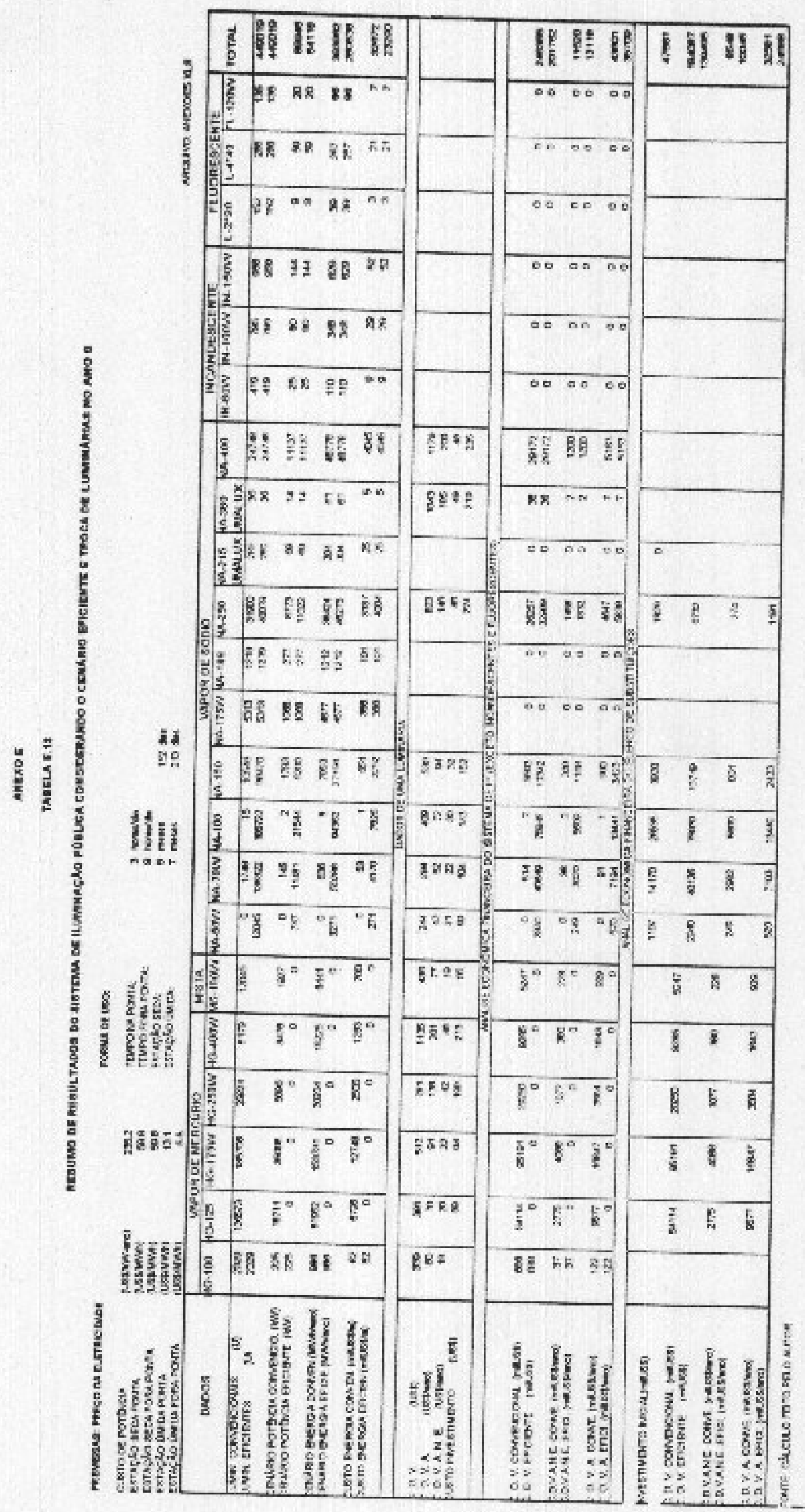




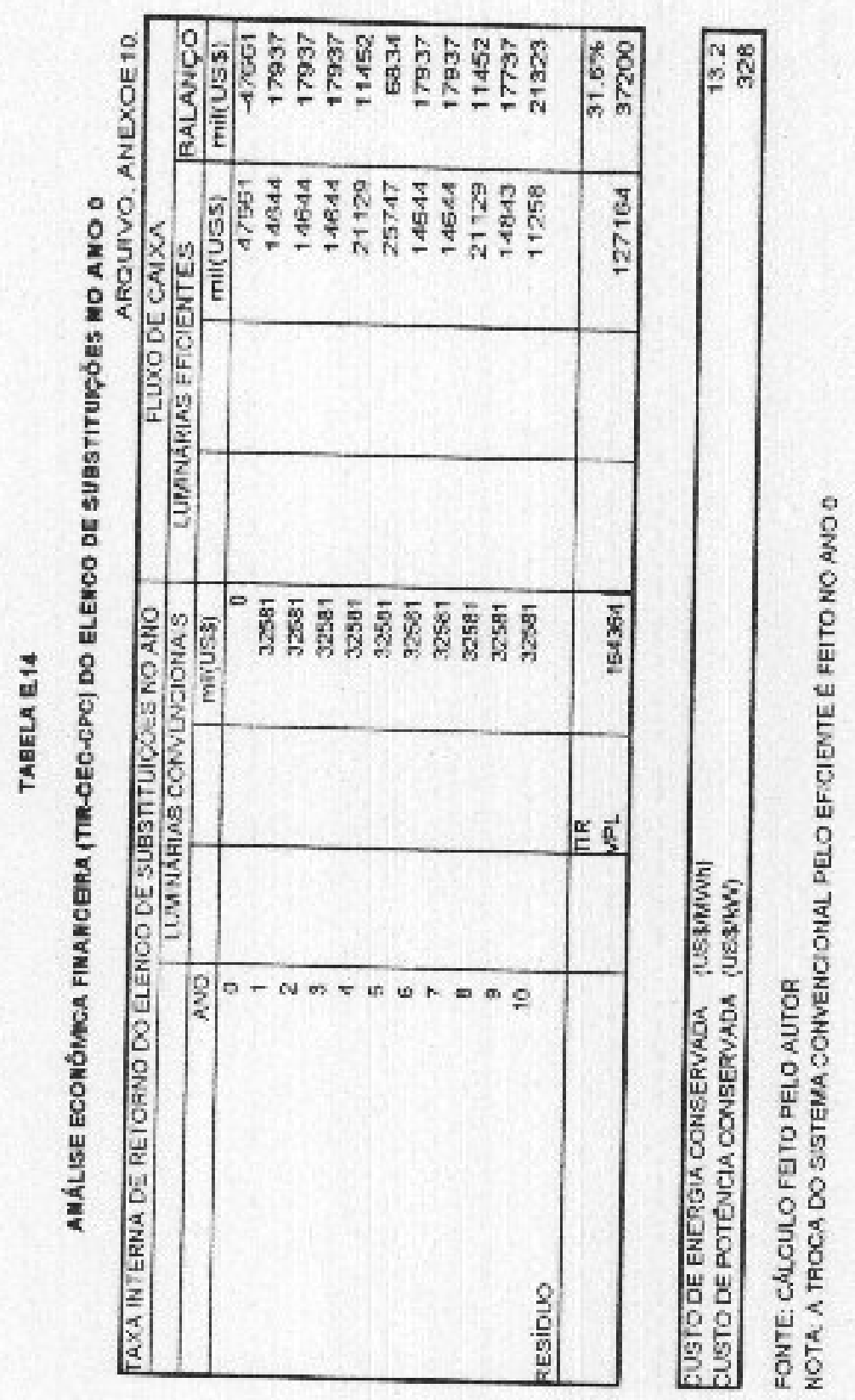




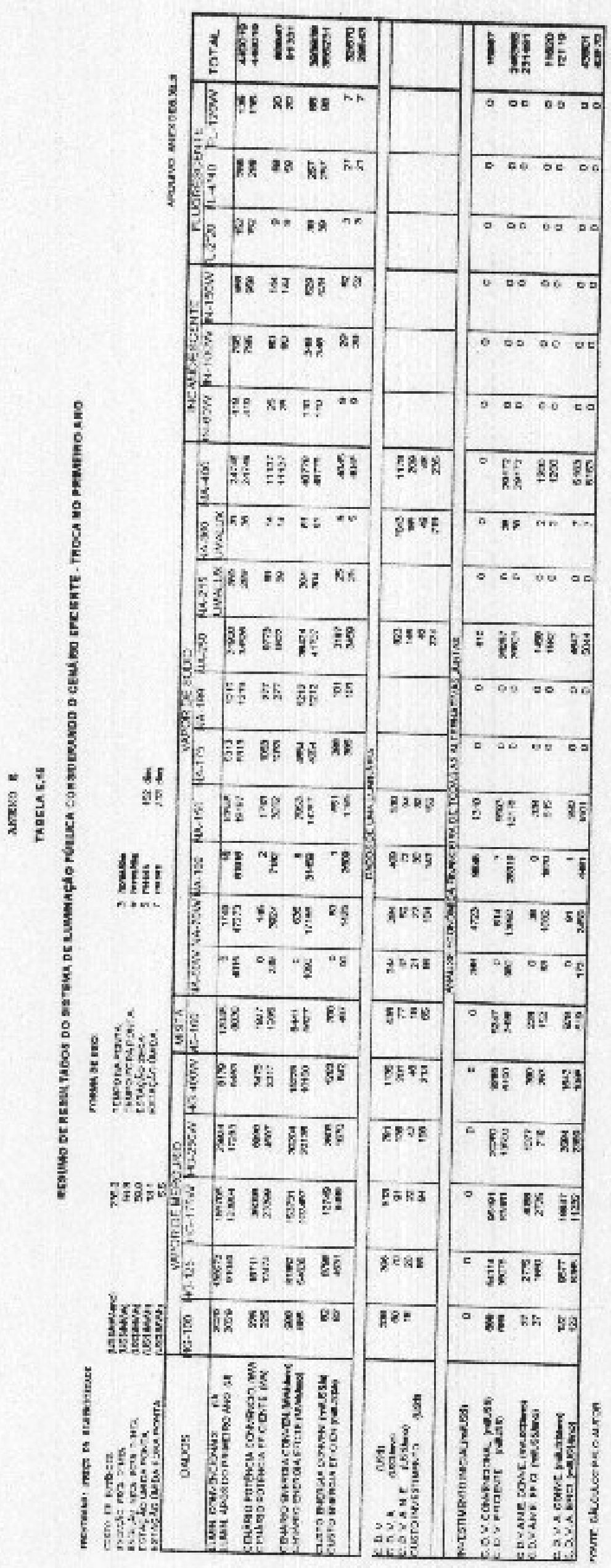




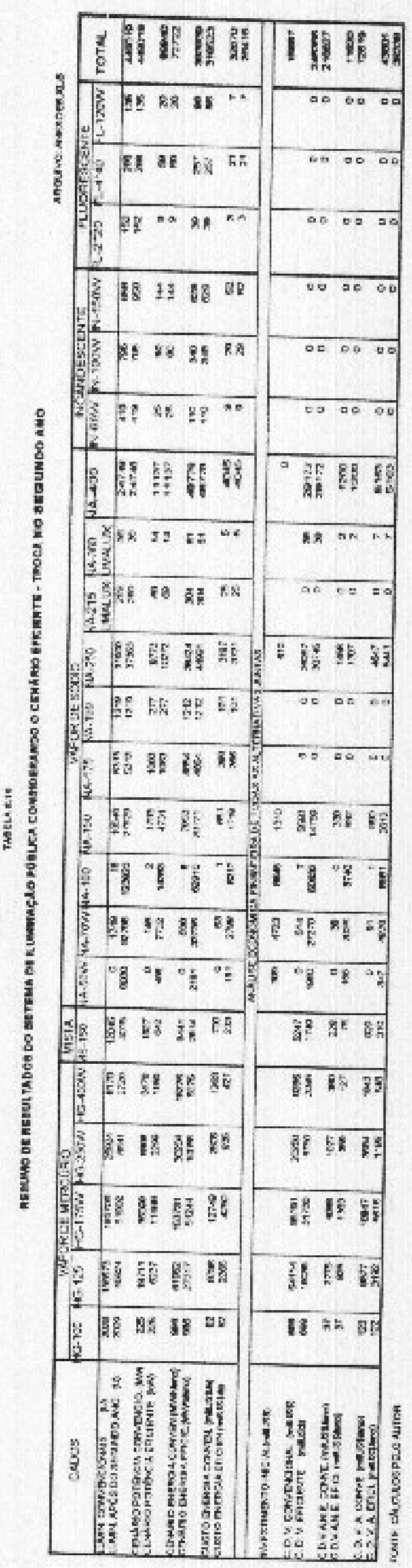




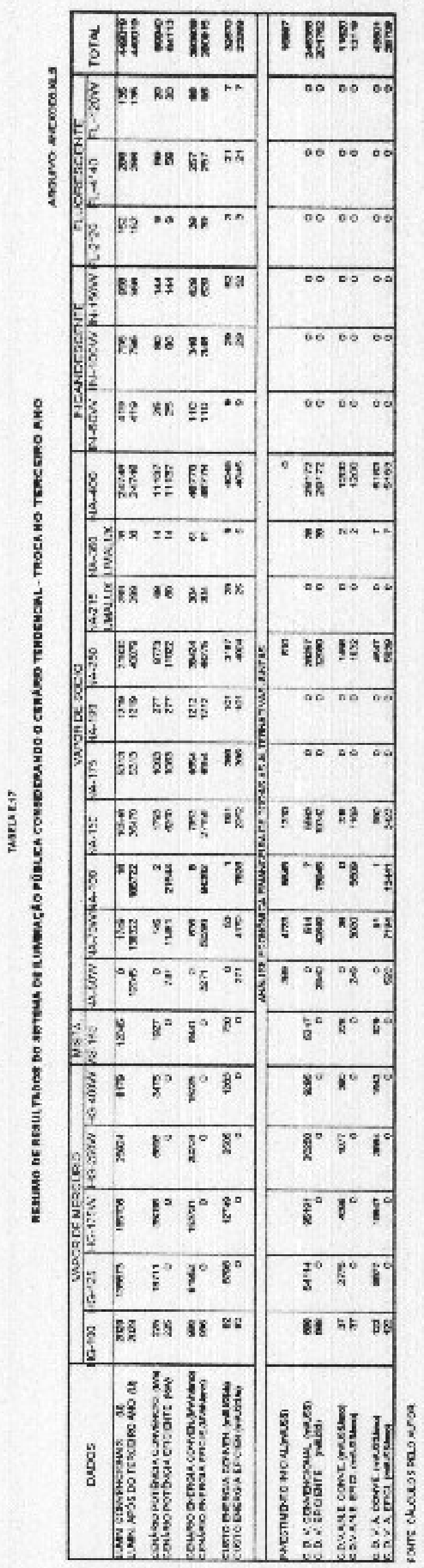




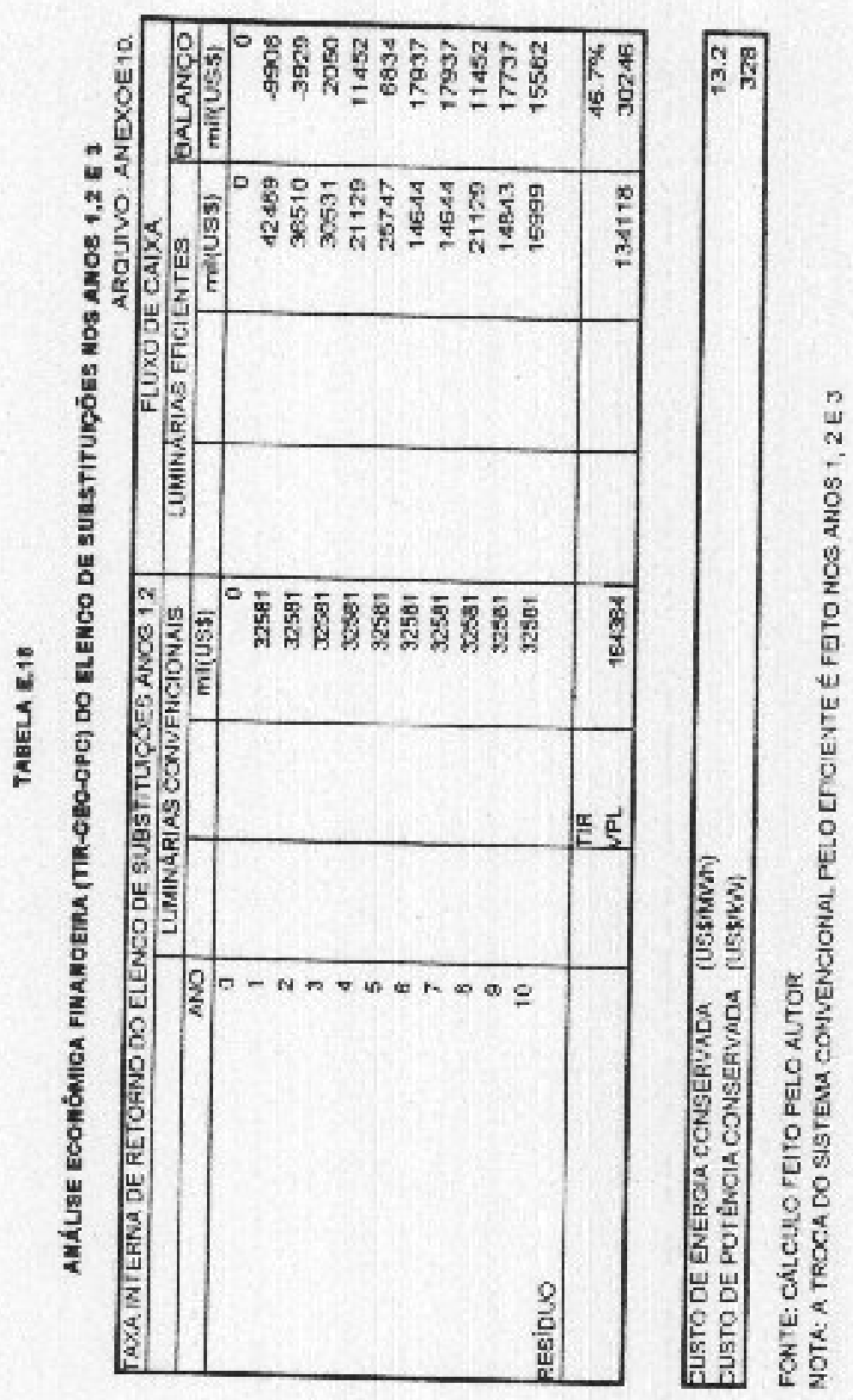




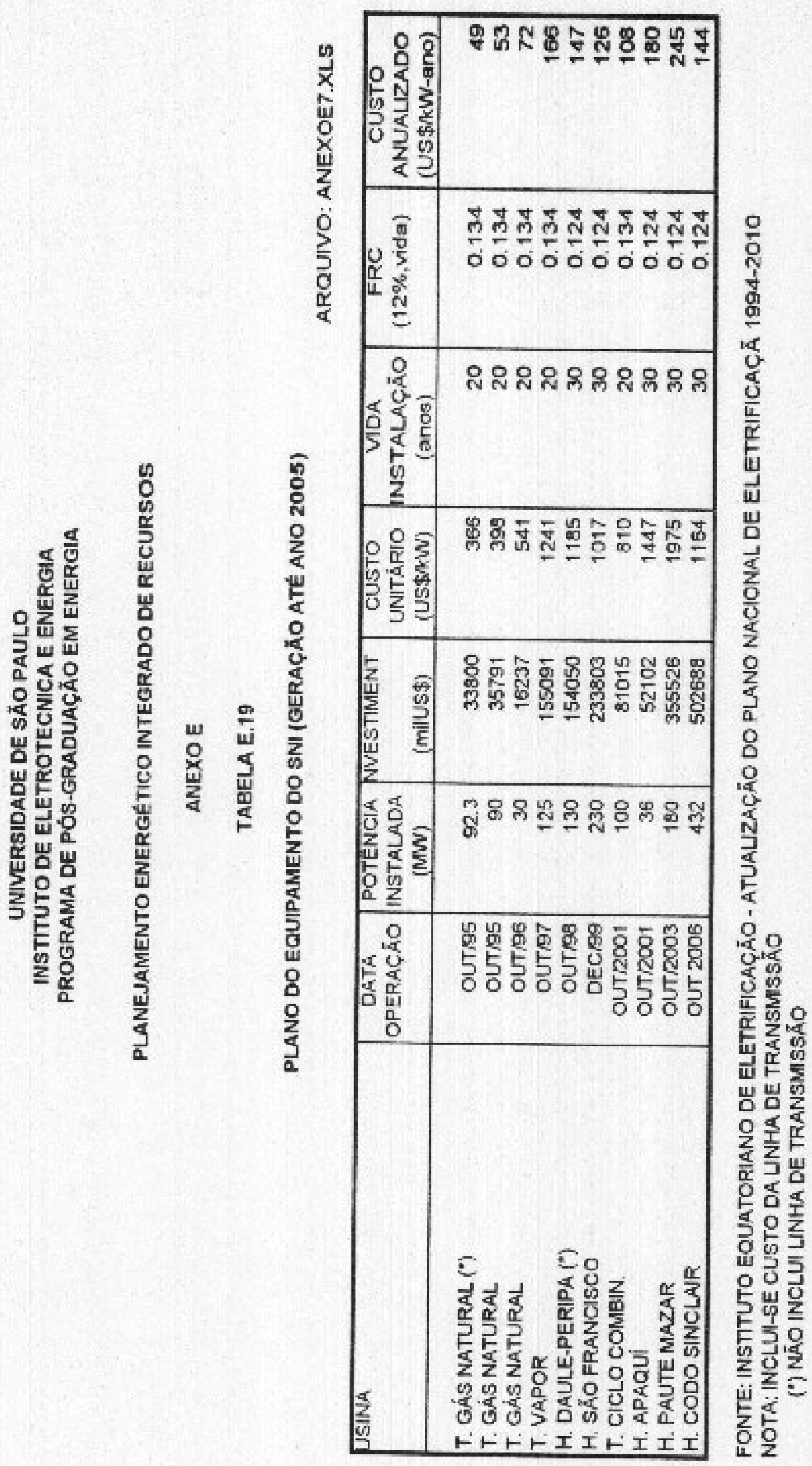




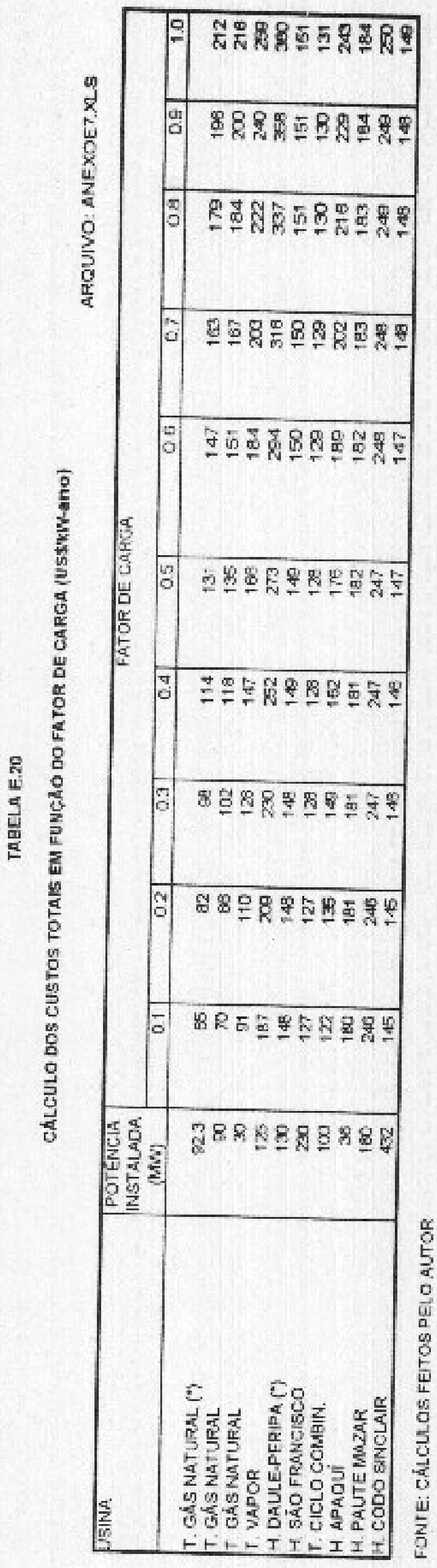


TABELE E.21

GÁLCULO dOS MPACTOS DOS PROORUMAS DE CONSERVAÇÀO

AROLIVO ANEXOET,XIS

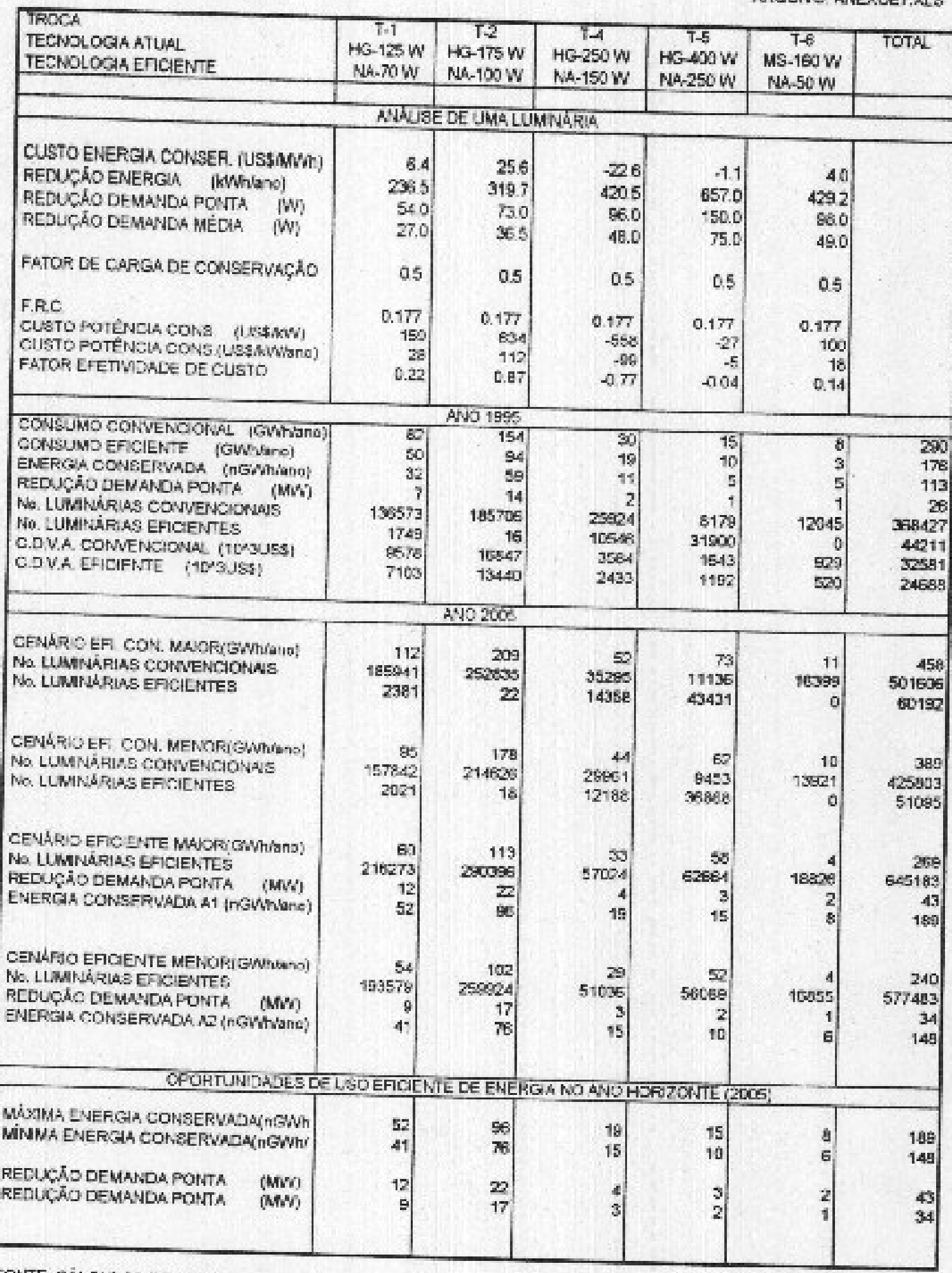

FONTE: CALLCLLOS FaTOS PELO AUTOR 


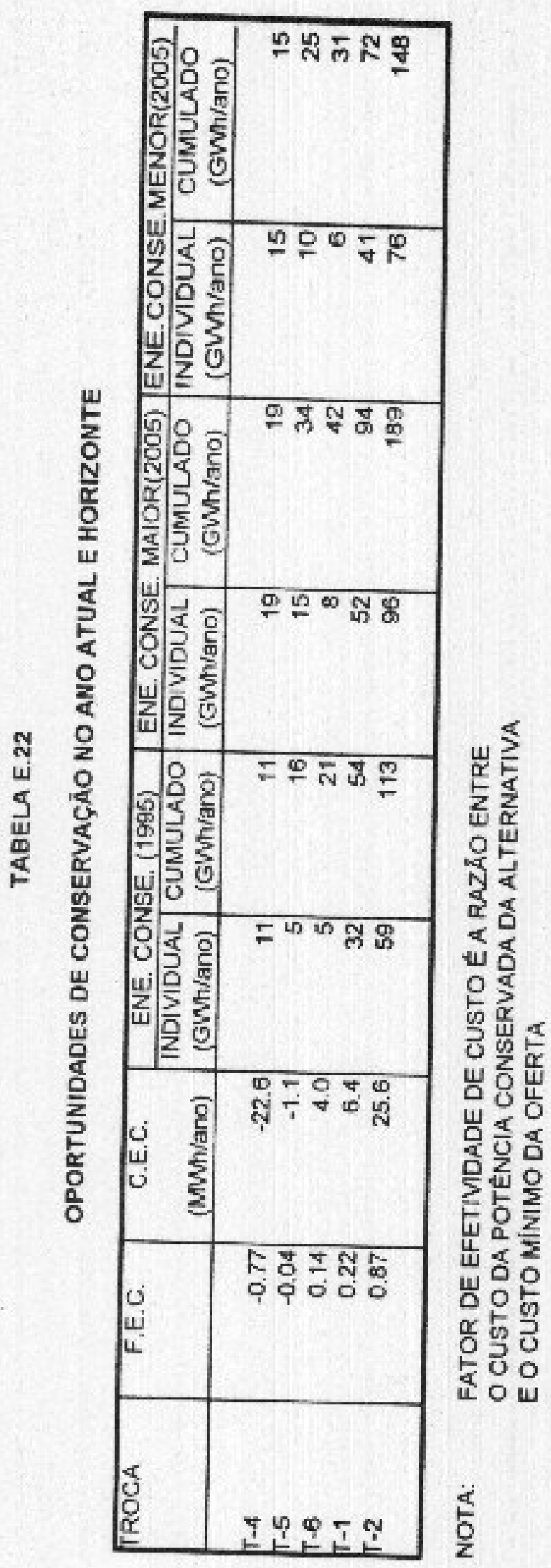




\begin{abstract}
ANEXO F
ESTATÍSTICAS E PROJEÇÕES DA POPULAĊ̃O DO EQUADOR
\end{abstract}

TABEI AS 

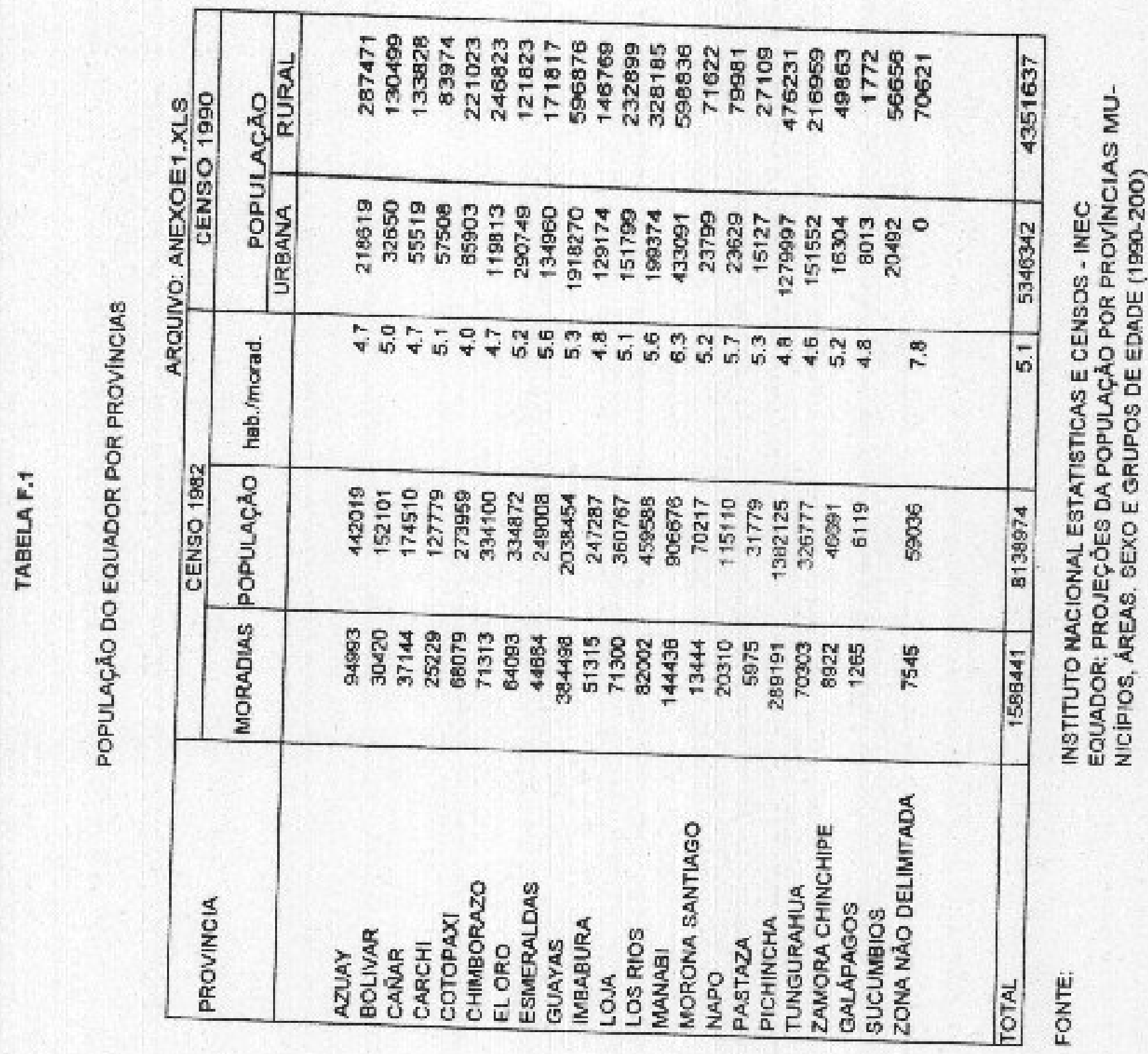


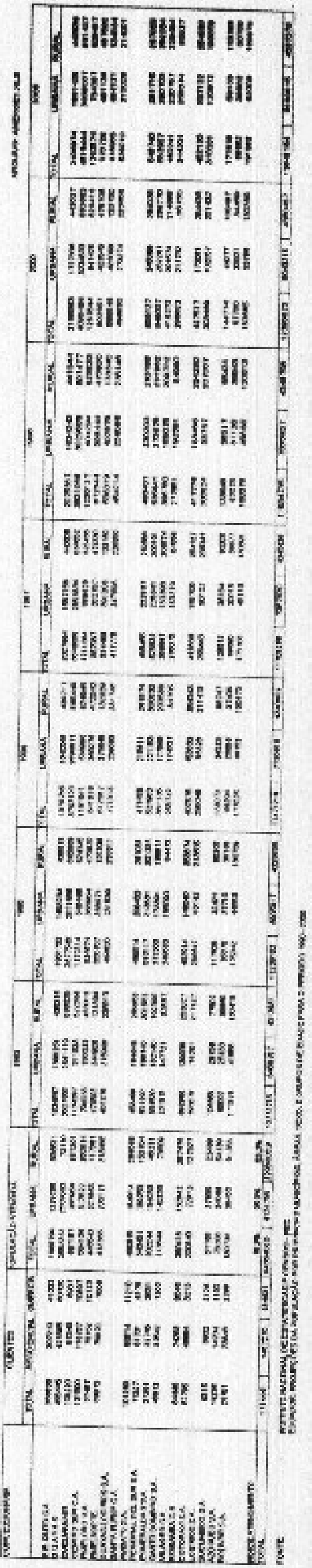




\section{BIBLIOGRAFIA}

ARAúJO, J. L., Modelos de Energin para Planejamento, Área Interdisciplinar de Energia, COPPE/UFR, São Paulo 1994.

ASSOCLAÇÃO BRASILEIRA DA INDÚSTRIA DE ILUMINAÇĀO - ABLUX, Uso Racional de Energia Elétrica em Edificações, lluminação, Agência para Aplicação de Energia, Eletrobrás, PROCEL, São Paulo abril 1992.

ASSOCIAÇÃO BRASILEIRA DE NORMAS TÉCNICAS - ABTN, Iluminação Pública, NBK-5101/85,

AYALA, L., Obtención de Curvas de Carga Sectoriales mediante Encuestas a Usuários, Instituto Ecuatoriano de Flectrificación, VI Congreso Latinoamericano y del Caribe sobre Tarifas Económicas de Energia Eléctricu, Mendoza-Argentima,
mayo de 1992 .

BANCO MUNTIAL, Energia: Eficiencia y Conservación en el Mundo en Desarrollo, Documento de Política del Banco Mundial, Washington 1993.

BANCO MUNDIAL, Primer Seminário sobre Reformas en el Sector Eléctrico Boloviano, Ministério de Energia e Hidrocarburos, La Paz Bolivia, Editorial

BENALCÁzAR, R R, Anúlisis del Dessrrollo Económico del Ecuador, Ediciones del Banco Central del Ecuador, Primera Edición, Quito-Ecuador 1989.

BITU, R ; BORN, P., Tarifas de Energia Elétrica - Aspectos Conceituais e Metodológicos, MM Editora Ltda., São Paulo 1993.

BURINI, E.C.; MEDINA, M.M.; SAUER, I.L., Bases para Políticas de fluminaçẫo Pública - Estudo de Casu, U Congresso Brasilciro de Planejamento Energético, Universidade Nacional de Campinas UNICAMP, Campinas dezembro 1994.

CAUVILLA, P. R, SAUER, I L., Custo do Lúmen-hora, Revista I az e Eşpaço, pág. 25 , dezembro 92

CENTRO DE FXCELÉNCIA EM DISTRIBUIÇÃO DE ENERGIA ELÉTRICA CEDEE, Planejamento Integrado de Recursos, Análises Prelíminares Diagnóstico, Instituto de Eletrotécnica e Fnergia, Universidade de São Paulo
1995.

COMISION ECUATORIANA DE BIENES DE CAPITAL - CEBCA, Inventario de Proyectos y Adquisiciones del Sector Eléctrico, Quito octubre 1993.

COMISIÓN NACIONAL DE ENERGIA DE CHILE - CNE, Estudio Mejoramícnto del Alumbrado Público (CNE), Energia Racional S.A., Santiago de Chile 1994. 


\section{DEPARTAMENTO NACIONAL DE ÁGUAS E ENERGIA ELÉTRICA- ELETROBRÁS, Nova Tarifa de Energia Elétrica - Metodologia e Aplicaçâo,
Ministério das Minas e Energia, Brasilia 1985.}

\section{DUTT, G.S., Electricity at Least Cost, A Manual on the End-Use Oriented} Approach to Eletricity Supply in India, The Center for Energy and Enviromental Studies-Princeton University, Angust 1993.

ELETROBRÁS, Centrais Elétricas Brasileiras S.A., Plano Nacional de Energia Elétrica 1993-2015, Plano 2015, Volume 1, Relatório Executivo Símtese, abril 1994. ELECTRO LDMA, Estudio Sohre la Renovación y Modernización del Alumbrado
Público del Area Metropolitana de Lima, Lima 1989.

EMPRESA ELÉCTRICA QUITO S.A., Normas para Sistemas de Distribución Parte A, Gúa para diseîn, EEQ Quito 1979.

ILUMINATING ENGINEERING SOCIETY OF NORTH AMERICA, lighting Handbook - Reference \& Aplication, Mark S. Rea, PhD Fies Editor in Chief Rensselaer Polytechnic Instituto, New York 1993,

INSTITUTO ECUATORLANO DE ELECTRIFICACIÓN - INECEL, Actualización del Plan Nacional de Electrificación - Períoto 1994-2010, Dirección de Planificación y Tarifas, DPT-021/94, Quito-Ecuador, octubre 1994.

INSTITUTO ECUATORIANO DE FLECTRIFICACIÓN - INECEL, Estadísticas Eléctricas - Boletín Estadístico No. 28, Dirección de Distribución y

INSTITUTO ECUATORIANO DE ELECTRIFICACION - INECEL, Estadistica Mensual de Mercado Eléctrico (Periodo ene/89-mar-94), Dirección de Planificación y Tarifas, Boletiu No. 70 DPT/014/94, Quito-Ecuador mayo 1994.

INSTITUTO ECUATORIANO DE ELECTRIFICACIÓN - INECEL, Plan Maestro de Electrificación, Periodo 1993-2003, Dirección de Planificación, PLM-001/93, Quito-Ecuador marzo 1993.

INSTITUTO ECUATORIANO DE ELECTRIFICACión - INECEL, Programa de Estudios Tarifarios, Estudio de Costos Marginales, Dirección de Estudios y Control de Tarifas, II,CSE,07-91, Junio de 1991.

INSTITUTO NACIONAL DE ESTADÍSTICAS Y CENSOS - INEC, Ecuador: Proyecciones de Población por Províncias, Cantones, Areas, Sexo y Grupos
de Edad. Período 1990-2000, Quito agosto 1994. 
JANNUZI, G. DF: M., Planejando o Comsumo de Energia Flétrica através de Programas de Difusảo de Tecnologias mais Eficientes, Revista Brasileira de Energia, Volume 3, No. I, Rio de Janeiro 1993.

KRAUSE, F; ETO, J., least-Cost Vtility Planuing Uandhook for Public Utifity Commissioners, Volume 2, The Demand Side: Conceptual and Methodological Issnes, Lawrence Berkeley Laboratory, Wastington december 1988.

LOHANI B.N. - AZIMI A.M., Barriers to Energy End-use efficiency. Workstiop Métodos de Análise Energética a partir dos Usos Finnis, Intemational Energy Initiative, IEL-CISP, Săn Pato março 1004.

MANUFACTURFRA DE BALASTROS S.A., Especifiencinnes Técnicas, Catálogo de balastros, Colombia 1987.

MINISTERIO DF MINAS F ENERGIA DE COLOMBIA, Plan de redueción del Consumo ale Fnergia Eléctrica en Alumbrado Públicon. Instituto de Ciencias Nucleares e Fnergias Alternativas, Hogoti marzo 1995

MOREIRA, A C, A consersaç̃̃o de energia no setor de tluminaçãn Pública, Revista Mundo Etétrico, Maio de 1989.

MOREIRA, J. R., Informaçâo yerbal dos custos das Visians Itrasileiras, Instituto de Eletrotécuica e Energia, Universidade de São Paulo, São Paulo 1 ตั) 5.

NARANIO, M., Frivatizacinnes: Elenentos para la Discusión, Centro de Planificación y Estudios Sociales CEPI AES. Quito agosto 1992

OJEDA SEGOVIA, L., Bondad y Perversidad de la Privatizacín, Opinión Pública y Publicada, Instituto Latinonmeticano de Investigaciones Sociales II.DIS, Quito
1092 .

THII.IPS, Manoal de Alumbrado, Centro de Ingenieria y Jiseño de Alumbrado, Editorial Paraninfo, Madrial 1983.

PIII IPS, Philips Alumbrado Catáloge Compacto Alumbrado Profesional, Philips Peruana S.A.

PINGUFLLI, L.R., A diferença entre a Privatização das Empresas Elétricas e a Participação Prizada necessária no setor Energético, Revista Brasileira de Energia, Vol. 3 No. 1, Săo Puulo 1993.

PRESIDENCIA DE LA REPUBLICA DEL ECUADOR, Proyecto de Ley de Régimen del Secter Eléctrico Ecuatoriano, l'sayecto de Ley enviado al Congreso Nacional, Quito junio 1994. 
PRFSIDFNCIA DE LA REPUBI.ICA DEL. ECUADOR, Reginmento Sustitutivo al Reglamento de Aplicación al literal g) del articulo 8 de la Iey Básica de Electrificación, Decreto de la Presidencia de la Republica, Quito 1903.

PROGRAMA NACIONAL DE CONSERVACAO DE ENERGIA ELÉTRICA (PROCFL), Eficiência Energética: Componente do Desenvolvimento Sustentrível, I Semiuśrio sobre Incentivos Ihuminaçāo Eficiente, São Paulo abril 1995.

REDDY AMULYA, K.N., Barriers to Improvements in Energy Effieiency, Workshop Métodos de Análise Energética a partir dos Usos Finais, International Energy Initiutive, IFE-USP, Sĭo Paulo março 1904.

REVISTA ELERRICIDADE MODERNA, Iluminaç̃̃o Show 95, ano XXIII No. 257. Aranda Editora、 São Paulo agosto 1995.

SAUER, I L., Iniciativa para o Plancjamento Integrado de Recursos do Setor Elétrico no Estado de Roraima, II Congresso Brasileiro de Planejamento Energético, Universidade Nacional de Gampinas, UNICAMP, Campinas dezembro 1994.

SISTEMA INFORMÁTICO ECONÖMICO ENERGÉTICO - SIEE, Software de Informação da Organização Latino-americana de Cnergia OLADE., IEE/USP. Sĩo Paulo 1994.

SMIT, L., Numinação Públich em Roulovias, lluminação Extema, Revista Caderno Técnico, Primeira Parte, púg. 147, São Paulo 1994.

TORRES DE ARAUJJO, IM - PAULO LEONELLI, O PROCEL e a lluminaçăo Eficiente Plano de Acão 1995-1997, I Seminário sobre Incentivos Iuminaçã̃ Eficiente, Sào Paulo abril 109s

VIEIRA DE CARVALhO, A, Fi Diseño de Programas de Conservación de Energia Kléetrica, Principales Aspectos a ser considerados en el Contexto de los países en Desarrollo, VII Congreso Latimomericano y del Caribe sobre Tarifas Económicas de Energia Eléctrica COTARE 94, San José-Costa Rica, marzo 1994. 